(Aus dem tierphysiol. Institut der Kgl. landw. Hochschule zu Berlin.)

\title{
Physiologische Studien über Vegetarismus ${ }^{1}$ ). Von

\author{
Dr. W. Caspari,
} \\ Privatdozent an der landw. Hochschule.
}

(Hierzu Tafel IX-XI.)

Unter Vegetarismus oder Vegetarian is mus versteht man eine Diätform, deren Bestandteile ausschliesslich aus dem Pflanzenreiche genommen sind. Aus der gewählten Definition geht hervor, dass die Ernährung der sogen. Laktovegetarier, welche lediglich den Fleischgenuss verwerfen, sonst aber eine gemischte animalischvegetabilische Nahrung zu sich nehmen, streng genommen nicht unter den Begriff des Vegetarismus fällt.

Leider muss ich es mir versagen, den Vegetarismus in seiner historischen Entwicklung zu zeigen, seine Bedeutung in ethischer, religiöser, ästhetischer, ethnologischer und wirtschaftlicher Beziehung zu würdigen. Wer sich für diese Gesichtspunkte interessiert, findet sie in trefflicher, nach Kräften unparteiischer Form in dem Werke Albu's über die vegetarische Diät auf Grund grossen literarischen Materials eingehend besprochen ${ }^{2}$ ). Hier soll die Frage nach der Wertigkeit der vegetarischen Diätform lediglich vom Standpunkte physiologischer Erwägungen erörtert werden, wobei man allerdings mit Albu übereinstimmen wird, dass gerade die physiologischen

1) Die vorliegende Arbeit erscheint über ein Jahr nach ihrer Fertigstellung. Es konnten daher diejenigen Veröffentlichungen auf dem einschlägigen Gebiete, welche im Verlaufe dieses Jahres publiziert worden sind, nicht mehr gebührend berücksichtigt werden. Es gilt dies besonders von der umfangreichen Arbeit Chittenden's. - Der Grund für die Verspätung der Publikation ist, dass vorliegende Abhandlung der hohen medizinischen Fakultät der Universität Berlin als Habilitationsschrift eingereicht war. Erst jetzt ist mir die Möglichkeit geworden, die Arbeit zu publizieren, nachdem mir die hohe medizinische Fakultät dieselbe zurückgegeben hat, ohne übrigens inzwischen von ihr Kenntnis zu nehmen.

2) Die vegetarische Diät. Georg Thieme, Leipzig 1902. Auch: Lafay et te B. Mendel, Some historical aspects of vegetarianism. März 1904. S.-A. E. Pflüger, Archiv für Physiologie. Bá. 109. 
Betrachtungen den Kernpunkt der ganzen Frage bedeuten, wenigstens für denjenigen, für den der Vegetarismus ein wissenschaftliches Frnährungsproblem ist, nicht ein Dogma oder eine Konsequenz mystischer Ethik. Diese hohe Bedeutung der physiologischen Betrachtungsweise einer Frage, welche eines gewissen aktuellen Interesses wohl nicht entbehrt, rechtfertigt eine eingehende erneute Untersuchung und Besprechung, zumal ich gerade in seinen physiologischen Auseinandersetzungen $A l b u$ nicht in allen Punkten folgen kann. Ich habe daher in den letzten Jahren einiges neue experimentelle Material zur Beurteilung der physiologischen Wertigkeit vegetarischer Kost gesammelt, das ich an dieser Stelle neben dem älteren kritisch für unsere Frage verwerten möchte. Es muss aber wohl gleich eingangs erwähnt werden, dass sich für die Beurteilung des Vegetarismus wesentlich neue Gesichtspunkte aus diesen Forschungen kaum ergeben haben; wenigstens der objektive und kritische Fachmann wird im allgemeinen nur eine weitere Bestätigung und festere Fundamentierung seiner Anschauungen finden. Anderseits haben aber die Versuche zu Ergebnissen geführt, welche, die Grenzen der Fragestellung überschreitend, allgemeinere biologische und ernährungsphysiologische Probleme beleuchten. Es sei mir daber gestattet, gegebenenfalls das Gebiet des eng begrenzten Themas zu verlassen und an der Hand der Versuchsresultate auch übergeordnete Fragen in das Bereich der Betrachtung zu ziehen.

Exakte experimentelle Untersuchungen über den Vegetarismus sind seit Beginn der modernen Stoffwechselphysiologie nur vereinzelt angestellt worden. Dennoch gestatteten dieselben ein richtiges Urteil, weil die Resultate der Versuche untereinander gut harmonierten. Doch sind meiner Meinung nach weitere Versuche auf diesem Gebiet nicht überflüssig. Bei einer Frage, die in solchem Masse wie die der Zuträglichkeit bezw. Durchführbarkeit rein vegetarischer Diät Gegenstand erregtester Diskussionen geworden ist, muss das wissenschaftliche Urteil sich auf mehr als fünf wohlgelungene Versuche stützen können. Vor allem aber wird nur dann die Beurteilung ein festes wissenschaftliches Fundament erhalten, wenn es gelingt, die auf dem Gebiete der Spezialfrage gesammelten Erfahrungen restlos aufgehen zu lassen in unseren allgemeinen biologischen Kenntnissen. Aus diesem Grunde aber ist es notwendig, mit dem Fortsehritte unseres Wissens auf dem Gebiete der Ernährungsphysiologie und dem weiteren Ausbau der Untersuchungs- 
methoden eine solche Spezialfrage von neuem zu prüfen, um zu sehen, $o b$ in der Beurteilung derselben durch die geänderten allgemeinen Anschauungen und Forschungsmethoden neue Gesichtspunkte eintreten oder alte verschoben werden.

Es kommt hinzu, dass die vegetarische Ernährungsweise zu sehr vielen $A b$ - und Spielarten geführt hat, welche ganz zweifellos nicht mehr in das Gebiet einer normalen Ernährung gehören. Dennoch ist eine Untersuchung auch dieser Diätformen notwendig, um dem Einwande zu begegnen, dass die Wissenschaft über dieselben, ohne sie zu prüfen, den Stab breche, während die praktische Erfahrung nach Ansicht der Apostel solcher Diät deren Bekömmlichkeit und ausreichenden Nährwert erweist. Ein grösserer Abschnitt dieser Arbeit wird sich mit einem derartigen Versuche befassen.

Bevor ich zur Mitteilung meiner eigenen Versuche übergehe, möchte ich kurz die bisher vorliegende Literatur besprechen.

Die alteste wertvolle Untersuchung auf diesem Gebiete wurde von Karl v. Voit nach den Versuchen von Erwin Voit und Constantinidi publiziert ${ }^{1}$ ). Versuchsobjekt war ein 28 jähriger Tapeziergehilfe, welcher bereits seit drei Jahren an rein vegetabilische Kost (Schwarzbrot, Obst und Öl) gewöhnt war. Der Versuch zerfiel in drei Perioden von insgesamt vierzehn Tagen Dauer. Die Nahrung bestand in den ersten beiden Perioden aus Pumpernickel, Grahambrot, Äpfeln, Feigen, Orangen, Datteln und Öl. In der dritten Periode wurden statt der Feigen Oliven gereicht. Es wurde in der ersten Periode im Mittel täglich mit der Nahrung eingeführt:

$$
\begin{aligned}
& 8,20 \mathrm{~g} \mathrm{~N}= 52,89 \mathrm{~g} \text { Eiweiss (davon } 46,53 \mathrm{~g} \text { Reineiweiss), } \\
& 21,06 \text { "Fett, } \\
& 297,83 \text { "Zucker, } \\
& 252,62 \text { "Stärke, } \\
& 17,21 \text { "Zellulose; }
\end{aligned}
$$

in der zweiten Periode:

$$
\begin{aligned}
8,39 \mathrm{~g} \mathrm{~N}= & 54,11 \mathrm{~g} \text { Eiweiss (davon } 48,47 \mathrm{~g} \text { Reineiweiss), } \\
16,47 & \text { "Fett, } \\
270,87 & \text { "Zucker, } \\
266,89 & \text { "Stärkemehl, } \\
16,20 & \text { "Zellulose; }
\end{aligned}
$$

1) Zeitschr. f. Biol. Bd. 25 S. 232.1889. 
in der dritten Periode:

$8,86 \mathrm{~g} \mathrm{~N}=57,15 \mathrm{~g}$ Eiweiss (davon $47,39 \mathrm{~g}$ Reineiweiss), 32,80 "Fett, 298,96 "Zucker, 285,87 , Stärke, 15,74 "Zellulose;

im Mittel aller drei Versuchsreihen wurden demnach gegeben:

$$
\begin{aligned}
8,4 \mathrm{~g} \mathrm{~N}= & 54,2 \text { "Fiweiss (davon } 47 \mathrm{~g} \text { Reineiweiss), } \\
22,0 & \text { "Fett, } \\
& 289,0 \text { "Zucker } \\
& 269,0 \text { "Stärkemehl } \\
16,0 & \text { "Zellulose. }
\end{aligned}
$$

Bei einem Körpergewicht der Versuchsperson von $57 \mathrm{~kg}$ enthält diese Nahrung pro Kilogramm Körpergewicht $0,15 \mathrm{~g} \mathrm{~N}=0,95 \mathrm{~g}$ Eiweiss, 0,38 g Fett und 9,77 g Kohlehydrat. Dies entspricht ca. 47 Kalorien physiologischer Nutzeffekt pro Kilogramm Körpergewicht nach den Rubner'schen Standardzahlen berechnet.

Faktisch ist dieser Wert, welcher auf einer mittleren Ausnutzung der gegebenen Nahrungsstoffe basiert, wohl ein etwas zu hoher wegen der schlechten Resorption der Nahrung. Es wurde nämlich im Kot ausgeschieden

$$
\begin{aligned}
& \text { vom Eiweiss . . . . . } 41 \% \\
& \text { "Fett . . . . . . . } 30 \text { " } \\
& \text { "Stärkemehl und Zucker } 3 \text { " }
\end{aligned}
$$

Die Stickstoffbilanz pro Tag im Mittel des gesamten Versuchs gestaltete sich folgendermassen:

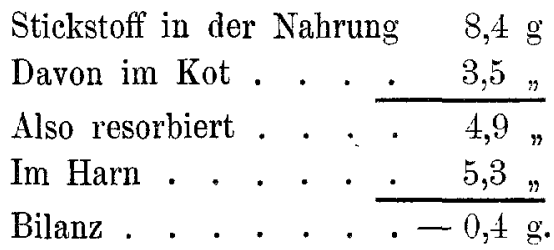

Es wurde also bei diesem Vegetarier das Stickstoffgleichgewicht nicht völlig erreicht.

Dies muss uns nach unseren neueren Erfahrungen wundernehmen. Gibt es doch jetzt eine ganze Anzahl von Untersuchungen, bei denen Stickstoffgleichgewicht konstatiert werden konnte, selbst bei geringerer Kalorien- und Stickstoffzufuhr auf das Kilogramm Körpergewicht. Vielleicht aber erhalten wir bezüglich der Deutung 
dieses Resultats einen Fingerzeig, wenn wir auf Grund der Angaben des Originals die Stickstoffbilanzen der einzelnen Perioden gesondert aufstellen.

\begin{tabular}{|c|c|c|c|}
\hline & I. Periode & II. Periode & III. Period \\
\hline N der Nahrung & 8,20 & 8,39 & 8,86 \\
\hline $\mathrm{N}$ im Kot. & 3,34 & 2,79 & 4,45 \\
\hline Resorbierter $\overline{\mathrm{N}}$ & 4,86 & 5,60 & 4,39 \\
\hline $\mathrm{N}$ im Harn. . & 5,22 & 5,21 & 5,55 \\
\hline Bilanz . . & $-0,36$ & $+0,39$ & 1,16 \\
\hline
\end{tabular}

Es zeigt sich also, dass in der I. Periode noch ein geringer Eiweissverlust bestand, in der II. Periode jedoch das Stickstoffgleichgewicht erreicht wurde, wie man es bei einer derartigen Diät auf Grund unserer heutigen Erfahrungen besonders bei einem seit drei Jahren an stickstoffarme Kost gewöhnten Individuum wohl auch erwarten muss. Wenn in der III. Periode dann ein ziemlich erheblicher Stickstoffverlust zutage tritt, trotzdem die Stickstoffzufuhr in Periode III etwas böher ist als in Periode I und II, und trotzdem der Brennwert der Nahrung in der III. Periode, wie aus den Angaben Voit's leicht $\mathrm{zu}$ berechnen, denjenigen der beiden ersten Perioden zweifellos übertrifft, so ist dafür lediglich die schlechte Verdauung des stickstoffhaltigen Materials in der letzten Versuchsperiode verantwortlich zu machen. Worauf dieselbe zurückzuführen ist, wird aus der Arbeit nicht ersichtlich. Vielleicht sind die Oliven, vielleicht auch ein zufälliger Darmkatarrh dafür verantwortlich zu machen. Jedenfalls aher ist anzunehmen, dass sich der Vegetarier Voit's anch mit der geringen Menge von 4,39 g resorbiertem Stickstoff im Mittel pro Tag in Stickstoffgleichgewicht gesetzt haben würde, wenn der Versuch länger ausgedehnt worden wäre. Dafür spricht die deutliche Einschränkung des Eiweissumsatzes während der III. Periode, wie sie sich in der verringerten N-Ausscheidung im Harn kundgibt. Es wurden nämlich ausgeschieden im Harn der III. Periode:

$\begin{array}{cc}\text { Tag } & \mathrm{N} \mathrm{in} \mathrm{g} \\ 1 . & 6,739 \\ 2 . & 5,875 \\ 3 . & 5,345 \\ 4 . & 4,780\end{array}$

Um zu sehen, ob ein an Pflanzenkost schon seit lange gewöhnter Vegetarianer dieselbe besser ausnutzt als ein Nicht-Vegetarier, unternahm Voit im Anschluss an den obenerwähnten Stoffwechselversuch 
einen weiteren an dem $74 \mathrm{~kg}$ schweren Institutsdiener. Die Elemente und Zusammensetzung der Nahrung entsprachen durchaus der Versuchskost des Vegetariers. Die Stickstoffbilanz ergab im Durchschnitt pro Tag einen Verlust von $4,95 \mathrm{~g} \mathrm{~N}$, am letzten Tage noch von $3,74 \mathrm{~g} \mathrm{~N}$. Doch betrug die Versuchsdauer nur drei Tage, eine Zeit, welche für einen an reichliche Fleischnahrung gewöhnten Mann sicher zu kurz ist, um sich einer Kost anzupassen, wie sie diese Person während des Versuches genoss. Auch war der Brennwert der Nahrung zwar absolut dem in der Kost des Vegetariers annähernd gleich, doch kamen pro Quadratmeter Körperoberfläche auf den Vegetarier 1401, auf den Institutsdiener nur $1210 \mathrm{Kal}$. Wichtig ist jedoch, und um diesen Nachweis war es Voit in erster Linie zu tun, dass der an Pflanzenkost nicht gewöhnte Diener die Nahrungsstoffe aus den Vegetabilien im Darmkanal nicht schlechter auslaugte wie der an diese Diätform seit Jahren gewöhnte Vegetarier.

Gleichzeitig mit der Publikation von Voit und Constantinidi haben Kellner und Mori ${ }^{1}$ ) eine Abhandlung über die Ernährung des Japaners mitgeteilt, welche auch für die Frage des Vegetarismus von Interesse ist. Mori, ein 23 Jahre alter kräftiger Japaner mit einem Körpergewicht von $52 \mathrm{~kg}$, stellte an sich selbst eine Reihe von Stoffwechselversuchen an, und zwar den ersten mit vegetabilischer Kost, wie dieselbe nach Angabe der Autoren von der überwiegenden Mehrzahl der fast ausnahmslos sehr armen, Landwirtschaft treibenden and niedere Arbeit verrichtenden Klassen des japanischen Landesinnern damals genossen wurde. Während der zweiten Versuchsreihe wurde eine gemischte Kost mit Fisch genossen, während der dritten gemischte Kost mit Fleisch und Milch. Der Versuch fiel zu ungunsten der vegetarischen Kostform aus. Dieselbe bestand aus

1. $1200 \mathrm{~g}$ einer Mischung aus zwei Teilen Reis und drei Teilen Gerste,

2. $400 \mathrm{~g}$ getrockneten Rettigs,

3. $300 \mathrm{~g}$ Wurzelgewächse (Kartoffeln usw.),

4. $150 \mathrm{~g}$ grünen Gemüses (Blätter von Brassica sinensis),

5. $100 \mathrm{~g}$ gesalzenen Rettigs,

6. $300 \mathrm{~g}$ Teeaufguss.

2, 3 und 4 wurden mit Miso genossen, dem bekannten, so überaus wohlschmeckenden und appetitreizenden Bohnenkäse der Japaner.

1) Untersuchungen über die Ernährung der Japaner. Zeitschr. f. Biologie Bd. 25 S. 102. 1889. 


\begin{tabular}{|c|c|c|c|c|}
\hline & $\begin{array}{c}\text { Roh- } \\
\text { protein } \\
\text { g } \\
(\mathrm{N}>5,25)\end{array}$ & $\begin{array}{l}\text { Stickstoff- } \\
\text { freie } \\
\text { Extrakt- } \\
\text { stoffe }\end{array}$ & Fett & $\begin{array}{l}\text { (Roh- } \\
\text { faser) }\end{array}$ \\
\hline $\begin{array}{l}\text { Die vegetarische Kost enthielt . } \\
\text { Die gemischte Kost mit Fisch enthielt } \\
\text { Die gemischte Kost mit Fleisch enthielt }\end{array}$ & $\begin{array}{r}70,86 \\
109,25 \\
122,96\end{array}$ & $\begin{array}{l}396,09 \\
461,23 \\
409,68\end{array}$ & $\begin{array}{l}11,58 \\
19,45 \\
20,76\end{array}$ & $\begin{array}{r}17,44 \\
4,56 \\
6,03\end{array}$ \\
\hline $\begin{array}{l}\text { Davon verdaut Prozent } \\
\text { Bei der vegetarischen Kost } \\
\text { Bei der gemischten Kost mit Fisch. } \\
\text { Bei der gemischten Kost mit Fleisch . }\end{array}$ & $\begin{array}{l}75,71 \\
87,33 \\
90,74\end{array}$ & \multicolumn{2}{|c|}{$\begin{array}{l}97,09 \\
99,16 \\
98,72\end{array}$} & $\begin{array}{l}75,97 \\
82,45 \\
91,38\end{array}$ \\
\hline
\end{tabular}

Bei der unverhältnismässig geringeren Nahrungs- und Eiweisszufuhr während der Reihe mit vegetarischer Kost kann es nicht verwundern, dass das Resultat für die vegetarische Diätform sehr ungünstig war. Denn während in den beiden Perioden mit gemischter Kost Stickstoffgleichgewicht bestand, verlor Mori noch in den letzten drei Tagen des sechstägigen Versuches mit vegetarischer Kost 1,16 g N pro Tag.

Dass die Nahrungszufuhr während dieses Versuchsabschnittes so gering war, lag aber nicht an einem Versuchsfehler, sondern war dadurch bedingt, dass die Versuchsperson grössere Mengen dieser Kost ohne Verdauungsstörungen nicht bewältigen konnte. Auch in

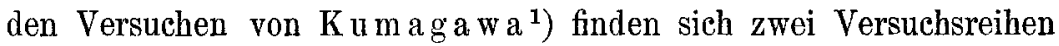
mit ausschliesslich vegetarischer Kost, bei welchen allerdings auch Alkohol in Form von Bier genossen wurde. Versuchsperson war Kumagawa selbst. In der ersten Versuchsreihe bestand die tägliche Kost aus:

$$
\begin{array}{rl}
450 & \mathrm{~g} \text { Reis, } \\
80 & \text { "Miso, } \\
250 & \text { "Kohlrüben, } \\
10 & \mathrm{ccm} \text { Schoyu, } \\
1000 & \text { "Teeinfus, } \\
800 & \text { " Bier. }
\end{array}
$$

In dieser Nahrung waren enthalten:

$$
\begin{array}{rl}
44,212 & g \text { Eiweiss, } \\
1,935 & \text { "Fett, } \\
441,766 & \text { " Kohlehydrate. }
\end{array}
$$

1) Vergleichende Untersuchungen über die Ernährung mit gemischter und rein vegetabilischer Kost mit Berücksichtigung des Eiweissbedarfes. Virchow's Archiv Bd. 116 S. 370. 
Das Eiweiss wurde verhältnismässig sehr gut, nämlich zu $81 \%$, resorbiert.

$\mathrm{Kumagawa}$ berechnet, dass in der resorbierten Nahrung 1940 Kalorien enthalten waren.

Der Versuch dauerte fünf Tage. In dieser Zeit wurden $51,41 \mathrm{~g}$ Eiweiss vom Körper verloren, also 10,28 g Eiweiss pro Tag. Eine Tendenz zur Einschränkung des Eiweissumsatzes, und allmähliche Annäherung an das Stickstoffgleichgewicht trat nicht hervor.

Der zweite Versuch mit rein vegetabilischer Kost schloss sich unmittelbar an den ersten an. Er dauerte neun Tage. In der täglichen Nahrung wurden genommen:

$$
\begin{aligned}
& 600 \mathrm{~g} \text { Reis, } \\
& 100 \text { "Miso, } \\
& 300 \text { "Kohlrüben, } \\
& 27,7 \mathrm{~g} \text { Rohrzucker, } \\
& 100 \mathrm{ccm} \text { Schoyu, } \\
& 594,4 \mathrm{ccm} \text { Bier, } \\
& 583,3 \text { "Teeinfus. }
\end{aligned}
$$

In dieser Nahrung waren enthalten:

$$
\begin{array}{cl}
54,706 & \mathrm{~g} \\
2,52 \text { Eiweiss (N haltige Substanz), } \\
569,832 \text { "Fett, } \\
\text { "Kohlehydrate. }
\end{array}
$$

$\mathrm{Kumagawa}$ berechnet, dass von den $54,7 \mathrm{~g}$ Nhaltiger Substanz $50,5 \mathrm{~g}$ Eiweiss war. In dem Kot fand er $12,69 \mathrm{~g}=$ ca. $25 \%$.

Während des neuntägigen Versuches fand ein merklicher Eiweissansatz, im ganzen $36,78 \mathrm{~g}$, statt. Doch ist derselbe zum Teil wohl auf den in dem ersten Versuche erfolgten Eiweissverlust zurückzuführen.

Den Brennwert der resorbierten Nahrung bezeichnet $\mathrm{Kuma}$ g a w a auf 2478 Kalorien pro Tag. Nach Rubner's Standardzahlen, in gewöhnlicher Weise angewandt, erhält man einen Brennwert von 2583,9 Kalorien $^{1}$ ). Da das Körpergewicht $\mathrm{K} \mathrm{u} \mathrm{mag} \mathrm{a} \mathrm{w} \mathrm{a's} 48 \mathrm{~kg}$ betrug, wurde also ein Eiweissansatz erzielt bei rein vegetarischer

1) Bei der Berechnung der Standardzahlen hat Rubner bereits für den Verlust im Kot einen Abzug gemacht. Kumagawa dagegen multipliziert die resorbierten Nährstoffmengen mit den Rubner'schen Standardwerten. Eigentümlicherweise schlägt Rubuer selbst in einer späteren Arbeit (Zeitschr. f. Biol. Bd. 42. 1902) denselben Weg ein. 
Kost, welches pro Kilogramm Körpergewicht enthielt: $0,18 \mathrm{~g} \mathrm{~N}$ und 53,8 Kalorien.

Ein weiterer Versuch, welcher sich eingehend mit dem Stoffwechsel des Vegetariers beschäftigte, wurde von $R u m p f$ und Schumm im Jahre 1900 publiziert $^{1}$ ). Der Versuch wurde an einem 19 jährigen Jüngling von etwa $63 \mathrm{~kg}$ Körpergewicht ausgeführt. Die Nahrung bestand aus Datteln, Quäkeroats, Reis, Zucker, Walnüssen, Grahambrot und Äpfeln. Oats und Reis wurden in gekochtem Zustande gegessen, die Äpfel teils rob, teils gekocht. Der Versuch erstreckte sich über acht Tage. Die tägliche Einnahme in der Nahrung betrug :

11,82 g $\mathrm{N}=73,88 \mathrm{~g}$ Eiweiss $=$ ca. $303 \mathrm{Kal}$. (nach Rubner

$$
\begin{array}{rlr}
698,21 & \text { "Kohlehydrate }= & 2863 " \\
28,64 \text { "Fett } & = & 266 \% \\
& \text { Summa } 3432 \mathrm{Kal} .
\end{array}
$$

berechnet)

Die Stickstoffbilanz pro Tag im Mittel gestaltete sich folgendermassen:

$$
\begin{aligned}
& \text { in der Nahrung } 11,82 \mathrm{~g} \mathrm{~N}
\end{aligned}
$$

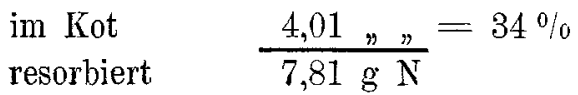

$$
\begin{aligned}
& \text { in Harn } \\
& \text { Bilanz }+\frac{6,91 \% n}{0,9 \mathrm{~g} \mathrm{~N} .}
\end{aligned}
$$

Die Nahrung enthielt also pro Kilogramm Körpergewicht $0,19 \mathrm{~g} \mathrm{~N}$ und ca. 54 Kal., war also ziemlich stickstoffarm, aber von sehr hohem Brennwerte. Obgleich nun $33,93 \%$ der stickstoffhaltigen Nährstoffe und $26,47 \%$ des Fettes im Kot den Körper verliessen, hat sich der jugendliche Vegetarier nicht nur in Stickstoffgleichgewicht gesetzt, sondern wahrscheinlich noch Eiweisssubstanz im Körper zurückbehalten. Es war auch während der acht Tage des Versuchs eine Gewichtszunahme von $1,7 \mathrm{~kg}$ zu konstatieren.

Voit sowohl wie Rumpf und Schumm schliessen aus ihren Versuchen, dass zwar ein Auskommen mit rein vegetarischer Kost möglich ist, dass diese Diätform jedoch unzweckmässig sei wegen des grossen Volumens der zur Ernährung notwendigen Speisen und der schlechten Ausnutzbarkeit der zellulosehaltigen Nahrungsmittel. Ferner gehören in die Reihe der Versuche mit streng vegetari-

1) Zeitschr. f. Biol. Bd. 39 S. 153.1900. 
scher Diät mehrere Versuchsreihen von Taniguti ${ }^{1}$ ). Es handelt sich um Stoffwechselversuche, welche im Jahre 1892 in grossem Umfange in Japan angestellt wurden zur Entscheidung der Frage, ob die Kost der japanischen Armee zu ändern sei. Bei dieser Gelegenheit hat auch Taniguti Stoffwechselversuche mit verschiedenen Kostsätzen ausgeführt. Der erste dieser Versuche fällt streng genommen nicht in den Rahmen unserer Betrachtungen, weil zu dem Reis, welcher mehrere Tage lang als alleiniges Nährmaterial gereicht wurde, Liebig'sches Fleischextrakt als Geschmackskorrigens hinzugefügt wurde. Wir werden hierauf später einzugehen Gelegenheit haben.

In der zweiten Versuchsreihe wurde Reis gereicht, der Versuchsperson aber gestattet, beliebige Zukost pflanzlicher Stoffe zu wählen. Die bei dieser Kost aufgenommene Nahrung hatte einen Brennwert von 2777-2790 Kalorien. Es wurden eingeführt:

im Durchschnitt der ersten zehn Tage 9,63 g $\mathrm{N}$

davon erschienen im Kot

also wurden resorbiert

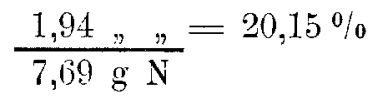

ausgeschieden im Harn

$$
\text { Bilanz }-\frac{9,24 " \%}{1,55 \mathrm{~g} \mathrm{~N}}
$$

Im Mittel der zweiten zehn Tage wurden in der Nahrung gegeben:

$$
\begin{aligned}
& 10,52 \mathrm{~g} \mathrm{~N}
\end{aligned}
$$

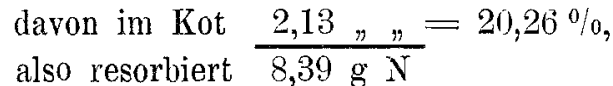

im Harn

$$
\operatorname{Bilanz}+\frac{8,36 \% \text {. }}{0,03 \mathrm{~g} .}
$$

Während der dritten zehn Tage in der Nahrung:

$$
10,35 \mathrm{~g} \mathrm{~N}
$$

$$
\begin{aligned}
& \text { im Kot } \frac{1,89, n}{8,46 \mathrm{~g} \mathrm{~N}}=18,27 \% \\
& \text { resorbiert } \\
& \text { im Harn } \frac{7,25 \% "}{\text { Bilanz }+1,21 \mathrm{~g} \mathrm{~N} .}
\end{aligned}
$$

Während der letzten fünf Tage in der Nahrung pro Tag:

$$
10,41 \mathrm{~g} \mathrm{~N}
$$

$$
\begin{aligned}
& \text { im Kot } \frac{2,39 " n}{8,02 \mathrm{~g}}=22,96 \% \\
& \text { resorbiert } \\
& \text { im Harn } \frac{7,52 \%,}{\quad \text { Bilanz }+0,5 \mathrm{~g} \mathrm{~N} .}
\end{aligned}
$$

1) Einige Versuche mit der japanischen Reiskost. Arbeit aus der kaiserl. japan. militärärztl. Lehranstalt Bd. 1. Tokio 1892. Zit. nach Maly 1892 Bd. 22. 
Auffallend ist an diesen Versuchen, ähnlich wie an denen $\mathrm{Ku} \mathrm{ma-}$ gawa's, die gute Ausnutzung des Nährmaterials, welche zweifellos auf die zweckmässige Wahl und Zubereitung der Kost zurückzuführen ist. Wichtig ferner, dass die Versuchsperson, welche vermutlich, wie alle Japaner der niederen Klassen, an vorwiegend (nicht ausschliesslich) vegetabilische Kost gewohnt war, während der ersten zehn. Tage mit einer Nabrung von 9,6 $\mathrm{g}$ Stickstoff pro Tag bei verhältnismässig guter Ausnutzung und wahrscheinlich ausreichendem Brennwerte der Nabrung sich nicht in Stickstoffgleichgewicht setzen konnte.

Über einen weiteren Stoffwechselversuch an einem Vegetarier hat $\mathrm{Hauer}^{1}$ ) berichtet. Die Versuchsperson war eine 36 jähriger Herr, welcher seit zwei Jahren während der warmen Jahreszeit als strenger Rohkostvegetarier lebte; im Winter jedoch nahm er seine Speisen aus einer vegetarischen Küche. Der Versuch erstreckte sich von 7. bis 12. Juli 1902, dauerte also sechs Tage. Die Nahrung bestand aus Brot, Kirschen, Erdbeeren, Feigen, Datteln, Mandeln, Wallnüssen und Paranüssen sowie Nussin, einer Art Pflanzenbutter, welche aus Erdnüssen gewonnen wird. Aus diesen Elementen wählte die Versuchsperson täglich selbständig die Bestandteile ihrer Mahlzeiten; auch war die Menge der aufzunehmenden Nahrung in ihr Belieben gestellt. Die Aufnahme an den einzelnen Tagen differierte nicht unerheblich. Im Mittel wurden pro Tag genommen: $10,95 \mathrm{~g}$ $\mathrm{N}, 112 \mathrm{~g}$ Fett und ca. $2789 \mathrm{Kal}$. Bei einem Körpergewicht von $64,93 \mathrm{~kg}$ kommen so auf das Kilogramm Körpergewicht $0,16 \mathrm{~g} \mathrm{~N}, 1,7 \mathrm{~g}$ Fett und 42,9 Kal. Aus der Bilanz geht mit Sicherheit hervor, dass Stickstoffgleichgewicht bestand, doch war die Ausnutzung der Kost eine recht schlechte. Es fanden sich im Kot $38 \%$ des Nahrungsstickstoffs sowie $22 \%$ des Fettes.

Auch aus diesem Versuche geht jedenfalls klar hervor, dass eine in jeder Beziehung ausreichende Ernährung mit vegetarischer Diät durchaus möglich ist.

Schliesslich ist noch ein Versuch von $\mathrm{Albu}^{2}$ ) zu erwähnen, doch spielen hier wohl schon pathologische Elemente mit; denn die Versuchsperson, eine 42 jährige Studentin der Medizin, besass nur ein Körpergewicht von $37,5 \mathrm{~kg}$ bei einer Grösse von $1,3 \mathrm{~m}$. Diese

1) Inaug.-Diss. Freiburg i. B. 1903.

2) Zeitschr. f. klin. Med. Bd. 23 S. 1. 
Dame nährte sich bereits seit sechs Jahren streng vegetarisch. Albu stellte nun bei ihr mit frei gewählter Nahrung einen Stoffwechselversuch von fünftägiger Dauer an. Die Elemente der Kost waren: Grahambrot, Äpfel, Pflaumen, Trauben, Nüsse, Datteln und Salat. Die Versuchsperson nahm täglich im Durchschnitt auf:

$$
\begin{array}{rl}
5,46 & \mathrm{~g} \\
36,44 & \mathrm{~g}=34,12 \mathrm{~g} \text { Fett, }
\end{array}
$$

und ca. 225,0 g Kohlehydrate.

Dies ergibt nach Albu's Berechnung einen Brennwert der Nahrung von 1400 Kalorien oder ca. 37 Kalorien pro Kilogramm Körpergewicht. Trotzdem 32,79\% des Nahrungsstickstoffes im Kot ausgeschieden wurden und augenscheinlich infolge der schlechten Verdaulichkeit der Nüsse nur $65 \%$ des Fettes resorbiert wurden, setzte sich die Versuchsperson Albu's in Stickstoffgleichgewicht. Die schlechte Resorption des Nahrung bei der seit sechs Jahren an vegetarische Diät gewohnten Dame ist neben den Voit'schen Versuchen ein weiterer Beweis, dass eine Gewöhnung an vegetabilische Kost nicht eintritt in dem Sinne, dass sich ein weitergehendes Ausnutzungsvermögen für Vegetabilien bei einem seit längerer Zeit vegetarisch lebenden Menschen eintritt ausbildet.

Hiermit ist, soweit mir bekannt, die einschlägige wissenschaftliche Literatur erschöpft. Ausserordentlich zahlreich sind Stoffwechselversuche, bei denen eine laktovegetabilische Kost gewöhnlich unter Hinzufügung von Eiern, manchmal mit Gaben von Alkohol, zur Anwendung kamen. Die betreffenden Autoren benutzten aber diese Diätform lediglich, um andere Fragestellungen, etwa die nach dem Eiweissminimum u. dergl., zu entscheiden. An sich bietet die Frage nach der Durchführbarkeit bezw. Bekömmlichkeit einer fleischfreien, sonst aber ausreichenden Kost, bei welcher besonders auch tierisches Eiweiss in nicht zu spärlicher und den Verdauungssäften leicht zugänglicher Form zur Anwendung gelangt, insofern kein Interesse, als man an der Möglichkeit ausreichender Ernährung mittelst derartiger Kost nie gezweifelt hat. Praktisch erscheint es höchst zweifelhaft, ob man berechtigt ist, Leute, welche etwa aus ethischen Gründen kein Fleisch geniessen, als Vegetarier zu bezeichnen. Dagegen ist es ein anderer Umstand, welcher vom physiologischen Standpunkt die vergleichende Beurteilung vegetarischer Kost und gewöhnlicher gemischter Nahrung erschwert; das ist die Enthaltsamkeit der Vegetarier von Reizmitteln, wie Alkohol und 
Nikotin. An sich hat die Abstinenz mit der pflanzlichen Ernährung ja gar nichts zu tun. Auch sind nicht alle strengen Vegetarier Abstinenzler. Die meisten Vegetarier jedoch enthalten sich des Alkohols und sind dadurch vielleicht im Vorteil gegen viele Gemischtkostler, welche Alkohol und Tabak, von bösartigeren Reizmitteln ganz abgesehen, gar zu oft in schädlichem Übermasse geniessen.

\section{Eigene Versuche.}

Der erste von mir selbst angestellte Versuch wurde in Gemeinschaft mit Herrn Dr. Glässner ausgeführt und ist bereits von uns publiziert worden ${ }^{1}$ ). Es sei mir gestattet, die Daten dieses Versuches kurz zu rekapitulieren, soweit sie für die spätere allgemeine Diskussion von Wichtigkeit sind. Der Versuch wurde dank der gütigen Erlaubnis des Herrn Geh. Rat Professor Dr. Ewald in strenger Klausur in der Isolierstation des Kaiserin Augusta-Hospitals zu Berlin ausgeführt. Die Versuchspersonen waren der 49 jährige Ingenieur Herr K. und seine 48jährige Gattin. Herr K. war von mittlerer Grösse, gutem Ernährungszustand ${ }^{2}$ ) und grosser Lebhaftigkeit, seine Gattin von grazilem Körperbau, gut ausgebildetem Fettpolster, schwächlich entwickelter Muskulatur und sehr blasser Hautund Gesichtsfarbe. Herr Geh. Rat Ewald hatte die Güte, einen genauen Status der Versuchspersonen aufzunehmen, welcher in der zitierten Arbeit veröffentlicht ist. Herr K. lebte seit dem Jahre 1883 von laktovegetabilischer Kost, welche aus gekochten Pflanzenspeisen, Eiern, Milch, Käse und Butter bestand. Seit dem Jahre 1891 ernährte er sich rein vegetarisch, und zwar schon seit dieser Zeit annähernd in gleicher Weise wie während des Versuches. Er war kein prinzipieller Abstinenzler, sondern hat zuweilen, wenn auch nur in sehr geringen Mengen, Alkohol genossen.

Frau K. lebte bis zum Jahre 1899 von gemischter Kost und ging dann unmittelbar zu einer rein vegetabilischen Diät über, wie sie während des Versuches innegehalten wurde. Sie soll, bevor sie sich der vegetarischen Ernährungsweise zuwandte, stets sehr elend und schwächlich gewesen sein. Besonders litt sie an Obstipation. Bereits im Alter von 25 Jahren soll ihr Haar völlig gebleicht gewesen sein.

1) Ein Stoffwechselversuch an Vegetarianern. Zeitschr. f. diätet. u. physik. Therapie Bd. 7 H. 9. 1908/1904.

2) Vgl. Tafel $X$. 
Im allgemeinen machte Herr K. einen frischeren und agileren Eirdruck als seine Gattin, die stets müde und abgespannt aussah und auch körperlichen Anstrengungen nicht in dem gleichem Masse gewachsen war.

Während der Klausur wurde dem Ehepaar körperliche Bewegung in Form von Turnübungen gestattet, die indes nur von Herrn $K$. in ausgiebiger Weise durchgeführt wurden. Doch gibt Herr $K$. an, sonst stärkere körperliche Arbeit geleistet zu haben.

Der Versuch erstreckte sich bei beiden Personen über je fünf Tage, vom 5. bis 9. Februar 1902. Die Nahrung bestand für Herrn K. aus einem Infus getrockneter Gerste, den er sich täglich mit $400 \mathrm{ccm}$ Wasser bereitete und samt dem Satze zu sich nahm, ferner aus Zucker, Datteln, Haselnüssen, Leinöl und Kartoffeln, die in der Schale gekocht gereicht wurden. Die Schalen wurden nicht mit gegessen. Da im weiteren Verlauf des Versuches das Bedürfnis nach Abwechslung der Speisen hervortrat, wurde der Diätzettel durch Zulage von getrockneten Karotten, welche mit Wasser gekocht wurden, erweitert. Nach Behauptung des Herrn K. trat dieses Bedürfnis im Gegensatze zu der Ernährung vor der Klausur deshalb ein, weil die Qualität der Kartoffeln zu wünschen übrig liess.

Die Ernährung der Frau K. unterschied sich von der ihres Gatten dadurch, dass sie Zucker verschmähte, Da sie die Einförmigkeit der Kost stärker als ihr Gatte empfand, so wurde dieselbe im Verlauf des Versuches durch Zulage von Cakes und Karotten behoben. Die Aufnahme von Kochsalz und Wasser war für beide Personen eine unbeschränkte. Es wurde den Versuchspersonen gestattet, von der Nahrung täglich nach Wohlbehagen zu nehmen. Die Menge der eimzelnen aufgenommenen Nahrungsbestandteile wurde dann später festgestellt. Es ergaben sich allerdings an den einzelnen Tagen Schwankungen in Stickstoff-, Kalorien- und Fettzufuhr. Im ganzen nahm Herr K. während der Versuchsdauer zu sich:

$$
\begin{array}{ccc}
\mathrm{N} & \text { Fett } & \begin{array}{c}
\text { Kalorien (durch direkte } \\
\text { Verbrennung festgestellt) }
\end{array} \\
39,15 \mathrm{~g} & \mathbf{1 0 9 9 , 1} \mathrm{g} & 22796
\end{array}
$$

also pro Tag im Durehschnitt

$$
\begin{array}{ccccc} 
& 7,83 \mathrm{~g} & 219,8 \mathrm{~g} & \multicolumn{2}{c}{4559 .} \\
\text { Frau K.: } & \mathrm{N} & \text { Fett } & \text { Kalorien } \\
& & 26,64 \mathrm{~g} & 495 \mathrm{~g} & 13575
\end{array}
$$

mithin pro Tag im Durehsehnitt:

$$
5,33 \mathrm{~g} \quad 99 \mathrm{~g} \quad 2715 .
$$


Die Kost enthielt für Herrn $K$. bei einem mittleren Körpergewicht von $68,8 \mathrm{~kg}$ im Mittel pro Tag und Kilogramm 0,114 g Stickstoff und 66 Kalorien, für Frau $K$. bei einem mittleren Gewicht von $58,0 \mathrm{~kg} \mathrm{0,092} \mathrm{g}$ Stickstoff und $47 \mathrm{Kalorien.} \mathrm{Es} \mathrm{wurden} \mathrm{ausgenutzt} \mathrm{von}$

Herrn K. Frau K.

$\begin{array}{lll}\text { von dem gegebenen Stickstoff } & 73,79 \% & 75,79 \% \\ \text { vom Fett } & 88,49 " & 89,92 " \\ \text { von den Kalorien } & 91,11 " & 92,93 \%\end{array}$

Die Stickstoffbilanz ergab für Herrn K. während der gesamten fünf Tage einen Ansatz von 5,20 g Stickstoff $=$ ca. $156 \mathrm{~g}$ Muskelfleisch; für Frau K. einen Gesamtansatz von 2,45 g Stickstoff $=$ ca. $73,5 \mathrm{~g}$ Fleisch. Das Körpergewicht stieg während der fünf Versuchstage bei Herrn K. um 0,8, bei Frau K. um 0,9 kg. Auf weitere Einzelheiten dieses Versuches werde ich noch im weiteren Verlauf der Besprechung zurückgreifen.

Der zweite meiner Versuche fällt in den Rahmen der Abarten der vegetarischen Diät und kann als ein allgemeingültiges Paradigma dieser Kost nicht verwendet werden, da durch die Art der Ernährung unphysiologische Bedingungen gesetzt und unphysiologische Resultate erzielt wurden.

Die Person, welche auf ihr eigenes dringendes Ersuchen von mir in einen Stoffwechselversuch genommen wurde, war der 50 jährige Hauptmann d. L. H. Über die Anamnese und die Gesichtspunkte, von welchen ausgehend dieser Herr sich den Unannehmlichkeiten des Versuches unterwarf, gibt nachfolgender Bericht Aufschluss. Ich halte mich für verpflichtet, denselben der Öffentlichkeit zu übergeben, weil Herr H. dies als berechtigtes Äquivalent seines opfermütigen und ausserordentlich geduldigen Entgegenkommens mir zur „ausdrücklichen Bedingung" gemacht hatte, weil ferner dieser Bericht genaue und, wie ich den Charakter des Herrn kennen gelernt Labe, zweifellos wahrheitsgetreue anamnestische Daten enthält, schliesslich weil er den ungewöhnlichen Ideengang, die Sinnes- und Denkweise dieses Herrn anschaulicher schildert, als ich es durch eine genaue Beschreibung zu tun vermöchte.

Krankheitsbericht des Hauptmanns H.

Geboren am 14. Juli 1853.

Vom 7.-14. Jahre: schwächlich, zart; Herzhypertrophie, darf nicht laufen, nicht kalt baden; Lebertrankur; mache beinah jedes Jahr ein heftiges gastrisches 
Fieber durch; auch einmal Gelenkrheumatismus; komme erst mit acht Jahren zur Schule.

Vom 14. Jahre ab: darf jetzt laufen und schwimmen.

Vom 20. Jahre ab: wegen Nasenpolypen mehrmonatige Kur durch in die Nasengänge eingezogene Tannintampons.

Vom 21. Jahre ab: einjährig gedient; anfangs bei Laufschritt heftiges Herzklopfen, dieses verliert sich aber allmählich ganz, und ich gedeihe während des Dienstjahres vortrefflich, so dass ich die Manöverstrapazen ganz ausgezeichnet (mit vollständigem, vorschriftsmässigem Mannschaftsgepäck) ertrage.

Vom 22.-24. Jahre ab: sehr gesund und kräftig.

Im 24. Jahre: erster Tlipper, dawert beinahe ein ganzes Jahr.

Im 27. Jahre: zweiter Tripper; im Anschlısse an denselben ein sehr heftiger Blasenkatarrh, kompliziert mit angeschwollener Prostata.

Von da ab litt ich dauernd an Strikturen, welche sich erst in der Mitte der neunziger Jahre etwas besserten und erst jetzt im Dezember 1902 vollständig geschwunden sind.

Im 30. Jahre (1883): wegen Nasenpolypen operiert.

Im 32. Jahre (1885): starke Gelbsucht ; "Hexenschuss"; Gicht in den Händen.

Im 34. Jahre (1887): Rheumatismus im Rücken und in rechten Oberarme.

In 54.-37. Jahre (1887-1890): sehr reichliche Hotel- und Restaurantkost.

Vom 37.-38. Jahre (1890/1891): wegen Nasenpolypen operiert; infolge des bei dieser Operation angewendeten Kokains entstehen bis auf das Zahnfleisch hindurchgehende, bösartige Geschwüre auf der Oberlippe; Barthaare fallen aus; Anschwellung des ganzen Gesichtes bis inkl. der Augen. Kurze Zeit darauf: Regenbogenhautentzündung. Deswegen sechs Wochen in der Augenklinik; hiel Atropinbehandlung und gleichzeitig sublkutane Quecksilbereinspritzung ins Gesäss. Einige Zeit darauf: Bart- und Kopfhaare fallen ans, die Zähne werden locker, und einige Zähne fallen aus. Alsdann einige Zeit später: Hodenwasserbruch; derselbe wird operiert (punktiert). In Wildungen Kur wegen Nierenleiden durchgemacht.

Vom 39. Jahre (1892): sehr elend; körperlich und geistig gebrochen; schwere chronische Hartleibigkeit verbunden mit Hämorrhoidalknoten am After. Ich führte damals keine sitzende Lebensweise, sondern war den ganzen Tag in Bewegung. Behandlung: Schweizer Pillen, verschiedene Abführmittel, Klistiere; alles hilft nicht, im Gegenteil, es wird immer schlimmer. Herbst 1892: im Manöver heftiger Magenkatarrh.

Ende 1892: Das Leiden wird unerträglich.

Dezember 1892 bis Herbst 1902: Zum Vegetarismus übergegangen. Besiegung der Hartleibigkeit. Die Hämorrhoidalknoten verschwinden allmählich, kehren aber dann und wann vorübergehend wieder, aber immer gradatim schwächer. Wiederaufleben. Es treten in halbjährigen Intervallen mehrwöchige heftige Körperreinigungskrisen, eine im Sommer und eine im Winter, ein, in welchen dicke, sehr stinkende, zähe, klebrige Schleimknoten und Schleimfäden aus dem Darm ausgeschieden werden, ferner Nierensteinkolik und Ausscheidung grosser Mengen harnsaurer Salze; auch starke, sehr stinkende Nachtschweisse; eine eitrige Masse sondert sich aus den Augenwinkeln ab. Nach den Krisen: jedes- 
mal gradatim erhöhtes Wohlbefinden. Werde immer kräftiger, kann schliesslich grosse Märsche $(50-100 \mathrm{~km})$ und Dauerlauf von einer deutschen Meile machen; hielt in den fünf letzten Jahren vier 8-14 tägige Hunger- und Durst-Perioden durch. Vorletzte Krisis (Sommerkrisis) August 1902.

Mein der Klausur vorhergehendes vorbereitendes Training zur ausschliesslichen Ernährung mit rohen frisehen nd getrockneten Frichten mit Ausschlass von Nïssen.

Ferner einige Mitteilungen aus meinen Erfahrungen über das Wesen der sogenanten Reinigungs- und Heilkrisen und aus meinen Erfahrungen über medizinische Therapie und über giftfreie Heilweise.

Nachdem ich in den letzten fünf Jahren meiner zehnjährigen vegetarischen alkohollosen Lebensführung den Schwerpunkt meiner Ernährung auf rohe frische und getrocknete Früchte und Nüsse gelegt, dazwischen durch aber auch gekochte, gebratene und gebackene vegetarische Speisen sowie Milch und Butterbrot in meine Nahrung einbezogen hatte, fasste ich den Entschluss, behufs gänzlicher Beseitigung and radikaler Ausheilung des letzten Restes meiner alten chronischen Übel, nunmehr eine längere Zeit, und zwar vom 1 . Mai $1902 \mathrm{ab}$, ganz ausschliesslich nur von rohen frischen und getrockneten Früchten mit gänzlichem Ausschlusse von Nüssen zu leben, die getrockneten Früchte zu denjenigen JahreszeitPerioden mit einbeziehend, in welchen frisches Obst rar und teuer wird und zu wenig Abwechselung bietet, und ferner auch aus dem Grunde, um vom volkswirtschaftlichen Standpunkte aus zu erproben, ob es mir möglich sein würde, meinen Lebensunterhalt mit dieser Nahrung mit einer Durchschnittssumme von möglichst nur 50 Pfennig pro Tag zu bestreiten.

Ich lebte also vom 1. Mai 1902 ab wie folgt:

Vom 1. Mai bis Mitte Juni täglich: Sechs Apfelsinen à 6-8 Pfennig per Stück; dazu, um Abwechslung zu haben, einige Bündchen (für 5-10 Pfennig) Radieschen und eine Handvoll getrockneter Feigen à 30 Pfennig per Pfund oder eine Handvoll Datteln à 35 Pfennig per Pfund.

Von Mitte Juni bis Anfang Juli täglich: Zwei Pfund Kirschen oder sechs Apfelsinen. - An denjenigen Tagen, an welchen ich Apfelsinen ass, nahm ich Feigen oder Datteln, auch hier und da Radieschen oder Rettich hinzu.

Von Anfang Juli bis Anfang August täglich: Zwei Pfund Kirschen oder zwei Pfund Trauben ohne Zusatz von getrockneten Früchten.

Während dieser Periode dieses mich zur Klausur vorbereitenden ErnährungsTrainings machte ich vom 1 . Mai bis 1 . August als Hospitant an hiesiger Universität einen schnell vorwärtsschreitenden, sehr anstrengenden Kursus im Griechischen mit, der mich, wollte ich den gestellten hohen Anforderungen genügen und ein befriedigendes Zeugnis̀ erringen, in täglicher angestrengter zwölf- und mehrstündiger geistiger Arbeit in Anspruch nahm. Ausserdem machte ich zwei- bis dreimal in der Woche an Tagen, an welchen kein griechischer Kursus stattfand, grosse Spaziergänge (von 5 Uhr morgens bis gegen $8 \mathrm{Uhr}$ abends) von ca. 25 bis $30 \mathrm{~km}$, was ja nicht viel ist, aber doch eine gewisse Anstrengung bedeutet,

E. Pflüger, Archiv für Physiologie. Bd. 109. 
da ich gleichzeitig während des Gehens griechische Syntax, Deklinations- und Konjugations-Tabellen repitierte und die griechischen unregelmässigen Verben memorierte und durchkonjugierte. Ich erwähne dies alles hier lediglich nur, um darzutun, dass ich in dieser Periode bei dieser Kost in jeder Beziehung angestrengt tätig war.

Anfang August brach wieder eine sogenannte Reinigungs- und Heilkrisis über mich herein, in welcher der Darm an einigen Tagen erst flüssige, sehr stinkende Schleimmassen entleerte (also gleichsam eine Art von Selbstklistierung des Darmes stattfand) und alsdann alte, sehr stinkende zähe Schleimknoten, klebrig wie Tischlerleim, und fingerlange, zähe, klebrige Schleimfäden absonderte (was auch in allen vorhergehenden Krisen, aber nicht so energisch wie dieses Mal, der Fall war) und sehr trüber und sehr stinkender Harn entleert wurde, sowie eiterartige Absonderungen aus den innern Augenwinkeln stattfanden.

Ich schalte hier ein, dass solche Reinigungs- und Heilkrisen beim Übergange zur vegetarischen Diät eintreten und je nach dem Zustande des betreffenden Individuums eventuell viele Jahre hindurch in ziemlich regelmässigen Intervallen sich wiederholen, wie dies bei mir der Fall gewesen ist. Ich komme weiter unten noch näher auf das Wesen dieser Krisen zurück.

Diese August-Krisis war bedeutend heftiger, aber auch in ihrem Reinigungseffekte bedeutend ergiebiger als alle Krisen, welche ich in den vorhergehenden Jahren durchmachte, und ich war mehrere Tage recht schwach und elend.

Um die Heftigkeit dieser Krisis abzuschwächen, ass ich von nun an in Zeiträumen von ein bis drei Tagen, je nach meinem Befinden, abwechselnd dazwischen auch mittags oder abends gekochte vegetarische Speisen und anf Spaziergängen, welche den ganzen Tag dauerten, Milch und Butterbrot, so dass ich also abwechselnd wieder einige Tage ausschliesslich von zwei Pfund Trauben lebte und dann wieder einige Tage lang mittags oder abends gekochte vegetarische Speisen ass. Als dann die Krisis allmählich vorüberging, lebte ich wieder in Perioden von 6-8 Tagen ausschliesslich nur von zwei Pfund Trauben täglich und ass dann wieder einige Tage lang gekochte vegetarische Speisen oder Milch und Butterbrot auf Märschen und so abwechselnd bis zum 21. Oktober, an welchem Tage ich die Klausur antrat.

Ich erwähne hier noch, dass ich in sämtlichen Krisen, also auch bei gekochter vegetarischer Kost, immer vorübergehend sehr stark abmagerte, doch holte ich den erlittenen Gewichtsverlust nach überstandener Krisis, qualitativ bei derselben Diät bleibend, quantitativ mich dem wachsenden Appetite anpassend, immer bald wieder ein. Dass ich in der durch Rohfruchtdiät entstandenen Augustkrisis behufs Abschwächung deren Heftigkeit qualitativ nicht genau bei derselben Diätform blieb, war eine Inkonsequenz meinerseits und ein therapeutischer Fehler, denn durch den geschilderten, wenn auch nur teilweisen Diätwechsel wurde die Krisis unterbrochen und konnte sich nicht gänzlich austoben und die folgende Krisis, welche mich dann einige Monate später während der Klausur befiel, wurde infolgedessen um so heftiger.

Dass das oben geschilderte, der Klausur vorhergehende Training meinem Körper schon einen gewissen Grad von Anpassung an diese Diät von täglich zwei Pfund rohen frischen Früchten verliehen hatte, geht aus folgendem hervor: 
Nachdem ich in der Klausur vom 21. Oktober ab vierzehn Tage lang von diesen zwei Pfund frischen Früchten pro Tag (meistens Trauben, aber dazwischen auch einige Male Äpfel) gelebt und während dieser Zeit durchschnittlich zwölf Stunden täglich, alles schriftlich arbeitend, studiert und abends zwischen 9 und 10 Uhr mich tüchtig im Dauerlauf trainiert und dazu häufig am l'age, oft alle Stunden, um mich auch körperlich zu betätigen und das viele Sitzen zu unterbrechen, je dreissig Kniebeugen und dreissig Hantelübungen mit Sandow's Federhanteln gemacht hatte, machte ich am 2. und 3. Nov. abends einen Dauerlauf von einer deutschen Meile, ohne hinterher müde, geschweige ausgepumpt zu sein, wobei zu dem noch zu berücksichtigen ist, dass ich dieses Jahr fünfzig Jahre alt werde.

Ich brauche wohl nicht zu versichern, dass ich Vorstehendes nicht niederschrieb, um mit meinen Leistungen in körperlicher und geistiger Beziehung zu prahlen, sondern ganz lediglich nur, um darzutun, welch ziemlich hohen Grad von Ausdauer und Leistungsfähigkeit selbst ein früher schwer chronischkrank gewesener Mensch (siehe meinen Krankheitsbericht) durch die vegetarische alkohollose Lebensweise zu erlangen vermag.

Den abendlichen Dauerlanf musste ich leider vom 4. November ab aufgeben, weil ein Schmerz im Gelenke meines rechten Fusses entstand, welcher vor einigen Jahren einmal verstaucht war; andernfalls würde ich den Dauerlauf ganz bestimmt noch bis gegen den 8 . Dezember haben leisten können, um welche Zeit die Krisis, welche mich während der Klausur heimsuchte, heftiger zn werden anfing, und daher Schonung geboten war. Durch das Eintreten des oben erwähnten Fussübels wurde mein Befinden während der weitern Klausurzeit recht ungünstig beeinflusst, denn ich musste den Fuss über drei Wochen lang vollständig schonen und daher den ganzen Tag sitzend zubringen, durch welche sitzende Lebensweise, ohne jede unterbrechende Bewegung, die Verdauang sehr erschwert wurde, indem der Kot sich zu harten Knoten zusammenballte, die nur mit grosser Beschwerde und Anstrengung entleert werden konnten. Auch die lange Freiheitsentziehung wirkte, obwobl sie ja eine freiwillige war, auf die Daner ungünstig auf mich ein und ebenso das ewige Einerlei des Klausurmilieus.

Dass mich gerade während der Klausurzeit nochmals eine so überaus heftige Krisis befallen würde, hatte ich allerdings nicht geahnt, sondern ich hatte geglaubt, nachdem ich im August noch solch eine heftige Krisis durchgemacht hatte, nun durch alles hindurch und durch das oben geschilderte Ernährungstraining anch genugsam an die ausschliessliche Zweipfundfruchtnahrung angepasst zu sein, sonst würde ich die Klausur noch um ein halbes Jahr verschoben haben, um mir vorher noch eine grössere Anpassung anzzeignen. (Um roliständig za berichten, schalte ich hier noch ein, dass ich im Laufe der letzten fünf Jahre vier Hunger- and Durstperioden von 8-14 Tagen zar Übung im Hungern und Dürsten bei starker körperlicher Anstrengung machte.)

Trotzdem es nun wirklich keine Annehmlichkeit war, während einer Klausur derartiges durchzumachen, freue ich mich aber doch, dass mich eine solche Krisis gerade während der Klausur befiel, weil leider das Wesen dieser Reinigungsund Heilkrisen, weil dabei eine Abmagerung und ein Kräfteverfall, aber alles nur vorïbergehend, eintritt, vielfach verkannt und unrichtig anfgefasst wird, 
da nur derjenige über diesen schon mit dem Übergange zur vegetarischen gekochten Diät, aber in noch schärfer akzentuierter Weise mit dem Übergange zur vegetarischen Rohkostdiät unzertrennlich und naturnotwendig verbundenen Wandlungsprozess im menschlichen Körper vollständig und eingehend unterrichtet sein kann, der dies alles am eigenen Körper in einer Reihe von Jahren kennen gelernt hat.

Der Vegetarismus erschliesst ja eben neue hochwertvolle Lichtblicke in das Wesen der Physiologie und in die Therapie der Zukunft und ist daher eine Fundgrube neuer bahnbrechender Wahrheiten, die auf das eingehendste studiert zu werden verdienen, und dies kann man nicht besser undeingehender, als wenn man dies alles selbst am eigenen Körper durch ununterbrochene Selbstbeobachtung (z. B. regelmägsige Beobachtung und Untersuchung des Kotes und des Harns) kennen lernt.

Durch den Umstand nun, dass diese Krisis mich gerade während der Klausur befiel, wurde den mich beobachtenden Herren Gelegenheit geboten, das Wesen einer solchen Reinigungs- und Heilkrisis an mir zu studieren, und ich vertraue fest auf deren Gerechtigkeitssinn, dass sie, da ja, wie gesagt, solche Krisisumstände, um sie ganz bis auf den tiefinnersten Grund richtig zu verstehen, selbst am eigenen Körper durchgemacht und d u r chemp funden werden müssen, auch auf meine Aufschlüsse darüber einigen Wert legen, meinen Worten, die ehrlich und wabr sind, Glauben schenken und aus allen diesem die richtigen Schlüsse ziehen werden.

Diese Reinigungs- (Ausscheidungs-, Absonderungs-, Abstossung-, Entgiftungs-) und Heilkrisis, welche ich während der Klausur durchgemacht habe, war eine überaus heftige, in die tiefsten ältesten Schichten meiner Körpersubstanz eindringende, aber die durch dieselbe erzielten Reinigungs- und Heilergebnisse befriedigen mich im höchsten Grade.

Diese Ergebnisse sind folgende:

1. Fis wurde eine sehr grosse Menge harnsaurer Salze ausgeschieden; harnsaure Salze aber sind Stcffwechselreste (Gichterzeuger), welche in einen ganz naturgemäss lebenden menschlichen Körper durchaus nicht hineingehören und welche, wenn der Mensch zu dieser naturgemässen Rohfruchtnahrung übergeht, durch die lösende, reinigende Eigenschaft des infolge der Fruchtsäfte chemisch veränderten Blutes ganz unweigerlich aus der Körpersubstanz losgelöst und mit dem Harne ausgeschieden werden; denn sie sowohl wie die sie enthaltende Körpersubstanz harmonieren nicht mit dem Fruchtsaftblut und also auch nicht mit der neuen Körpersubstanz, welche sich aus der Fruchtnabrung aufbauen will, und sie müsse also, unter gleichzeitiger Zersetzung des sie enthaltenden Körpereiweisses, weichen. Wenn nun auch, wie ja der während der Klausur gradatim fortschreitende Rückgang meines Körpergewichtes zeigt, die Anpassung meines Körpers an die ausschliessliche Rohfruchtdiät ohne Nüsse noch nicht gross genug war, um mein Körpergleichgewicht zu erhalten, so ist dieser Gewichtsverlust aber doch nicht einzig und und allein auf diesen Grund resp. auf unzulängliche Ernährung zurückzuführen, sondern diese Krisis und speziell diese starke Ausscheidnng von harnsauren Salzen spielt auch dabei eine wichtige Rolle, und es ist doch auch zu berücksichtigen, dass ich in jeder der Krisen der vorhergehenden Jahre immer sehr 
stark, aber immer nur vorübergehend, abgemagert bin, und ich kann zudem den grossen Verlust an Körpereiweiss auch durchaus gar nicht als eine Schädigung meiner Gesundheit aufassen, sondern ganz im Gegenteil als eine hochwertrolle Förderung derselben, denn ohne solchen hätte der Reinigungs- und Heilprozess nicht so in den tiefinnersten ältesten Kern meiner Körpersubstanz eindringen und nicht eine so gründliche Reinigung stattfinden können. Hieraus und aus dem Klausurschlussergebnis, dass ich in den Ietzten Tagen der Klausur bei einem Körpergewichte von nur $41 \mathrm{~kg}$, trotz dieser starken Abmagerung, trotz des grossen Körpereiweissverlustes und trotz meines sehr schlechten, einem Typhuskranken ähnelnden Aussehens, eine nicht unbedentende Kraft entwickeln konnte (wovon sich die mich beobachtenden Herren durch persönliches Ringen mit mir überzeugt haben), glaube ich den Schluss ziehen zu dürfen, dass der Mensch ohne Gefahr für sein Leben und ohne jeden Schaden für seine edlen Organe und für seine Lebenskraft einen erheblichen Teil seines Körpereiweisses zeitweise und vorübergehend entbehren; kann; denn wenn ich auch noch nicht meine volle Kraft und Ausdaner zurückgewonnen habe, was aber - ich fühle das auf das bestimmteste - in einigen Monaten der Fall sein wird, so bin ich doch schon wieder recht kräftig und mindestens so kräftig wie viele Männer meines Alters. Zur nähern Illustration des oben Gesagten erwähne ich noch, dass die schlimmste Zeit dieser Krisis in die letzte Woche des Dezember fiel, zu welcher Zeit ich mich einige Tage recht angegriffen fühlte, aber, nachdem ich diesen Kulminationspunkt der Krisis überwunden batte, konnte ich schon wieder vierzehn Tage darauf, also in den letzten Tagen der Klausur, oben erwähntes Ringen anstellen, woraus hervorgeht, wie schnell sich nach überwundener Krisis die Kräfte wieder heben.

2. Es fanden wieder, wie auch schon in früheren Krisen, eitrige Absonderungen aus den innern Winkeln meiner früher mit Atropin behandelten Augen statt.

3. Während der Nacht zum 26. Dezember wurde ein gestielter Nasenpolyp mit geringer Blutung abgestossen. Diese Abstossung eines Polypen ist ein ganz besonders charakteristischer Beweis dafür, dass während einer solchen Krisis das im menschlichen Körper vorhandene Bestreben, alles was nicht in ihn hineingehört, loszulösen, auszuscheiden, abzusondern, abzustossen, in energischster Weise angefacht und verstärkt wird, denn ein Polyp ist eine Neubildung und gehört absolut nicht in einen naturgemäss lebenden menschlichen Körper hinein und wird also nun, nachdem die Fruchtsäfte die abstossende Fähigkeit des Körpers in hohem Grade gekräftigt haben, abgestossen. Hier könnte man nun einwenden, dass es auch bei nicht vegetarisch lebenden Menschen vorkommt, dass Polypen sich von selbst abstossen, aber bei mir ist dies durchaus nicht der Fall gewesen, sondern ich habe mich von meinem 20. Jahre an (siehe meinen Krankheitsbericht) verschiedenen Eingriffen und Operationen wegen dieser Nasenpolypen unterziehen müssen, welche aber alle nichts halfen (weil ja solche Operationen die Grundursachen keineswegs beheben, da durch dieselben das Übel nicht an der Wurzel angepackt werden kann), sondern ganz im Gegenteil das Übel nur verschlimmerten, denn die betreffenden Stellen in der Nase wurden nur dadurch noch mehr gereizt und nach einigen Jahren waren die neu gebildeten Polypen in noch lästigerer 
Weise wieder da: also trotz Operation kamen sie wieder - und jetzt wird einer ganz von selbst, ganz schmerzlos abgestossen!

4. Es sind im Verlaufe dieser Krisis die Strikturen, unter welchen ich noch immer zu leiden hatte, vollständig behoben worden; die Harnwege sind offener, weiter, freier geworden und ich kann jetzt ganz leicht und ohne jede Beschwerde harnen, welch schöne Ausheilung ich nicht hoch genug veranschlagen kann.

5. Vom 7.-12. Januar wurde ein reichliches Quantum breiigen, schleimigen, sehr stinkenden Kotes entleert und seitdem ist meine Zunge, welche bis dahin die letzten zwölf Jahre hindurch immer stark belegt gewesen ist (das Zeichen eines chronischen Magen- und Darmkatarrhs und besonders das einer chronischen Darmverschleimung), schön rot und ohne jeden Belag; Hand in Hand damit geht das Erwachen einer grösseren Esslust.

6. Es bildete sieh in den letzten Wochen ein tüchtiges Reinigungsgeschwür an der Wade meines linken Beines. Also wieder ein weiterer Beweis, dass jetzt eine Reinigungskrisis in meinem Körper im Gange ist und dass in einer solchen Krisis eine Reinigung des Körpers von alten Schlacken stattfindet. Dieses Geschwür ist nicht etwa durch eine äussere Verletzung, durch eine offene Stelle, in welche etwa etwas hineingekommen wäre, entstanden, sondern dasselbe hat sich ganz von selbst von innen heraus entwickelt und ist, ebenso wie die anderen Ausscheidungen, das Resultat der durch die Fruchtsäfte energischst angeregten Ausscheidungskraft und Selbstheilkraft des Körpers. Ich habe während der letzten Jahre mehrere Reinigungsgeschwüre gehabt, und ist meine Behandlungsweise von Geschwüren an meinem eignen also vegetarisch lebenden Körper gänzlich nihilistisch; ich tue nämlich nichts daran: Kein Schneiden, kein Ausdrücken, kein Auswaschen, keinen Verband, absolut nichts. So habe ich auch dieses Geschwür behandelt und nur ein leinenes Läppchen über dasselbe gehängt, damit keine Reibung durch das Beinkleid stattfinden konnte; das Geschwür hat so behandelt tüchtig ausgetragen und ist dann in wenigen Tagen, ohne eine Narbe zu hinterlassen, abgeheilt.

7. Meine Barthaare, die vor der Vergiftung meines Körpers durch subkutanes Einspritzen von Quecksilber (siehe meinen Krankheitsbericht) immer auffallend lang und kräftig waren, nach der Quecksilberbehandlung aber zuerst gänzlich ausfielen und dann nur immer kümmerlich wuchsen, fangen an wieder kräftiger zu wachsen und mehr Glanz zu bekommen. Dieses kräftigere Wachstum der Haare - auch die Kopfhaare zeigen eine Tendenz zu besserem Wachstume und oben auf dem Kopfe entwickeln sich neue junge Haare - ist ein weiterer schlagender Beweis der stattgefundenen Körperreinigung und -entgiftung.

Dies alles verdanke ich dieser letzten, überaus heftigen, tief durchgreifenden Reinigungs- und Heilkrisis, und wenn man die Summe obiger sieben Positionen zieht, so kann man sich doch wahrlich ganz unmöglich der Erkenntnis verschliessen, dass während der Klausur eine solche Reinigungskrisis in meinem Körper stattgefunden hat, dass in einer solchen Krisis ein erhöhtes lebhaftes Bestreben des Körpers zutage tritt, sich zu reinigen, ihm Schädliches auszuscheiden, abzusondern, nicht zu ihm Gehörendes (z. B. Nasenpolypen) abzustossen, mit einem Worte, eine Reinigung des Körpers von Grund aus in seinen verborgensten Winkeln und im Anschlusse an diese Reinigung eine Ausheilung 
alter chronischer Schäden und Übel, denen die Medizintherapieja vollständig machtlos gegenüber steht, herbeizuführen, dass eine solche Krisis also keine Schädigung, sondern in ihren Folgen, in ihrem Endresultate, eine überaus wohltätige, segensreiche, grosse Förderung der Gesundheit bewirkt, dass die Lehre von diesen Reinigungs- und Heilkrisen also keine schädliche Irrlehre, sondern eine auf dem ehernen Naturgesetze felsenfest beruhende Wahrheit ist, eine Wahrheit, welche der Therapie neue ungeahnte Perspektiven eröfnet, und dass daher diese Lehre und somit der Vegetarismus und die Naturheilmethode überhaupt nicht bekämpft werden dürfen, sondern wissenschaftlich auf das Allereingehendste studiert, begründet und dann in allen Volksschichten verbreitet werden müssen, und zwar muss diese Belehrung und Aufklärung des Volkes schon in der Schule beginnen. -

In solchen Krisen geht das Befinden auf und ab, und wenn man schon einen oder auch mehrere Tage hindurch sich schon viel wohler und kräftiger fühlt, überfällt einen dann plötzlich, meistens nachts, wieder irgendein, oft mehrere Stunden anhaltender, oft äusserst heftiger und schliesslich mit irgendeiner kritischen Ausscheidung endigender Schmerz in Darm, Blase, Nieren, Lunge oder Galle usw., also an denjenigen kranken belasteten Stellen der Organe des chronisch-kranken Körpers, deren Reinigung und darauf folgende Ausheilung der Zweck dieser Reinigungs-(Entgiftungs-) und Heilkrisen ist, aus welcher Organreinigung und -ausheilung heraus sich dann späterhin die Kräftigung und Regeneration (Verjüngung) des ganzen Körpers entwickelt, da nummehr wieder in allen Organen, welche vorher belastet, beengt und daher schlecht funktionierend (chronisch-krank) waren, èn besseres, leichteres, freieres und wieder richtiges, geregeltes Funktionieren stattfindet. Auch die Haut beteiligt sich an dem Ausscheidungs- und Reinigungsgeschäfte, indem im Verlaufe der Krisen häufig starke, teilweise sehr stinkende Nachtschweisse eintreten.

Die Tatsache dieser mit dem Übergange zur vegetarischen Diät eintretenden und sich je nach der Hartnäckigkeit des Falles eventuell eine längere Reihe von Jahren hindurch in ziemlich regelmässigen Perioden bis zur völligen Reinigung und völligen Ausheilung wiederholenden Reinigungs- und Heilkrisen, die fernere, schon oben erwähnte Tatsache, dass diese Krisen bei dem Übergange zur ausschliesslichen vegetarischen Rohkost noch viel heftiger, stärker, durchgreifender, aber auch heilkräftiger sind als bei dem Übergange zur vegetarischen gekochten Kost, und die weitere Tatsache, dass bei Körpern wie der meinige, welche viel mediziniert haben und deren Übel also durch dieses Medizinieren zu chronischen Leiden verschlimmert und vertieft worden sind, und besonders bei solchen Körpern, in welche Gifte subkutan eingespritzt worden sind, solche Krisen sich eventuell durch eine sehr lange Reihe von Jahren hindurch wiederholen müssen und am allerheftigsten auftreten, alle diese Tatsachen sind von Hunderten ehrenwerter Mannern - und darunter sind viele hochehrenwerte, von der Wichtigkeit und dem hohen Werte des Vegetarismus und der Naturheilmethode und von der unumstösslichen Wahrheit der 
Lehren und Heilerfolge derselben durch langjährige Erfahrung im Tiefinnersten überzengte, wissenschaftlich gebildete, promovierte, approbierte Ärzte - als ganz unzweifelhaft richtige Wahrheiten festgestellt worden.

Es wäre sehr zu wünschen, dass junge Mediziner einige Jahre in den von diesen abprobierten Ärzten geleiteten Naturheilanstalten zubrächten, um die Naturheilmethode (giftfreie physikalisch-diätetische Heilweise) gründlichst kennen zu lernen; dann würden bald die ganz unhaltbaren Zustände aufbören, dass ein grosser Teil der Mediziner heute noch die so überaus segensreiche Naturheilmethode für gemeingefährliche Kurpfuscherei hält und auf das allerschärfste bekämpft!

Zu meiner obigen Bemerkung über das Verhalten solcher Körper, in welche Gifte subkutan eingespritzt worden sind, füge ich noch hinzu, dass dies bei mir (siehe meinen Krankheitsbericht) mit Quecksilber der Fall ist, welches ja mit dem Körpereiweiss chemische Verbindungen eingeht, sich so in die Körpersubstanz gleichsam einkrallt und daher nurdurcheine so langjährige, mit Körpereiweisszersetzung verbundene Radikalkur, wie ich sie durchgemacht habe, gänzlich wieder aus dem Körper hinausgebracht werden kann, und welches dnrch seine Giftwirkung die Funktionen des Körpers und des Geistes in bösester Weise lähmt und infolgedessen anf das Empfinden der Seele anf das allerschlimmste, auf das verhängnisvollste einwirkt, woher es kommt, dass so viele mit Quecksilber Behandelte durch Selbstmord enden!

Die Reinigungs- und Heilkrisen sind gleichsam Etappen auf dem sichern, aber allerdings dornenvollen Wege, auf welchem sich der Chronischkranke, selbst wenn, wie in meinem Falle, seine Übel ein Jahrzehnt und mehr alt sind, zur Wiedergesundung emporringen kann, er muss nur, wie es a uch komme, fest vertrauen, fest beharren und sich durch niemanden, durch nichts von dem eingeschlagenen Wege ablenken lassen!

Derjenige aber, der fest beharrt hat, der dies alles an seinem eigenen Körper durchgemacht hat und sieht, wie er sich durch diese Krisen hindurch Schritt für Schritt aus bösem chronischen Krankheitsclende zur vollständigen Wiedergesundung, ja zu einer Körperverjüngung hindurch- und emporringt, der hegt den heissen Wunsch, dass dieser so überaus hohe therapeutische Wert des Vegetarismus und das Wesen der mit demselben unzertrennlich verbundenen Reinigungs- (Entschleimungs-, Entfettungs-, Entgiftungs-) und Heilkrisis doch von der Medizinwissenschaft nicht verkannt, sondern eingehend nachgeprüft und anerkannt, und dass von ihr diese vorzügliche unübertreffliche Heilweise im Vereine mit den Heilfaktoren der giftfreien Behandlungsweise der Naturheilmethode, welche beide vereint dic Therapie der Zukunft bilden, angewandt werden möge!

Denn die heute leider noch immer offiziell geltende symptomatische Therapie unter Anwendung von Medizingiften ist ja in Wirklichkeit gar keine Therapie, da sie durch ihre lähmende Giftwirkung ganz lediglich nur eine Veränderung des Krankheitsbildes, nämlich nar das Verschwinden der Symptome, herbeiführt, 
woraus die verhängnisvolle irrige Annahme entsteht, dass die Krankheit behoben sei. Dies ist aber nicht der Fall, denn diese Medizinalbehandlung hat durchaus gar keine wirkliche Heilung von Grund aus bewirkt, da keine Körperreinigung stattfinden konnte, weil diese Gifttherapie ganz unausbleiblich eine giftige Nebenwirkung zur Folge haben muss, welche einen lähmenden Einfluss auf das Nervensystem, auf die Tätigkeit der Organe und somit auch auf das natürliche Reinigungs- und Heilbestreben des Körpers ausübt; hieraus entwickeln sich dann, da zudem das ursprüngliche Übel, nunmehr latent weiter schlummernd, fortwährend aber vergeblich nach Ausheilung ringt, die verschlimmerten Rückfälle, kompliziert durch Affektionen edler Organe, und schliesslich die bösen chronischkranken Zustände, welche, wenn mit der Giftbehandlung fortgefahren wird, zu unheilbaren ausarten.

In den Reinigungs- und Heilkrisen findet nun ein Rückwärtswiederaufrollen der früher durch Medizingiftbehandlung nicht aus dem Körper hinausgeheilten, sondern in ihn hinein zurückgetriebenen, in ihm festgehaltenen, - ja ich möchte sagen - in ihn gleichsam "hineingewickelten" und dadurch, wie oben erwähnt, nunmehr latent (gebunden) in ihm schlummernden früberen akuten Übel statt, welche also in diesen Krisen aus diesem latenten chronischen wieder in ihren ursprünglichen akuten Zustand übergeführt werden und jetzt erst zur wirklichen A usheilung vermittelst der in den Krisen eintretenden energischen Körperreinigung gelangen.

Eine akute Krankheit äussert sich in dem heftigen, mit Fieber verbundenen Bestreben des Körpers, in ihm befindliches Unreines, ihm Fremdes, nicht in ihn Hineingehörenden durch eine erhöhte Lebenstätigkeit - das ist nämlich das Fieber - hinauszuwerfen, und dieses Bestreben muss eine richtige Therapie unterstützen, aber nicht lähmen, wie dies die Medizingifttherapie tut, entgegen dem vornehmsten Grundsatze aller Heilkunst: nunquam nocere! Diese Unterstützung besteht in der giftfreien Therapie der Naturheilmethode hauptsächlich darin, dass sie das Fieber nicht etwa unterdrückt, wie das durch die Medizingifte geschieht, sondern solches durch sanfte Wasseranwendungen, also durch eine Anregung der Ausscheidungstätigkeit der Haut, solche also gleichsam als Ventil benutzend, nur in den nötigen Schranken hält, im übrigen aber als wertvollstes Heilmittel nach aller Möglichkeit ausnützt.

Krankheit überhaupt, sowohl akute wie chronische, ist also ein Behaftetsein, ein Belastetsein des Körpers mit ihn krankmachenden, ihm fremden, nicht in ihn hineingehörenden unreinen Stoffen, Stoffwechselresten (z. B. harnsaure Salze, Fettablagerungen) usw., und der Unterschied zwischen akuter und chronischer Krankheit ist der, dass bei der akuten oben genanntes Reinigungs- und Heilbestreben des Körpers noch energisch vorhanden ist, dass dagegen solches bei chronischer Krankheit vollständig gelähmt darnieder liegt und nur durch vegetarische Diät und die Heilfaktoren der Naturheilmethode wieder erweckt werden kann, wenn überhaupt noch Hilfe möglich und die nötige Lebenskraft vorhanden ist. Aber selbst in den bösesten unheilbaren Fällen bietet die giftfreie Naturheilweise in ihren Heilfaktoren wirksamste Mittel zur Linderung der Schmerzen und Leiden.

Eine weitere Lehre dor Naturhoilmethode ist die, dass die Beschaffenheit des Blutes eine grosse und wichtige Rolle bei Krankheiten (z. B. bei Krebsleiden) 
und deren Heilung spielt. Eine durchgreifende regenerierende Einwirkung auf die Beschaffenheit des Blutes hat nun aber die vegetarische Diät, und es ergibt sich aus der Tatsache der durch das Blut vermittelten körperreinigenden Heilkraft der vegetarischen Diät der schlagende Beweis für die Richtigkeit dieser Lehre; so kommt also die alte Lehre der Humoralpathologie wieder zu ihrem Rechte.

Die Bakterien sind als Begleiterscheinung der Krankheiten, als naturnotwendige Produkte, ja eventuell sogar als nötige Mithelfer des Krankheitsprozesses aufzufassen, und soweit sie bei ansteckenden Krankheiten als Krankheitserreger in Frage kommen, sind sie nur die Auslöser der Krankheit und nicht die Ursache derselben: die Krankheitsursache liegt tiefer und ist ganz lediglich nur in oben erwähntem Belastetsein des Körpers mit ihn verunreinigenden Fremdstoffen zu suchen, denn nur in einem solchen unreinen kranken Körper finden die Bakterien Nahrung und Lebensbedingung, aber einem reinen, gesunden, mässig, und naturgemäss lebenden Körper können sie nichts anhaben, weil solcher ihnen keinen Nährboden bietet.

Diese mit zwingend-überzeugender Logik aufgebaute Krankheitslehre der Naturheilmethode, welche ich oben nur fluchtig in ibren Grundlinien skizziert habe, aber erwähnen musste, um meine Ausfübrungen über das Wesen der Reinigungs- und Heilkrisen in das richtige Licht zu rücken, wird leider als eine Irrlehre aufgefasst, sie ist es aber wahrlich nicht, denn die Praxis beweist und erhärtet ihre Richtigkeit in tausenden und abertausenden Fällen; es kann ja auch nicht anders sein, denn die Anwendungsformen der giftfreien Heilfaktoren der Naturheilmethode sowie deren Wirkungen fügen sich in ihre Krankheitslehre zu einem logisch-harmonischen Ganzen ein.

Das was zur unrichtigen Beurteilung der Reinigungs- und Heilkrisen und damit auch zur unrichtigen Beurteilung des Vegetarismus und der Naturbeilmethode überhaupt führt, ist der schon oben kurz erwähnte Umstand, dass vorübergehend eine starke Abmagerung, ein Sinken der Kraft, schlechtes Aussehen, schwacher Puls, sowie eine starke Tendenz zu kalten Händen und Füssen eintritt, welche Symptome irrtümlicherweise als eine Verschlimmerung, ja sogar als eine bleibende Schädigung aufgefasst werden; aber dies alles ist, wie jeder in den Krisen nicht wankende, fest beharrende Patient zu seiner hohen Freude an sich erfährt, ja nur vorïbergehend! Die Abmagerung wird ja bald wieder überwunden, die Kraft hebt sich ja bald wieder, ja sie wird nach überstandener Reinigung eine grössere wie vor der Krisis, und das schlechte Aussehen verwandelt sich in ein Wiederaufblühen! Wenn nun in einer Krisis eine solche scheinbare Verschlimmerung eintritt, werden manche Patienten, die das wirkliche Wesen und die Notwendigkeit dieser Krisen nicht begriffen haben, wankelmütig und fahnenflüchtig und eilen wehklagend und auf die Naturheilmethode schimpfend zum Mediziner; so wird denn diese segensreiche Heilmethode, diese hehre Helferin der kranken Menschheit, diskreditiert und beschimpft, weil diese willensschwachen Patienten nicht begreifen konnten, dass diese scheinbare Verschlechterung ihres Zustandes nur vorübergehend war, dass sie fest durchhalten mussten, um den Preis zu erringen und dass hier der Spruch gilt: Per aspera ad astra! - Dass Abmagerung und ein Sinken der Kraft in den Krisen vorübergehend eintritt, ist ja auch ganz erklärlich, denn der Körper hat ja, indem sich in ihm dieser 
Reinigungsprozess vollzieht, eine grosse, ihn sehr anstrengende, innere Arbeit zu Ieisten, welche nun in erster Linie vorgeht, und infolgedessen muss auch während dieser Zeit das Ernährungsgeschäft in den Hintergrund treten. Diese Momente müssen bei Beurteilung der Phasen, welche mein Körper während der Klausur durchgemacht hat, unbedingt mit in Rechnung gestellt werden. -

Ich schalte hier noch als charakteristisch ein, dass jedesmal einige Stunden vorher, ehe der mit den früher erwähnten zähen stinkenden Schleimknoten und Schleimfäden behaftete Kot ausgeschieden wurde, meine Hände immer ganz besonders kalt und blutleer waren; einige Fingerköpfe waren oft dabei leichenblass und wie leblos und ohne Gefühl. Sobald jedoch dieser kritische Kot entleert war, flutete das Blut wieder kräftig in die Hände zurück und wurden solche dann schön warm und von rötlicher Farbe. Auch mein Allgemeinbefinden hob sich dann immer sofort sehr.

Zum weiteren Beweise des hohen therapeutischen Wertes der vegetarischen Diät und der Heilfaktoren der Naturheilmethode führe ich, einen für viele, hier folgenden Fall an: Im Frühjahre 1900 wohnte ich einige Wochen im Lichtluftbadeparke des unter der Leitung eines approbierten Arztes stehenden Kronbergschen Erholungsheims und Sanatoriums in Neustadi (Südharz). Zu dieser Zeit kam dort ein den gebildeten Kreisen angehörender Berliner Herr hin, welcher sehr schwer von Syphilis infiziert war; er war am ganzen Körper inkl. Gesicht und Kopf über und über mit syphilitischem Ausschlage bedeckt und sah ganz schrecklich aus. Dieser Herr ist nun dort durch vegetarische gekochte Diät und durch Anwendung von Lichtluft- und Sonnenbädern, durch sanfte Wasserbehandlung und Wohnen und Schlafen in einer Lufthütte radikal geheilt worden und ist wieder dauernd ganz gesund und arbeitskräftig, wie ich mich noch dieser Tage durch einen Besuch bei ihm überzeugt habe. Leider geht es aus begreiflichen Rücksichten nicht an, den Namen dieses Herrn zu nennen, aber ich verbürge die Wahrheit des oben Gesagten mit meinem Worte.

Da ich nun einerseits körperlich, geistig und seelisch so unsäglich schwer unter der bösen giftigen Nachwirkung des subkutan in mich hineingespritzten Quecksilbergiftes habe leiden müssen und ich mich anderseits an obigem eklatanten Falle durch eigene Anschauung davon überzeugt habe, dass ein solch schwerer Fall von Syphilis durch oben geschilderte Behandlungsweise radikal heilbar ist, so habe ich in dieser wissenschaftlichen Frage, wenn ich auch nur ein Laie bin, das Recht der Kompetenz erworben, und es erwächst mir daraus die Gewissenspflicht, an alle Ärzte die dringendste Bitte zu richten, doch Syphilis nie und nimmer mehr mit Quecksilber zu behandeln, sondern solche mit vegetarischer Diät und den giftfreien Heilfaktoren der Naturheilmethode zu heilen!

Zum Schlusse ergreife ich mit Freuden diese Gelegenheit, den sämtlichen Herren, unter deren wissenschaftlicher Beobachtung ich während der Klausur gestanden habe, für die mir erzeigte grosse Fürsorge und das mir erwiesene freundliche Wohlwollen meinen herzlichsten Dank zu sagen!

Berlin, Anfang Februar 1903. 
Eine kurze Kritik meinerseits soll hier nur der Begriff „Heilkrise" finden, welcher in vielen Publikationen und Erörterungen der Vegetarier eine erhebliche Rolle spielt. Es handelt sich hier m. E. um folgenden Vorgang: Bei dem Übergang zu einer neuen eigenartigen Diät stellen sich Störungen des allgemeinen Woblbefindens und speziell solche der Verdauungsorgane ein, welche um so heftiger und nachdrücklicher sind, je mehr die Kost von derjenigen abweicht, die auf Grund millionenfacher praktischer Erfahrungen und vielfacher wissenschaftlicher Belege als die rationelle für die menschliche Ernährung erkannt worden ist. Allmählich allerdings tritt in den meisten Fällen eine Gewöhnung an die neue Kost ein, sei es, dass der Eiweissbestand des Körpers derartig zurückgeht, dass der Organismus mit einer geringeren Eiweisszufubr auszukommen vermag, sei es, dass die Verdauungsorgane durch erhöhte Tätigkeit die gärungsfähigen und schwerer verdaulichen Stoffe, welche eine stark cellulosehaltige Pflanzennahrung dem Organismus zuführt, zu schnellerer Ausscheidung aus dem Körper bringen lernen. Auch in bezug auf verschiedene Ernährungsformen zeigt der Organismus eine erstaunliche Anpassungsfähigkeit, und, ist auf solche Weise eine Gewöhnung an die betreffende Diät eingetreten, hat der Körper die durch dieselbe bedingten Schädlichkeiten überwunden, so tritt ein relatives Wohlbefinden ein, welche nach den Unannehmlichkeiten der "Krisis" besonders wohltuend empfunden wird, und den gläubigen Vegetarier nun erst recht von der rationellen Zusammensetzung seiner Kost überzeugt. Dass diese Anpassungsfähigkeit des Organismus allerdings nicht ins unbegrenzte geht, dafür wird, wie ich glaube, dieser Versuch ein Beispiel geben, welches an Überzeugungskraft nichts zu wünschen übrig lässt.

Neben den in der Niederschrift des Herrn H. enthaltenen Gesichtspunkten, welche ihn veranlassten, eine derartige Kost zu wählen, nämlich dem Vertrauen in die Heilkraft dieser Diätform und den angeführten volkswirtschaftlichen Erwägungen, muss ich aber noch zwei weitere Gründe anführen, welche Herr H. zu Beginn des Versuches geltend machte. Dieselben waren, dass in der Tat die reine Fruchtnahrung die einzige Form der Ernährung sei, welche als wahrhaft naturgemäss bezeichnet werden könne; denn selbst der Ackerbau sei bereits ein Erzeugnis der degenerierenden Kultur, da er den Menschen veranlasse, künstlich zubereitete Nahrung, wie Brot, aufzunehmen. Nur in den Früchten, welche genau in derselben Form, wie sie in der Natur erzeugt sind, vom Menschen genossen 
werden können, sei die wahrhaft ideale Ernährung gegeben. Ferner ging Herr H. von dem gewiss nicht ganz unberechtigten Gedankengange aus, dass im allgemeinen die Nahrungszufuhr unserer gebildeten Stände eine überreichliche und daher dem Organismus wenig zuträgliche sei. So war er der Meinung, dass mit $1 \mathrm{~kg}$ Früchte der Mensch seine Nahrungsbedürfnisse bestreiten könne, und schlug mir vor, ihn in Beobachtung zu nehmen, während er sich in dieser Weise ernährte. Es ist selbstverständlich, duss ich meine grossen Bedenken hatte, diesen Versuch auszuführen, und dass ich mir wohl bewusst war, wie leicht dabei Gesundheit, ja das Leben der Versuchsperson aufs Spiel gesetzt werden könne. Doch war das Ersuchen des Herrn H. ein so dringliches, dass ich demselben bei dem hohen Interesse, welches eine derartige Untersuchung zu haben schien, nicht zu widerstehen vermochte. Schliesslich fühlte ich mich zu der Ausführung des Versuches geradezu verpflichtet, als mir Herr H. ehrenwörtlich versicherte, dass er den Versuch auf jeden Fall unternehmen werde. Denn ich musste mir sagen, dass der für seine Idee begeisterte Mann sich ohne ärztliche Beobachtung noch in weit höherem Masse durch einen derartigen Versuch gefährde, als wenn ich ibn unter ständiger Kontrolle hielt. Doch erklärte ich von vornherein, dass ich mit dem Augenblicke, wo ich die Fortsetzung des Versuches für die Versuchsperson als gefährlich ansehen müsse, denselben abbrechen würde, und ich für denselben dann keinerlei weitere Verantwortung übernehmen könne. Obgleich bei dem durchaus vornehmen und ehrlichen Charakter des Herrn, sowie bei seiner grossen Energie und der festen Überzeugung von der Richtigkeit seiner Idee mir persönlich jeder Betrug ausgeschlossen erschien, wurde der Versuch dennoch in strenger Klausur unter ständiger Beobachtung durchgeführt, was sich auch durchaus mit den Wünschen des Herrn Hauptmanns deckte, welcher auf diese Weise eine zweifellose Attestierung seines gelungenen Ernährungsversuches erwartete.

Durch das ausserordentlich liebenswürdige Entgegenkommen des Herrn Geh. Rats Prof. D r. Gold scheider wurde mir gestattet, Herrn H. in dem Einzelzimmer einer Baracke des biesigen städtischen Krankenhauses Moabit während der Versuchsdauer unterzubringen. Herrn Geh. Rat G o l d s e h e id e r sowohl wie dem damaligen Assistenten der Station, Herrn Dr. Alexander, bin ich zu ausserordentlichem Danke verpflichtet. Über die aligemeine Lebensweise der Versuchsperson gibt sein eigener Bericht ein zutreffendes Bild. 
Zu Beginn des Versuches am 30. Oktober 1902 stellte sich Herr H. als ein schlanker, hagerer Mann von 1,685 m Körpergrösse dar. Sein Gewicht betrug nur $53,5 \mathrm{~kg}$. Seine Gesichtsfarbe war eine gute, rosige, sein Puls war langsam, aber voll und kräftig, etwa 76 in der Minute. Die Folgen der vorhergehenden Ernährung, welche aus der von ihm selbst gegebenen Anamnese erhellt, waren nicht ausgeblieben. Sie zeigten sich in einem ausserordentlichen Fettschwund, welcher sich, in eigentümlichem Gegensatze zu dem blühenden Ausdrucke des Gesichts, in schlaffer, welker Haut zu erkennen gab, die sich überall in grossen Falten abheben liess. Die Muskulatur war dabei leidlich kräftig entwickelt. Subjektiv bestand vollkommenes Woblbefinden. Eine Untersuchung ergab keine wesentlichen pathologischen Merkmale. Nur ist zu bemerken, dass die Zähne schlecht waren und fortdauerndes Tränen der Augen bestand.

Der Versuch begann am 30. Oktober 1902, nachdem am Abend vorher durch Klystier eine starke Kotentleerung erreicht worden war. Er erstreckte sich in ununterbrochener Folge bis zum 13. Januar 1903, dauerte also 76 Tage. Der Versuch zerfiel durch Verschiedenheit der Ernährung in drei Perioden. In der ersten Periode, welche vom 30. Oktober bis zum 9. Dezember, also 41 Tage lang währte, nährte sich die Versuchsperson von $1 \mathrm{~kg}$. Trauben täglich. An einigen wenigen Tagen mussten, da Trauben nicht zu beschaffen waren, dieselben durch das gleiche Gewicht Äpfel ersetzt werden. Die zweite Periode dauerte vom 10. bis 30 . Dezember, also 21 Tage. In ihr wurde täglich $1 \mathrm{~kg}$ Äpfel verabreicht mit Ausnahme der Tage vom 25. bis 27. Dezember inkl., bei welchem ein Teiì der Äpfel durch das gleiche Gewicht getrockneter Feigen ersetzt wurde. In der dritten Periode, vom 31. Dezember 1902 bis 13. Januar 1903, war die Nahrung eine reichhaltigere und weniger gleichmässige. Sie setzte sich zusammen aus Äpfeln dreier verschiedener Sorten, Feigen und Apfelsinen.

Von sämtlichen Nahrungsmitteln wurden täglich grössere Proben entnommen, dieselben zu einer Durehschnittsprobe vereinigt und diese Durehschnittsprobe auf Stickstoff nach Kjeldabl und auf ihren Brennwert in der Bertbelot'schen Bombe analysiert. In derselben Weise wurde mit Harn und Kot verfahren. Ferner wurden in allen Nahrungsmitteln sowie im Kot Reineiweissbestimmungen nach Stutzer ausgefüht. Die nach diesem Verfahren gewonnenen Werte werden als "N aus Eiweiss" in Rechnung gestellt; obgleich 
ich mir bewusst bin, dass diese Bezeichnung keineswegs absolut zutreffend ist.

Eine Abgrenzung des Kotes der verschiedenen Perioden erwies sich als unnötig, da die Zugehörigkeit desselben durch die stets rejchlich in ihm enthaltenen Nahrungsreste zweifellos zutage trat und bei der Dauer der einzelnen Perioden auch abgesehen davon eine geringe Verschiebung nicht ins Gewicht gefallen wäre.

Mit einigen Worten muss ich noch auf die Bestimmung des Brennwertes im Harn eingehen, weil dies der wunde Punkt bei der Anstellung eines Kraftwechselversuchs zu sein pflegt, um so mehr, wenn bei einer stickstoffarmen Nahrung wie in diesem Falle der Brennwert des Harns ein ausserordentlich geringer ist. Es sind bekanntlich verschiedene Vorschläge gemacht worden, den Harn zur kalorimetrischen Bestimmung vorzubereiten. Besonders viel geübt und in einer grossen Anzahl von Fällen auch sicherlich vortrefflich ist das von Kellner ${ }^{1}$ ) angegebene Verfahren, den Harn im Vakuum auf einem gewogenen Zelluloseblöckchen einzutrocknen und mit demselben zu verbrennen. Gegen dieses Verfahren hat Rubner ${ }^{2}$ ) den Einwand erhoben, dass bei dem hohen Brennwert der Zellulose im Verhältnis zu demjenigen der zu untersuchenden Substanz eine Fehlerquelle in die Analyse hineingetragen würde, welche von unverhältnismässiger Grösse sei. Ferner hat man ja auch keine Garantie dafür, dass nicht auch bei dieser gewiss sehr schonenden Methode des Eintrocknens Zersetzungen und Verluste an brennbarer Substanz im Harn entstehen. Man hat daher vielfach unter Umgehung der Zelluloseblöckchen den Harn eingetrocknet bei einem Zusatze von Säuren, speziell von Oxalsäure (Rubner). Aber auch diese Art des Vorgehens scheint nicht ohne Bedenken zu sein. Wie die auf Tangl's Veranlassung ausgeführten Untersuchungen von K. Farkas und M. Korbuly ${ }^{3}$ ) ergaben, wird beim Eintrocknen mit Zusatz von Säure zwar der Stickstoffverlust vermieden, aber der kalorische Wert des Harns wesentlich verändert. In dem Versuche, welchen Glässner und ich publiziert haben, verfuhren wir in der Weise,

1) O. KeIlner, Untersuchungen über den Stoft- und Energieumsatz volljähriger Ochsen. Die landwirtsch. Versuchsstationen Bd. 47 S. 275.

2) Der Energiewert der Kost des Menschen. Zeitschr. f. Biologie Bd. 42 S. 270.1900 .

3) Kritisch-experimentelle Studien über die Kalorimetrie des Harns. Pflüger's Arch. Bd. 104. 1904. 
dass wir eine grössere Menge des Harns zunächst in einem Porzellanschälchen zu sirupöser Konsistenz eindampften und den Rückstand darauf mit möglichst wenig Wasser in das Platinschälchen der kalorimetrischen Bombe brachten und im Vakuum vollends eintrockneten. Wir wählten dieses Verfahren, obgleich wir uns bewusst waren, dass auch bei diesem die Fehlerquellen nicht gering sind. Doch waren wir der Ansicht, dass bei dem sehr geringen Brennwerte, welchen der Harn gegenüber dem hohen Energiegehalt von Nahrung und Kot repräsentierte und der grossen Menge des Harns, welche wir bei diesem Verfahren zu einer einmaligen Probe benutzen konnten, der Fehler, der durch Zersetzung des Harns bedingt war, nicht wesentlich ins Gewicht fallen könne. Schwieriger lagen die Verhältnisse bei der Untersuchung des Harns des Hauptmanns H. Auch hier konnte ich von vornherein sicher sein, nur einen äusserst geringen Brennwert des Harns zu finden, und es verbot sich daher das sonst so beliebte und bequeme Verfahren Kellners auzuwenden. Andrerseits spielte bei der Bilanz der Brennwert des Harns eine sehr viel grössere Rolle als in dem Versuche am Ingenieur K. und seiner Gattin, weil die Gesamtenergiezufuhr eine ansserordentlich spärliche war und daher selbst der geringe Energiegehalt des Harns von Bedeutung sein musste. Ich bemühte mich daher, das Verfahren, welches Glässner und ich angewandt hatten, dadurch $\mathrm{zu}$ einem genaueren zu gestalten, dass ich den Stickstoffverlust beim Eintrocknen zu bestimmen und in Rechnung zu stellen suchte, wie dies in etwas anderer Form schon von Kellner u. A. ausgeführt worden ist. Ich bestimmte also den Stickstoffgehalt in der Volumeinheit des Harns und bereitete dann ein Quantum desselben zur kalorischen Verbrennung vor. Zu diesem Zweck wurde der Harn zunächst im Vakuum bis auf ein kleines Volumen eingedampft. Es führte dies Verfahren jedoch im Gegensatze zu unseren Exfahrungen bei normalem Harn niemals zu befriedigender Trocknung, wie $R u b n$ er dies gleichfalls bereits für einige Versuche angibt. Der Grund liegt in unserem Falle in dem geringen Gehalte des Harns an organischer Substanz bei grossem Reichtum an Salzen. Es musste daher stets eine weitere Eindampfung bei höherer Temperatur folgen.

In einer andern Probe des Harns, welche genau in gleicher Weise behandelt worden war, ermittelte ich den Stickstoff im Harnrückstande nach der Trọcknung. Aus dem Vergleich des Stickstoffs im 
frischen Harn und in dem zur Verbrennung präparierten Harnrückstande schloss ich auf den Verlust an brennbarem Material während des Eintrocknens. Ich rechnete den Verlust an Stickstoff auf Harnstoff um und stellte ihn mit dem Brennwerte von 2,5419 kal. pro Milligramm Harnstoff in Rechnung.

Die Verluste an Stickstoff bei dieser Prozedur waren durchaus nicht unbedeutend. Um ein Beispiel zu geben: In zwei Proben eines Mischharns à $50 \mathrm{cem}$ wird der N-Gehalt zu 0,315 bezw. $0,305 \mathrm{~g} \mathrm{~N}$ ermittelt. Der Rückstand der Probe I enthält $0,28 \mathrm{~g} \mathrm{~N}$, derjenige der Probe II $0,27 \mathrm{~g}$ N. Daraus ergibt sich auf $50 \mathrm{cem}$ des Harns eine Differenz von $35 \mathrm{mg} \mathrm{N}$, welche bei der Prozedur des Eindampfens verloren gegangen sind. Diese $35 \mathrm{mg} \mathrm{N}$ entsprechen $75 \mathrm{mg}$ Harnstoff.

Die Harne wurden für die kalorimetrische Bestimmung in einzelne Perioden eingeteilt, aus diesen Perioden die sauer reagierenden gewählt, aus ihnen ein Mischharn hergestellt, in welchem die kalorimetrische Bestimmung ausgeführt wurde. Der erste Mischharn enthielt die Periode vom 31. Oktober bis 19. November 1902. Der zweite umfasste die Periode vom 4. Dezember bis 9. Dezember, der dritte vom 16. Dezember bis 24. Dezember, der vierte vom 6. Januar bis 9. Januar 1903 , der fünfte vom 10. Januar bis 13. Januar. In letzterem Falle reagierte der Harn alkalisch, und wurde daher der Fehler, welcher durch den Verlust an Brennwert entstand, sowohl auf Ammoniak als auch auf Harnstoff berechnet. Doch stellte sich heraus, dass der Unterschied nur ein äusserst geringer war. Auf $100 \mathrm{ccm}$ betrug der Verlust an Brennwert, berechnet auf Harnstoff $268 \mathrm{kal}$, , auf $\mathrm{NH}_{3} 321 \mathrm{kal}$, so dass in dem ersten Falle der Brennwert von $100 \mathrm{cem}$ Mischharn 14,53, im zweiten Falle 14,58 kal. war, was für die Gesamtbilanz nicht in Betracht kam.

Man kann daraus ersehen, dass diese Methode der kalorimetrischen Bestimmung auch im alkalisch reagierenden Harn ohne allzu grosses Bedenken angewandt werden kann, wenn ich auch keineswegs glaube, dass dieselbe als eine ideale anzusehen ist.

Wesentliche Schwierigkeiten bot auch die Analyse der Weintrauben, und zwar deswegen, weil es sich als unmöglich erwies, die Trauben in toto zu trocknen und zur weiteren Verarbeitung geeignet zu machen. Ich sah mich daher genötigt, dieselben zu pressen und den Saft der Trauben gesondert von dem Rückstande, den 
Schalen und Kernen, zu untersuchen. Der so aus einer bekannten Menge frischer Weintrauben gewonnene Saft wurde auf ein gemessenes Volumen aufgefüllt und in ihm Brennwert- und Stickstoffbestimmungen vorgenommen. Bei der Verbrennung verfuhr ich in der Art, dass ich $10 \mathrm{cem}$ zur sirupösen Konsistenz eindampfte und in dem Platinschälchen der Bombe im Vakuum bei nicht erhöhter Temperatur vollständig trocknete, wobei ich allerdings sorgfältig darauf acht geben musste, dass nicht ein zu starkes Schäumen und so ein Verspritzen der Flüssigkeit statthatte. Ich erhielt auf diese Weise sehr gut übereinstimmende analytische Werte.

Der Pressrückstand wurde in Form von Pastillen verbrannt.

Ich lasse nunmehr den Versuch am Hauptmann H. in möglichst übersichtlicher Form in Gestalt von Tabellen folgen (siehe S. 508 bis 517).

$\mathrm{Zu}$ diesen Tabellen möchte ich noch folgendes bemerken: Im Harn vom 20. November bis zum 3. Dezember hat eine Bestimmung des Brennwertes des Harns nicht stattgefunden. Der Brennwert ist vielmehr aus den Werten des Mischharns I vom 31. Oktober bis 19. November und des Mischharns II vom 4. bis 9. Dezember ermittelt worden. Dies war deswegen zulässig, weil die Ernährung ja eine sehr gleichmässige war und der Brennwert der Mischharne I und II nur sehr wenig differierte. Für die Tage vom 10. bis 15. Dezember wurde der Wert, welcher sich für den Mischharn vom 16. bis 24. Dezember ergeben hatte, in Rechnung gestellt, was bei der absolut gleichmässigen Nahrung durchaus zulässig erscheint. Andrerseits mussten für die Tage vom 25. bis 27. Dezember eine Berücksichtigung des Brennwertes im Harn unterbleiben, weil die Ernährung an diesen Tagen zu sehr von dem Durchschnitt abwich. Dagegen wurde vom 28. bis 30. Dezember wiederum der Brennwert des Harns vom 16. bis 24. Dezember als richtig angenommen. Vom 31. Dezember bis zum 5. Januar konnte der Brennwert im Harn nicht bestimmt werden, da derselbe durch Unachtsamkeit beim Auffangen unbekannte Mengen von Petroleum enthielt, welche den Brennwert in nicht zu ubersehender Weise beeinflusst hätten. Auch wich die Ernährung an diesen Tagen immerhin so erheblich von der vorhergehenden und von der nachfolgenden $a b$, dass ich eine Interpolation der Brennwerte nicht ausführen wollte. Im übrigen ist unter der Rubrik "Bemerkungen" in der Tabelle stets angegeben, 
an welchen Stellen die Brennwerte des Harnes experimentell gefunden, und an welchen rechnerisch festgestellte Mittelwerte zur Verwendung gelangten. Der Gesamtbrennwert des Mischharns wurde auf die einzelnen Tage gemäss dem Stickstoffgehalte der betreffenden Harne verteilt. Wenn auch, wie bei Betrachtung der kalorischen Quotienten ausgeführt werden wird, diese Verteilung vielleicht mit Unsicherheiten behaftet ist, so erhält man doch auf diese Weise geringere Schwankungen im Brennwerte der Harne, als wenn die Verteilung einfach nach dem Volumen vor sich geht. Dies ist ja auch erklärlich, wenn man bedenkt, von wie vielen wechselnden äusseren Umständen das Volumen des Harns abhängig ist. Auf die tägliche Bilanz des Kraftwechsels haben diese Überlegungen jedoch nur einen sehr geringen Einfluss, entsprechend dem an und für sich so geringen Brennwerte des Harns.

Auf weitere Einzelheiten der Tabelle soll erst später eingegangen werden.

Stellen wir aus den Daten, welche uns die Tabelle an die Hand gibt, die Gesamtbilanzen der einzelnen Perioden auf, so finden wir folgendes: In der ersten Periode wurden Weintrauben gereicht, und zwar täglich $1 \mathrm{~kg}$, mit Stielen und Kämmen gewogen. Die letzteren wurden nicht mitgegessen und am nächsten Tage zusammen mit etwaigen schlechten und daher ungeniessbaren Beeren zurückgewogen. Die Beeren selbst wurden mit Schalen und Kernen genossen, und zwar ohne dass eine sorgfältige Zerkleinerung der letzteren oder ein sorgsames Kauen die in den Kernen enthaltenen Nährstoffe dem Organismus zugänglich gemacht hätte. Die Analyse der Weinbeeren (ohne Kämme und Stiele) ergab im Kilogramm frischer Beeren

$\begin{array}{ccc}\mathrm{N} & \mathrm{N} \text { aus Eiweiss } & \text { Brennwert } \\ 1,23 \mathrm{~g} & 0,88 \mathrm{~g} & 800,3 \mathrm{Kal} .\end{array}$

Wie aus der Tabelle ersichtlich, wurden an fünf Tagen Äpfel genossen, weil keine Trauben beschafft werden konnten. Fs waren rotschalige Amerikaner von geringer Qualität und mehligem, nicht sehr süssem Geschmack. Dieselben wurden mit Schalen, aber ohne Stiele, Kerne und Gehäuse verzehrt und der Rückstand täglich zurückgewogen. Die Analyse des Materials, so wie es genossen wurde, ergab für $1000 \mathrm{~g}$ :

$$
\begin{array}{ccc}
\mathrm{N} & \mathrm{N} \text { aus Eiweiss } & \text { Brennwert } \\
1,20 \mathrm{~g} & 0,67 \mathrm{~g} & 674,88 \mathrm{Kal} .
\end{array}
$$


Periode I,

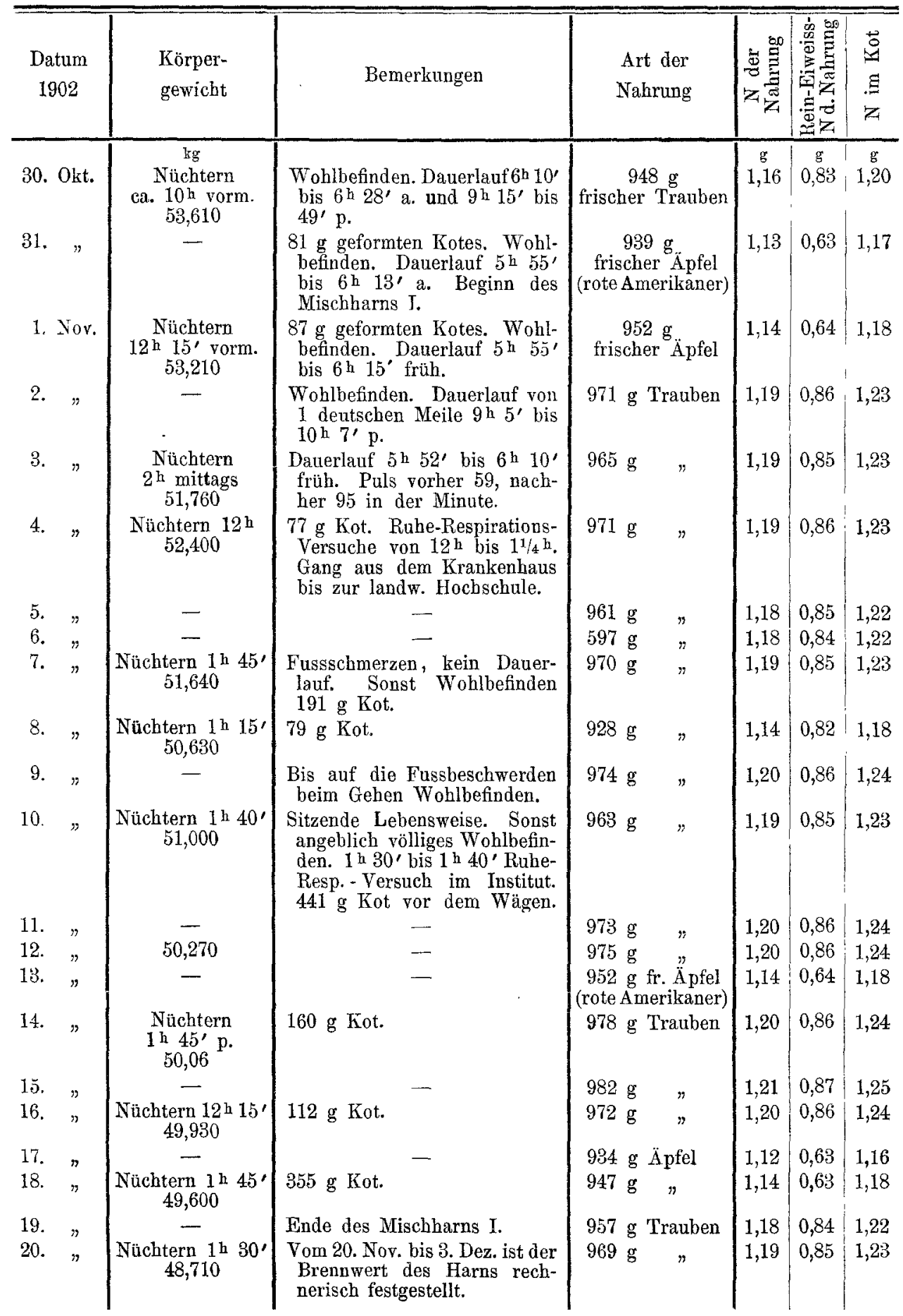


Periode I.

\begin{tabular}{|c|c|c|c|c|c|c|c|c|c|c|c|}
\hline 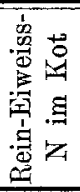 & 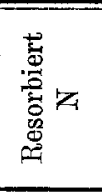 & 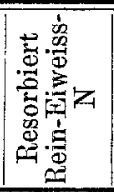 & 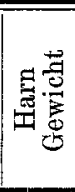 & 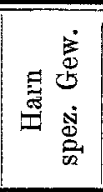 & 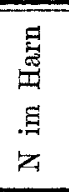 & $\frac{N}{\stackrel{N}{\underline{n}}}$ & 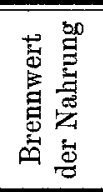 & 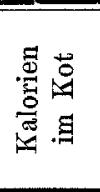 & 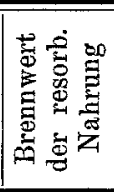 & 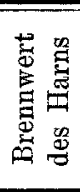 & 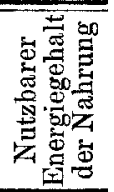 \\
\hline$\stackrel{\mathrm{g}}{\mathrm{g}}$ & $\begin{array}{c}g \\
-0,04\end{array}$ & \begin{tabular}{|c|}
$g$ \\
$-0,22$
\end{tabular} & $\stackrel{\mathrm{g}}{304}$ & 1017,5 & $\stackrel{g}{g}$ & $-2,59$ & $\begin{array}{c}\text { Kal. } \\
758,68\end{array}$ & 178,60 & $\begin{array}{c}\text { Kal. } \\
580,08\end{array}$ & $\begin{array}{l}\text { Kal. } \\
33,85\end{array}$ & $\begin{array}{c}\text { Kal. } \\
546,23\end{array}$ \\
\hline 0,87 & $-0,04$ & $-0,24$ & 468 & 1014,0 & 3,09 & $-3,13$ & 633,73 & 149,73 & 484,55 & 41,02 & 443,53 \\
\hline 0,89 & $-0,04$ & $-0,25$ & 517 & 1011,5 & 2,96 & $-3,00$ & 642,50 & 151,25 & 491,25 & 39,30 & 451,95 \\
\hline 1,19 & $-0,04$ & $-0,33$ & 586 & 1011,0 & 2,52 & $-2,56$ & 777,08 & 182,94 & 594,14 & 33,45 & 560,69 \\
\hline 1,18 & $-0,04$ & $-0,33$ & 318 & 1024,0 & 2,76 & $-2,80$ & 772,28 & 181,80 & 590,48 & 36,64 & 553,84 \\
\hline 1,19 & $-0,04$ & $-0,33$ & 351 & 1020,0 & 2,98 & $-3,02$ & 777,08 & 182,94 & 595,14 & 39,56 & 555,58 \\
\hline 118 & $-0,04$ & $-0,33$ & 452 & 1015,0 & 2,97 & $-3,01$ & 769,08 & 181,05 & 588,03 & 39,43 & 548,60 \\
\hline 1,16 & $-0,04$ & $-0,32$ & 394 & 1016,0 & 2,48 & $-2,52$ & 765,88 & 180,29 & 585,59 & 33,77 & 551,82 \\
\hline 1,18 & $-0,04$ & $-0,33$ & 322 & 1017,0 & 2,23 & $-2,27$ & 776,28 & 182,74 & 593,54 & 29,60 & 563,94 \\
\hline 1,14 & $-0,04$ & $-0,32$ & 518 & 1018,0 & 2,80 & $-2,84$ & 742,68 & 174,83 & 567,85 & 37,17 & 530,68 \\
\hline 1,19 & $-0,04$ & $-0,33$ & 685 & 1010,0 & 2,68 & $-2,72$ & 779,48 & 183,50 & 595,98 & 35,58 & 560,40 \\
\hline 1,18 & $-0,04$ & $-0,33$ & 490 & 1013,0 & 2,87 & $-2,91$ & 770,68 & 181,44 & 589,24 & 38,10 & 551,14 \\
\hline 1,19 & $-0,04$ & $-0,33$ & 660 & 1010,5 & 2,98 & $-2,97$ & 778,68 & 188,31 & 595,37 & 38,90 & 556,47 \\
\hline 1,19 & $-0,04$ & $-0,33$ & 496 & 1011,5 & 2,91 & $-2,95$ & 780,28 & 183,68 & 596,60 & 38,63 & 557,97 \\
\hline 0,89 & $-0,04$ & $-0,25$ & 466 & 1012,5 & 3,22 & $-3,26$ & 642,50 & 151,25 & 491,25 & 42,75 & 448,50 \\
\hline 1,19 & $-0,04$ & $-0,33$ & 682 & 1010,0 & 3,03 & $-3,07$ & 782,68 & 184,25 & 598,43 & 40,22 & 558,21 \\
\hline 1,20 & $-0,04$ & $-0,33$ & 381 & 1015,0 & 2,61 & $-2,65$ & 785,88 & 185,00 & 600,88 & 34,65 & 560,23 \\
\hline 1,19 & $-0,04$ & $-0,33$ & 479 & 1013,0 & 2,88 & $-2,92$ & 777,90 & 183,12 & 594,78 & 38,23 & 556,55 \\
\hline 0,87 & $-0,04$ & $-0,24$ & 581 & 1011,0 & 3,16 & $-3,20$ & 630,34 & 148,73 & 481,61 & 41,95 & 439,66 \\
\hline 0,87 & $-0,04$ & $-0,24$ & 640 & 1011,0 & 3,26 & $-3,30$ & 639,11 & 150,45 & 488,66 & 43,28 & 445,38 - \\
\hline 1,16 & $-0,04$ & $-0,32$ & 491 & 1012,5 & 2,51 & $-2,55$ & 765,88 & 180,29 & 585,59 & 33,32 & 552,27 \\
\hline 1,18 & $-0,04$ & $-0,33$ & 349 & 1016,0 & 2,40 & $-2,44$ & 775,48 & 182,55 & 592,93 & 25,81 & 567,14 \\
\hline
\end{tabular}


Periode I (Fortsetzung).

\begin{tabular}{|c|c|c|c|c|c|c|c|}
\hline $\begin{array}{l}\text { Datum } \\
1902\end{array}$ & $\begin{array}{l}\text { Körper- } \\
\text { gewicht }\end{array}$ & Bemerkungen & \multicolumn{2}{|c|}{$\begin{array}{l}\text { Art der } \\
\text { Nahrung }\end{array}$} & 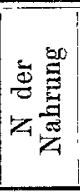 & 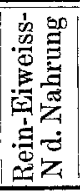 & 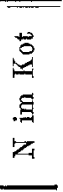 \\
\hline 21. Nov. & $\begin{array}{c}\mathrm{kg} \\
\text { Nüchtern } 1 \mathrm{~h} \\
48,585\end{array}$ & $\begin{array}{l}\text { Respirationsversuche v. } 1 \text { h } 15^{\prime} \\
\text { bis } 2 \mathrm{~b} 15^{\prime} \text { bei Ruhe im } \\
\text { Krankenhaus. }\end{array}$ & $966 \mathrm{~g}$ & auben & $\stackrel{\mathrm{g}}{1,19}$ & $\stackrel{8}{0,85}$ & $\stackrel{\mathrm{g}}{1,23}$ \\
\hline & 一 & 220 g Kot. & 952, & & 1,17 & 0,84 & 1,21 \\
\hline 23. ." & - & - & 968 & & 1,19 & 0,85 & 1,23 \\
\hline 24. & - & - & $962 "$ & $\eta$ & 1,18 & 0,85 & 1,22 \\
\hline 25. & $\begin{array}{l}\text { Nüchtern } \\
47,970\end{array}$ & $\begin{array}{l}\text { Marschversuch auf der 'Tret- } \\
\text { bahn } 2^{\mathrm{h}} 4^{\prime} \text { bis } 3 \mathrm{~h} 8^{\prime} \text {. }\end{array}$ & $956 n$ & $"$ & 1,18 & 0,84 & 1,22 \\
\hline 26. & - & $\begin{array}{l}101 \mathrm{~g} \mathrm{Kot.} 1 / 2 \text { Std. spazieren } \\
\text { gegangen. }\end{array}$ & 963 & $"$ & 1,19 & 0,85 & 1,28 \\
\hline 27. & $\begin{array}{l}\text { Nüchtern } \\
1 \mathrm{~b} 30^{\prime} 47,535\end{array}$ & $1 / 2$ Std. Spaziergang. & 966, & & 1,19 & 0,85 & 1,23 \\
\hline 28. & - & $\begin{array}{l}\text { Mittags sitzend Puls } 70 \text {, später } \\
65, \quad \text { klein, unregelmässig. } \\
\text { Temp. in der Achselhöhle } \\
36,6^{\circ} .1 / 2 \text { Std. Spaziergang. }\end{array}$ & $967 n$ & $n$ & 1,19 & 0,85 & 1,23 \\
\hline 29. & $\begin{array}{r}\text { Nüchtern } \\
1 \mathrm{~h} 46,870\end{array}$ & $\begin{array}{l}\text { 1/a Std. Spaziergang. } 2 \text { h } 15^{\prime} \\
\text { bis } 3 \text { h } 20^{\prime} \text { Respirations-Rube- } \\
\text { versuche im Krankenhaus. }\end{array}$ & 966, & 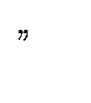 & 1,19 & 0,85 & 1,23 \\
\hline 30. & - & $\begin{array}{l}\text { Kot } 91 \text { g. Temp. abends } 11 \mathrm{~h} \\
\text { im Bett } 36,8^{\circ} .1 / 2 \text { Std. Spazier- } \\
\text { gang. }\end{array}$ & 967 , & $"$ & 1,19 & 0,85 & 1,23 \\
\hline 1. Dez. & $\begin{array}{l}\text { Nüchtern } \\
2^{\text {h }} 46,610\end{array}$ & $\begin{array}{l}\text { Respirations - Marschversuche } \\
\text { von } 3^{1 / 2} \text { bis } 4^{\mathrm{h}} \text {. Kot } 212 \mathrm{~g} \text {. } \\
\text { 1/2 Std. Spaziergang. Temp. } \\
6^{\mathrm{h}} \text { abends } 36,8^{\mathrm{O}} .9^{1 / 2 \mathrm{~h}} \mathrm{im} \\
\text { Bett } 36,8^{\circ} \text {. }\end{array}$ & 969 , & $\eta$ & 1,19 & 0,85 & 1,23 \\
\hline 2. & - & 1/2 Std. Spaziergang. & 976, & $n$ & 1,20 & 0,86 & 1,24 \\
\hline 3. & - & $\begin{array}{l}\text { Mittags } 12 \mathrm{~h} \text { Puls } 72 \text {, voll, } \\
\text { kräftig, wenn die Hand frei } \\
\text { in der Luft gehalten wird; } \\
\text { liegt die Hand ruhig auf, so } \\
\text { sind es nur } 62 \text { Pulse. Der } \\
\text { Puls etwas flatternd, von Zeit } \\
\text { zu Zeit aussetzend. Wegen } \\
\text { steigender Fussbeschwerden } \\
\text { kein Spaziergang. Temp. } \\
\text { abends } 10 \mathrm{~h} 36,70^{\circ} \text {. }\end{array}$ & 974, & & 1,20 & 0,86 & 1,24 \\
\hline 4. & 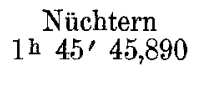 & $\begin{array}{l}\text { Kein Spaziergang. Ruhe-Respi- } \\
\text { rationsversucb. Kot } 36 \text { g. } \\
\text { Beginn des Mischharns II. }\end{array}$ & 985, & $\#$ & 1,21 & 0,87 & 1,25 \\
\hline 5. & - & $\begin{array}{l}\text { Kein Spaziergang wegen Fuss- } \\
\text { schmerzen. }\end{array}$ & 988, & $"$ & 1,22 & 0,87 & 1,26 \\
\hline 6. & $\begin{array}{l}\text { Nüchtern } \\
2 \mathrm{~h} 45,430\end{array}$ & $\begin{array}{l}\text { Kein Spaziergang. } 84 \text { Puls } \\
\text { sitzend, wenn der Arrn frei } \\
\text { gehalten wird. } 80 \text { Pulse bei } \\
\text { aufgestätztem Arm. Kot } 240 \mathrm{~g} \text {. }\end{array}$ & 987 & $n$ & 1,21 & 0,87 & 1,25 \\
\hline 7. & - & - & 982 & $"$ & 1,21 & 0,87 & 1,25 \\
\hline & $\begin{array}{c}\text { Nüchtern } \\
2 \mathrm{~h} 55^{\prime} 45,403\end{array}$ & $\begin{array}{l}\text { Arbeitsversuch im Institut von } \\
3^{\mathrm{h}} 50^{\prime} \text { bis } 4 \mathrm{~h} 30^{\prime} \text {. }\end{array}$ & 981, & $"$ & 1,21 & 0,86 & 1,25 \\
\hline 9 & - & $\begin{array}{l}\text { Kot } 345 \text { g. Ende des Misch- } \\
\text { harns II. }\end{array}$ & 984, & $"$ & 1,21 & 0,87 & 1,25 \\
\hline
\end{tabular}


Per i o d e I (Fortsetzung).

\begin{tabular}{|c|c|c|c|c|c|c|c|c|c|c|c|}
\hline 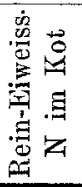 & 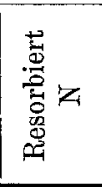 & 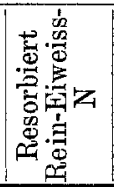 & 焉 & 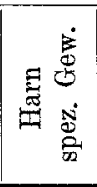 & 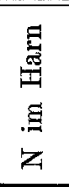 & 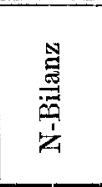 & 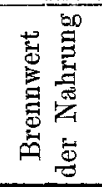 & 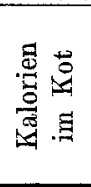 & 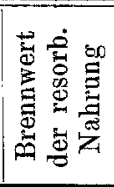 & 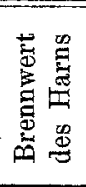 & 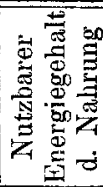 \\
\hline $\begin{array}{c}\mathrm{g} \\
1,18\end{array}$ & $\begin{array}{c}\mathbf{g} \\
-0,04\end{array}$ & $\begin{array}{c}\mathrm{g} \\
-0,33\end{array}$ & $\stackrel{g}{g}$ & 1013,0 & $\begin{array}{c}g \\
2,93\end{array}$ & $-2,97$ & $\begin{array}{c}\text { Kal. } \\
778,08\end{array}$ & 181,99 & $\begin{array}{c}\text { Kal. } \\
591,09\end{array}$ & $\begin{array}{c}\text { Kal. } \\
31,51\end{array}$ & $\begin{array}{c}\text { Kal. } \\
559,58\end{array}$ \\
\hline 1,16 & $-0,04$ & $-0,32$ & 456 & 1011,5 & 2,80 & $-2,84$ & 761,88 & 179,35 & 582,53 & 30,11 & 552,42 \\
\hline 1,18 & $-0,04$ & $-0,33$ & 442 & 1013,0 & 2,88 & $-2,92$ & 774,70 & 182,37 & 592,33 & 30,97 & 561,36 \\
\hline 1,18 & $-0,04$ & $-0,33$ & 402 & 1013,5 & 2,70 & $-2,74$ & 769,90 & 181,24 & 588,66 & 29,03 & 559,63 \\
\hline 1,16 & $-0,04$ & $-0,32$ & 385 & 1016,0 & 2,84 & $-2,88$ & 765,08 & 180,11 & 584,37 & 90,54 & 558,83 \\
\hline 1,18 & $-0,04$ & $-0,33$ & 550 & 1012,0 & 3,33 & $-3,37$ & 770,68 & 181,44 & 589,24 & 35,81 & 553,43 \\
\hline 1,18 & $-0,04$ & $-0,33$ & 403 & 1012,5 & $2, € 8$ & $-2,72$ & 773,08 & 181,99 & 591,09 & 28,82 & 562,27 \\
\hline 1,18 & $-0,04$ & $-0,33$ & 498 & 1012,0 & 3,01 & $-3,05$ & 773,90 & 182,18 & 591,72 & 32,37 & 559,35 \\
\hline 1,18 & $-0,04$ & $-0,33$ & 512 & 1012,0 & 3,08 & $-3,12$ & 773,08 & 11,99 & 591,09 & 33,12 & 557,97 \\
\hline 1,18 & $-0,04$ & $-0,33$ & 484 & 1012,0 & 3,01 & $-3,05$ & 778,90 & 182,18 & 591,72 & 32,37 & 559,35 \\
\hline 1,18 & $-0,04$ & $-0,33$ & 291 & 1021,5 & 2,55 & $-2,59$ & 775,48 & 182,55 & 592,93 & 27,42 & 565,51 \\
\hline 1,19 & $-0,04$ & $-0,33$ & 664 & 1010,0 & 3,78 & $-3,82$ & 781,08 & 183,87 & 597,21 & 40,65 & 556,56 \\
\hline 1,19 & $-0,04$ & $-0,33$ & 448 & 1012,0 & 3,03 & $-8,07$ & 779,48 & 183,50 & 595,88 & 32,58 & 563,40 \\
\hline 1,20 & $-0,04$ & $-0,33$ & 553 & 1010,5 & 3,17 & $-3,21$ & 788,30 & 185,57 & 602,73 & 33,27 & 569,46 \\
\hline 1,20 & $-0,04$ & $-0,33$ & 575 & 1010,0 & 3,12 & $-3,16$ & 790,70 & 186,13 & 604,57 & 32,75 & 571,82 \\
\hline 1,20 & $-0,04$ & $-0,33$ & 486 & 1011,0 & 3,03 & $-3,07$ & 789,90 & 185,95 & 603,95 & 31,80 & 572,15 \\
\hline 1,20 & $-0,04$ & $-0,33$ & 534 & 1009,5 & 3,14 & $-3,18$ & 785,88 & 185,00 & 600,88 & 32,96 & 567,92 \\
\hline 1,19 & $-0,04$ & $-0,33$ & 477 & 1009,0 & 2,80 & $-2,84$ & 785,10 & 184,82 & 600,28 & 29,39 & 570,89 \\
\hline 1,20 & $-0,04$ & $-0,33$ & 372 & 1013,5 & 2,60 & $-2,64$ & 787,50 & 185,38 & 602,12 & 27,29 & 574,83 \\
\hline
\end{tabular}


W. Caspari:

Periode II.

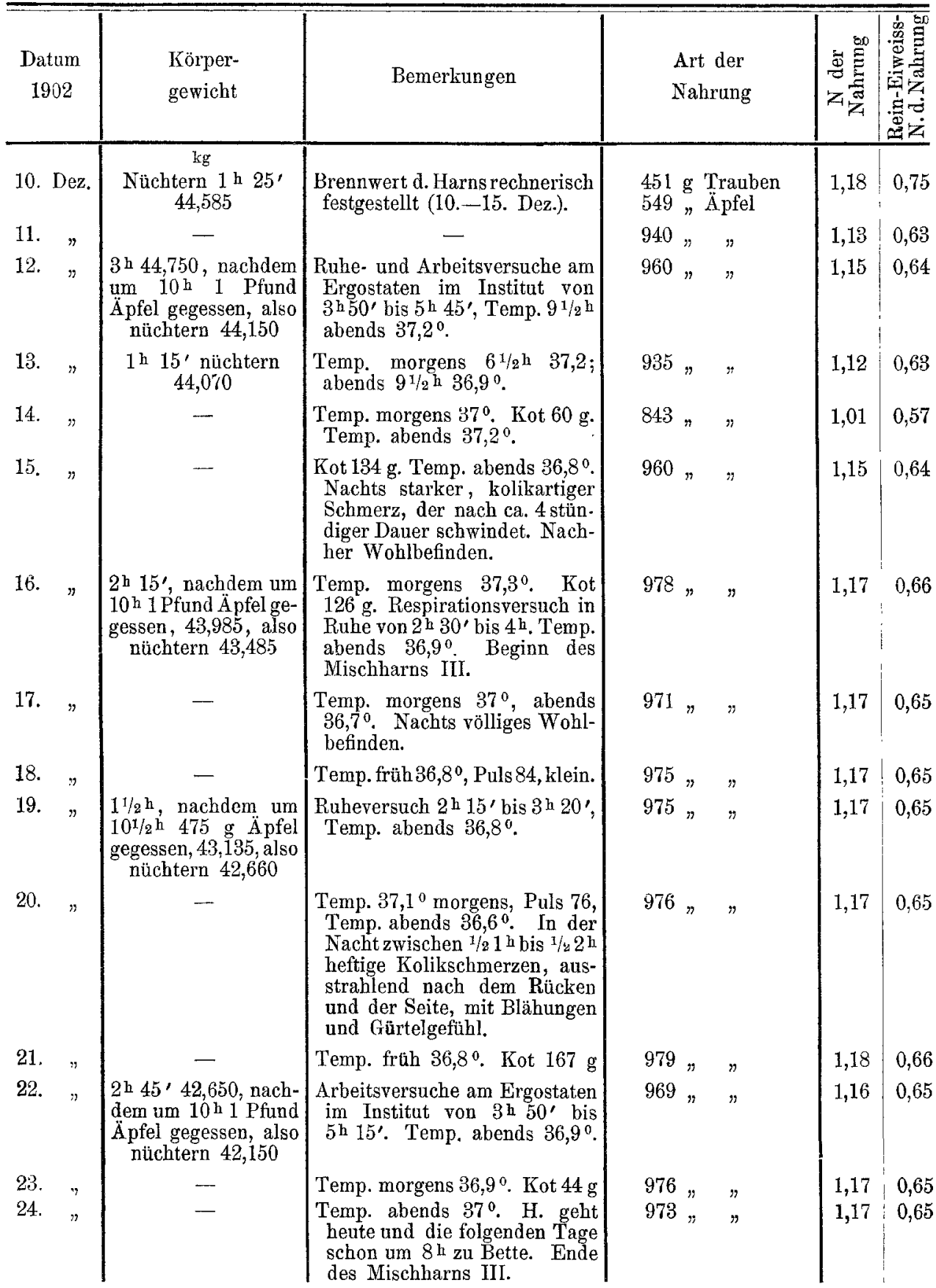


Periode II.

\begin{tabular}{|c|c|c|c|c|c|c|c|c|c|c|c|c|}
\hline $\begin{array}{l}\vec{a} \\
\overrightarrow{4} \\
.7 \\
\overrightarrow{7}\end{array}$ & 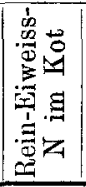 & 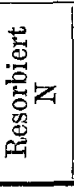 & 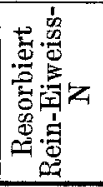 & 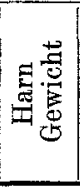 & 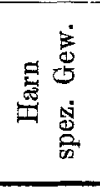 & 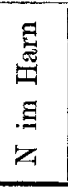 & $\frac{N}{5}$ & 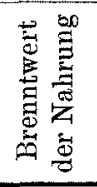 & 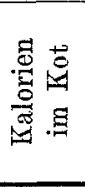 & 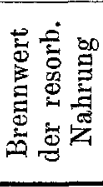 & 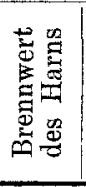 & 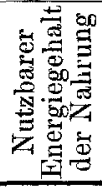 \\
\hline$\stackrel{g}{g}$ & $\begin{array}{c}\mathrm{g} \\
0,74\end{array}$ & $\stackrel{\mathrm{g}}{0,41}$ & $\stackrel{\mathbf{g}}{0,01}$ & $\begin{array}{c}\mathrm{g} \\
425\end{array}$ & 1011,5 & $\underset{2,76}{\mathrm{~g}}$ & $-2,35$ & $\begin{array}{c}\text { KaI. } \\
731,44\end{array}$ & 85,43 & $\begin{array}{c}\text { Kal. } \\
646,01\end{array}$ & 37,17 & $\begin{array}{c}\text { KaI. } \\
608,84\end{array}$ \\
\hline 0,74 & 0,62 & 0,39 & 0,01 & 389 & 1012,0 & 2,71 & $-2,32$ & 634,54 & 77,61 & 556,93 & 36,50 & 520,43 \\
\hline 0,75 & 0,63 & 0,40 & 0,01 & 455 & 1011,0 & 2,67 & $-2,27$ & 647,89 & 79,25 & 568,64 & 35,96 & 532,68 \\
\hline 0,73 & 0,62 & 0,39 & 0,01 & 611 & 1010,0 & 3,03 & $-2,64$ & 631,01 & 77,17 & 553,84 & 40,80 & 513,04 \\
\hline 0,66 & 0,56 & 0,35 & 0,01 & 524 & 1010,0 & 2,63 & $-2,28$ & 568,93 & 69,58 & 499,35 & 35,42 & 463,93 \\
\hline 0,75 & 0,63 & 0,40 & 0,01 & 287 & 1017,5 & 2,28 & $-1,88$ & 647,89 & 79,25 & 568,64 & 30,71 & 537,93 \\
\hline 0,76 & 0,65 & 0,41 & 0,01 & 643 & 1009,0 & 2,84 & $-2,43$ & 660,04 & 80,72 & 579,32 & 38,25 & 541,07 \\
\hline 0.76 & 0,64 & 0,41 & 0,01 & 580 & 1009,5 & 2,82 & $-2,41$ & 655,31 & 80,15 & 575,16 & 38,06 & 537,10 \\
\hline 0,76 & 0,64 & 0,41 & 0,01 & 523 & 1011,0 & 3,05 & $-2,64$ & 658,00 & 80,48 & 577,52 & 41,07 & 536,45 \\
\hline 0,76 & 0,64 & 0,41 & 0,01 & 612 & 1008,5 & 2,93 & $-2,52$ & 658,00 & 80,48 & 577,52 & 39,46 & 538,06 \\
\hline 0,76 & 0,64 & 0,41 & 0,01 & 474 & 1011,0 & 2,78 & $-2,37$ & 659,69 & 80,56 & 578,13 & 37,44 & 540,69 \\
\hline 0,77 & 0,65 & 0,41 & 0,01 & 630 & 1010,0 & 3,19 & $-2,78$ & 660,71 & 80,81 & 579,90 & 42,96 & 536,94 \\
\hline 0,76 & 0,64 & 0,40 & 0,01 & 562 & 1011,0 & 2,80 & $-2,40$ & 653,96 & 79,98 & 573,98 & 37,71 & 536,27 \\
\hline 0,76 & 0,64 & 0,41 & 0,01 & 487 & 1012,0 & 2,55 & $-2,14$ & 658,69 & 80,56 & 578,13 & 34,34 & 543,79 \\
\hline 0,76 & 0,64 & 0,41 & 0,01 & 528 & 1013,5 & 3,42 & $-3,01$ & 656,66 & 80,31 & 576,35 & 46,06 & 530,29 \\
\hline
\end{tabular}


Periode II (Fortsetzung).

\begin{tabular}{|c|c|c|c|c|c|}
\hline $\begin{array}{c}\text { Datum } \\
1902\end{array}$ & $\begin{array}{l}\text { Körper- } \\
\text { gewicht }\end{array}$ & Bemerkungen & $\begin{array}{l}\text { Art der } \\
\text { Nahrung }\end{array}$ & 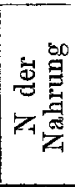 & 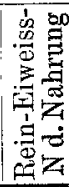 \\
\hline 25. Dez. & kg & $\begin{array}{l}\text { Ternp. morg. } 37,10 \text {. Kot } 200 \text { g. } \\
\text { Harn von } 25 \text {. bis } 27 \text {. Kal. nicht } \\
\text { bestimmt und, da die Nahrung } \\
\text { sehr wechselnd, auch rechner. } \\
\text { nicht ermittelt. }\end{array}$ & $\begin{array}{l}773 \text { g Apfel } \\
199 \text { " Feigen }\end{array}$ & 2,5 & $\frac{g}{1,25}$ \\
\hline 26. & $\begin{array}{l}\text { Nachdem um } 10 \mathrm{~h} \\
1 \text { Pfd. Obst gegessen, } \\
5 \text { h } 41,930, \text { also nüch- } \\
\text { tern } 41,430\end{array}$ & $\begin{array}{l}\text { Temp. abends } 37,3^{0} \text {. Nachts } \\
\text { stösst sich ein gestielter Nasen- } \\
\text { polyp ab unter geringer Blu- } \\
\text { tung. Nachher angebl. ausser- } \\
\text { gewöhnl. Wohlbefinden. }\end{array}$ & $\begin{array}{ll}770 & \text { Äpfel } \\
199 ” \text { Feigen }\end{array}$ & 2,54 & 1,55 \\
\hline 27. " & - & $\begin{array}{l}\text { Temp. morgens } 37,2^{\circ} \text {, abends } \\
37,4^{0} \text { Nachm. steigert sich } \\
\text { das Wohlbefinden. Nachts } \\
\text { besteht angenehmes Wärme- } \\
\text { gefühl. }\end{array}$ & $\begin{array}{l}766 \text { " Äpfel } \\
199 \text { "Feigen }\end{array}$ & 2,54 & 1,55 \\
\hline 28. & - & $\begin{array}{l}\text { Temp. morgens } 37,9^{\circ} \text {. Kot } \\
212 \text { g. Puls } 84, \text { klein, regel- } \\
\text { mässig. Subjektiv starkes } \\
\text { Wohlgefühl, infolgedessen } \\
\text { kehrt H. zu seiner Apfelkost } \\
\text { zurück. Vom 28.-30. Dez. } \\
\text { wird der Brennwert des nnter- } \\
\text { suchten Harns vom 16. - 24. } \\
\text { Dez. übertragen. }\end{array}$ & 975 \# Äpfel & 1,17 & 0,65 \\
\hline 29. " & $\begin{array}{l}1 \mathrm{~h}, \text { nachdem un } 11 \mathrm{~h} \\
1 \text { Pfund Äpfel ge- } \\
\text { gessen, } 41,660 \text {, also } \\
\text { nüchtern } 41,160\end{array}$ & $\begin{array}{l}\text { Temp. } 1^{\mathrm{h}} 36,1^{\circ} \text {. Puls sehr } \\
\text { klein. } 3 \mathrm{~h} 20^{\prime} \text { bis } 4 \mathrm{~h} 20^{\prime} \text {. } \\
\text { Respirations-Ruheversuch. }\end{array}$ & $977 "$ & 1,17 & 0,65 \\
\hline 30. & 一 & $\begin{array}{l}\text { Puls } 80, \text { sehr klein, Kot } 48 \mathrm{~g} . \\
\text { Temp. abends } 36,8^{\circ} \text {. }\end{array}$ & $979 " \quad "$ & 1,18 & 0,66 \\
\hline \multicolumn{6}{|c|}{ Periode III. } \\
\hline 31. Dez. & $\begin{array}{l}1 \text { h nachdem } 1 \text { Pfund } \\
\text { Äpfel gegessen, } \\
41,290 \text {. Also } \\
\text { nüchtern } 40,790\end{array}$ & $\begin{array}{l}\text { Temp. morgens } 36,8^{0} \text {. Nachm. } \\
\text { beim Zahnarzt. Am Abend n. } \\
\text { reichl. Stuhl Hungergefühl. } \\
\text { Daher Zulage zur Nahrung. } \\
\text { Yom 31. Dez. bis } 5 \text {. Jan. keine } \\
\text { Kalorienbestimmung im Harn, } \\
\text { da Petroleum in denselben } \\
\text { gelangt ist. Kot } 324 \mathrm{~g} \text {, breiig. } \\
\text { Temp. abends } 37,0^{\circ} \text {. Nachts } \\
\text { Wadenkrampf. }\end{array}$ & $\begin{array}{l}518 \mathrm{~g} \text { Äpfel } \\
240 \% \text { Feigen } \\
480 \% \text { Apfelsinen }\end{array}$ & 3,48 & 2,04 \\
\hline 1. Jan. & - & $\begin{array}{l}1 \mathrm{~h} \text { Temp. in der Achselhöhle } \\
36,4^{0} \text {. Besond. Wohlbefinden. }\end{array}$ & $\begin{array}{l}971 \text { \# Apfel } \\
248 \text { "Feigen }\end{array}$ & 3,19 & 1,93 \\
\hline 2. & $1^{\text {h }}$ nüchtern 41,205 & $\begin{array}{l}\text { Temp. } 36,5^{\circ} . \quad \text { Gesteigertes } \\
\text { Wohlbefinden. Kot } 131 \mathrm{~g} \text {. } \\
\text { Nachmittags beim Zahnarzt. } \\
\text { Temp. abends } 36,5^{\circ} \text {. }\end{array}$ & $\begin{array}{l}954 \pi \text { Äpfel } \\
248 \% \text { Feigen }\end{array}$ & 3,17 & 1,92 \\
\hline
\end{tabular}


Physiologische Studien über Vegetarismus.

Periode II (Fortsetzung).

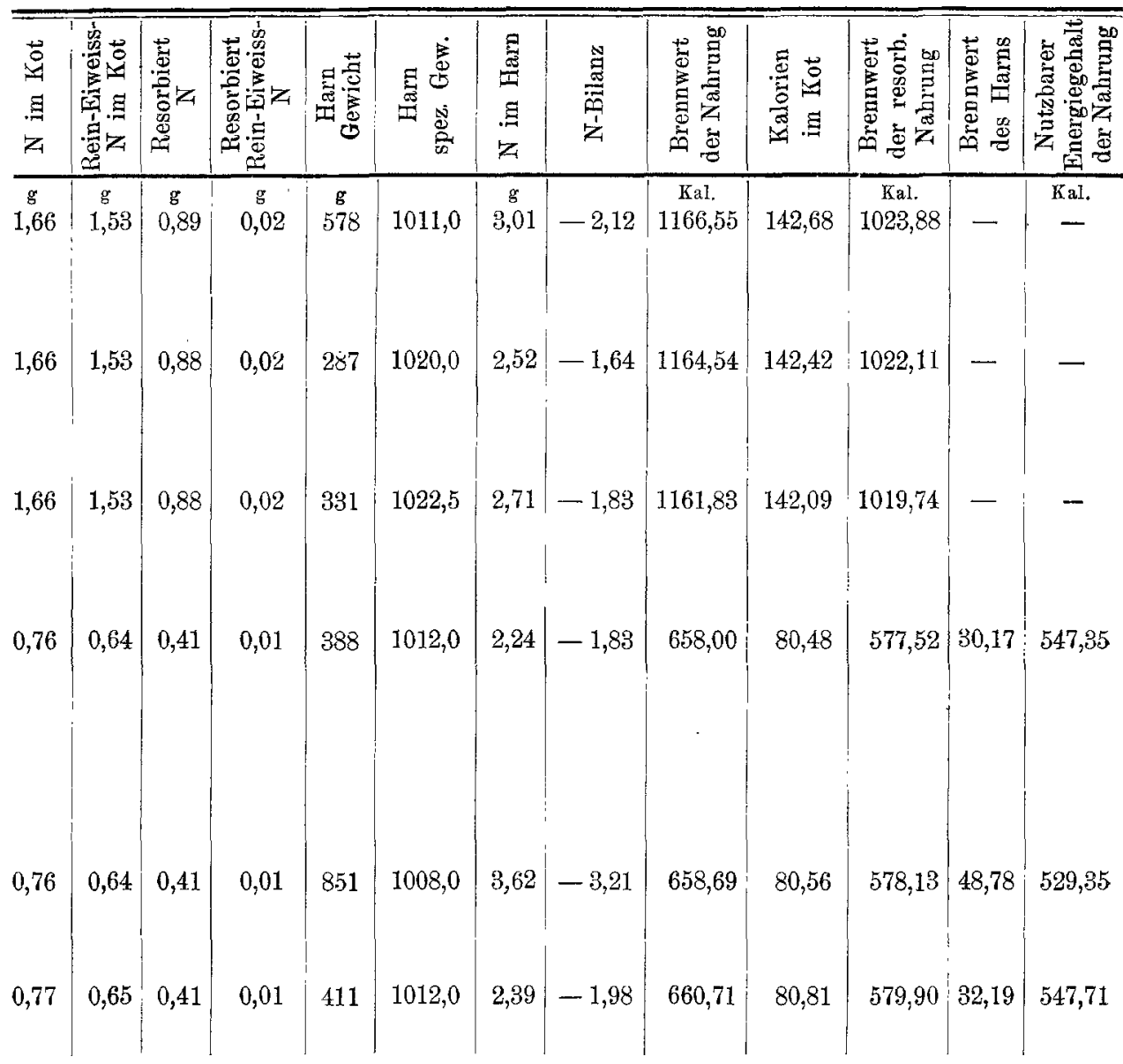

Periode III.

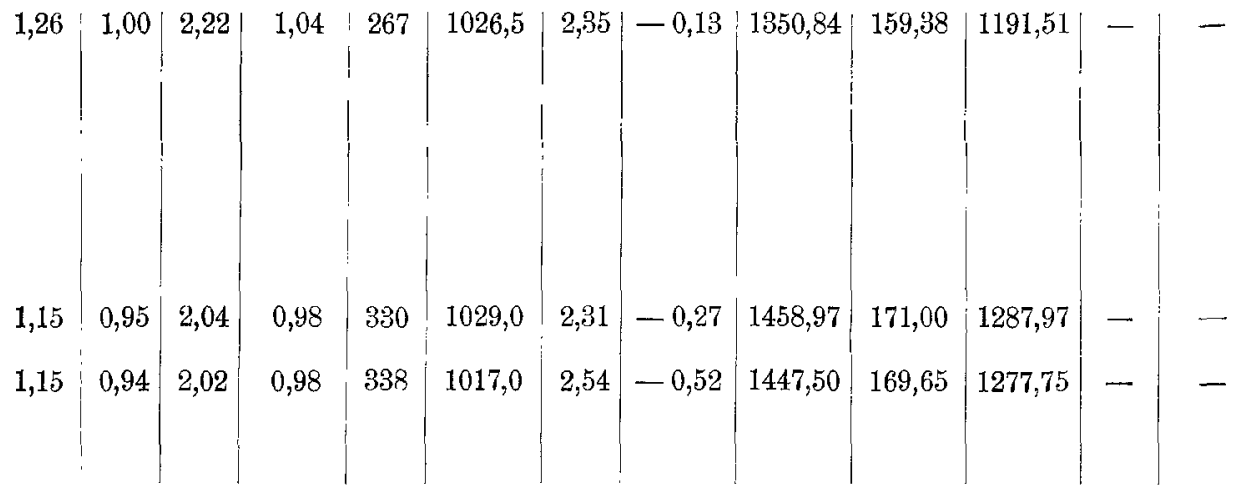


Periode III (Fortsetzung).

\begin{tabular}{|c|c|c|c|c|c|}
\hline $\begin{array}{l}\text { Datum } \\
1903\end{array}$ & $\begin{array}{l}\text { Körper- } \\
\text { gewicht }\end{array}$ & Bemerkungen & $\begin{array}{l}\text { Art der } \\
\text { Nahrung }\end{array}$ & 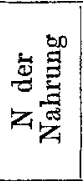 & 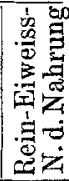 \\
\hline 3. Jan. & kg & $\begin{array}{l}\text { Temp. morgens } 36,5^{\circ} . \text { Kot } \\
391 \text { g. Temp. abends } 36,5^{\circ} \text {. }\end{array}$ & $\begin{array}{l}488 \mathrm{~g} \text { Äpfel Qual. II. } \\
\text { (Deutsche Rauhscha- } \\
\text { len), } 488 \mathrm{~g} \text { A pfelsinen, } \\
248 \text { Feigen }\end{array}$ & $\begin{array}{c}\mathrm{g} \\
3,56\end{array}$ & $\underset{2,21}{g}$ \\
\hline 4. & - & $\begin{array}{l}\text { Temp. morgens } 36,0^{0} \text {, abends } \\
36,5^{\circ} \text {. Mittags beim Zahnarzt. }\end{array}$ & $\begin{array}{l}496 \mathrm{~g} \text { Äpfel Qual. I } \\
\text { (Amer.Rauhschalen), } \\
532 \mathrm{~g} \text { Apfelsinen, } \\
248 \text { "Feigen }\end{array}$ & 3,58 & 2,17 \\
\hline 5 & $\begin{array}{c}21 / 2 \text { h } 41,470, \text { nach } \\
\text { Genuss von } 570 \mathrm{~g} \\
\text { Obst. Also nüchtern } \\
40,900\end{array}$ & $\begin{array}{l}\text { Temp. morgens } 36,75^{\circ} \text {. Von } \\
3^{\mathrm{b}} \text { bis } 4^{\mathrm{h}} \text { Ruhe-Respirations- } \\
\text { versuche im Krankenhaus. }\end{array}$ & $\begin{array}{l}470 \mathrm{~g} \text { Äpfel III (rote } \\
\text { Amerikaner), } 542 \mathrm{~g} \\
\text { Apfelsinen, } 248 \mathrm{~g} \\
\text { Feigen }\end{array}$ & 3,59 & 2,14 \\
\hline 6. & - & $\begin{array}{l}\text { Mitags Temp. } 36,5^{\circ} . \text { Kot } 410 \mathrm{~g} . \\
\text { Beginn des Mischharns IV. }\end{array}$ & $\begin{array}{l}473 \mathrm{~g} \text { Äpfel I, } \\
468 \text { Apfelsinen, } \\
347 \text { Feigen }\end{array}$ & 4,24 & 2,61 \\
\hline 7. & $\begin{array}{c}\text { 1h } 40^{\prime} 41,540 \mathrm{nach} \\
\text { Genuss von } 600 \mathrm{~g} \\
\text { Obst. Also nüchtern } \\
40,940\end{array}$ & $\begin{array}{l}\text { Temp. morgens } 36,5^{\circ} \text {. Kot } \\
373 \text { g (breiig). Temp. abends } \\
36,5^{\circ} \text { Nachm. beim Zahn- } \\
\text { arzt. Nachts Zahnschmerzen. }\end{array}$ & $\begin{array}{l}472 \text { "Äpfel II, } \\
514 \text { Apfelsinen, } \\
347 " \text { Feigen }\end{array}$ & 4,40 & 2,73 \\
\hline 8. & - & $\begin{array}{l}\text { Temp. morgens } 36,5^{\circ} \text {, abends } \\
36,5^{\circ} \text {. }\end{array}$ & $\begin{array}{l}487 \text { "Äpfel I, } \\
482 \text { " Apfelsinen, } \\
347 \text { Feigen }\end{array}$ & 4,28 & 2,63 \\
\hline 9. & $\begin{array}{cc}12^{\mathrm{h}} \text { 41,580 nach } \\
\text { Genuss von } 700 \mathrm{~g} \\
\text { Obst. Also nüchtern } \\
40,830\end{array}$ & $\begin{array}{l}\text { Temp. morgens } 36,5^{\circ} \text {, abends } \\
36,7^{\circ} \text { Ende des Misch- } \\
\text { harns IV. }\end{array}$ & $\begin{array}{l}478 \text { "Äpfel III, } \\
496 " \text { Apfelsinen, } \\
347 " \text { Feigen }\end{array}$ & 4,33 & 2,59 \\
\hline 10. & - & $\begin{array}{l}\text { Temp. morgens } 71 / 2 \mathrm{~h} 36,5^{0} \text {. } \\
\text { Kot Vormittag } 374 \mathrm{~g} \text {. Puls } \\
2 \mathrm{~h} 112 \text {, voller als sonst bei } \\
\text { nicht aufgestützter Hand; bei } \\
\text { aufgestützter Hand } 96 \text {. Temp. } \\
\text { abends } 1 / 210 \mathrm{~h} 36,5^{\circ} \text {. Beginn } \\
\text { des Mischharns } \mathrm{V} \text {. }\end{array}$ & $\begin{array}{l}468 \text { \# Äpfel II, } \\
514 \text { ApfeIsinen, } \\
347 \text { " Feigen }\end{array}$ & 4,39 & 2,73 \\
\hline 11. & $\begin{array}{l}1 \text { h } 41,005 \text { nach Ge- } \\
\text { nuss von } 100 \mathrm{~g} \text { Obst. } \\
\text { Also nüchtern } 40,905\end{array}$ & $\begin{array}{c}\text { Temp. morgens } 36,7^{\circ} \text {. Kot } \\
184 \text { g. Temp. abends } 36,7^{\circ} .\end{array}$ & $\begin{array}{l}486 \text { Äpfel II, } \\
504 \text { A Apfelsinen, } \\
347 \% \text { Feigen }\end{array}$ & 4,39 & 2,74 \\
\hline 12. & - & $\begin{array}{l}\text { Temp. morgens } 36,5^{0} \text {. Kot } \\
511 \mathrm{~g} \text {, breilg, schleimig, stark } \\
\text { stinkend. Temp. abends } 36,5^{\circ} .\end{array}$ & $\begin{array}{l}286 \text { "Äpfel, } \\
700 " \text { Apfelsinen, } \\
347 " \text { Feigen }\end{array}$ & 4,48 & 2,65 \\
\hline 13. & - & $\begin{array}{l}\text { Temp. morgens } 36,6^{\circ} \text {. Abends } \\
8 \mathrm{~h} 151 \mathrm{~g} \text { Kot nach Klistier. } \\
\text { Temp. abends } 36,5^{\circ} \text {. }\end{array}$ & $\begin{array}{l}320 \text { " Äpfel, } \\
648 \text { " Apfelsinen, } \\
347 \text { "Feigen }\end{array}$ & 4,45 & 2.72 \\
\hline 14. $"$ & $11^{\text {h }}$ nüchtern 40,690 & $\begin{array}{l}\text { Temp. morgens } 36,5^{\circ} \text {. Schluss } \\
\text { des Versuches. }\end{array}$ & - & - & - \\
\hline
\end{tabular}


Physiologische Studien über Vegetarismus.

Periode III (Fortsetzung).

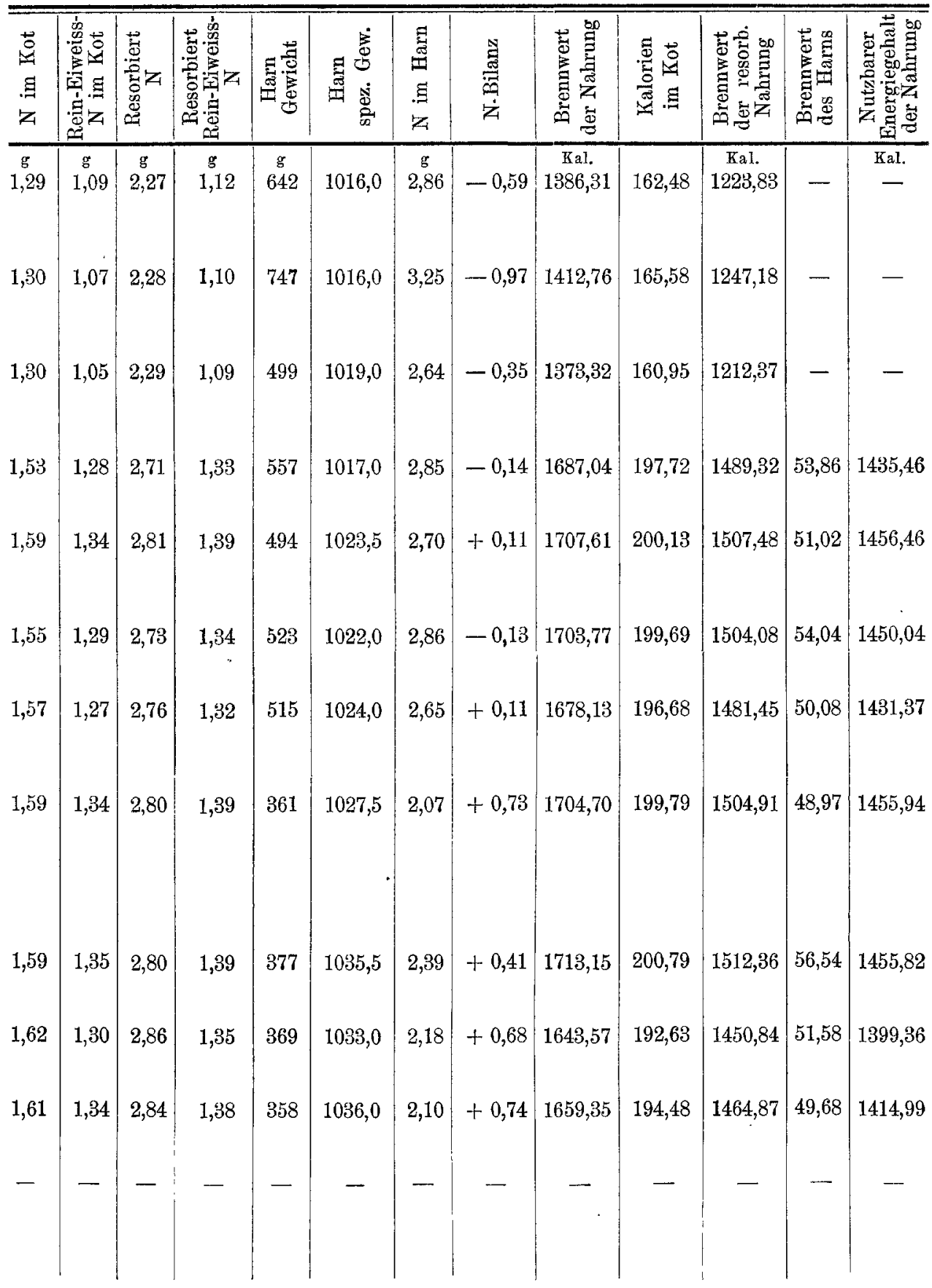


Während der gesamten ersten Periode wurden demnach verabfolgt

\begin{tabular}{|c|c|c|c|}
\hline & $N$ & $N$ aus Eiweiss & $\begin{array}{c}\text { Kalorien } \\
31097\end{array}$ \\
\hline Es waren im Kot enthalten & $50,28,=103,5 \%$ & $46,95,=138 \%$ & $7321=28,54 \%$ \\
\hline $\begin{array}{l}\text { Es verblieben also im } \\
\text { Körper resp. wurden }\end{array}$ & des Nahrungs-N & $\begin{array}{c}N \text { des Nahrungs-N } \\
\text { aus Eiweiss }\end{array}$ & \\
\hline $\begin{array}{l}\text { von ihm abgeben. } \\
\text { Im Harn wurden ausge- } \\
\text { schieden während der }\end{array}$ & $-1,70 \mathrm{~g}$ & $-13,5 \mathrm{~g}$ & 23776 \\
\hline gesamten Periode & $118,28 \%$ & - & \\
\hline
\end{tabular}

Es ergibt sich also ein Stickstoffverlust während der ersten Periode von $119,98 \mathrm{~g}$. Nach ublicher Art berechnet, würde dies ca. $3,6 \mathrm{~kg}$ Fleisch ausmachen. Das Körpergewicht betrug am $30 . \mathrm{Ok}-$ tober $53,610 \mathrm{~kg}$; am 10. Dezember, dem ersten Tage der II. Periode, $44,585 \mathrm{~kg}$. Der Gewichtsverlust betrug also $9,025 \mathrm{~kg}$. Wenn wir diesen, was wahrscheinlich berechtigt ist, als durch Fleisch- und Fettverlust bedingt ansehen, so würde sich nach Abzug der $3,6 \mathrm{~kg}$ Fleisch ein Verlust von $5,4 \mathrm{~kg}$ Fettgewebe ergeben. Die Bilanz der Kalorien dieser Tage betrachten wir am besten gesondert für die Tage, welche der Mischharn I umfasst, und diejenigen des Mischharns II. Es wurden gegeben in der Nahrung vom 31. Oktober bis 19. November 14790 Kalorien; im Kot dieser Tage fanden sich 3482 Kalorien, im Harn 755 Kalorien, also für die Leistungen des Körpers disponibel 10553 Kalorien in 20 Tagen. Das macht pro Tag 528 Kalorien.

In den Tagen vom 4. bis 9. Dezember:

\begin{tabular}{lc} 
gegeben & 4727 Kal. \\
im Kot & $1113 \%$ \\
also verdaut & 3614 Kal. \\
im Harn & 188, \\
\hline
\end{tabular}

also im Körper verwertbar $3426 \mathrm{Kal} .=571 \mathrm{Kal}$. pro Tag.

Die Nahrungszufuhr der ersten Periode ergibt pro Tag im Mittel $\frac{48, \breve{3} 8}{41}=1,18 \mathrm{~g}$ Stickstoff, also pro Tag und Kilogramm Körpergewicht bei einem mittleren Gewicht von $49,1 \mathrm{~kg} 0,024 \mathrm{~g} \mathrm{~N}$. Ferner pro Tag im Durchschnitt 758 Kalorien, also pro Kilogramm Körpergewicht 15,44 Kalorien, in der resorbierten Nahrung 11,81 Kalorien pro Kilogramm Körpergewicht. Aus der zugeführten Nahrung und dem Verluste an Eiweiss und Fett können 
wir auch den Kraftverbrauch des Hauptmanns $H$. während dieser Periode berechnen. Diese Berechnung ist annähernd exakt zu nennen, weil, wie ich später zeigen werde, das Körpergewicht in unserem Versuche nur ganz vorübergehend durch Schwankungen des Wassergehaltes beeinflusst wird und daher mit ausserordentlicher Exaktheit den Ernährungszustand der Versuchsperson anzeigt. Den Stickstoffgehalt des Harns können wir fast seiner ganzen Menge nach auf zerfallenes Körperfleisch beziehen. Nach Frentzel und Schreuer ${ }^{1}$ ) unter Berücksichtigung der Fleischanalysen von Köhler ${ }^{2}$ ) kommen beim Zerfall von Fleisch auf jedes im Harn ausgeschiedene Gramm N 26,51 Kalorien. Es ergibt sich dann für die 41 Tage der I. Periode:

Verbraucht an Körperfleisch . . 118,28 $\times 26,51=3110 \mathrm{Kal}$. Köperferfett (das

Fettgewebe zu $90 \%$ aus Fett gerechnet) . . . . . . .

Im ganzen . . . . . . . . . . . . $49280 \mathrm{Kal}$.

Oder pro Tag. . . . . . . . . . . . . . 1202 "

In der Nahrung an nutzbarem Brennwert

Pro Tag im Mittel . . . . . . . . . . . . 555 " Gesamtverbrauch pro Tag . . . . . . . . 1757 Kal. Davon 555 Kalorien $=$ ca. $32 \%$ in der Nahrung.

Auf alle weiteren Einzelheiten muss später im Zusammenhang eingegangen werden.

Nehmen wir nunmehr einen allgemeinen Überblick über die II. Periode, so erstreckte sich dieselbe vom 10. Dezember bis 30. Dezember inkl., also über 21 Tage. Im allgemeinen wurden täglich $1 \mathrm{~kg}$ Äpfel gereicht. Es war wiederum dieselbe Sorte roter Amerikaner, deren Analyse oben mitgeteilt ist. Am ersten Tage dieser Periode bestand die Nahrung aus Äpfeln und Trauben. Am 25., 26. und 27. Dezember gelangten auch getrocknete Feigen zur Verwendung, deren Analyse ergab in $1000 \mathrm{~g}$ Substanz:

$$
\begin{array}{ccc}
\mathrm{N} & \mathrm{N} \text { aus Eiweiss } & \text { Brennwert } \\
8,14 \mathrm{~g} & 5,18 \mathrm{~g} & 3240,5 \mathrm{Kal} .
\end{array}
$$

1) Frentzel und Schreuer, Verbrennungswärme und physiologischer Nutzwert der Nährstofie. Vier Abhandlungen. Engelmann's Arch. 1901-1903.

2) Köhler, Zur Kenntnis der elementaren Zusammensetzung und Verbrennungswärme der Muskelsubstanz. Zeitschr. f. physiol. Chemie Bd. 31 S. 479. 
In der II. Periode wurden gegeben:

$$
\mathrm{N} \quad \mathrm{N} \text { aus Eiweiss Kalorien }
$$

In der Nahrung $28,42 \mathrm{~g} \quad 16,34 \mathrm{~g} \quad 15252$

im Kot. . . 18,52 ${ }_{n}=65 \% \quad 16,08,=98 \% \quad 1865=12,23 \%$ also verdaut . $9,90 \mathrm{~g} \quad 0,26 \mathrm{~g} \quad 13387$ im Harn . . . 58,95,

Bilanz ... $=-49,05 \mathrm{~g}$, entsprechend einem Verlust von ca. $1,5 \mathrm{~kg}$ Muskelfleisch.

Das Körpergewicht am 10. Dezember $44,585 \mathrm{~kg}$, am 31. Dezember $40,79 \mathrm{~kg}$, also Gewichtsverlust $3,885 \mathrm{~kg}$. Dies ergibt, wie oben, einen Verlust von ca. 2,4 kg Fettgewebe.

Die Bilanz der Kalorien betrachten wir wiederum am besten für den Abschnitt der Periode II, in welcher der Brennwert des Harns experimentell festgestellt worden ist. Es sind dies die Tage vom 16. bis 24. Dezember. In dieser Zeit wurden eingeführt:

mit der Nabrung $5920 \mathrm{Kal}$.

es waren im Kot

also verdaut

$\frac{724 \quad}{5196 \mathrm{Kal}}$

im Harn

355

also zur Verfügung im Organismus $\overline{4841 \mathrm{Kal}}$ in neun Tagen, also pro Tag 538,

In derselben Weise wie in der ersten Periode pro Tag und Kilogramm Körpergewicht berechnet, erhalten wir bei einem mittleren Körpergewicht von 42,688 kg: gegeben pro Tag im Mittel $\frac{28,42}{21}=1,35 \mathrm{~g} \mathrm{~N}$, das sind $0,032 \mathrm{~g} \mathrm{~N}$ pro Tag und Kilogramm Körpergewicht. An Kalorien wurde pro Tag gegeben $\frac{15252}{21}=726 \mathrm{Ka}-$ lorien; das sind 17 Kalorien pro Tag und Kilogramm in der Nahrung, und in der verdauten Nahrung 15 Kalorien.

In der II. Periode berechnet sich der tägliche Energieverbrauch folgendermassen :

Verlust an Stickstoff i. d. II. Periode $49,05 \times 25,92=1272$ Kal.

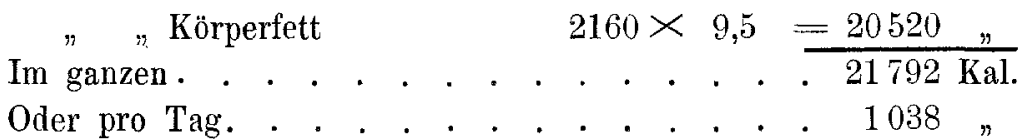

In der Nahrung pro Tag im Durchschnitt an nutz-

barer Energie. . . . . . . . . . . . . 538 n

Gesamtverbrauch pro Tag . . . . . . . $1676 \mathrm{Kal}$.

Davon in der Nahrung 538 Kalorien $=34 \%$. 
In der III. Periode, vom 31. Dezember 1902 bis 13. Januar 1903 , also in 14 Tagen, wurden eingeführt:

$\begin{array}{ccc}\mathrm{N} & \mathrm{N} \text { aus Eiweiss } & \text { Kalorien } \\ 55,53 \mathrm{~g} & 33,81 \mathrm{~g} & 21927\end{array}$

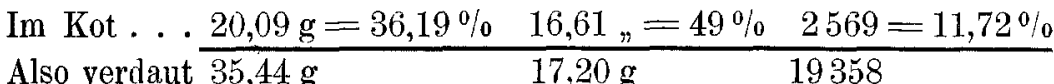

Im Harn . . 35,75,

Bilanz. . . . $-0,31 \mathrm{~g}$.

Wie ersichtlich, war das Resultat dieser Periode wesentlich günstiger als das der vorhergehenden. Dieses Ergebnis wurde durch mehrere Umstände bedingt. Erstens nämlich war in dieser Periode die Nahrung nicht unwesentlich reicher, da pro Tag im Mittel 1566 Kalorien verabreicht wurden. Auch der Stickstoff ist mit $3,97 \mathrm{~g}$ pro Tag beträchtlich höher als in den vorhergehenden Perioden. Dies wird nicht nur durch die grössere Menge der Nahrung bewirkt, sondern vor allem auch dadurch, dass die Zulage zum Teil in Form von Feigen geschah, welche naturgemäss ein ausserordentlich viel konzentrierteres Nahrungsmittel abgeben als ungetrocknete Früchte. Denn während bei letzteren der Wassergehalt durchschnittlich etwa $80 \%$ betrug, enthielten die Feigen nur etwa $15 \%$ Wasser. Demzufolge repräsentieren denn auch $100 \mathrm{~g}$ Feigen mit dem Wassergebalte, mit dem sie zur Verwendung kamen, einen Brennwert von 324 Kalorien, während $100 \mathrm{~g}$ frischer Äpfel nur 64,5, $100 \mathrm{~g}$ Trauben 80 Kalorien enthielten. Hierzu kommt, dass die Ausnutzung, wie aus den angegebenen Daten hervorgeht, in dieser Periode eine wesentlich bessere war, als wir sie in den auderen gefunden haben. Dies liegt wohl im wesentlichen daran, dass die Haupteiweissträger, die Kerne, bei dem Genuss von Feigen zum grossen Teil zerbissen und dadurch der Verdauung zugänglich gemacht werden, während vornehmlich bei dem Genuss von Weintrauben die Kerne den Magendarmkanal unverändert passierten. Doch nicht nur reichhaltiger gestaltete sich die Nahrung der III. Periode, sondern auch mannigfaltiger und schmackhafter. Dies wurde erreicht ausser durch die Verwendung von Feigen durch abwechselnde Darreichung dreier verschiedener Sorten Äpfel, welche als Qualität I, II und III in der Tabelle gekennzeichnet sind. Qualität I waren amerikanische Rauhschalen, eine feine Qualität, welche durch ein ausserordentlich starkes Aroma und besondere Saftigkeit ausgezeichnet 
war. Die Analyse ergab, auf frisches Material berechnet, für $1000 \mathrm{~g}$ :

$$
\begin{array}{ccc}
\mathrm{N} & \mathrm{N} \text { aus Eiweiss } & \text { Breunwert } \\
1,12 \mathrm{~g} & 0,786 \mathrm{~g} & 728,43 \text { Kal. }
\end{array}
$$

Beträchtlich feiner im Geschmack, aber weniger saftig waren die Äpfel der Qualität II, deutsche Rauhschalen. In $1000 \mathrm{~g}$ frischer Früchte waren hier enthalten:

$$
\begin{array}{ccc}
\mathrm{N} & \mathrm{N} \text { aus Eiweiss } & \text { Brennwert } \\
1,28 \mathrm{~g} & 0,96 \mathrm{~s} \mathrm{~g} & 728,17 \mathrm{Kal} .
\end{array}
$$

Als Qualität III sind die roten Amerikaner bezeichnet, welche schon in den früheren Perioden zur Verwendung gelangten.

Täglich wurden ferner Apfelsinen geıossen, was zwar für die Nahrungszufuhr von geringerer Bedlentung, für den Wohlgeschmack der Kost aber sicher sehr wichtig war. Diese Apfelsinen waren von geringer Süsse; sie wurden von der Versuchsperson sehr sororsam geschält und die Kerne nicht initgenossen, so dass dieselben stets zurückgewogen werden mussten. Zur Analyse wurde Material verwendet, das vom Hauptmann $H$. in derselben sorgfältigen Weise, wie er es bei den für die Nahrung bestimmten Apfelsinen zu tun pflegte, präpariert wurde. Die Zusammensetzung der frischen Substanz war in $1 \mathrm{~kg}$ :

$$
\begin{array}{ccc}
\mathrm{N} & \mathrm{N} \text { aus Eiweiss } & \text { Brennwert } \\
\mathbf{1 , 8 7} \mathrm{g} & 0,94 \mathrm{~g} & 465,79 \mathrm{Kal} .
\end{array}
$$

Die Nahrungsmenge sowohl wie die Art der Ernährung war eine wechselnde. Wenn wir das Tagesmittel berechnen, so ergibt sich

$$
\begin{array}{ccc}
\mathrm{N} & \mathrm{N} \text { aus Eiweiss } & \text { Brennwert } \\
3,97 \mathrm{~g} & 2,415 \mathrm{~g} & 1566 \mathrm{Kal} .
\end{array}
$$

Bei einem mittleren Gewicht von $40,894 \mathrm{~kg}$ erhalten wir pro Tag und Kilogramm:

$$
\begin{array}{ccc}
\mathrm{N} & \mathrm{N} \text { aus Eiweiss } & \text { Brennwert } \\
0,097 \mathrm{~g} & 0,059 \mathrm{~g} & 38 \mathrm{Kal} .
\end{array}
$$

In der resorbierten Nahrung waren euthalten pro Tag:

$\begin{array}{ccc}\mathrm{N} & \mathrm{N} \text { aus Eiweiss } & \text { Brennwert } \\ 2,53 \mathrm{~g} & 1,23 \mathrm{~g} & 1383 \mathrm{Kal} .\end{array}$

Dies sind pro Kilogramm Körpergewicht:

$\begin{array}{ccc}\mathrm{N} & \mathrm{N} \text { aus Eiweiss } & \text { Brennwert } \\ 0,062 \mathrm{~g} & 0,03 \mathrm{~g} & 34 \mathrm{Kal} .\end{array}$


Durch die Verschiedenartigkeit der Nahrung zerfällt die Periode III ihrerseits in drei Teile, von welchen der erste (III a) vom 31. Dezember his 5. Januar, der zweite (III b) vom 6. bis 9. Januar und der dritte (III c) vom 10. bis 13 . Januar reichen.

In Periode III a wurden eingeführt:

\begin{tabular}{|c|c|c|c|}
\hline & $\mathrm{N}$ & $\mathrm{N}$ aus Eiweiss & Kalorien \\
\hline & $20,57 \mathrm{~g}$ & $12,41 \mathrm{~g}$ & 8430 \\
\hline Im Kot & 7,41, & $6,10 n$ & 989 \\
\hline Verdaut & $13,16 \mathrm{~g}$ & $6,31 \mathrm{~g}$ & 7441 \\
\hline Im Harn & $15,95 \ldots$ & & ht bestimm \\
\hline
\end{tabular}

Das Tagesmittel der Nahrung enthielt also:

N N aus Eiweiss Kalorien

$3,43 \mathrm{~g} \quad 2,07 \mathrm{~g} \quad 1405$

Das mittlere Körpergewicht betrug 40,965 kg.

Pro Kilogramm Körpergewicht wurde also täglich mit der Nahrung eingeführt:

$$
\begin{array}{ccc}
\mathrm{N} & \mathrm{N} \text { aus Eiweiss } & \text { Kalorien } \\
0,084 \mathrm{~g} & 0,05 \mathrm{~g} & 34
\end{array}
$$

Die resorbierte Nahrung enthielt pro Tag:

$$
\begin{array}{ccc}
\mathrm{N} & \mathrm{N} \text { aus Eiweiss } & \text { Kalorien } \\
2,19 \mathrm{~g} & 1,05 \mathrm{~g} & 1240
\end{array}
$$

Und pro Kilogramm Körpergewicht:

\begin{tabular}{|c|c|c|c|}
\hline Im Kot & 6,24 & 5,24, & 794 \\
\hline & 11,01 & $5,32 \mathrm{~g}$ & 598 \\
\hline
\end{tabular}

$$
\begin{array}{ccc}
\mathrm{N} & \mathrm{N} \text { aus Eiweiss } & \text { Kalorien } \\
0,053 \mathrm{~g} & 0,026 & 30
\end{array}
$$

In Periode III $b$ gereicht in der Nahrung in vier Tagen :

$$
\begin{array}{ccc}
\mathrm{N} & \mathrm{N} \text { aus Eiweiss } & \text { Kalorien } \\
17,25 \mathrm{~g} & 10,56 \mathrm{~g} & 6777
\end{array}
$$

$\begin{array}{rrrr}\text { In Harn } & 11,06 \eta & - & 209 \\ \text { Bilanz }-0,05 \mathrm{~g} & 5774\end{array}$

Das Tagesmittel der Nahrung enthielt:

$\begin{array}{ccc}\mathrm{N} & \mathrm{N} \text { aus Eiweiss } & \text { Kalorien } \\ 4,31 \mathrm{~g} & \mathbf{2 , 6 4 \mathrm { g }} & \mathbf{1 6 9 4}\end{array}$

Das mittlere Körpergewicht betrug 40,885 kg. Pro Kilogramm Körpergewicht wurde also gereicht: 


$$
\begin{array}{ccc}
\mathrm{N} & \mathrm{N} \text { aus Eiweiss } & \text { Kalorien } \\
0,10 \mathrm{~g} & 0,065 \mathrm{~g} & 41
\end{array}
$$

In der resorbierten Nahrung pro Tag:

$$
\begin{array}{ccc}
\mathrm{N} & \mathrm{N} \text { aus Eiweiss } & \text { Kalorien } \\
2,75 \mathrm{~g} & 1,33 \mathrm{~g} & 1443
\end{array}
$$

Und pro Kilogramm Körpergewicht in der resorbierten Nahrung:

$$
\begin{array}{ccc}
\mathrm{N} & \mathrm{N} \text { aus Eiweiss } & \text { Kalorien } \\
0,067 \mathrm{~g} & 0,033 \mathrm{~g} & 35
\end{array}
$$

Stellt man die N-Bilanz der einzelnen Tage dieser Periode auf, so findet man, wie aus der Tabelle hervorgeht, am

$$
\begin{aligned}
& \text { 6. Januar - 0,14, } \\
& \text { 7. } \quad+0,11, \\
& \text { 8. } \quad=0,13, \\
& \text { 9. } \quad+0,11 .
\end{aligned}
$$

Daraus geht hervor, dass die negative Schlussbilanz der Per. III b von - $0,05 \mathrm{~g} \mathrm{~N}$ auf Zufälligkeit beruht und de facto während dieser vier Tage ein Schwanken um die Nullbilanz stattfindet, welche zeigt, dass das Stickstoffgleichgewicht knapp erreicht ist. Auch das Körpergewicht bleibt annäherud konstant. Der Energieverbrauch wurde also in Periode III b durch die nutzbare Energie der Nahrung ungefähr gedeckt. Dieselbe

$$
\begin{aligned}
& \text { betrug im ganzen } 5774 \text { Kalorien, } \\
& \text { also pro Tag } 1443
\end{aligned}
$$

In der Schlussperiode dieses Versuches, vom 10. bis 13. Januar, wurde gegeben in der Nahrung

\begin{tabular}{lccr} 
& $\mathrm{N}$ & $\mathrm{N}$ aus Eiweiss & Kalorien \\
& $17,71 \mathrm{~g}$ & $10,84 \mathrm{~g}$ & 6721 \\
Im Kot & $6,41 \mathrm{~g}$ & $5,33 \mathrm{~g}$ & 788 \\
\cline { 2 - 4 } Also verdaut & $11,30 \mathrm{~g}$ & $5,51 \mathrm{~g}$ & 5933 \\
Im Harn & $8,74 \mathrm{~g}$ & & 207 \\
\cline { 2 - 4 } Bilanz $+2,56 \mathrm{~g}$ & \multicolumn{3}{c}{5727} \\
entspr. einem Fleischansatz von ca. $77 \mathrm{~g}$.
\end{tabular}

Im Mittel enthielt die Nahrung pro Tag:

$$
\begin{array}{ccc}
\mathrm{N} & \mathrm{N} \text { aus Eiweiss } & \text { Kalorien } \\
4,43 \mathrm{~g} & 2,71 \mathrm{~g} & 1680 .
\end{array}
$$

Das mittlere Körpergewicht war $40,905 \mathrm{~kg}$.

Es kamen daher in der täglichen Nabrung auf das Kilogramm Körpergewicht: 


$$
\begin{array}{ccc}
\mathbf{N} & \mathbf{N} \text { aus Eiweiss } & \text { Kalorien } \\
0,108 \mathrm{~g} & 0,066 & 41 .
\end{array}
$$

In der resorbierten Nahrung waren täglich im Mittel enthalten : $\mathrm{N} \quad \mathrm{N}$ aus Eiweiss Kalorien

$$
2,825 \mathrm{~g} \quad 1,38 \mathrm{~g} \quad 1483 .
$$

Dies sind pro Kilogramm Körpergewicht:

$$
\begin{array}{ccc}
\mathrm{N} & \mathrm{N} \text { aus Eiweiss } & \text { Kalorien } \\
0,069 \mathrm{~g} & 0,034 \mathrm{~g} & 36 .
\end{array}
$$

Ähnlich wie in Periode III b wurden in Periode III c 1483 Kal. täglich verbraucht, wobei der geringe Fleischansatz während dieser Periode nicht berücksichtigt ist. Der kleine Gewichtsverlust am 14. Januar ist durch reichlichere Kotentleerung bedingt.

Es ergibt sich also, dass während der III. Periode bei einer täglichen Zufuhr von $3,43 \mathrm{~g} \mathrm{~N}$ und 1405 Kalorien $(0,08 \mathrm{~g} \mathrm{~N}$ und 34 Kalorien pro Kilogramm) noch ein Verlust an Eiweisssubstanz stattfand, bei einer Zufuhr von $4,31 \mathrm{~g} \mathrm{~N}$ und 1694 Wärmeeinheiten $(0,10 \mathrm{~g} \mathrm{~N}$ und 41 Kalorien pro Kilogramm) der Organismus sich ins Gleichgewicht setzte, und schliesslich bei einer Zufuhr von $4,43 \mathrm{~g} \mathrm{~N}$ und 1680 Kalorien $(0,11 \mathrm{~g} \mathrm{~N}$ und 41 Kalorien pro Kilogramm) ein deutlicher Ansatz von Körpersubstanz erfolgte. Bei der Bilanz ist dem insensiblen Verluste an Stickstoff nicht Rechnung getragen worden. Da die Lebensweise des Herrn H. vom Beginn der Fussbeschwerden an (7. November) eine sehr ruhige, die umgebende Temperatur niemals eine sehr hohe war, so dürfte eine Schweissabsonderung nur in äusserst geringem Masse vorgekommen sein. Es ist daher nicht anzunehmen, dass durch Nichtberücksichtigung der Stickstoffverluste durch Schweiss, Epidermisschuppen usw. im vorliegenden Falle ein nennenswerter Fehler begangen ist.

Den Verlauf des ganzen Versuches kann man zweckmässig auf der Kurve ${ }^{1}$ ) verfolgen. Fs bedeutet auf derselben die schwarze ausgezogene Linie die Stickstoff bilanz, und zwar ist der Massstab derart gewählt, dass jeder Teilstrich der Ordinate $0,1 \mathrm{~g}$ Stickstoff entspricht ${ }^{2}$ ). Eine Folge dieses gross gewählten Massstabes sind die weiten Zacken der Kurve. Doch sind die Schwankungen im allgemeinen nicht grösser, als sie bei jedem derartigen Versuch von Tag zu Tag einzutreten pflegen. Dagegen bemerkt man deutlich eine Unregelmässigkeit. Es ist dies die ausserordentliche Zunahme des Stickstoffverlustes am 2. Dezember.

1) Siehe Tafel XI.

2) Die zugehörigen Zahlen stehen links auf der Tafel. 
Zum Teil ist diese sicher durch eine vorhergehende Harnretention bedingt, wie die geringe Harnausfubr vom 1. Dezember, die geringste der ganzen Periode, beweist (siehe Tabelle). Ob daneben am 2. Dezember noch durch irgendwelche besonderen Reize der $\mathrm{N}$ Umsatz eine Erböhung erfahren hat, war nicht festzustellen.

Man kann die Besserung der Bilanz deutlich beobachten mit dem Einsetzen der II. Periode am 10. Dezember, wo es bedingt ist durch die bessere Resorption der Nahrung. Dann bemerkt man sehr eklatant das Ansteigen der Bilanz am 26., 27. und 28. Dezember, bedingt durch die Verwendung von $199 \mathrm{~g}$ Feigen anstatt des gleichen Gewichtes Äpfel. Es ist nicht uninteressant, zu sehen, dass die Hebung der Kurve am 26, 27. und 28. statthat, während die vermehrte Zufuhr der Nahrung am 25., 26. und 27. stattfindet, so dass man also deutlich hier die durch vielfache Stoffwechselversuche festgestellte Tatsache bemerken kann, dass der Organismus für eine Veränderung der Diät meist erst am Tage nach der eingetretenen Veränderung den entsprechenden Ausschlag gibt. Wir sehen dann in der III. Periode ein sehr starkes Ansteigen der Stickstoffbilanz, welchem in Periode III b ein Schwanken um die Nullinie, also Stickstoffgleichgewicht, in Periode III c der deutliche Ansatz folgt.

Die gestrichelte Kurve (-.) bedeutet die Stickstoffzufuhr in der Nahrung. Hier entspricht ebenfalls jeder Teilstrich der Ordinate $0,1 \mathrm{~g} \mathrm{~N}$, also derselbe Massstab wie in der Bilanzkurve.

Die punktierte Kurve $(\cdots)$ ist in gleichem Massstabe angelegt wie die gestrichelte. Sie gibt den resorbierten Stickstoff an ${ }^{\mathbf{1}}$ ).

Die aus abwechselnden Punkten und Strichen bestehende Kurve $(\cdot \cdots)$ zeigt die Kalorienzufuhr in der Nahrung, und zwar entspricht jeder Teilstrich 40 Kalorien $^{2}$ ). Man sieht nun, wie die Bilanzkurve in ausserordentlicher Regelmässigkeit den Schwankungen der anderen Kurven folgt und besonders dort sehr fein auf dieselbe reagiert, wo Nahrungsstickstoff und Nahrungskalorienkurven gleichsinnig verlaufen, so z. B. am 13. November, am 18. November usw. Sehr deutlich tritt die Änderung der Stickstoftbilanz im Verhältnis zur Kalorien- oder Stickstoffzufuhr hervor beim Übergang zur II. Periode, bedingt durch die Besserung der Resorptionsverhältnisse. Sie folgt daher in diesem Abschnitte am ehesten der punktierten Kurve, welche den resorbierten Stickstoff angibt.

1) Die zugehörigen Zahlen für diese beiden Kurven stehen rechts.

2) Die Zahlen stehen rechts am Rand. 
In der III. Periode sieht man beim Vergleichen aller Kurven mit besonderer Deutlichkeit, wie auch hier die Bilanzkurve gleichsinnigen Schwankungen der Kalorien- und Nahrungsstickstoffkurven folgt, aber mit einer gewissen Verzögerung.

Zum allgemeinen Überblicke des Versuches ist noch zu bemerken, dass der Hauptmann H. Getränke während dieses Versuches nicht zu sich genommen hat. Es erscheint dies auch von unwesentlicher Bedeutung, da die Nahrung ja ausserordentlich wasserreich war und er im Durchschnitt pro Tag etwa $800 \mathrm{ccm}$ Wasser in den Früchten aufnahm.

Von grossem Interesse ist das Verhalten des Körpergewichts, dessen einzelne Daten aus der Tabelle zu entnehmen sind. Der Verlauf des Körpergewichts des ganzen Versuches wird durch die Kurve ${ }^{1}$ ) verdeutlicht. Es zeigt sich bei Betrachtung derselben, ein wie ausserordentlich feines Reagens die Veränderungen des Körpergewichts darstellen, wenn man, wie bei diesem Versuche, instande ist, die Bedingungen, unter welchen dieses Körpergewicht zustande kommt, klar zu übersehen. Wie aus der Tabelle ersichtlich ist, wurde das Körpergewicht durchaus nicht stets zur selben Stunde von mir festgestellt, wohl aber wusste ich bei jeder Bestimmung genau, welche Einnahmen und Ausgaben bis zur Wägung stattgefunden hatten, so dass ich für jeden Tag das Nüchterngewicht berechnen konnte. Es stellt sich so die Kurve des Körpergewichts während der ersten beiden Perioden als eine ausserordentlich regelmässige dar, und zwar in so hohem Masse, dass jẹde Abweichung von dem gleichmässigen Verlauf in der Tat durch das Verhalten der Versuchsperson eine befriedigeride Erklärung findet. So sind die Abfälle am fünften und zehnten Tage des Versuches bedingt durch grössere körperliche Anstrengungen. Am 3. November war es der grosse Dauerlauf vom vierten Tage (2. November); am 8. November die durch das Gehen bei bestehenden Fussschmerzen am 7. November bedingte Anstrengung, welche augenscheinlich zu Schweissbildung und Wasserverlust führten. Die Richtigkeit dieser Anschauung geht auch mit Deutlichkeit aus der geringen Harnmenge am 3. und 7. November hervor, welche nur 318 bezw. $322 \mathrm{ccm}$ betrug (siehe Tabelle). Nach dem Gewichtsabfall steigt denn auch stets das Körpergewicht der Versuchsperson an, allerdings nur so

1) Siehe Tafel XI. 
weit, dass es durchaus im regelmässigen Verlaufe der Kurve unterhalb desjenigen Körpergewichtes bleibt, welches vor der grösseren körperlichen Anstrengung bestimmt wurde.

Das Stehenbleiben des Körpergewichts zwischen dem 26. und 28. Dezember ist durch die vorangehende Verwendung von Feigen erklärt. Es unterliegt nach dieser Betrachtung meiner Ansicht nach keinem Zweifel, dass die Kontrolle des Körpergewichts z. B. bei klinischen Versuchen zu Unrecht in Misskredit gekommen ist, und dass bei Beherrschung aller Nebenumstände der Verlauf der Körpergewichtskurve in befriedigendster Weise eine Unterstützung für die Beurteilung des Stoffumsatzes einer Versuchsperson resp. eines Patienten zu geben in der Lage ist. Dass dieses vorzügliche Resultat nicht auf Zufälligkeit beruht, dafür kann zum Beweise dienen, dass auch andere Forscher ein ähnlich feines Reagieren des Körpergewichts gefunden haben. Ich verweise auf die verblüffende Übereinstimmung zwischen berechneter und tatsächlicher Gewichtszunahme in den Mastversuchen $\mathrm{Pflügers}{ }^{x}$ ).

\section{Diskussion der Frage nach der Wertigkeit vegetarischer Ernährung auf Grund des vorliegenden Materials.}

Nachdem wir so in grossen Zügen das vorliegende Versuchsmaterial an uns haben vorübergehen lassen, wollen wir nunmehr die Folgerungen aus demselben ziehen, indem wir an der Hand der alten und neuen Versuche die Bedeutung der vegetarischen Diät diskutieren. Es erscheint am praktischsten, dass man dabei der Reihe nach alle diejenigen Punkte betrachtet, in welchen sich die vegetarische Diätform wesentlich von der gewöhnlichen gemischten Kost unterscheidet, und sich die Frage vorlegt, ob diese Ernährungsform gegenüber der gemischten Diät wesentliche Nachteile oder in der einen oder anderen Beziehung auch wesentliche Vorteile zu gewähren imstande ist.

\section{Die Ausnutzung der vegetarischen Kost.}

Derjenige Einwand, welcher am klarsten aus allem bisher vorhandenen Versuchsmaterial in das Auge springt, ist die schlechte Ausnutzung der gegebenen Nahrung. Die schlechte Ausnutzung betrifft dabei in erster Linie das Eiweiss. Dies ist gerade bei der

1) Über Fleisch- und Fettmästung. Pflüger's Arch. Bd. 52 S. 67. 1892. 
vegetarischen Kost eine ganz besonders unangenehme Erscheinung, weil sich ja dieselbe überhaupt durch einen verhältnismässigen Mangel an Eiweisssubstanzen auszeichnet, worauf wir später einzugehen haben werden. Um die Ausnutzung der Kost bei vegetarischer und nichtvegetarischer Diät miteinander zu vergleichen, habe ich die folgende Tabelle zusammengestellt, aus welcher sich mit Deutlichkeit ergibt, dass selbst bei der besten Ausnutzung vegetarischen Nährmaterials die schlechteste Ausnutzung gemischter Kost kaum erreicht wird.

\section{Stickst offausnutzung.}

Es finden sich im Kot in Prozenten des Nahrungsstickstoffs

bei vegetarischer Kost:

Voit u. Constantinidi . . 40,73

Kellner und Mori . . . . . 24,29

Kumagawa . . . . . . 19 bez. 25

Rumpf und Schumm . . . . . 33,93

Albu. . . . . . . . . 32,79

Taniguti . . . . . . 20,15

" . . . . . . . . . . 20,26

" $\quad \ldots . . . . . . .18,27$

$n$

Hauer......... . 38,00

Caspari und Glässner. . . 26,10

Versuch an Hauptmann H.

Periode I . . . . . . 103,5 (138) ${ }^{1}$ )

" II . . . . . . 65,0 (98)

" III . . . . . . 36,19 (49) bei gemischter Kost:

Plasmon-Versuch Caspari . . 10,62

$" \quad " \quad$ ". . 5,18

$" n \quad " \quad$. . 4,27

Selbstversuch Löwy . . . . . 19,8

Müller . . . 13,7

Caspari... . 8,75

".... 11,77

Zuntz..... . 11,1

$"$ (Somatose) $\cdot 18,5$

Versuche an i Zuntz und 8,48

marsch. Soldaten $\}$ Schumburg $\{11,61$

Atwater und Benedict im

Mitúel von 50 Versuchen . . . . 9,2

Maximum . . . . . . 16,4

Minimum. . . . . . . . 3,2

Ich babe bei der Zusammenstellung von Beispielen für die Ausnutzung gemischter Nahrung absichtlich auch solche berïcksichtigt, welche eine aussergewöhnliche schlechte Resorption besonders der Eiweisssubstanzen zeigen. Hierher gehört der Selbstversuch von Löwy, bei welchem $19,8 \%$ des Stickstoffs im Kot wiederersehienen - hier wurde die schlechte Ausnutzung durch einen Darmkatarrh bedingt -, und ferner der Selbstversuch von $\mathrm{Zu} n \mathrm{tz}$, welcher unternommen wurde, um die Wirkung der Somatose zu untersuchen, und bei der gerade die resorptionsschädigende Wirkung der Albumosen besonders eklatant hervortrat.

Die Gründe für die schlechte Ausnutzung vegetarischer Kost

1) Die eingeklammerten Zahlen geben die gleichen Werte für das nach Stutzer bestimmte Rein-Eiweiss. 
sind mannigfaltiger Natur. Erstens nämlich wird die schlechte Ausnutzung der vegetarischen Ernährung bedingt durch den hohen Zellulosegehalt der Nahrung. Da besonders die eiweisshaltigen Substanzen der Pflanzen in Zellulosehüllen eingeschlossen sind, die letzteren aber von den Verdauungssekreten des Menschen nicht oder sicher nur in geringem Maasstabe angreifbar sind, so ergibt sich schon daraus, dass gerade die Eiweissausnutzung eine schlechte sein muss. Wie ausserordentlich für die Ausnutzung eines Nährmaterials der Gehalt an Zeliulose mitspricht, dafür sind die Versuche von Plagge und Lebbin ${ }^{1}$ ) über das Soldatenbrot ein besonders augenfälliger Beweis. Aus diesen Versuchen geht hervor, wie die Ausnutzung eines Brotes Schritt für Schritt eine schlechtere wird mit der Vermehrung des Kleiegehaltes.

Doch scheint mir die schlechte Resorption, soweit sie durch den Zellulosegehalt der Nabrung bedingt ist, kein unüberwindliches Hindernis gegen die Verwendung vegetarischer Diät zu sein. Wir wissen aus zahlreichen Versuchen, wie viel besser ein pflanzliches Material ausgenutzt wird, wenn wir dasselbe in Püreeform geniessen. Das geht z. B. aus den Versuchen von Constantinidi²) für die Kartoffel hervor. Natürlich tritt bei dem strengen Rohkostvegetarier der Umstand, dass die Nahrung durch ihren Reichtum an Zellulose einer günstigen Ausnutzung hinderlich ist, mit ganz besonderer Schärfe hervor und könnte nur allenfalls durch sehr sorgfältige Zerkleinerung des Materials einigermassen gemindert werden. Doch würden sich wohl auch hierzu die gewissenhaftesten Rohkostler kaum verstehen. Fällt doch selbst eine feine Zermahlung in das Gebiet der Zubereitung der Nahrungsmittel, durch welche dieselben künstlich verändert werden.

Ein zweiter Umstand, welcher bei der schlechten Ausnutzung der stickstoffhaltigen Bestandteile bei vegetarischer Kost in Betracht kommt, ist folgender: Wir sind gewohnt, bei der Bilanzaufstellung den Stickstoff des Kotes derartig zu verwerten, dass wir annehmen, er stelle den unverdauten Nabrungsstickstoff dar. Dabei wissen wir natürlich, und es ist von zahlreichen Autoren darauf hingewiesen worden, dass diese Annabme faktisch nicht richtig ist, der Stickstoff

1) Veröffentlichungen aus dem Gebiete des Militärsanitätswesens. Herausgegeben von der Medizinalabteilung des Kgl. preuss. Kriegsministeriums. Berlin 1897.

2) Zeitschr. f. Biol. Bd. 23 S. 453. 1887. 
des Kotes vielmehr sich aus zwei Bestandteilen zusammensetzt, von denen der eine allerdings auf unverdauten Nahrungsstickstoff zurückzuführen ist, während die andere Komponente den mit dem Kote ausgeschiedenen Verdauungssekreten zukommt. Für die Bilanzaufstellung des Stickstoffes kommt der Unterschied nicht wesentlich in Betracbt, weil ja auch der Stickstoft aus den Verdauungssekreten einen Verlust an Körperstickstoff bedeutet. Für die Feststellung der Ausnutzung können wir ebenfalls diese Komponente des Kotstickstoffs meist vernachlässigen, weil bei reichlicher Stickstoffzufuhr der N-Gehalt der mit dem Kot ausgeschiedenen Verdauungssekrete nicht wesentlich in Betracht kommt und bei der Berechung der prozentischen Ausnutzung des Nahrungsstoffes eine erbebliche Rolle kaum spielen kann. Ganz anders verbält es sich aber, wenn, wie fast stets bei vegetarischer Diät, die Stickstoffzufuhr in der Nahrung eine ausserordentlich geringe ist, während die Absonderung von Darmsekret kaum eine herabgesetzte, ja sogar, wie nicht unwahrscheinlich, durch den Reiz der stark zellulosehaltigen Nahrung eine vermehrte ist. Dass der Stickstoff des Kotes nicht allein auf unresorbierten Stickstoff der Nahrung zurückzuführen sein kann, geht ja deutlich aus der I. Periode des Versuches am Hauptmann $H$. hervor, bei welchem mehr Stickstoff im Kot erschien, als in der Nahrung verabfolgt wurde. Dieser Fall ist nicht einzig dastehend. So hat $R u b n e r^{1}$ ) über einen Versuch berichtet, in dem bei einer Nahrung, welche aus einem Kuchen aus Stärkemehl, Zucker und Schmalz unter Zugabe von etwas leichtem Rheinwein bestand, pro Tag 1,36 $\mathrm{g} \mathrm{N}$ eingeführt and im Kot $1,39 \mathrm{~g} \mathrm{~N}$ ausgeschieden wurden. Rubner bezieht diese 1,39 $\mathrm{g} \mathrm{N}$ ganz auf Darmsekret.

Ähnliche Versuche hat dann Rie de ${ }^{2}$ ) bei stickstofffreier Kost aus Stärkemehl, Zucker und Schmalz angestellt. Er fand im Kot

$$
\begin{aligned}
& 0,54 \mathrm{~g} \mathrm{~N} \\
& 0,87 " \Rightarrow \\
& 0,78 " \text { " }
\end{aligned}
$$

und mittelt daraus den Wert von $0,73 \mathrm{~g} \mathrm{~N}$, aus Darmsekreten stammend. Auch Praussnitz ${ }^{3}$ ) und Tsuboi ${ }^{4}$ ) baben sich mit dieser Frage beschäftigt. Letzterer stellte bei einem Hunde fest,

1) Zeitschr. f. Biol. Bd. 14 S. $198 . ' 1879$.

2) Zeitschr. f. Biol. Bd. 20 S. 378. 1884.

3) Zeitschr. f. Biol. Bd. 35 S. 335. 1897.

4) Zeitschr. f. Biol. Bd. 35 S. 68.1897. 
dass bei absolutem Hunger der tägliche Kotstickstoff $0,14 \mathrm{~g}$ betrug, bei einer Nahrung von $70 \mathrm{~g}$ Stärke, $50 \mathrm{~g}$ Fett und $12 \mathrm{~g}$ Zucker $0,24 \mathrm{~g}$, bei einer solehen von $200 \mathrm{~g}$ Stärke, $80 \mathrm{~g}$ Fett und $25 \mathrm{~g}$ Zucker $0,57 \mathrm{~g} \mathrm{~N}$. Schon aus dieser Zusammenstellung geht klar hervor, dass auch bei stickstofffreier Kost der Stickstoffgehalt des Kotes ein ausserordentlich wechselnder ist, augenscheinlich abhängig von der Menge und Art der zugeführten Nahrung, wie dies ja auch bei der Abhängigkeit der Absonderung der Verdauungssekrete von der Nahrung gar nicht anders zu erwarten ist. Es erscheint daher unmöglich, eine auch nur annähernde Norm zu finden, welche uns gegebenen Falles den Stickstoffoehalt des Kotes in seine beiden Bestandteile: Nahrungsrückstand und Darmsekret, zu sondern erlaubt.

Doch können wir uns für die I. Periode der Enährung unseres Vegetariers einigermassen ein Bild davon machen, wieviel von der im Kot ausgeschiedenen Stickstoffmenge auf Restbestandteile des Darmsekretes zurückzuführen ist.

Es wurde oben erwähnt, dass es unmöglich war, die Trauben in toto zu trocknen und solchergestalt für die Analyse vorzubereiten. Vielmehr mussten dieselben ausgepresst und Traubensaft und Traubentrester gesondert untersucht werden. Nun kann man zweifellos, ohne einen grösseren Fehler zu begehen, annelımen, dass die Nahrungsrückstände im Kot im wesentlichen Schalen und Kerne waren. Das ergab auch das makroskopische Aussehen des Kotes, welcher ganz aus unveränderten Schalen und Kernen bestand, die durch eine bräunlich-schleimige Masse zusammengehalten wurden. Andrerseits kann man wohl mit ziemlicher Sicherheit annehmen, dass der Traubensaft, dessen Bestandteile ja leicht resorbierbar sind, in vollkommenster Weise rom Organismus ausgenutzt wurde. Die Analyse der Weintrauben ergab nun, dass $77 \%$ des Stickstoffes in den Schalen und Kernen, $23 \%$ desselben im Saft enthalten waren. Fs wurden nun von 41 Tagen in der $I$. Periode an fünf Tagen, wie aus der Tabelle zu ersehen, Äpfel, an 36 Tagen Trauben gereicht. In den Äpfeln der fünf Tage waren enthalten $5,67 \mathrm{~g}$ N. Aus der II. Periode, deren Nahrung im wesentlichen aus Äpfeln bestand, geht hervor, dass von den Äpfeln ca. $65 \%$ des $N$ im Kot wiedererschienen. Es würden demnach den $5,67 \mathrm{~g} \mathrm{~N}$ in den Äpfeln $3,69 \mathrm{~g} \mathrm{~N}$ im Kot entsprechen. Wenn wir dieses in Abzug bringen, so erhalten wir während der 36 Tage auf $42,91 \mathrm{~g} \mathrm{~N}$ in der Nahrung $46,59 \mathrm{~g} \mathrm{~N}$ im Kot. Von den $42,91 \mathrm{~g} \mathrm{~N}$ der Nahrung sind $77 \%$ d. h. 
33,04 $\mathrm{g}$ in den Schalen und Kernen, enthalten. Ziehen wir diese $33,04 \mathrm{~g} \mathrm{~N}$ von den $46,59 \mathrm{~g}$ Kotstickstoff ab, so erbalten wir $13,55 \mathrm{~g}$ $\mathrm{N}$ im Kot der 36 Tage, welche vermutlich aus Darmsekret herrühren. Das entspricht etwa $0,38 \mathrm{~g} N$ pro Tag aus Darmsekret oder etwa 29,1\% des Kotstiekstoffs. Man ersieht daraus, dass die schlechte Verdaulichkeit des Eiweisses bei vegetarischer Diät zum Teil wohl nur vorgetäuscht ist durch die Ausscheidung der Darmsekrete, die bei dem absolut niedrigen Stickstoffgehalte der Nahrung in weit höherem Masse als bei gewöhnlicher Kost ins Gewicht fällt.

\section{Reizlosigkeit der vegetarischen Kost.}

Bei der schlechten Ausnutzung der vegetarischen Diät im allgemeinen spielt aber wohl zweifellos ausser dem hohen Zellulosegehalt, dessen Nachteil sich ja bis zu einem gewissen Grade vermeiden lässt, noch ein anderer Umstand mit, dessen hohe Bedeutung uns erst die Erfahrungen der letzten Jahre klar vor Augen geführt haben. Es ist dies die Reizlosigkeit und E införmigkeit der vegetarischen Ernährungsweise. Man war früher der Ansicht, dass die Absonderung der Verdauungssekrete im wesentlichen abhängig sei von der Einführung der Nahrung, und dass die mechanische Reizung der Wände des Verdauungskanals genüge, um eine Absonderung der verdauenden Sekrete herbeizufübren. Heute wissen wir durch die Versuche $\mathrm{Pawlows}$ und seiner Schüler, in wie eminentem Grade die Sekretion der Verdaungssäfte bedingt ist durch die nervösen und psychischen Funktionen, welche wir als Appetit zu bezeichnen pflegen. Nun behauptet ja der Vegetarier stets, dass seine Kost ausserordentlich sclimackhaft sei, und es lässt sich wohl auch nicht leugnen, dass sich durch Variation des Speisezettels eine gewisse Abwechslung herbeiführen lässt, besonders durch Verwendung wohlschmeckender, vielfach sehr aromatischer Früchte. Im allgemeinen wird man aber zugeben müssen, dass die vegetarische Kost im Gegensatze zu der gemischten vieler. Würzen und Appetitreize entbehrt. Wir wissen auch von all denjenigen Völkern, welche vorwiegend vegetabilisch leben, - die Existenz rein vegetarisch lebender Volksstämme hat, wie mir von Fachleuten versichert wurde, bisher niemals nachgewiesen werden können --, dass dieselben mit ausserordentlichem Eifer sich animalische Kost terrestrischer oder maritimer Herkunft zu verschaffen suchen, und zwar scheint ihr Bedürfnis nach Fleischnahrung weniger bedingt zu sein durch die 
Eiweissarmut ihrer Nahrung als vielmehr durch die Reizlosigkeit derselben. In dieser Beziehung verdanke ich Herrn Prof. v o n den Steinen einige sehr interessante Mitteilungen, aus denen ich folgendes anführen möchte: Herr von den Steinen schreibt mir:

"Auf den Marquesas lautet das Wort, von dem ich Ibnen sprach, inai, und dass ich nicht ganz unrecht hatte, es in der Erinnerung zunächst mit ,Würze‘ zu übersetzen, ersehen Sie aus der Übersetzung eines kleinen französischen Wörterbuchs: inai: assaissonner, met d'assaissonnement. Hier ist immer etwas Fisch oder maritime Nahrung gemeint, wie ich bestimmt weiss, die dem Brotfruchtpudding, dem Nationalgericht, zugesetzt wird, und die den Leuten dringend erwünscht ist. Dasselbe Wort existiert auch bei den übrigen Polynesiern. So sagt das tahitische Wörterbuch: inai ,anything to eat with bread or vegetables, such as pork, fish or fowl', fügt dann aber hinzu: ,also bread or vegetables to accompany flesh!" Ursprünglich bedentet es vielleicht nur Zusatzspeise; so in Neuseeland: kinaki (die alte Form von inai): foor eaten with other food; to eat one kind of food withanother."

Wir finden denn auch, dass diejenigen Völker, welche bei hochentwickelter allgemeiner Kultur einer vorwiegend vegetabilischen Diätform buldigen, in ausserordentlich geschickter Weise diesem Mangel der vegetabilischen Kost zu begegnen sich bemübt haben. Hier sind in erster Linie die Japaner zu nennen. Wenn auch heutzutage eine rein vegetariscile Diätform in Japan nicht mehr in grösserer Auslehnung vorzukommen scheint, so nähren sich doch auch hier die unteren Volksschichten im wesentlichen von Reis, welchem sie nach Kräften andere Zukost pflanzlicher und, wo sie können, animalischer Form beigeben. Zwar hat B älz-Tokio ${ }^{1}$ ) behauptet, dass Millionen Japaner vegetarisch leben. Im weiteren Verlaufe seiner Mitteilung schränkt $B a ̈ l z$ jedoch seine Behauptung wesentlich ein, indem er von seinen Vegetariern sagt:

„Aber auch diese Leute essen, wenn sie etwas Geld haben, Fleisch und Fische, nicht, um sich kräftig zu machen, sondern weil die reichen Leute es essen."

Der erwähnten Angabe von Bälz ist auch von anderer Seite

1) Über vegetarische Massenernährung und über das Leistungsgleichgewicht. Berl. klin. Wochenschr. Bd. 38 Nr. 26. 1901. 
widersprochen worden. So von Herrn Geh. Rat Dönitz, welcher gleich Herrn $\mathrm{Bälz}$ viele Jahre lang in Japan gelebt hat, gesprächsweise, und auch japanische Kollegen, welche ich um Auskunft ersuchte, haben mir die Ansicht des Prof. Bälz nicht bestätigen können. Desgleichen hat Herr Prof. Grünwedel, Leiter der asiatischen Abteilung des Museums für Völkerkunde, eine rein vegetabilische Diät in dem von uns in der Einleitung näher präzisierten Sinne, wie für die anderen buddhistischen Völker, so auch für die Japaner in Abrede gestellt. Speziell leugnet dieser Herr auch die von Bälz angeführte Behauptung, dass bei der indischen Brahminen der Vegetarismus sehr streng gehalten werde. Dennoch wird man, wie gesagt, nicht daran zweifeln dürfen, dass für den unbemittelten Japaner Reis, Bohnen und Rüben den Grundstock der Ennährung bilden, wie ja auch in anderen Ländern bei den unbemittelten Klassen die vegetabilischen Komponenten der Nahrung die animalischen beträchtlich zu überwiegen pflegen. Dies geht auch aus den Angaben von $\mathrm{Eijkm} \mathrm{a}^{1}$ ) hervor, welcher für die Insassen eines Gefängnisses in Tokio eine reiu pflanzliche Kost angibt, und ebenso aus denen von Tawara ${ }^{2}$ ), welcher mitteilt, dass in einem grossen Kaufhause in Tokio den Bediensteten wenigstens an drei Beobachtungstagen keine animalische Nahrung geboten wurde. In den übrigen von $\mathrm{T}$ a wa ra auf die Beköstigung der Insassen geprüften Anstalten wurde dagegen stets gemischte Kost mit Fisch oder Rindfleisch verabfolgt. Jedenfalls hat es nun aber der Japaner verstanden, aus seiner vegetabilischen Nahrung unter Benutzung von Sprosspilzen sehr angenehme Geschmacksstoffe zu bereiten, und so stellt das japanische Miso und Schoju in der Tat sehr schmackhafte Speisen dar. Diese höbere Zufubr von Reizstoffen ist neben der Wahl des gut resorbierbaren Reises als Gruudstock der vegetarischen Diät vielleicht nicht ohne Bedeutung für die verhältnismässig günstigen Resultate, welche Taniguti und Kumaga wa bei ihren Versuchen für die Ausnutzung des Nahrungsstickstoffs erhielten, die besten, welche für die Stickstoffausnutzung bei vegetarischer Kost bisher festgestellt wurden Es kann das nicht daran liegen, dass die Japaner hesonders an vegetabilische Kost gewöhnt wären; denn aus den zitierten Versuchen von

1) Zitat nach Kellner und Mori, l. c. S. 106.

2) Ebenda S. 107 ff. 
Voit und Constantinidi geht wobl mit Klarheit hervor, dass ein Untersehied in der Ausnutzung vegetarischer Kost, etwa in Folge Gewöhnung an Zelluloseverdauung, zwischen einem gewohnten Vegetarier und einem vorübergehend vegetarisch lebenden Gemischtkostler nicht besteht. Dass übrigens auch der Japaner gegen die Einförmigkeit vegetarischer Kost empfindlich ist, ergibt sich daraus, dass $\mathrm{T}$ aniguti in seiner ersten Versucbsreihe bei reiner Reiskost sich genötigt sah, Fleischextrakt, das verpönte Reizmittel der animalischen Ernährungweise, der Nahrung zuzusetzen.

\section{Volumen der vegetarischen Kost.}

Ein weiterer Einwand verwirft die vegetarische Kost als unzweckmässig wegen des grossen Volumens an Nährmaterial, das dem Körper zugeführt werden muss, um eine ausreichende Ernäbrung des Individuums mit rein vegetarischer Diät zu erreichen. Das Volumen der Nahrung ist für denjenigen, welchem es an Zeit für die Speiseaufnahme gebricht, sicherlich kein gleichgültiger Faktor, wie Rubne ${ }^{1}$ ) in seiner Physiologie der Nahrung und Ernährung klar auseinandergesetzt hat. Er weist dabei darauf hin, dass die Dehnung der Magenwandung, welche durch die allzu voluminöse Kost bedingt wird, die motorische Tätigkeit des Magens herabsetzt, zu Dyspepsien und anderen Verdauungsbeschwerden führen muss. Auch das Gefülıl der Überfüllung, das besonders beim Überoang von einer weniger voluminösen zu einer sehr voluminösen Kost eintritt, erzeugt Ekel und Überdruss. Ausserdem erscheint es aber auch durehaus nicht ausgeschlossen, dass die Ausnutzbarkeit einer voluminösen Kost derjenigen einer weniger massigen Ernährung nachsteht. Denn man kann sich leicht ein Bild davon machen, dass, wenn grössere Anhäufungen von Nahrung im Verdauungskanal stattfinden, der Zutritt der Verdauungssäfte zu den der Wandung des Magendarmschlauches nicht anliegenden Nahrungsbestandteilen ein erschwerter ist. Dieser Einwand würde gerade bei einer vegetarischen Diät, bei welcher, wie wir gesehen haben, die Ausnutzbarkeit der Nahrung überhaupt eine zweifellos herabgesetzte ist, doppelt schwer ins Gewicht fallen.

Das grosse Volumen einer vegetarischen Nahrung zeigt sich besonders gut an den Versuchen Mori's, wie oben angeführt wurde.

1) Leyden's Handbuch der Ernährungstherapie S. 135. Thieme's Verlag, Leipzig. 
Auch die Kost des Vegetariers K. war sehr voluminös, freilich auch überreichlich. Sie enthielt z. B. am fünften Versuchstage:

$$
\begin{aligned}
20 & \text { g Gerstenkaffee, } \\
75 & \text { "Zucker, } \\
242 & \text { " Datteln, } \\
102 & \text { Nüsse, } \\
179 & \text { "Leinöl, } \\
1246 & \text { "Kartoffeln, } \\
30 & \text { " Karotten. }
\end{aligned}
$$

Eine so voluminöse Kost wird, wie Rubner mit Recht hervorhebt, besonders bei den nicht daran Gewöhnten Trägheit und Unlust zur Arbeit hervorrufen. Andrerseits legt aber der Umstand, dass meist ein grosses Volumen der Nahrung notwendig ist, um eine ausreichende Ernährung des Vegetariers herbeizuführen, die Gefabr ausserordentlich nahe, dass vegetarisch sich ernährende Personen ihr Nahrungsbedürfnis in unvollkommener Weise decken. Ist doch unser Sättigungsgefühl kein absolut sicherer Regulator für die genügende Nährkraft der Kost, und so kann man das angenehme Gefühl der Dehnung der Magenwände, welches uns die Empfindung des Sattseins vermittelt, herbeiführen, wenn man den Magen mit schlecht resorbierbarer zellulosehaltiger Nahrung anfüllt und so das subjektive Gefühl der Sättigung dazu benutzt, den Organismus um seine ausreichende Ernährung zu betrügen. Ist doch selbst nach dem übereinstimmenden Zeugnis aller Fastenkünstler das Hungergefühl eine vorübergehende Erscheinung, die nach einigen Tagen schwindet. In die Kategorie dieser mangelhaft ernährten Personen gehört zweifellos die Versuchsperson Albus und der Hauptmann H. Ebenso ist aber auch der schlechte Ausfall der Versuche von Mori hier zu erwähnen, welcher die genügende Menge Nahrungsmaterial nicht aufzunehmen imstande war, obgleich er sich der Unzulänglichkeit der aufgenommenen Kost wohl bewusst war.

Einsichtige Vegetarier haben nun selbst die schlechte Ausnutzbarkeit und das hohe Volumen ibrer Diätform als unzweckmässig empfunden, und diese Erwägung hat einen ibrer amerikanischen Vorkämpfer, Dr. Kellogg, dazu bewogen, Nährpräparate aus rein vegetarischen Bestandteilen darzustellen, welche jetzt auch in den Kreisen deutscher Vegetarier unter den schönen Namen "Bromose" und "Protose" sich einer ziemlich weiten Verbreitung erfreuen. Dieselben beruhen darauf, dass Körnerfrüchte und hauptsächlich 
verschiedene Nussarten in fein zermahlenem bezw. gemalztem Zustande dargereicht werden, wodurch sie der Verdauung ausserordentlich viel besser zugänglich werden. Demzufolge repräsentiert naturgemäss die Gewichtseinheitsubstanz auch einen höheren Nährwert, wodurch das Volumen der zur ausreichenden Ernährung notwendigen Kost ein wesentlich geringeres wird.

In ähnlicher Weise verwenden diese Anhänger des Vegetarismus Öle und Pflanzenbutter, ebenso aus feinst zermahlener Körnerfrucht hergestellte Backware (Gluten, Granola, Granose). Wenn man auch mit Albu zugeben muss, dass mit dieser vegetarischen Diätform ein Einlenken derselben in die Bahn einer rationellen Ernährung gegeben ist, so wird man doch demselben Autor zustimmen müssen, wenn er dartut, dass damit die strengste Form des Vegetarismus, welche eine Zubereitung der Speisen überhaupt verwirft, durchbrochen wird. Infolgedessen wollen auch die reinen Rohkostvegetarier, wie z. B. der Hauptmann H., wenig von diesen Präparaten wissen, deren Schmackhaftigkeit sie meiner Meinung nach mit vollem Rechte energisch bestreiten ${ }^{1}$ ).

\section{Eiweissarmut der vegetarischen Kost.}

Ein weiterer vielfach betonter Finwand gegen die vegetabilische Kost ist ihre Eiweis sarmut, welche ganz besonders noch durch die schlechte Ausnutzung des Eiweisses verstärkt wird. Die Frage nach der Zulässigkeit einer eiweissarmen Diät hängt innig zusammen mit derjenigen nach dem Eiweissminimum überhaupt, d. h. der Frage nach der untersten Grenze des Eiweissbedarfs. Ich selbst habe seinerzeit mich mit dieser Frage beschäftigt ${ }^{2}$ ) und bin zu dem Ergebnis gekommen, dass es verfehlt sei, nach einem Eiweissminimum zu suchen, da die Fragestellung eine falsche ist. Denn es gibt kein einheitliches Eiweissminimum und kann keines geben. Ich bin damals zu dieser Anschauung gelangt, ohne mir bewusst zu sein, dass $\mathrm{Rubner}^{3}$ ) bereits vorher eine vollkommen gleiche Ansicht ausgesprochen hatte. Es sei mir gestattet, an dieser Stelle nochmals unter Benutzung des neuen Materials eingehender auseinander-

1) Der Vegetarier M. teilt mir mit, dass die Kellog'schen Präparate von einer Mannheimer Fabrik jetzt in wohlschmeckenderer Form in den Handel gebracht worden sind.

2) Arch. f. Anat. u. Physiol. 1901 S. 323.

3) 1. c. S. 126 . 
zusetzen, warum ein Eiweissminimum als ein ebenso unmögliches Problem erscheint wie der Stein der Weisen. Das geht daraus hervor, dass das Eiweissminimum notgedrungen abhängig sein muss von einer grossen Reihe verschiedenartiger Faktoren, so dass eine allgemein gültige zahlenmässige Feststellung dieses Begriffes ausgeschlossen bleiben muss.

Die Verbältnisse werden sich gut überblicken lassen, wenn wir umstehende Tabelle betrachten, welche eine Zusammenstellung der Versuche mit geringer Eiweisszufuhr darstellt. Wenn sich dabei der Versuch von Sivén mit $6,26 \mathrm{~g}$ Stickstoff als Mindesteiweisszufuhr, bei welcher Gleichgewicht eintrat, gegenüber seiner Angabe von $4,52 \mathrm{~g} \mathrm{~N}$ findet, so entspricht das meiner früheren Darlegung, dass Sivén sich in der Versuchsperiode, in welcher 4,52 g Stickstoff pro Tag gereicht wurden, nicht im Gleichgewicht befunden hat ${ }^{1}$ ). Auch die Einwendungen, welche Sivén in seiner zweiten Arbeit ${ }^{2}$ ) gegen die gleiche Anschauung J. Munk's erhoben hat, erscheinen mir nicht geeignet, diese Meinung zu entkräften. Für die Sache übrigens ist diese Differenz nicht wesentlich, da meiner Ansicht nach die Frage nicht so liegt, bei welcher Mindesteiweisszufuhr ein besonders dazu veranlagtes Individuum in mehr oder weniger deutlicher Weise sein Stickstoffgleichgewicht behalten kann, sondern die Frage muss doch wohl, wenigstens im Sinne all der Forscher, welche derselben eine Bedeutung beimessen, allgemeiner gefasst werden, derart, welches wohl die mindeste Eiweissmenge ist, mit der unter gewöhnlichen Umständen ein erwachsener Mann seinen Bedarf zu decken imstande ist, und die man daher einer Norm für Massenernährung zugrunde legen darf. Wenn wir uns aber die Frage vorlegen, so finden wir eine solche Fülle von Umständen, welche nachweisbar in weiten Grenzen diese Zahl beeinflussen müssen, dass an eine eindeutige Lösung eben nicht gedacht werden kann.

(Siehe die Tabelle auf S. 540.)

Die Anschauung, dass die Frage nach einem einheitlichen Eiweissminimum ein unlösbares Problem darstellt, wird hente vielfach bereits anerkannt. Wenigstens scheint dies daraus hervorzugehen, dass diejenigen Forscher, welche in neuester Zeit das einschlägige Thema behandelt haben, die Fragestellung in zwar zweckmässiger, aber von der bisherigen abweichender Form ver-

1) 1. c. S. 326 .

2) Skandinav. Arch. f. Phys. Bd. 11 S. 308. 1901. 
Versuche mit geringer Eiweisszufuhr am Menschen.

a) Bei nichtrein vegetarischer Ernährung.

\begin{tabular}{|c|c|c|c|c|c|c|}
\hline Autor & 竞泀 & 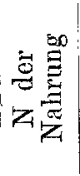 & 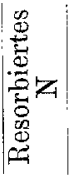 & 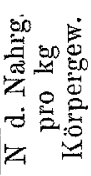 & 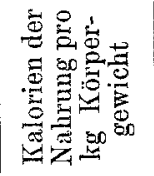 & Bemerkungen \\
\hline Hirschfeld. & $73^{\mathrm{kg}}$ & $\stackrel{\mathrm{g}}{7,44}$ & $\mid \begin{array}{c}\mathrm{g} \\
5,78\end{array}$ & 0,1 & 47,4 & FastN-Gleichgewieht. Bilanz \\
\hline $\begin{array}{c}\text { Klemperer. } \\
" .\end{array}$ & $\begin{array}{l}64 \\
65,5\end{array}$ & $\begin{array}{l}5,28 \\
5,28\end{array}$ & $\begin{array}{l}4,02 \\
4,25\end{array}$ & $\begin{array}{l}0,08 \\
0,08\end{array}$ & $\begin{array}{l}78,4 \\
76,6\end{array}$ & Znletzt N-Gleichgewicht. \\
\hline Sivén. . . . & 59,65 & 6,26 & 4,52 & 0,14 & 41,6 & Gleichgewicht. Bilanz \\
\hline Caspari... & 65,3 & 10,11 & 8,92 & 0,15 & $\left.50,1(48,1)^{1}\right)$ & $\begin{array}{l}\text { Kein Gleichgewicht. Bilanz } \\
-0,82 \mathrm{~g} \text { N pro Tag. }\end{array}$ \\
\hline \multicolumn{7}{|c|}{ b) Vegetarier. } \\
\hline $\begin{array}{l}\text { Voitud Constan- } \\
\text { tinidi }\end{array}$ & 57 & 8,4 & 4,9 & 0,15 & 47 & Bilanz $-0,4 \mathrm{~g} N$ pro Tag. \\
\hline $\begin{array}{l}\text { Voitu. Constan- } \\
\text { tinidi.... }\end{array}$ & 74 & 8,25 & 4,75 & 0,11 & 35 & $\begin{array}{l}\text { Nicht-Vegetarier bei streng } \\
\text { vegetariseher Kost. Bilanz }\end{array}$ \\
\hline $\begin{array}{l}\text { Rumpf and } \\
\text { Schumm. }\end{array}$ & 63 & 11,82 & 7,81 & 0,19 & 54 & $\begin{array}{l}-4,95 \text { of } \mathrm{N} \text { pro Tag. } \\
\text { Bilanz + } 0,9 \mathrm{~g} \text {. } \mathrm{N} \text { pro Tug. } \\
\text { Gleich }\end{array}$ \\
\hline Kumagawa. . & 48 & 8,75 & 6,72 & 0,18 & 53,8 & $\begin{array}{l}\text { Nicht-Yegetarier bei vegetar. } \\
\text { Kost. Bilanz }+0,5 \mathrm{~g} \text {. } \\
\text { Tag. Gleichgewicht. }\end{array}$ \\
\hline Albu.... & 37,5 & 5,46 & 3,67 & 0,15 & 37 & $\begin{array}{l}\text { Bilanz }+0,37 \mathrm{~g} \text { N pro Tag. } \\
\text { N-Gleichgewicht. }\end{array}$ \\
\hline $\begin{array}{l}\text { Caspari und } \\
\text { Glässner. }\end{array}$ & 68,8 & 7,83 & 5,78 & 0,11 & $66(60)$ & $\begin{array}{l}\text { Bilanz }+1,05 \mathrm{~g} \mathrm{~N} \text { pro Tag. } \\
\text { Ansatz. }\end{array}$ \\
\hline $\begin{array}{l}\text { Caspari und } \\
\text { Gläsner. } \\
\text { Caspari }\end{array}$ & 57,9 & 5,33 & 4,04 & 0,09 & $47(44)$ & Bilanz $+0,49$ g N pro Tag. \\
\hline Hauptm. H. I & 49,1 & 1,18 & - & 0,02 & $15(12)$ & $\begin{array}{c}\text { Bilanz }-2,93 \mathrm{~g} N \text { pro Tag. } \\
\text { (Dauer } 41 \text { Tage.) }\end{array}$ \\
\hline II . & 42,688 & 1,35 & - & 0,03 & $17(15)$ & $\begin{array}{l}\text { Bilanz - 2,34g y pro Tag. } \\
\text { (Daner } 11 \text { Tage })\end{array}$ \\
\hline III . & 40,89 & 3,97 & 2,53 & 0,10 & $38(34)$ & Bilanz -0,02 $\mathrm{g} \mathrm{N}$ pro Tag. \\
\hline $\begin{array}{l}\text { III } a \\
\text { III } b \\
\text { III } \mathrm{e}\end{array}$ & $\begin{array}{l}40,965 \\
40,885 \\
40,905\end{array}$ & $\begin{array}{l}3,43 \\
4,31 \\
4,43\end{array}$ & $\begin{array}{l}2,19 \\
2,75 \\
2,83\end{array}$ & $\begin{array}{l}0,08 \\
0,10 \\
0,11\end{array}$ & $\begin{array}{l}34(30) \\
41(35) \\
41(36)\end{array}$ & $\begin{array}{l}\text { Bilanz }-0,47 \mathrm{~g} \text { N pro Tag. } \\
\text { N-Gleichgewicht. } \\
\text { Bilanz + } 0,64 \mathrm{~g} \mathrm{~N} \text { pro Tag. }\end{array}$ \\
\hline & & & & & & \\
\hline
\end{tabular}

schoben haben. So sagt Larguier des Bancels"): „Faut-il toutefois, en présence des résultats fournis par les experiences les plus récentes et les plus sûres, ađmettre avec Caspari que le minimum azoté ne saurait être envisagé comme une grandeur définie, au moins dans telle espèce, mais qu'il présent des variations individuelles étendues.... Les travaux qu'on a signalés plus haut ont un trait commun. Ils supposent implicitement l'existence d'un

1) Die eingeklammerten Zahlen bedeuten die resorbierten Kalorien.

2) De l'influence de la température extérieure sur l'alimentation p. 52. Paris 1903. 
minimum azoté, caractéristique de l'individu à l'état d'entretien. Mais la réalité de ce minimum est loin d'être évidente a priori et le succès des expériences n'a pas démonstré après coup la légitimité d'un tel postulat. ... Et il y a lieu de se demander si, à la notion du minimum unique, il ne serait pas temps de substituer celle des minima multiples." Und äbnlich wird die Frage von Jägerroos ${ }^{1}$ ) formuliert:

„So verfehlt, wie dies Caspari annimmt, ist es doch wohl nicht, ein Mindestmass des Eiweissbedarfes festzustellen zu versuchen. Die Sache darf nur nicht so aufgefasst werden, dass es überhaupt nur ein absolutes, für alle Menschen und Fälle ganz bestimmtes Eiweissminimum gäbe, sondern man hat vielmehr durch zahlreiche Untersuchungen festzustellen, innerhalb welcher Grenzen das Eiweissminimum bei den verschiedenen Individuen unter verschiedenen Verhältnissen wechselt."

Also wie man sieht, trotz einigen Widerspruchs in der Form wird der von mir vertretene Standpunkt akzeptiert; andrerseits aber die gesamte Position gewechselt, um dem gefährdeten Problem eine bessere Verteidigungsstellung zu versehaffen.

Es scheint mir jedoch, als ob die Frage nach dem Eiweissminimum auch in der neuen Fassung ein kaum lösbares Problem sei. Man muss sich doch zunächst einmal klarmachen, von welchen Umständen denn nachweislich die geringste auskömmliche Eiweissmenge bei einem und demselben Menschen abhängt. Hier bereits treten uns eine Fülle von Faktoren entgegen, welche das Eiweissminimum zweifellos zu beeinflussen in der Lage sind, derart, dass wir schon bei derselben Person eine unübersehbare Anzahl verschiedener Eiweissminima feststellen müssten.

Zunächst ist die Abhängigkeit des Eiweissminimums von der Tätigkeit des Organismus zu diskutieren. Allerdings wissen wir heute, dass die Arbeitsleistung nicht unbedingt eine Erhöhung des Eiweissumsatzes bedingt. Dafür wird jedoch die Frage um so komplizierter durch die Mannigfaltigkeit der Einwirkung der Arbeitsleistung auf den Eiweisshausbalt unter wechselnden Lebensbedingungen. Die Wirkung, welche die Muskelarbeit auf den Eiweissverbrauch ausübt, ist ja keine eindeutige. Sie hängt ab von dem Verhältnis der Arbeitsleistung zu der Gesamtzufuhr an stickstofffreiem und

1) Skandinav. Arch. f. Physiol. 1902 S. 382. 
stickstoffhaltigem Material. Reichen die zirkulierenden stickstofffreien Nährstoffe, welche dem Organismus zugeführt werden, aus, um jederzeit die Kosten der Arbeit bestreiten zu können, so erscheint es nach unseren Erfahrungen wahrscheinlich, dass bei Steigerung der körperlichen Arbeit eine Sparung an Eiweiss stattfinden kann und die paradoxe Erscheinung eintritt, dass bei Erhöhung der Arbeitsleistung das Eiweissminimum wenigstens eine Zeitlang herabgedrückt wird. Der Eintritt dieser Möglichkeit hängt aber nicht nur von der gesamten Nahrung $a b$, sondern in gleicher Weise auch von dem vorhandeven Reservematerial des Körpers, welches bei der durch Körperarbeit gesteigerten Tendenz zur Eiweisssparung von dem Organismus für seinen Verbrauch mit herangezogen werden kann.

Andrerseits natürlich muss bei ungenügender Gesamtzufuhr und mangelndem Reservematerial eventuell für die gleiche Tätigkeit Eiweissmaterial mit verwendet werden, und so wird in diesem Falle der Eiweissumsatz steigen, das Eiweissminimum ein höheres sein. Dasselbe wird eintreten, wenn Dyspnoe oder Sauerstoffmangel statthat, ebenso wenn Überhitzung des Körpers bei der Arbeitsleistung eintritt, was viel häufiger vorkommen dürfte, als man gewöhnlich annimmt.

Schon aus obigen Überlegungen ergibt sich des weiteren die Abhängigkeit des Eiweisminimums von dem Gesamtbrennwert der Nahrung, speziell also in diesem Falle von der Energiemenge, welche in dem stickstofffreien Material dem Organismus zur Verfügung gestellt wird. Für die Wichtigkeit dieses Faktors sprechen ganz besonders die Versuche von Klemperer, der bei exzessiv hoher Gesamtzufuhr mit 0,08 g Stickstoff pro Kilogramm Körpergewicht sogar noch einen Eiweissansatz erzielen konnte. Andrerseits sprechen die Versuche Si vén's dafür, dass die Erböhung der Kalorienzufuhr kein unbedingtes Erfordernis ist für ein Herabdrücken des Eiweissminimums, was dieser Autor auch besonders betont.

Die Wirkung der stickstofffreien Stoffe, welche man sich gewöhnt hat, mit dem Namen der Eiweissparung zu bezeichnen, kann gar nicht besser illustriert werden, als wenn wir die Werte, welche wir für den Eiweissumsatz bei dem Versuche am Hauptmann $H$. gefunden haben, vergleichen mit denjenigen, welche von $L \mathrm{e} h \mathrm{~m}$ a $\mathrm{n} \mathbf{n}$, Fr. Müller, J. Munk, Senat or und $\mathrm{Zuntz}$ bei den Hungerern Cetti und Breithaupt ${ }^{1}$ ) und von Luciani bei Sucei ${ }^{2}$ ) fest-

1) Virchow's Arch. 1893 Bd. 131 Suppl.

2) Luciani, Das Hungern. Autoris. Übersetzung. Verlag von Leopold Voss, Hamburg und Leipzig 1890. 
gestellt wurden. Der Stickstoffumsatz des Hauptmanns H. ist nämlich der niedrigste, welcher bisher jemals in Versuchen am Menschen beobachtet worden ist. Er betrug im Mittel pro Tag:

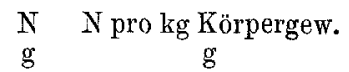

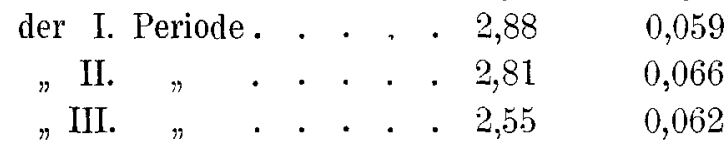

Wenn wir die III. Periode gemäss den oben angeführten Überlegungen und Daten ihrerseits wiederum in drei Teile teilen, so erhalten wir in

$$
\begin{aligned}
& \text { Periode III a } \quad \text {. . . . . } 2,66 \quad 0,065 \\
& \text { " III b . . . . . . } 2,765 \quad 0,068 \\
& \text { " III c . . . . . 2,185 } 0,053
\end{aligned}
$$

\begin{tabular}{|c|c|c|c|c|c|c|c|}
\hline \multirow[t]{2}{*}{ Tag } & \multirow{2}{*}{$\begin{array}{c}\text { Cetti } \\
\text { (26 J.alt) }\end{array}$} & \multirow{2}{*}{$\begin{array}{l}\text { Breit- } \\
\text { haupt } \\
(21 \mathrm{~J} . \text { alt })\end{array}$} & \multirow{2}{*}{$\begin{array}{c}\text { S a c ci } \\
(40 \mathrm{~J} . \mathrm{alt})\end{array}$} & \multirow{2}{*}{$\begin{array}{c}\left.\text { J. A. }{ }^{1}\right) \\
(26 \text { J. alt })\end{array}$} & \multicolumn{2}{|c|}{$\begin{array}{l}\text { Schreiber und } \\
\text { Waldvogel's }{ }^{2} \text { ) } \\
\text { Versuchspersonen }\end{array}$} & \multirow{2}{*}{$\begin{array}{c}\operatorname{Ln}^{3} \text { ) } \\
\text { (22 J.alt) }\end{array}$} \\
\hline & & & & & I & II & \\
\hline 1. & 13,55 & 10,01 & 13,806 & 12,72 & 8,82 & 9,48 & 13,60 \\
\hline$\ddot{2}$. & 12.59 & 9,92 & 11,026 & 13,48 & 10,09 & 11,36 & 13,43 \\
\hline 3. & 13,12 & 13,29 & 13,857 & 13,56 & 11,68 & 14,33 & 15,13 \\
\hline 4. & 12,39 & 12,78 & 12,801 & 11,34 & - & - & 13,87 \\
\hline 5. & 10,70 & 10,95 & 12,835 & - & - & - & - \\
\hline 6. & 10,10 & 9,88 & 10,120 & - & - & - & - \\
\hline 7. & 10,89 & - & 9,374 & $\ldots$ & - & - & - \\
\hline$\ddot{8}$. & 8,90 & $\ldots$ & 8,427 & - & - & - & - \\
\hline 9. & 10,83 & _- & 7,782 & $\longrightarrow$ & - & - & - \\
\hline 10. & 9,47 & - & 6,754 & - & - & - & - \\
\hline 11. & - & - & 7,880 & $\ldots$ & - & - & - \\
\hline 12. & - & $\ldots$ & 7,162 & - & - & - & - \\
\hline 13. & - & - & 3,509 & - & $-\infty$ & - & - \\
\hline 14. & - & - & 5,336 & - & - & - & - \\
\hline 15. & $\ldots$ & - & 5,142 & - & - & - & - \\
\hline 16. & - & - & 5,504 & $\ldots$ & - & - & - \\
\hline 17. & - & - & 6,160 & - & 一 & - & - \\
\hline 18. & - & - & 5,456 & - & - & - & - \\
\hline
\end{tabular}

Dagegen betrug der Umsatz bei den Hungerern:

1) Beiträge zur Kenntnis des Stoffwechsels beim hungernden Menschen von J. E. Johansson, E. Landergren, Klas Sondén und Robert Tigerstedt. Skandinav. Arch. f. Physiol. 1896 S. 29.

2) Beiträge zur Kenntnis der Harnsäureausscheidung in physiologischen und pathologischen Verhältnissen. Arch. f. exp. Pathol. u. Pharm. Bd. 42 S. 69.

3) Ernst Landergren, Untersuchungen über die Eiweissumsetzung des Menschen. Skandinav. Arch. f. Physiol. Bd. 14 S. 166.1903. 


\begin{tabular}{l|c|c|c}
\hline Tag & $\begin{array}{c}\text { Succi } \\
\text { (40 J. alt) }\end{array}$ & Tag & $\begin{array}{c}\text { Succi } \\
(40 \text { J. alt) }\end{array}$ \\
\hline & & & \\
19. & 5,036 & 25. & 6,042 \\
20. & 4,385 & 26. & 5,061 \\
21. & 3,880 & 27. & 5,368 \\
22. & 3,202 & 28. & 5,599 \\
23. & 4,756 & 29. & 4,080 \\
24. & 5,557 & 30. & 6,620
\end{tabular}

Berechnen wir aus diesen Daten den mittleren Stickstoffumsatz pro Tag, so ergibt sich für Cetti $11,25 \mathrm{~g} \mathrm{~N}$, für Breithaupt $11,14 \mathrm{~g} \mathrm{~N}$, für Succi $6,91 \mathrm{~g} \mathrm{~N}$, für Landergren $14,01 \mathrm{~g} \mathrm{~N}$, J. A. $12,78 \mathrm{~g} \mathrm{~N}$, für Schreiber und Waldvogel I $10,20 \mathrm{~g} \mathrm{~N}$, II $11,72 \mathrm{~g} \mathrm{~N}$.

Es unterliegt wohl keinem Zweifel, dass dieser eklatante Unterschied in dem täglichen Eiweissumsatze des Hauptmanns H. im Vergleich zu demjenigen der hungernden Menschen in erster Linie zurückzuführen ist auf die Wirkung der Kohlehydratzufuhr. Diese Tatsache wird noch besonders gut illustriert durch den Versuch Luciani's an Succi. Dort finden wir den niedrigsten Wert am 22. Tage mit 3,2 g Stickstoff im Harn: allerdings ein Wert, welcher bei dem Versuche am Hauptmann $\mathrm{H}$. zu den höchsten gehört und nicht unerheblich über dem Durchsehnittswert einer jeden Periode liegt. Da das Körpergewicht Succi's an dem betreffenden Tage $52,5 \mathrm{~kg}$ betrug, so war der Umsatz pro Kilogramm Körpergewicht $0,06 \mathrm{~g}$, ein Wert, welcher dem durchschnittlichen Stickstoffumsatze, der beim Hauptmann H. pro Kilogramm Körpergewicht gefunden worden ist, annähernd gleichkommt. Dieser geringe Umsatz am 22. Hungertage Succi's wurde jedoch erreicht, nachdem am 20 . und 21. zusammen etwa $61 \mathrm{~g}$ Traubenzucker als Klysma aufgenommen waren. Wir haben es also auch hier mit einer Wirkung der Kohlehydrate zu tun.

Des weiteren wird diese Wirkung der Kohlehydrate auf das vorzüglichste veranschaulicht durch die eben erwähnten Untersuchungen von Landergren. Landergren stellte Versuche an, welche einen Begriff geben sollten von der kleinsten Stickstoff- bezw. Eiweissmenge, deren Zersetzung für den Unterhalt der Lebensfunktionen im Organismus unbedingt nötig ist. Er suchte diese Frage zu lösen, indem er bei möglichst stickstoffarmer Kost eine reichliche Zufuhr stickstofffreier Nahrungsmittel einführte. Wohl bemerkt, handelt es 
sich bei der Untersuchung Landergren's nicht um die Frage nach dem Eiweissminimum. Denn der Verfasser legte keinen Wert darauf, ob der Organismus sich im Stickstoffgleichgewicht befand oder nicht.

N-Verbrauch bei spezifischem N-Hunger und Kohlehydratkost.

Versuchsperson B. J., 22 J. alt.

\begin{tabular}{c|c|c}
\hline \hline \multirow{2}{*}{ Tag } & \multicolumn{2}{|c}{ N im Harn } \\
\cline { 2 - 3 } & $\begin{array}{c}\text { Zufuhr 52 Kal. } \\
\text { pro kg }\end{array}$ & $\begin{array}{c}\text { Zufuhr 45,2 Kal. } \\
\text { pro kg }\end{array}$ \\
\hline & & \\
1. & 12,16 & 8,91 \\
2. & 8,37 & 5,15 \\
3. & 5,02 & 4,30 \\
4. & 4,50 & 3,76 \\
5. & 4,01 & - \\
6. & 3,36 & -
\end{tabular}

Dies ergibt pro Tag, wenn wir den Stickstoffumsatz des ersten Tages als durch die vorhergehende Ernährung beeinflusst ausschalten, im ersten Versuche einen Umsatz von $4,77 \mathrm{~g}$ Stickstoff, im zweiten einen solchen von $4,40 \mathrm{~g}$. Diese Werte liegen allerdings noch beträchtlich höher als diejenigen, welche beim Hauptmann $H$. gefunden worden sind. Dagegen ist der Verbrauch pro Kilogramm Körpergewicht bei Landergren's Versuchen absolut in derselben Grössenordnung wie derjenige beim Hauptmann $H$., nämlich 0,067 bezw. $0,063 \mathrm{~g} \mathrm{~N}$ pro Kilogramm Körpergewicht. Wenn wir allerdings nur den 7. Tag des Versuches I mit dem niedrigsten Stickstoffumsatze von $3,34 \mathrm{~g}$ berücksichtigen, so erhalten wir pro Kilogramm Körpergewicht einen Umsatz von $0,047 \mathrm{~g} \mathrm{~N}$, während der niedrigste tägliche Umsatz des Hauptmanns H. immer noch 0,050 g Stickstoff pro Kilogramm Körpergewicht beträgt. Diese Tatsache stimmt vollkommen mit unseren obigen Überlegungen hinsichtlich der Bedeutung der Kohlehydrate für die Herabdrückung des Eiweissumsatzes überein. Denn die Zufuhr an Brennmaterialien bei der Versuchsperson Landergren's betrug 52 Kal. pro Kilogramm Körpergewicht, bei der meinigen nur 41. Ferner repräsentiert auch das Kilogramm lebende Substanz bei der kräftigen und wohlgenährten Versuchsperson Landergren's zweifellos einen anderen Wert als bei dem äusserst reduzierten, fettarmen Hauptmann H. Wenn bei letzterem 
die Fettarmut das Verhältnis des aktiven Materials zum Körpergewicht erhöht, so wird das Verhältnis andrerseits im umgekehrten Sinne beeinflusst durch das relative Überwiegen des Knochensystems und der Bindesubstanzen. Wie schliesslich durch das Gegeneinanderwirken beider Momente der Stoffumsatz beeinflusst wurde, wage ich nicht zu entscheiden.

Ferner besteht wohl auch noch ein Untersehied $z$ wischen den frühen und späteren Abschnitten des Inanitionszustandes. Berechnen wir nämlich den Stickstoffumsatz bei den hungernden Individuen auf das Kilogramm Körpergewicht, so finden wir in den ersten Tagen des Hungerns eine ganz auffällige Übereinstimmung der Werte.

Wenn wir von denjenigen Hungerversuchen, bei welchen das Körpergewicht genau verfolgt worden ist, den Stickstoffumsatz pro Kilogramm am letzten Tage der Versuche feststellen, so finden wir:

\begin{tabular}{|c|c|c|c|c|}
\hline Name & $\begin{array}{l}\text { Tag des } \\
\text { Versuchs }\end{array}$ & im $\stackrel{N}{\text { Harn }}$ & $\underset{\substack{\text { Körpergew. } \\
\text { kg }}}{ }$ & $\begin{array}{l}\mathrm{N} g \text { pro kg } \\
\text { Körpergew. }\end{array}$ \\
\hline $\begin{array}{l}\text { Cetti } \\
\text { Landergren. } \\
\text { Breithaupt . } \\
\text { Versuchsperson J. A. }\end{array}$ & $\begin{array}{c}10 . \\
4 . \\
6 . \\
5 .\end{array}$ & $\begin{array}{r}9,47 \\
13,87 \\
9,88 \\
11,34\end{array}$ & $\begin{array}{l}50,65 \\
74,43 \\
56,45 \\
63,47\end{array}$ & $\begin{array}{l}0,187 \\
0,186 \\
0,176 \\
0,175\end{array}$ \\
\hline
\end{tabular}

Dagegen finden wir bei Succi, bei welchem der Versuch länger ausgedehnt wurde, in dem ersten Teil des Versuches allerdings Werte, welche in der gleichen Grössenordnung liegen, wie wir sie für die anderen Hungerer festgestellt haben, z. B.

$$
\begin{array}{ll|l|l|l}
\text { I } & 6 . & 11,13 & 58,65 & 0,190
\end{array}
$$

Im weiteren Verlauf des Versuches dagegen sinken diese Werte nicht unwesentlich, und wir erhalten $z$. B.

$$
\begin{array}{l|l|l:l}
19 . & 5,036 & 53,20 & 0,094 \\
20 . & 5,599 & 50,76 & 0,11
\end{array}
$$

Es scheint also im weiteren Verlaufe des Hungerns oder der Unterernährung noch eine gewisse Anpassung einzutreten.

Wenden wir uns nunmehr zu der Frage des Eiweissminimums zurück, so glaube ich, dass aus der angeführten Überlegung die Wichtigkeit klar erwiesen ist, welche für den Eiweissumsatz und also auch für den geringsten Wert des Eiweissumsatzes, mit welchem ein Gleichgewicht erreicht werden kann, der Zufuhr der stickstofffreien Stoffe zukommt. Denn eine Art Anpassung, welche wir beim Hauptmann H., der, wie aus der Anamnese hervorgeht, schon längere 
Zeit vor Beginn des Versuches eine äusserst knappe und eiweissarme Diät zu sich genommen hat, ebenso wie bei Succi als zweites Moment mit in Betracht ziehen können, würde jedenfalls gegenüber der Wichtigkeit der Zufuhr an stickstofffreiem Nährmaterial keine wesentliche Rolle spielen. Dies geht schon daraus hervor, dass auch pro Kilogramm Körpergewicht bei Succi am Ende des Versuchs trotz der erwähnten Anpassung etwa doppelt so viel Stickstoff umgesetzt wird als beim Hauptmann H. in der I. Periode.

Die Frage nach der Bedeutung der stickstofffreien Nährmaterialien für das Problem des Eiweissminimums wird aber noch weiter kompliziert durch die Ungleichwertigkeit der Fette und Kohlehydrate in dieser Beziehung. Es steht fest, dass die Kohlehydrate bessere Eiweisssparer sind als die Fette. Andrerseits hat Talquist ${ }^{1}$ ) bei Rubner nachgewiessen, dass bei Einhaltung der gleichen Albumenmenge und gleichen Kaloriengehaltes in der Nahrung das Stickstoffgleichgewicht ebensogut erhalten werden kann durch eine Kost, in der die stickstofffreien Stoffe zu 60 wie zu $90 \%$ durch Kohlehydrate vertreten werden. Wenn es aber auch nach Talquist in gewissen Grenzen für die Frage des Fiweissminimums gleichgültig sein mag, in welcher Weise in der stickstofffreien Kost Fette und Kohlehydrate gemischt sind, so geht doch andrerseits aus den umfassenden Stoffwechselversuchen von Atwater und Benedict (Experiments on the metabolism of matter and energy in the human body 1900-1902 p. $176 \mathrm{f}$. Washington 1903) die Überlegenheit der Kohlehydrate den Fetten gegenüber in bezug auf die Eiweisssparung deutlich hervor. Auch in den zitierten Versuchen Landergren's zeigt sich, dass die Gleichwertigkeit der Fette und Kohlehydrate für die Eiweisssparung. ihre Grenzen hat. Gerade diese so evident hervortretende Ungleichheit der Kohlehydrate und Fette als Eiweisssparer bei einseitiger Ernährung hat ja Landergren zu seiner so interessanten Theorie geführt, welche darin gipfelt, dass bei Kohlehydratmangel in der Nahrung ein Teil des gegebenen Eiweisses dazu verwendet werden muss, um dem Organismus die für denselben notwendige Kohlebydratmenge zu bilden. Wenn auch die Landergren'sche Hypothese durch Pflüger's jüngste Publikationen zweifelhaft geworden ist, habe ich dieselbe doch insoweit herangezogen, um zu zeigen, dass das Eiweissminimum nicht nur stets von der Menge der stick-

1) Zeitschrift für Biologie 1902, 1. c. 
stofffreien Näbrmaterialien abhängt, sondern mitunter auch davon, wie in derselben Fette und Kohlehydrate gemischt sind.

In der eiweissfreien Beikost kommen ja aber nicht nur Fette und Kohlehydrate in Betracht, sondern auch andere Substanzen, vor allem der Alkohol, worauf Largujer des Bancels ${ }^{1}$ ) mit vollem Recht hinwies, und es ist wohl kein Zufall, dass bei den meisten Versuchen, bei welchen die Frage nach dem Eiweissminimum am Menschen geprüft wurde, grössere oder geringere Mengen dieses Nähr- und Genussstoffes zur Verwendung kamen. Wir wissen aber aus den zahlreichen Versuchen, welche über den Nährwert des Alkohols angestellt worden sind, dass gerade für den Stickstoffumsatz und die eventuelle Eiweissersparnis die Rolle des Alkohols keine eindeutige ist, sondern eine komplizierte, je nachdem der Organismus an Alkohol gewöhnt ist oder nicht. Ausserdem möchte ich binzufügen, dass von Substanzen, welche nicht Eiweiss sind, auch leimgebende Stoffe und andere stickstoffhaltige Körper in der Nahrung enthalten sind, welche das Eiweissminimum beeinflussen. Erst kürzlich hat Kirchmann ${ }^{2}$ ) die diesbezüglichen Verhältnisse von neuem untersucht und festgestellt, dass bei einer Leimzufuhr, die etwa $12 \%$ des Energiebedarfs ausmachte, der Eiweisszerfall beim hungernden Hunde um $27 \%$ zurückging. Die höchste Sparung wurde zu $35 \%$ gefunden, wobei der Leim $62 \%$ des Energiebedarfes deckte.

Auch in einer anderen Beziehung muss das Eiweissminimum von der gereichten Nahrung abhängen. Wir haben oben gesehen, dass die mit dem Kote abgehenden Verdauungssäfte einen nicht ganz unerheblichen Verlust an Eiweiss oder Eiweissderivaten repräsentieren. Wir hatten aber auch aus den Daten der Literatur entnommen, dass die Grösse des hierdurch bedingten Stickstoffverlustes je nach der Art der Nahrung in ziemlich weiten Grenzen wechseln kann.

Ferner muss das Eiweissminimum bei ein und derselben Person in einer gewissen Abhängigkeit stehen von der Temperatur. Dies wird bereits wahrscheinlich durch die Arbeit von Larguier des Bancels ${ }^{3}$, welche bei Tauben die Abhängigkeit des Eiweissminimums von der Temperatur nachgewiesen hat. Wichtiger noch sind die Resultate von $\mathrm{Rubner}^{4}$, aus welchen hervorgeht, dass der

1) l. c. S. 54 .

2) Zeitschr. f. Biologie Bd. 40. 1900.

3) l. c.

4) Die Gesetze des Energieverbrauchs usw. S. $168 \mathrm{ff}$. 
Eiweissumsatz von der Temperatur abhängt. Rubner fand, dass für $1^{0}$ Temperaturabnahme eine Steigerung der Eiweisszersetzung um 1,32\% eintrat. Allerdings ist dieses Resultat beim Karnivoren mit reiner Fleischfütterung erreicht, und es ist meines Wissens nicht bekannt, wie Temperaturdifferenzen bei der Versuchsanordnung wirken, welche zur Entscheidung der Frage nach dem Eiweissminimum eingeschlagen werden müsste. Wahrscheinlich ist es ja, dass in diesem Falle nur die stickstoff freien Bestandteile der Nahrung zur Wärmeregulation herangezogen werden. Da aber, wie wir gesehen haben, das Eiweissminimum seinerseits in Abhängigkeitsverhältnis von der zugeführten stickstofffreien Nahrung steht, so ist es nicht gleichgültig, ob ein grösserer oder geringerer Teil derselben für die Wärmeregulation des Organismus verbraucht wird.

So sehen wir, dass bereits bei der Entscheidung der Frage nach dem Eiweissminimum für eine einzig e Person eine ausserordentlich grosse Anzahl von Nebenumständen zu beobachten sind, dass wir auch hier bereits zahlreiche Eiweissminima werden feststellen können, je nachdem wir diejenigen Faktoren, welche diesen Wert beeinflussen, in verschiedener Weise miteinander kombinieren und variieren. Hierbei bleibt immer noch die Frage offen, ob die von uns erwähnten Bedingungen, von welchen die Höhe des Eiweissminimums abhängig: ist, erschöpfend sind, und ob nicht noch andere unerwähnte oder unbekannte Faktoren die Lösung der Frage weiter komplizieren.

Wenn wir aber auf diese Weise eine Reihe von verschiedenen Eiweissminimen selbst für ein und di eselbe Person festgestellt haben, so erseheint es mir ganz unmöglich, diese Frage für eine grössere Allgemeinheit von Menschen zu lösen. Ich weiss wohl, dass mit dem Worte "individuelle Verschiedenheiten" seit jeher in physiologischen und medizinischen Betrachtungen ein erheblicher Missbrauch getrieben worden ist, und auch noch getrieben wird. In diesem Falle aber sind wir in der Lage, die individuellen Verschiedenheiten zu kennen und zum Teil zahlenmässig ausdrücken zu können.

Der erste Faktor, von welchem wir das Eiweissminimum abhängig sahen, war die Tätigk eit des Organismus, und ich hatte daraut hingewiesen, wie schwer es ist, die Einwirkung dieser Tätigkeit eindeutig zu bestimmen. Noch schwieriger wird aber diese Frage, wenn wir sehen, dass die durch annähernd gleiche Arbeitsleistung hervorgerufene Steigerung des Energieverbrauchs, von welchem der Stick- 
stoffumsatz doch ganz sicherlich in Abhängiokeit sein muss, für verschiedene Personen eine ausserordentlich verschiedene ist. So fand Johansson ${ }^{1}$ ) bei seiner gewöhnlichen Tätigkeit eine Steigerung des Energieverbrauches von $61 \%$ über seinen Ruhewert. Annähernd ebenso gross $(51 \%)$ ist ein Wert, welcher sich aus Atwater und Benedict ${ }^{2}$ ) berechnen lässt. Ähnlich fanden Zuntz und Schumburg ${ }^{3}$ ) an zwei Versuchspersonen in einem Fall eine Steigerung von ca. 46 , im anderen dagegen eine solche von $73 \%$, während Lö $\mathrm{w}^{4}$ ) eine Stejgerung von $96 \%$ über seinen Ruhebedarf zeigte. Daraus geht also mit Sicherheit hervor, ein wie verschiedenes Energiequantum bei verschiedenen Leuten die gewöhnliche Tätigkeit beansprucht, und ich glaube, das ist auch der Grund, warum Sivén mit einer Zufuhr von $0,14 \mathrm{~g}$ Stickstoff und 41,6 Kalorien pro Kilogramm Körpergewicht sich ins Gleichgewicht setzen konnte, während ich selbst mit einer höheren Zufubr von $0,15 \mathrm{~g} \mathrm{~N}$ und 50 Kalorien pro Kilogramm Körpergewicht das Gleichgewicht nicht erreichte. Dieser wechselvolle Verbrauch für die gewöhnliche Tätigkeit ist doch wahrscheinlich die Folge verschiedenen Temperamentes, der grösseren Lebhaftigkeit und der demzufolge stattfindenden zahlreichen Luxusbewegungen, die den Verbrauch in so erheblicher Weise steigern.

Wie sehr sich die Ausgaben für derartige Luxusbewegungen summieren können, geht ja in deutlicher Weise aus den Versuchen von $\mathrm{Zuntz}$ und Hagemann ${ }^{5}$ ) am Pferde hervor, bei welchen durch zeitweises Herumtreten, Sichschütteln, Fussstampfen u. dgl. eine Steigerung des Stoffwechsels um etwa $10 \%$ festgestellt wurde.

Erschwert wird ferner die Vergleichung verschiedener Individuen durch den verschiedenen Ernährungszustand derselben. Es bedarf wohl kaum einer weiteren Auseinandersetzung, dass gerade für die Frage des Eiweissminimums der Eiweissbestand des Körpers selbst, sein Gehalt an Reservefett und nach den Versuchen Lander gren's auch sein Vorrat an Kohlehydraten die Höhe des Eiweiss-

1) Über die Tagesschwankungen des Stoffwechsels. Skand. Archiv für Physiol. Bd. 8 S. 119. 1888.

2) Bulletin of experimental stations. No. 63. Experiment No. 25.

3) Physiologie des Marsches S. 175-183.

4) Löwy und Müller, Beiträge zum Stoff- und Energieumsatz des Menschen. Arch. f. Anat. und Physiol. 1901 S. 316.

5) Untersuchungen über den Stoffwechsel des Pferdes bei Ruhe und Arbeit. Paul Parey, Berlin 1898. 
minimums beeinflussen muss. Die $\Lambda$ bhängigkeit des Stoffverbrauches und der Stickstoffausscheidung von dem Ernährungszustande geht übrigens auch klar aus den Angaben Rubner's hervor ${ }^{1}$ ).

Es sind aber noch andere Punkte, welche eine Vergleichung verschiedener Individuen hinsichtlich ihres minimalen Eiweissbedarfs erschweren. Hierher gehören psychische Momente, so vor allem die Anspruchslosigkeit des Geschmacks. Eine eiweissarme Kost ist fast immer mehr oder weniger reizlos, und ein an Genussmittel gewöhnter Organismus wird daher eine derartige Kost mit geringerem Appetit, ja, unter Umständen mit Ekelgefühl aufnehmen. Dass aber derartige anormale Zustände die Resorption der Nahrung und das allgemeine Wohlbefinden, von welchem sicherlich doch auch der Ernährungszustand abhängig ist, schädlich beeinflussen können, ist zweifellos. Ich glaube daher auch, dass es kein Zufall ist, dass die niedrigsten Werte für das Eiweissminimum in denjenigen Fällen erreicht worden sind, wo, wie besonders im Versuche von K lemperer, grössere Mengen Alkohol der Versuchsperson gereicht wurden.

Mir scheint es demnach auch in der neuen Formulierung der Frage ein fast unlösliches Problem, ein Eiweissminimum festzustellen und es wenigstens derartig zu begrenzen, dass innerhalb nicht allzu grosser Schwankungen sich ein allgemeingültiges Kostmass aufstellen lässt. Denn dieses ist doch, darauf muss ich hier wiederum hinweisen, das Ziel gewesen, welches man mit Erörterung der Frage nach dem Eiweissminimum zu erreichen suchte. Durchaus nicht leugnen will ich, dass es sicherlich von Interesse ist, die Bedingungen des Eiweissminimums, wie wir sie kennen gelernt haben, für möglichst viele Fälle und Zustände zu studieren. Hüten muss man sich aber, an einer oder auch an mehreren Personen gewonnene Resultate auf die Allgemeinheit zu übertragen und daraus weitgehende Schlüsse zu ziehen. Denn man darf nicht vergessen, dass in diesem Falle den Ernährungsphysiologen eine grosse Verantwortung aufgebürdet ist. Die Gefahr liegt ja nahe, dass Resultate von Versuchen zur praktischen Anwendung gelangen, welche, trotzdem der Versuch selbst tadellos richtig und zuverlässig ist, dennoch geeignet sind, das Gemeinwohl in erheblicher Weise zu schädigen, weil ibre Verallgemeinerung unstatthaft ist.

1) Gesetze des Energieverbrauchs etc. S. 294. 
Wenn wir uns von der allgemeinen Frage des Eiweissminimums dem speziellen Gebiete des Eiweissgehaltes der vegetarischen Kost zuwenden, so haben wir uns zu fragen, ob bei vegetarischer Diät eine genügende Zufuhr resorbierbaren Eiweisses möglich ist, um alle Bedürfnisse des Organismus zu bestreiten. Ich glaube, man kann diese Frage unbedenklich mit $\mathrm{J}$ a beantworten. Denn wenn auch durchgehends die Eiweisszufuhr bei vegetarischer Diät eine so geringe ist, wie sie bei gemischter Kost selten angetroffen wird, so sprechen doch sowohl die Versuche von Rumpf und Schumm wie besonders diejenigen, welche Glässner und ich an dem Ehepaar K. angestellt haben, dafür, dass mit dieser Kost nicht nur ein Erhalten des Eiweissbestandes, sondern sogar eine Vermehrung desselben möglich ist, auch wenn der Organismus der Versuchsperson nicht zu Beginn des Versuches ein reduzierter war, wie der des Hauptmanns H., der sich ja ebenfalls schliesslich ins Stickstoffgleichgewicht setzen konnte. Wenn aber auch die Zufuhr an Eiweisssubstanzen bei vegetarischer Kost nicht unbedingt eine zu niedrige ist, so bietet doch diese Diätform in ganz besonders hohem Masse die Gefahr einer zu niedrigen Eiweisszufuhr. Neben der geringen Gesamtmenge des Eiweisses in der Nahrung und der schlechten Resorption desselben spielt dabei auch das grosse Volumen dieser Kost eine schädliche Rolle. Denn hierdurch kann bewirlt werden, dass Lust und Eifer zur Nahrungsaufnahme erlahmen, bevor die nötige Menge Eiweiss oder aber die nötige Menge stickstofffreier Nahrungsmittel, welche ein Auskommen mit der geringen Eiweissmenge ermöglichen, stattgefunden hat. In solchen Fällen tritt dann eine allmähliche Verarmung des Organismus an Eiweiss ein, und schliesslich wird wohl auch mit dieser vegetarischen Ernährung ein Eiweissminimum erreicht, welches dem reduzierten Körperbestande entspricht. Hierfür ist der Fall des Hauptmanns H. und, wie ich überzeugt bin, auch die Dame des Herrn Alb u als Beispiel zu verwerten. In diesem allmählichen Einstellen des Organismus auf die gereichte Eiweissmenge ist m. E. wohl mit Sicherheit wenigstens teilweise das Auftreten der als „Heilkrisen" bezeichneten Krankheitsanfälle zurückżuführen, welche beim Übergange zu strengerer vegetarischer Diät einzutreten pflegen. Andrerseits beweist das Vorkommen so ausseror dentlich muskelstarker strenger Vegetarier wie des Dauergängers M., dass für einen sorgsamen und intelligenten Menschen auch bei vegetarischer Kost das Erwerben eines hervorragend eiweissreichen 
muskelkräftigen Körpers und dessen Erhaltung auf leistungsfähigster Höhe möglich ist, wobei sicherlich die erwähnten Kellog'schen Präparate diese Aufgabe wesentlich zu erleichtern imstande sind.

\section{Energiezufuhr bei vegetarischer Kost.}

Günstiger als die Frage nach der Eiweisszufuhr stellen sich die Verhältnisse bei der vegetarischen Ernährung hinsichtlich der Deckung des Kraftbedarfs. Hier besteht wohl kein Zweifel, dass eine ausreichende Zufuhr resorbierbaren Materials leicht erreicht werden kann. Dies folgert schon aus den verhältnismässig günstigen Resorptionsverbältnissen für den Brennwert der Nahrung, welche hauptsächlich durch die leichte Verdaulichkeit der Zucker- und Stärkesubstanzen bedingt sind. Die gute Verwertung des Brennwertes der Nahrung geht ja mit Deutlichkeit aus den Versuchen an dem Ehepaar K. und demjenigen am Hauptmann H. hervor. Denn während bei Herrn K. der Stickstoff nur zu 74, das Fett zu $88 \%$ ausgenutzt wurde, wurde der Brennwert zu $91 \%$ verwertet. Noch besser waren die Verhältnisse bei Frau K., bei welcher die Kalorien sogar zu $93 \%$ ausgenutzt wurden. Selbst bei den ungünstigen Resorptionsverhältnissen des Hauptmanns H. betrug die Ausnutzung des Brennwertes in der I. Periode 76 , in der II. und III. $88 \%$. Von diesem Standpunkt aus ist also ein Einwand gegen die vegetarische Kost nicht zu erheben.

\section{Physiologischer Nutzeffekt.}

Die Wertigkeit einer Kost hinsichtlich ihres Brennwertes spricht sich am klarsten aus, wenn wir den physiologischen Nutzeffekt derselben ermitteln. Unter dem physiologischen Nutzeffekt versteht $\mathrm{Rubner}$ bekanntlich, „wieviel, in Prozenten ausgedrückt, von dem Brennwerte einer Nahrung nach Abzug des Brennwertes von Harn und Kot dem Organismus zur Verfügung steht". Auf solche Weise bat $\mathrm{Rubner}$ gefunden:

\begin{tabular}{|c|c|c|c|}
\hline Nahrung & Ver & $e \%$ & Physiologischer \\
\hline Gemischte Kost, fettreich & 387 & 5,73 & Provacheav \\
\hline$" \quad "$ fettarm & 4,65 & 6,0 & 89,3 \\
\hline
\end{tabular}

Diesen Werten für gemischte Kost erweisen sich die Werte, welche bei dem Ehepaar K. gefunden wurden, durchaus analog.

$\begin{array}{llll}\text { Vegetarische Kost, Herr K. } & 1,4 & 8,9 & 89,7\end{array}$

$1,3 \quad 7,1 \quad 91,6$

E. Pflüger, Archiv für Physiologie. Bd. 109. 
Ebenso günstig stellte sich ein Versuch Rubner's mit Kartoffelkost:

Kartoffelkost . . . . . . $\quad 2,0 \quad \breve{0,6} \quad 92,3$

Es ergibt sich also daraus, dass der physiologische Nutzeffekt bei vegetarischer Kost demjenigen bei gemischter zum mindesten vollkommen gleich sein kann. Dies wird dadurch erreicht, dass der durch die häufig schlechte Resorption bedingte höhere Brennwert des Kotes durch den niedrigeren des Harns kompensiert wird. Wesentlich schlechter liegen die Resultate für den Hauptmann $\mathrm{H}$. Hier verhalten sich die Werte folgendermassen:

\begin{tabular}{|c|c|c|c|}
\hline \multirow{2}{*}{ Periode } & \multirow{2}{*}{\multicolumn{2}{|c|}{$\begin{array}{l}\text { Verluste } \% \\
\text { Harn }\end{array}$}} & Physiologische \\
\hline & & & \\
\hline I a & 5,1 & 23,5 & 71,35 \\
\hline $\mathrm{Ib}$ & 4,0 & 23,5 & 72,49 \\
\hline II & 6,0 & 12,2 & 81,77 \\
\hline III b & 3,1 & 11,7 & 85,19 \\
\hline III e & 3,1 & 11,7 & 85,20 \\
\hline
\end{tabular}

Daraus folgt, dass die reine Obstkost, anch abgesehen von der absolut zu geringen Zufuhr an Eiweiss und stickstofffreien Nährstoffen, an sich eine unzweckmässige genannt werden muss. Sie steht in dieser Beziehung etwa auf gleicher Stufe wie eine Kost, welche aus ganzkörnigem Brot und aus Brot mit Kleie gewonnen worden ist. Für diese Kostarten hat $R u b n \in r^{1}$ ) folgende Werte gefunden :

\begin{tabular}{|c|c|c|c|}
\hline & \multicolumn{2}{|c|}{ Verluste $\%$} & \multirow{2}{*}{$\begin{array}{l}\text { Physiologische } \\
\text { Nutzeffekt }\end{array}$} \\
\hline & Harn & Kot & \\
\hline Brot aus ganzem Korn & 2,4 & 15,5 & 82,1 \\
\hline$" \quad "$ Kleie . . . & 2,2 & 24,3 & 73,5 \\
\hline
\end{tabular}

Auffallend ist, wenn wir diese Zusammenstellung betrachten, dass bei dem Versuche am Hauptmann H. nicht nur die Werte für den prozentischen Verlust im Kot, sondern auch diejenigen im Harn recht hohe sind. Man sollte nach den Erfahrungen am Ehepaar K. annehmen, dass der Wärmeverlust im Harn entsprechend der niedrigeren Eiweisszufuhr bei den Versuchen am Hauptmann H. ein ausserordentlich geringer sein würde. Offenbar aber spielen hier noch andere Faktoren mit, welche den Brennwert der Harnes beeinflussen.

1) Der Energiewert der Kost des Menschen. Zeitschr. f. Biol. Bd. 42 S. 306. 1901 . 
In erster Linie ist naturgemäss derselbe abhängig von den stickstoffhaltigen Resten des umgesetzten Eiweisses. Daneben müssen aber augenscheinlich bei Pflanzenkost Bestandteile in den Harn übergehen, welche seinen Brennwert steigern. Dies ergibt sich, wenn wir die kalorischen Quotienten des Harns zusammenstellen, soweit dieselben bisher ermittelt worden sind. Es wurden folgende Werte gefunden:

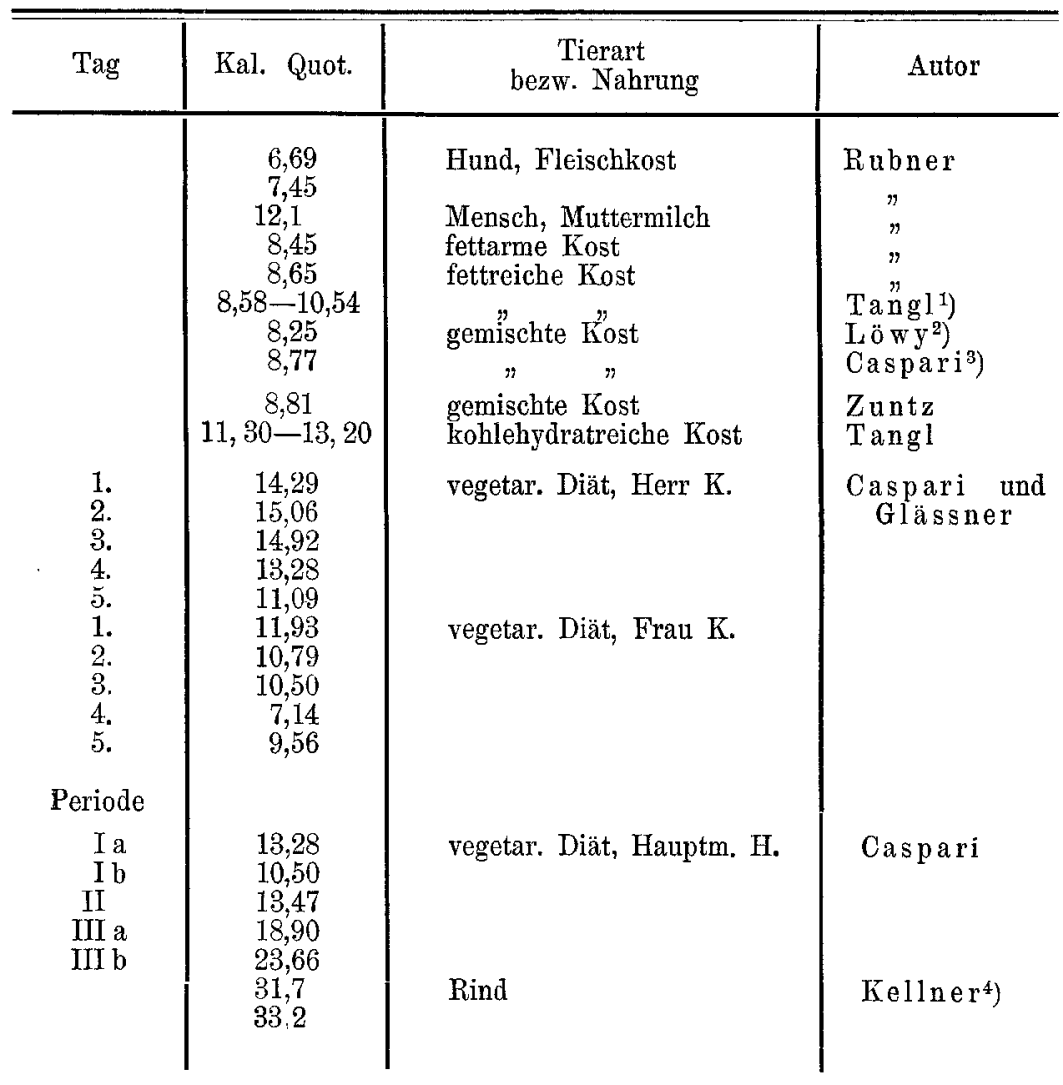

1) Beitrag zur Kenntnis des menschlichen Harns. Arch. f. Anat. u. Physiol, 1899 Suppl.

2) Beiträge zum Stoff- und Energieumsatz des Menschen. Arch. f. Anat u. Physiol. 1901 S. 317.

3) Ebenda S. 323.

4) Untersuchungen über den Stoff- und Energieumsatź volljähriger Ochsen bei Ernährungsfutter. Landwirtschaftl. Jahrbücher Bd. 47 S. 275. 1896. 
Wenn also auch einige noch nicht geklärte Differenzen, besonders zwischen den Angaben von Tangl bei kohlehydratreich genährten Menschen und von Rubner am fettarm, also wohl kohlehydratreich, ernährten Menschen bestehen, so ergibt sich doch, wie mir scheint, im allgemeinen eine geschlossene, gleichmässige Reihe, welche vom Karnivoren über den gemischte Kost nehmenden Menschen zum Vegetarier und von diesem weiter zu den Herbivoren führt. Augenscheinlich ist dies, wie gesagt, darauf zurückzuführen, dass bei pflanzenreicher Kost Substanzen in den Harn übergehen, welche bei hohem Verbrennungswert stickstoffarm resp. stickstofffrei sein müssen. Welcher Art diese Substanzen sind, ist nicht bekannt. Tangl, $\mathrm{Rubner}$ und auch ich selbst haben versucht, Zucker im Harn nachzuweisen, jedoch mit geringem (Rubner) oder ohne Erfolg. Es muss weiteren Untersuchungen vorbehalten bleiben, die Natur dieser Substanz oder Substanzen festzustellen. Es sind hier augenscheinlich die Versuche fortzuführen, welche $R u b n \in r^{1}$ ) begonnen hatte, um das Wachsen des Quotienten $\frac{\mathrm{C}}{\mathrm{N}}$ im Harn zu erklären. Ru bne r wies damals im Harn Indoxylschwefelsäure, Kreatinin, Phenol, Kresol, Kynurensäure nach, alles Substanzen, welche reicher an Kohlenstoff und ärmer an Stickstoff sind als der Harnstoff. Beim Herbivoren, besonders bei vorwiegend aus Gramineen bestehender Nahrung, ist der Reichtum des Harns an aromatischen Substanzen, speziell an Hippursäure, der Grund des hohen kalorischen Quotienten.

\section{Vorzüge der vegetarischen Diät.}

Wir haben bisher eine Reihe von Gesichtspunkten erörtert, in welchen mit mehr oder minder Recht der vegetarischen Diät eine minderwertige Stellung gegenüber der gemischten Kost zugewiesen wird. Es erübrigt jetzt, einige zu erwähnen, in welchen die Anbänger der vegetarischen Ernährungsweise einen besonderen Vorteil ihrer Diätform gegenüber der gemischten Kost sehen. Hier ist zunächst der Mangel an Harnsäurebildnern zu erwähnen. Es ist ausserordentlich schwer, sich vom Stande unserer heutigen Kenntnisse aus ein Urteil zu bilden darüber, ob dieser Vorteil der vegetarischen Diät ein eingebildeter oder ein wirklicher ist. Für beide Gesichtspunkte lassen sich Momente anführen. Die Fanatischen unter den Vege-

1) Zeitschr. f. Biologie Bd. 21 S. 279. 
tariern allerdings, welche leicht geneigt sind, dasjenige als erwiesen zu erachten, was ihren Tendenzen entspricht, sind zum grossen Teil von der verderblichen Wirkung der Harnsäure überzeugt und schwören in diesem Falle auf die Lehre des englischen Klinikers $\mathrm{Haig}^{\mathbf{1}}$ ). Haig selbst steht nicht auf dem Standpunkt, dass eine absolut vegetarische Diät notwendig sei, um die Gefahren, welche die Harnsäure seiner Meinung nach mit sich bringt, zu vermeiden. Andrerseits enthalten ja auch eine Anzahl dem Pflanzenreich entnommener Substanzen, wie Tee, Kakao, Kaffee, grosse Mengen Purinkörper, und gerade die nahrhaftesten Repräsentanten der Pflanzenkost, die Hülsenfrüchte, Bohnen, Erbsen usw., sind gleichfalls so reich an diesen Stoffen, dass nach den Angaben Haig's eine Aufnahme von Hülsenfrüchten zu schweren Schädigungen geführt hat. Ebenso hat auch Walker $\mathrm{Hall}^{2}$ ) nachgewiesen, dass Hafermehl, Erbsenmehl und besonders Bohnen nicht unerhebliche Mengen Purinkörper enthalten. Haig zieht denn auch die Konsequenzen aus diesen Erfahrungen, indem er auch diese eiweissreichen Repräsentanten der Pflanzenkost von seinem und seiner Patienten Diätzettel streicht. Mir scheint, dass der objektive Beobachter auf einem weit weniger sicheren Standpunkt steht, als er von diesem radikalen Autor vertreten wird. Diejenigen Erkrankungen, welche ja in erster Linie als eine Folge der Aufnahme von Purinkörpern angesehen wird, sind die Gicht und gewisse Nierenerkrankungen. Fragen. wir uns aber, was uns denn bisher über den Zusammenhang der Gicht mit den Körpern der Purinreihe bekannt ist, so finden sich einzig und allein die Tatsachen, dass bei Gichtikern nicht nur harnsaure Konkremente an den verschiedensten Stellen des Körpers sich ablagern, sondern auch das Blut reicher ist an Harnsäure als bei dem normalen Menschen; dass ferner der Harnsäuregehalt des Blutes gesteigert werden kann durch Aufnahme purinreicher Nahrungsmittel, insbesondere Leber, Thymus u. dgl. Andrerseits steht aber auch fest, dass dieser vermehrte Harnsäuregehalt des Blutes durch verminderte Ausscheidung der Harnsäure bedingt sein kann. Dass wenigstens zeitweilig eine derartige Retention von Harnsäure

1) Alexander Haig, Die Harnsäure als ein Faktor bei der Entstehung von Krankheiten. Autorisierte Übersetzung der 5. Aufl. Verlag von Otto Salle, Berlin 1902.

2) The relation of purine bodies to certain metabolic disorders. The British med. Journal 1902 p. 1461. 
vorkommt, muss als erwiesen betrachtet werden. Ferner kommt eine Erhöhung der Harnsäurebildung als Ursache in Betracht. Gegen eine Krankheitsdisposition jedoch, welche sich in erhöhter Harnsäurebildung äussert, würde eine purinfreje oder purinarme Diät ein ausreichendes Schutzmittel nicht abgeben können. Wir haben uns nach dem Vorgange von Burian und Schur ${ }^{1}$ ) daran gewöhnt, die Harnsäure, welche im Organismus gefunden und von demselben ausgeschieden wird, zu zerlegen in einen endogenen und einen exogenen Anteil, und nur der exogene kann von der eingeführten Nahrung beeinflusst werden, während der endogene innerhalb weiter Grenzen von der Ernährung unabhängig zu sein scheint. Da wo eine vermehrte Bildung von Harnsäure im Organismus stattfindet, ist aber naturgemäss der Anteil vermehrt, welcher im allgemeinen durch die Ernährung nicht zu beeinflussen ist. Womöglich noch unsicherer sind unsere Kenntnisse über den Zusammenhang von Nierenerkrankungen und Fleischkost.

Da also experimentell sichergestelltes wissenschaftliches Material uns über die Schädlichkeit der Fleischzufuhr in der Kost - denn eine Vermehrung der Harnsäureausscheidung nach Zufuhr gewisser Fleischarten bedingt doch noch keine Schädigung des Organismus bisher keinen sicheren Aufschluss gibt, so wird man gut tun, in dieser Hinsicht der Erfahrung und den Beobachtungen zuverlässiger Autoren eine erhebliche Bedeutung beizumessen. Dabei wird man zugeben müssen, dass Millionen von Menschen eine oft sehr purinreiche Kost zu sich nehmen, ohne im geringsten Schädigungen durch dieselbe zu erleiden. Andrerseits wird man als erwiesen erachten müssen, dass eine nicht unerhebliche Anzahl von Menschen in der Tat durch die Aufnahme allzu grosser Mengen von Purinkörpern geschädigt wird, und dass für diese der Übergang zur vegetarischen Kost nutzbringend und oft heilsam ist. Man braucht andrerseits durchaus nicht Vegetarier zu sein, um unumwunden einzuräumen, dass besonders in England und Deutschland von den gutsituierten Klassen oft ganz ungebührlich hohe Mengen Fleisch verbraucht werden. Dass aber ein Übermass des Fleischgenusses schädlich wirken kann, ist nach allem, was wir experimentell über die Einwirkung gewisser Alloxurbasen festgestellt haben, durchaus nicht.

1) Burian und Schur, C̈ber die Stellung der Purinkörper im menschlichen Stoffwechsel. Pflüger's Archiv Bd. 87 S. 239. 1901. 
erstaunlich. Mir scheint also, dass an dieser vegetarischen Behauptung so viel richtig ist, dass ein Heruntergehen in der Fleischzufuhr bei sehr vielen Menschen von gesundheitlicher Bedeutung. wäre. Selbst vorübergehende oder dauernde Anwendung rein vegetarischer Kost bei solchen Leuten, welche an harnsaurer Diathese oder Gicht leiden, mag vollauf berechtigt sein. Doch ist diese Verwendung im wesentlichen als ein Heilmittel bei pathologischen $\mathrm{Zu}$ ständen aufzufassen. Für Nierenkrankheiten hat die Erfahrung gelehrt, dass eine vorwiegende Milchdiät von besonders günstiger Wirkung ist, eine Kost also, welche nicht unter das rein vegetarische Regime fällt.

Die ausserordentlich zahlreichen Untersuchungen, welche über die Bedeutung der Harnsäure für die Physiologie und Pathologie angestellt worden sind ${ }^{1}$ ), erweisen mit ziemlicher Klarheit, dass auf die Harnsäure a u s s c h eid ung als solche ein verhältnismässig geringer Wert zu legen ist, weil gerade bei barnsaurer Diathese die Ausscheidung der Harnsäure eine geringe, ja eine herabgesetzte sein kann, weil andrerseits bei der Gicht Perioden vermehrter mit solchen verminderter Ausscheidung zu wechseln pflegen. Dennoch entbehrt es vielleicht nicht jeden Interesses, festzustellen, wie sich bei unseren Versuchspersonen die Harnsäureausscheidung verhalten hat. Es ergeben sich da folgende Werte:

$\overline{\mathrm{U}}$ pro Tag im Mittel

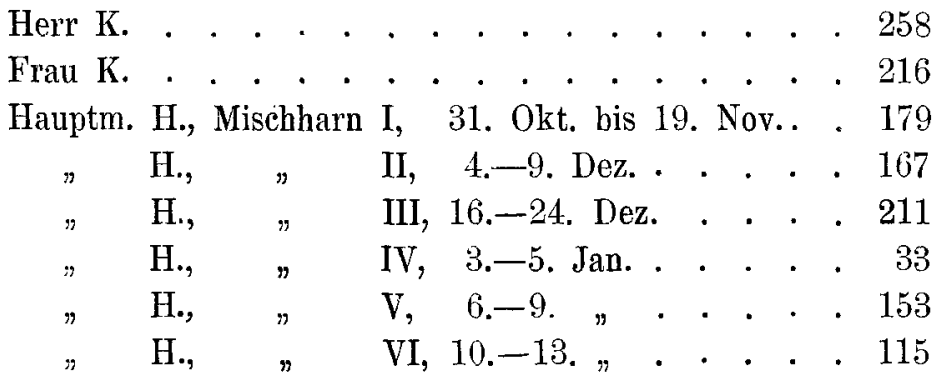

Was zunächst die Werte der Harnsäureausscheidung bei Herrn und Frau K. betrifft, so sind dieselben ausserordentlich niedrig. Sie sind etwa von derselben Grösse, wie sie von Burian und Schur ${ }^{2}$ )

1) Vgl. Wiener, Die Harnsäure. Ergebnisse der Physiologie I. Jahrg. 1902 und Die Harnsäure in ihrer Bedeutung fựr die Pathologie. Ebenda, II. Jahrg. 1903.

2) Das quantitative Verhalten der menschlichen Harnpurinausscheidung. Pflüger's Archiv 1902 S. 289. 
an mehreren Versuchspersonen bei Ernährung mit purinfreier Kost festgestellt worden sind. Auch Minkowski ${ }^{1}$ ) bat Werte gleicher Grössenordnung gefunden bei einer Kost, welche aus Milch, Eiern, Käse, Brot, Reis und Wein bestand, also nicht als streng vegetarisch bezeichnet werden darf, während allerdings bei einer gemischten fleischhaltigen Kost etwa das Vierfache dieser Menge ausgeschieden wird ${ }^{2}$ ). Andrerseits hat Sivén ${ }^{3}$ ) bei ebenfalls nukleinfreier Diät, welche aus Milch, Eiern, Brot, Käse und Bier zusammengesetzt war, etwa doppelt so hohe Werte wie Minkowski pro Tag im Durchschnitt festgestellt. Es stïtzt dies also im wesentlichen die Anschaungen von Burian und Schur, dass die endogene Harnsäureausscheidung eine individuell wechselnde Grösse darstellt. Dagegen scheinen die Werte, wie sie sich bei dem Versuche am Hauptmann $\mathrm{H}$. finden, auf eine gewisse Abhängigkeit der endogenen Harnsäureausscheidung von der Ernährung hinzudeuten. Es spricht sich dies, wie mir scheint, darin aus, dass während des schlechten Ernährungszustandes der Periode I ein sehr niedriger Wert der Harnsäureausscheidung sich erhält. In der Zeit vom 16. bis 24. Dezember steigt derselbe jedoch an. Man wird kaum fehlgehen, wenn man annimmt, dass in dieser Zeit besonders starker Unterernährung und dauernden Eiweissverlustes ein wachsendes Einschmelzen von Körperzellen eintrat, welches mit erhöhtem Verbrauch von Kernsubstanzen einherging. Diese Zeit war die kritischste des ganzen Versuches, was sich auch in dem Allgemeinbefinden der Hauptmanns $\mathrm{H}$. deutlich aussprach. Als dann die Zufuhr an Eiweiss und Kalorien zu Beginn der III. Periode eine günstigere wird, sinkt die Harnsäureausscheidung in Mischharn IV auf ein Minimum herab, entsprechend der Einschränkung des Zerfalls an Körpereiweiss, um später allerdings, als Stiekstoffgleichgewicht und dann sogar ein Eiweissansatz stattfindet, wiederum anzusteigen. Wir finden also mit einem starken Zerfall von Gewebssubstanz eine steigende Ausfuhr von Harnsäure, während mit der Beschränkung des Eiweisszerfalles die Harnsäureausscheidung fast auf Null reduziert wird. Mit dem Erreichen einer auch nur annähernd normalen Ernährung nimmt daun die Harnsäureausscheidung wieder zu, obgleich

1) Arch. f. experiment. Path. u. Ther. Bd. 41 s. 406.

2) Vgl. z. B. Löwi, Untersuchungen über Nukleinstoffwechsel. Arch. f. exper. Ther. u. Pharmak. Bd. 45. 1901.

3) Skandinav. Arch. f. Physiol. Bd. 11 S. 123. 1900. 
keine Purinbildner in der Nahrung vorhanden waren. Sollte hierin eine Abhängigkeit der endogenen Harnsäurezufuhr von der Ernährung gefunden sein, so spricht dies trotzdem nicht gegen die Anschauung von Burian und Schur, welche die Unabhängigkeit der endogenen Harnsäureausscheidung von der Ernährung betont. Denn der Fall des Hauptmanns H. gehört sicher zu den Ernährungsanomalien, für welche die genannten Autoren eine gewisse Abhängigkeit der endogenen Harnsäurebildung von der Nahrung ausdrücklich zugeben.

Eine weitere Erwägung, welche von den Vegetariern zugunsten ihrer Diät ins Feld geführt wird, ist die, dass durch die Reizlosigkeit der Kost der Durst vermindert wird und infolgedessen bei rein vegetarischer Ernährung schon durch die Art der Nahrung selbst dem Alkoholmissbrauch gesteuert werde. Dass die vegetarische Kost sich durch besondere Reizlosigkeit auszeichnet, unterliegt mir keinem Zweifel. Ich habe in einem früheren Abschnitte dieser $A b$ handlung klarzulegen versucht, mit welchen Unzuträglichkeiten eine solche reizlose Diät verknüpft ist. Es ist wohl unbedingt zuzugeben, dass andrerseits durch die gewürzreiche und oft stark gesalzene Ernährungsweise, welche besonders in Norddeutschland und England üblich ist, der Durst in sehr starkem Masse erregt wird. Doch glaube ich, darf man im allgemeinen wohl annehmen, dass es der Durst nicht ist, welcher den Alkoholmissbrauch bedingt. Nicht umsonst lautet die Redeweise: ein Glas über den Durst trinken. Anderseits wird kein einziger leugnen, dass die vegetarische Bewegung sich ein ausserordentliches Verdienst erworben hat und erwirbt durch ihre Bemühungen, den Alkoholmissbrauch einzuschränken. Dass sie dieses durch Verkündung absoluter Abstinenz tut, scheint mir wissenschaftlich ebensowenig begründet $\mathrm{zu}$ sein, wie es andrerseits praktisch geboten ist. Denn ein so tief eingesessenes und den Volkswohlstand und die Volksgesundheit derartig untergrabendes Übel wie der Alkoholmissbrauch kann wenigstens für die weniger gebildeten Volksschichten, welche, wie ich glaube, das Hauptkontingent der Alkoholisten stellen, nur durch radikale Massnahmen beseitigt werden, nicht durch die Auseinandersetzung der Temperenzler, obgleich dieselben den Ergebnissen der wissenschaftlichen Forschung weit mehr Rechnung tragen, als dieses die strengen $\mathrm{Ab}$ stinenzler tun. Doch scheint mir, dass die Verquickung des Vegetarismus mit der Alkoholfrage eine rein äusserliche ist, und dass sich genau ebensogut eine vegetarische Ernährung mit der Aufnahme 
von Alkohol vertragen würde, wie denn auch unsere Versuchsperson, der Ingenieur K., trotz einer streng vegetarischen Kost kein absoluter Analkoholist war.

Ein weiterer Vorteil der vegetarischen Diät ist, dass man eine ausreichende Ernährung nit geringerem Geldaufwande erreichen kann. Auch diese Ansicht ist wohl im allgemeinen eine gerechtfertigte, obgleich sich sehr wohl denken liesse, dass bei der Vervollkommnung der vegetarischen Küche und bei Heranziehung mannigfaltiger, darunter auch seltener und daher kostspieliger Pflanzenarten die Kosten auch bei rein vegetarischer Ernährung nicht unerheblich wachsen würden. Andrerseits ist gerade dieses Ziel erstrebenswert, weil der Einförmigkeit der vegetarischen Ernährungsweise dadurch, wie ich glaube, erfolgreich entgegengearbeitet werden könnte. Näher auf diese Frage einzugehen, liegt ausserhalb des Rahmens dieser Arbeit, welche sich lediglich mit der Physiologie des Vegetarismus $\mathrm{zu}$ beschäftigen hat.

\section{Die Leistungsfähigkeit bei vegetarischer Diät.}

Eines der wichtigsten und zugleich interessantesten Gebiete ist die Frage nach der Leistungsfähigkeit bei vegetarischer Diät. Es ist hehauptet worden, dass die vegetarische Kost durch Vermehrung der Verdauungsarbeit, Überfüllung des Magendarmkanals durch schlecht resorbierbares, sehr voluminöses Material, durch die häufig notwendige Nahrungsaufnahme, die Leistungsfähigkeit der betreffenden Personen herabsetzen muss. Diese Anschauung ist in vielen Fällen richtig, aber wir haben bereits gesehen, dass es bei rein vegetarischer Kost möglich ist, die Unzweckmässigkeiten, wie sie eben geschildert worden sind, durch geeignete Zubereitung dieser Kost zu vermeiden. Andrerseits ist von vegetarischer Seite vielfach behauptet worden, dass diese Diät der gemischten nicht nur gleichwertig, sondern sogar überlegen wäre.

Vom rein theoretisehen Standpunkte wird sich bei Vermeidung ebengenannter Schädlichkeiten kein Grund absehen lassen, warum die vegetarische Kost den Organismus nicht leistungsfähig erhalten sollte. Die Armut jener Diätform an Eiweiss kann heute nicht mehr als ein Grund für verminderte Leistungsfähigkeit ins Feld geführt werden. Diese Frage hängt innig zusammen mit dem vie] erörterten und experimentell von allen Seiten untersuchten Problem nach der Quelle der Muskelkraft. Hauptsächlich dank den Unter- 
suchungen von $\mathrm{Zuntz}{ }^{1}$ ) und seinen. Schülern wissen wir heute, dass jede der drei grossen Nährstoffgruppen geeignet ist, als Quelle der Muskellkraft zu dienen, und dass sich die verschiedenen Nährstoffe annähernd im Verbältnis ihrer Verbrennungswärme bei der Muskelarbeit vertreten. Es darf dabei vielleicht betont werden, dass dieses Resultat dezennienlanger Forschung zweifellos dasjenige ist, welches dem natürlichen Empfinden am meisten Rechnung trägt. Denn es entspräche kaum der Weisheit der Natur, wenn der wichtigsten Funktion des Organismus derartige Schranken gesetzt wären, dass die Gegenwart eines bestimmten Nährstoffes zu ihrer Ausübung notwendig wäre.

Experimentelle Untersuchungen über die Leistungsfähigkeit streng vegetarisch lebender Individuen lagen zu Beginn dieser Arbeit meines Wissens nicht vor. In dieser Beziehung zu erwähnen ist nur die Mitteilung von $B \ddot{l l z}{ }^{2}$ ), welche von erstaunlichen Leistungen japaniseher Wagenzieher bei rein vegetarischer Diät berichtet. Doch wird hier nur die Tatsache der ausserordentlichen Leistungsfähigkeit dieser Leute bewiesen; in die Verhältnisse des Energieverbrauchs bei der Arbeitsleistung und in die Verwertung der Nährstoffe für dieselbe gewährt die Publikation jedoch keinen Einblick. Wir haben es also wohl mit einer sehr interessanten und sicher sehr wertvollen Beobachtung zu tun, jedoch nicht mit einem wissenschaftlichen Experiment.

Um so mehr musste mir daran liegen, die Leistungsfähigkeit der Vegetarier, welche sich einem Versuch unterwarfen, zu prüfen. Glässner und ich hatten bei unseren Versuchen an dem Ehepaar K. dazu keine Gèlegenheit, da die uns zur Verfügung stehende Zeit zu kurz war. Dennoch darf so viel gesagt werden, dass Herr K. den Eindruck eines körperlich und geistig durchaus leistungsfähigen und kräftigen Mannes hervorrief ${ }^{3}$ ), und dass er von den Turngeräten des Augusta-Hospitals einen ziemlich reichlichen täglichen Gebranch machte.

Ich habe dann versucht, die genaueren Verhältnisse der Leistungsfähigkeit bei vegetarischer Diät durch Experimente am

1) N. Zuntz, Über den Wert der wichtigsten Nährstoffe für die Muskelarbeit. Untersuchung am Menschen. Sitzung d. Berliner Physiol. Gesellsch. am 25. Juni 1897.

2) Über regetarische Massenernährung und über das Leistungsgleichg€wicht. Berl. klin. Wochenschr. Bd. 38 S. 689. 1901.

3) Siehe Tafel $X$. 
Hauptmann H. festzustellen. Leider muss ich dieses Bemühen als gescheitert bezeichnen. Naturgemäss benutzte ich bei meinen Versuchen die von $\mathrm{Zuntz}$ ausgearbeitete Methode der Bestimmung des respiratorischen Stoffwechsels bei der Muskelarbeit, welche ja gerade für die Entscheidung des Problems der Quelle ỉer Muskelkraft sich als so ausserordentlich nützlich und praktisch erwiesen hat. In diesem Falle aber zeigte es sich, wo die Grenzen dieser Methode auch für eine derartige Fragestellung gelegen sind. Die Methode bestimmt bekanntlich den Verbrauch bei einer gemessenen Muskelarbeit, indem sie die Steigerung desselben feststellt gegenüber einem Grundwerte in gleichem Verdauungszustand und absolutester Körperruhe. Die absolute Körperruhe war jedoch bei der Versuchsperson nicht durchzuführen. Dem Hauptmann H., welcher sonst in dankenswertester Bereitwilligkeit alle Beschwerden des Versuches in liebenswürdiger Stimmung über sich ergehen liess, waren diese Ruheversuche ganz besonders verhasst. Nicht weil sie unmässige Anforderungen an ihn stellten, sondern weil er ein absolutes Stillliegen für durchaus unphysiologisch erklärte und den dadurch bedingten Resultaten ein ausserordentliches Misstrauen entgegenbrachte. In der ersten Zeit versuchte er wiederholt dem Mangel durch willkürliche Muskelbewegung abzuhelfen, aber auch später erregte ihn die Vorstellung, dass durch diese fehlerhafte Versuchsanordnung die Idee, um derentwillen er sich solchen Strapazen unterzog, geschädigt werden müsse, in recht erheblichem Masse und verhinderte augenscheinlich ein absolut ruhiges Verhalten. Ich versuchte durch Hänfung des Materials zur Feststellung eines einigermassen berechtigten Mittelwertes des Verbrauchs bei Körperruhe zu gelangen. Bei der späteren Zusammenstellung der zahlreichen Versuche ergab sich jedoch, dass dieselben dergestalt im Sauerstoffverbrauch voneinander abwichen, dass an eine Verwendung der Werte nicht gedacht werden konnte. Es schwankte der Sauerstoffverbrauch pro Kilogramm und Minute zwischen 3,27 und 5,64 ccm. Eine Konsequenz der Tatsache, dass ein sicherer Ruhewert nicht festgestellt werden konnte, ist natürlich auch die Unbrauchbarkeit der Arbeitsversuche, so dass dieser Teil der Untersuchung am Hauptmann H. als missglückt angesehen werden muss. Nur einen Punkt möchte ich erwähnen, weil er mir zweifellos gesichert erscheint und des Interesses nicht entbehrt. Es ist das das ausserordentlich schnelle Absinken des respiratorischen Quotienten bei der Arbeitsleistung, welches sich fast durchweg bei den Arbeitsversuchen findet. Es 
beweist dieses Absinken des respiratorischen Quotienten, dass der Versuchsperson zu Anfang der Arbeit zwar Kohlehydrate zur Verfügung standen. Diese Kohlehydratmenge war aber ausserordentlich gering, denn sie wurde sehr schnell aufgebraucht, und für die weitere Arbeitsleistung Körpermaterial, Fett und Eiweiss, herangezogen. Die Geringfügigkeit des Kohlehydratbestandes tritt recht instruktiv hervor, wenn wir die Grösse der Arbeit, welche in unserem Falle ein Sinken des respiratorischen Quotienten bewirkte, vergleichen mit derjenigen, welche bei normal genährten Mensehen den gleichen Effekt hervorrief. Ähnliche Verhältnisse sind nämlich bereits von Zuntz und Schumburg ${ }^{1}$ ) am marschierenden Soldaten festgestellt worden, und diese Autoren weisen ausdrücklichauf die genannte Tatsache hin (vgl. die Tabelle l. e. S. 258). Ich habe in der folgenden kleinen Tabelle zum Vergleich einen Versuch aus dem ZuntzSchumburg'schen Buche herausgegriffen, für welchen ich gerade den kalorischen Wert der Marscharbeit berechnet fand. Den kalorischen Wert der Arbeitsleistung, welche bei den Versuchen am Hauptmann II. dem Sinken des respiratorischen Quotienten vorausging, habe ich in der gleichen Weise berechnet unter der Annahme, dass nur Fett und Kohlehydrate bei der Arbeitsleistung in Betracht kamen, eine Annahme, welche ja vielleicht nicht streng gerechtfertigt ist, bei derartigen Durchschnittszahlen aber eine genügende Annäherung gestattet. Der Berechnung des kalorischen Wertes der Arbeit wurde der respiratorische Quotient der vorhergehenden Versuchsreihe zugrunde gelegt: ein Verfahren, welches ebenfalls sicherlich nicht berechtigt ist, von mir aber deswegen eingeschlagen wurde, weil der respiratorische Quotient im ersten Versuche stets ein höherer war, und der für die Arbeit berechnete Energieverbrauch mit dem Steigen des respiratorischen Quotienten ansteigt. Denn ein Liter Sauerstoff liefert bei Verbrennung von Stärke 5,047, bei derjenigen von Fett nur 4,686 Kalorien. Wir kommen also bei Verwendung des höheren respiratorischen Quotienten zu Maximalwerten für den Arbeitsverbrauch des Herrn H., welche das Resultat a fortiori gelten lassen. Auf diese Weise erhalten wir folgende kurze Zusammenstellung, welche das Gesagte hinreichend illustriert.

1) Zuntz and Schumburg, Physiologie des Marsches. Verlag von Hirschwald, Berlin 1901. 


\begin{tabular}{|c|c|c|c|}
\hline Versuchsperson & Datum & $\begin{array}{l}\text { Wärmewert der } \\
\text { Arbeitsleistung }\end{array}$ & R. $-Q$. \\
\hline $\begin{array}{l}\text { Hauptmann H. . . . . } \\
" \text { " . . . } \\
\text { " } " \cdot \ldots \cdot \\
\text { cand. med. P. bei Zuntz- } \\
\text { Schumburg, Vers. Nr. } 25\}\end{array}$ & 28. Mai & 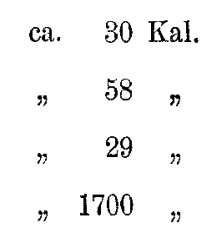 & $\left\{\begin{array}{l}1,09 \\
0,69 \\
0,91 \\
0,73 \\
0,85 \\
0,74 \\
0,84 \\
0,785\end{array}\right.$ \\
\hline
\end{tabular}

Das Absinken des respiratorischen Quntienten bei der Arbeit wurde übrigens auch von $\mathrm{Zuntz}$ und Hagemann bei ihren Versuchen über den Stoffwechsel des Pferdes beobachtet, was bei der kohlehydratreichen Kost dieser Tiere besonders plausibel erscheint.

Da also die Respirationsversuche beim Hauptmann H. zur Entscheidung der Frage der Leistungsfähigkeit bei vegetarischer Diät nicht herangezogen werden können, so müssen wir uns in diesem Falle mit Daten der allgemeinen Beobachtung begnügen. In dieser Beziehung bietet die von Herrn H. selbst gegebene Darstellung seines Aufenthaltes in der Klausur ein durchaus zutreffendes Bild. Es geht daraus hervor, dass die körperliche Leistungsfähigkeit im allgemeinen als eine sehr herabgesetzte bezeichnet werden muss, was auch dem Ernährungszustande des Körpers durchaus entsprach. Schon durch die Lebensweise der vorhergehenden Zeit war ja der Organismus des Hauptmanns H. ausserordentlich reduziert, als er sich in die Klausur begab. Infolgedessen wurden auch die zuerst energisch betriebenen Dauerläufe bald aufgegeben. Sie mussten aufgegeben werden wegen einer Schmerzhaftigkeit des Fusses, die Herr H. auf eine alte Verletzung zurückfübren zu müssen glaubte. Wie überhaupt, zweifle ich auch in diesem Falle nicht an der objektiven Richtigkeit der Aussage des Herrn H., dass er ohne diese Schmerzen den Dauerlauf noch einige Zeit lang hätte fortsetzen können. Dagegen möchte ich sehr bezweifeln, dass die Fortsetzung des Danerlaufs noch für längere Zeit möglich gewesen wäre, da der allgemeine Kräfteverfall ein stets fortschreitender während des Versuches war und gegen Ende Dezember einen hochgradigen Charakter annahm. Auch in der Deutung des Fussübels möchte ich mich der Ansicht des Herrn H. nicht anschliessen. Ich habe durchaus den Findruck, dass die Schmerzen im Fusse, welche ein weiteres Ausführen der Dauerläufe unmöglich machten, bedingt wurden durch den Schwund 
des Fettes an der Planta pedis. Dies scheint mir daraus hervorzugehen, dass erstens ein Nachweis einer Verletzung oder Schwellung unmöglich war: weder die behandelnden Herren des Krankenhauses noch ich selbst konnten das geringste nachweisen. Ferner steigerten sich die Beschwerden trotz grosser Schonung, und im weiteren Verlauf des Versuches wurde auch ruhiges Gehen durch Schmerzen in beiden Füssen sehr erschwert, ja, zum Schlusse war selbst das Stehen mit unangenehmen Empfindungen verbunden. Auch die vorher betriebenen Kniebeugen wurden mit dem Beginn des Fussleidens aufgegeben und nur die Hantelübungen fortgesetzt. Über die Grösse dieser Muskelarbeit lässt sich schwer etwas aussagen, da die Sandow'schen Hanteln, welche zur Verwendung kamen, aus einer Anzahl Spiralfedern gebildet sind, deren Zusammendrücken mit dem Heben und Senken der Hanteln verbunden wird, so dass also die Arbeitsleistung je nach dem stärkeren oder geringeren $\mathrm{Zu}$ sammenpressen der Federn eine äusserst verschiedene sein kann. Doch beobachtete ich auch bei den Arbeitsversuchen im Laboratorium ein baldiges Ermüden. Dieser Umstand ist aber zum Teil wiederum auf den Fettschwund an der Fusssohle und das dadurch bedingte unsichere und schmerzhafte Gehen und Stehen zurückzuführen; denn wir wissen aus den Versuchen von Zuntz und Schumburg ${ }^{1}$, dass derartig erschwerende Momente den Energieverbrauch bei einer Muskelarbeit nicht unwesentlich steigern.

Im Gegensatz zu diesem allgemeinen Nachlassen der Körperkräfte steht die vom Hauptmann $H$. in seinen Angaben mitgeteilte Tatsache; dass er auch am Ende des Versuches seine Muskelkraft dadurch zeigte, dass er mit einer Anzahl von Herren gerungen hat und dabei eine verhältnismässig erhebliche Kraft entwickelte. Er rang damals mit Herm Geheimrat Professor Dr. Goldscheider, Herrn Geheimrat Professor Dr. Zuntz, Herrn Dr. Alexander, dem damaligen Leiter der Station, Herrn Dr. Völtz und mir. Ein jeder der Herren war über die dabei von Herrn H. entwickelte Muskelkraft erstaunt. Hierbei ist aber zu bemerken, dass dieses Ringen am Ende des Versuches statthatte, also zu einer Zeit, in welchem der Allgemeinzustand des Herrn H., wie die Daten des Versuchs lehren, ein wesentlich besserer war als in den vorhergehenden Versuchsabschnitten. Dennoch muss man die Kraftleistung als eine verblüffende bezeichnen, wenn man die beiliegenden Photo-

1) 1. c. S. 265 . 
graphien ${ }^{1}$ ) betrachtet, welche den Körperzustand des Herrn H. an Ende des Versuches wiedergeben. Diese Photographien sprechen wohl für sich selbst und bedürfen keiner weiteren Erläuterung. Sie zeigen das Bild eines Körpers, wie wir ihn sonst wohl nur bei den hochgradigsten Kachexien zu sehen bekommen; doch ist gerade die Oberarmmuskulatur wie das eine der Bilder erkennen lässt, verhältnismässig gut erhalten. Aufmerksam machen möchte ich auch auf die Auftreibung des Abdomens, welche durch die Anhäufung und Gärung von zellulosehaltigen Nahrungsmittelbestandteilen im Magendarmkanal bedingt sein dürfte.

Wenn wir aber eine derartige Muskelleistung wie diejenige, welche Herr H. am Ende des Versuches beim Ringen zeigte, richtig würdigen wollen, dürfen wir auch das psychische Moment nicht ausser acht lassen. Es ist ganz zweifellose Erfahrungstatsache, dass der Wille in körperlicher Beziehung Ausserordentliches vermag, und wohl jeder, der selbst in die Lage gekommen ist, Körperleistungen bis zur vollkommenen Erschöpfung auszuführen, kennt diesen Einfluss der Willenskraft auf die Muskelleistungen. Ein sehr lebrreiches Analogon zu dieser Körperleistung des Herrn H. bietet ja auch der ergographische Versuch, welchen Succi am 29. Hungertage ausgeführt hat. 'Trotzdem die ergographische Leistung Succi's durchaus nicht erheblich gegenüber derjenigen von Luciani selbst zurücksteht, wird dennoch wohl niemand auf den Gedanken kommen, ein 29 tägiges Hungern für eine geeignete Form der Ernährung zu halten. Auf den kolossalen Einfluss der Willenskraft auf körperliche Maximalleistungen werden wir im weiteren Verlaufe näher einzugehen haben.

Völlig, zutreffend sind ferner die Angaben, welche Herr H. über seine geistige Arbeit macht. In der Tat war dieser Herr während der Klausur von ganz erstaunlichem Fleisse, und dicke Hefte füllten sich mit schön geschriebenen Übersetzungen in lateinischer, französischer, englischer Sprache, zablreichen deutschen Aufsätzen und mathematischen Übungen. Wie weit allerdings diese Tätigkeit eine äusserliche gewesen ist, vermag ich nicht $\mathrm{zu}$ beurteilen. Man wird zugeben, dass in dieser Beziehung ein gar zu ausschliessliches schriftliches Arbeiten immerhin einigen Verdacht erregen muss. Andrerseits ist ja die dauernde geistige Arbeitsfähigkeit bei einer fortschreitenden schlechten Ernährung des Körpers nicht so sehr

1) Siehe Tafel IX. 
erstaunlich. Denn einerseits wissen wir aus den Versuchen von Speck ${ }^{1}$ ), dass geistige Tätigkeit mit einem ausserordentlich geringen Stoffverbrauch verbunden ist, andrerseits haben uns z. B. die Versuche von Sedlmair ${ }^{2}$ ) gelehrt, dass beim verhungerten Tiere das Gehirn kaum an Gewicht abnimmt. Auch die oft grossen geistigen Leistungen an schweren Erschöpfungskrankheiten Leidender sind bekannt.

Erfreulicherweise gelang es mir, die Lücke, welche durch das Misslingen der Respirationsversuche an Herrn H. gelassen war, dureh eine Reihe anderer Untersuchungen befriedigend auszufülen. Hierzu hatte ich Gelegenheit anlässlich eines Dauermarsches, welchen der Sportklub „Komet" im Frühjahr des Jahres 1902 unternahm. Über den allgemeinen Verlauf dieses Marsches habe ich bereits in Gemeinschaft mit Herrn Albu, welcher die klinischen Beobachtungen übernommen hatte, eine kurze Mitteilung publiziert ${ }^{3}$ ). Hier möchte ich nun die von mir bei den physiologischen Untersuchungen während des Trainings der Versuchspersonen gewonnenen Daten mitteilen. Diese Versuchspersonen waren die beiden Champions des Sportklubs. Von diesen war der eine, Herr K. M., ein junger Kaufmann, am 5. März 1874 geboren, war also damals 28 Jahre alt. Im Jahre 1894 gab er infolge der Lektüre des Buches von Professor Förster: "Die soziale Bedeutung des Vegetarismus" den Fleischgenuss auf. Von Ende März 1901 ab lebte er streng vegetarisch, d. h. ohne Milch, Butter, Käse oder Eier. Seit Anfang des Jahres 1898 schon vermied er als Anhänger Haig's den Genuss der Hülsenfrüchte. Seit dem Jahre 1900 genoss er Kellogg'sche Präparate, besonders Erdnuss (pea-nut), auch Bromose. Von Sport trieb er seit März 1896 das Radfahren. Er war bald bester Strassenfahrer der Radfahrvereinigung der Berliner Turnerschaft. Im Jahre 1898 trug er seinen ersten Erfolg als Dauergänger davon. Er gewann damals den Marsch rund um Berlin. M. legte die Strecke von 15 Meilen in 14 Stunden 11 Minuten zurück.

Seine vorzüglichen körperlichen Fähigkeiten verdankte er aber weniger besonderen Sportübungen als vielmehr „einer mit pedantischer Gewissenhaftigkeit betriebenen durchgreifenden Körperausbildung

1) Physiologie des menschlichen Atmens. Leipzig 1892.

2) Zeitschr. f. Biol. Bd. 37 S. 25. 1898.

3) Bericht über die Untersuchungen bei den Dauergehern beim Distanzmarsch Dresden-Berlin am 18. und 19. Mai 1902. Deutsche med. Wochenschr. 
nach Sandow". Diese allgemeine Ausbildung seines Körpers befähigt Herrn M. nach seiner Meinung, sich mit jedem Sport zu befassen und dabei gute Durchschnittswerte oder gar Maximalleistungen zu erreichen.

Der zweite Favorit war Herr J. B., ein junger Mechaniker, geboren am 11. Februar 1876, war also damals im Alter von 26 Jahren. Seit dem Jahre 1895 trainierte er vorschriftsmässig im Gehsport. Er gewann schon im selben Jahre die "Meisterschaft von Berlin im

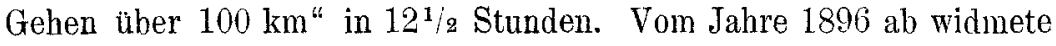
er sich auch dem Laufsport und errang 1897 die „Meisterschaft von Deutschland im Laufen über $7500 \mathrm{~m}$ " in 26 Minuten 6 Sekunden. 1898 gewann er die "Meisterschaft von Österreich im Laufen über vier englische Meilen" usw. Nach dem Wettmarsch, hat er am 13. September 1903, den Weltrekord im Gehen über 1/4 englisehe Meile $(402,25 \mathrm{~m})$ in 1 Minute 20,5 Sekunden aufgestellt.

Jedenfalls geht aus diesen Angaben hervor, dass wir es mit einem Sportsman erster Klasse zu tun hatten.

B. genoss eine gemischte, soweit wir es beobachten konnten, sogar reichlich Fleisch enthaltende Kost. M. war strengster Abstinenzler; B. dagegen nahm alkoholische Getränke zu sich. Der Dauermarsch, welcher geplant war, war für Fussgänger aller Nationen offen und sollte in der Zurücklegung der Strecke von Dresden nach Berlin bestehen. Diese Strecke beträgt $202 \mathrm{~km}=27$ deutsche Meilen: Herr M. und Herr B. stellten sich uns nun während des Trainings für einige Versuche zur Verfügung. Dieselben wurden in der Weise ausgeführt, dass die Versuchspersonen morgens in aller Frühe erschienen und nach vorhergehender Wägung auf die oft beschriebene Tretbahn geführt wurden. Dort wurden mehrere Atemversuche im Gehen an ihnen angestellt. Darauf marschierten sie von der landwirtschaftlichen Hochschule nach Saatwinkel und kehrten dann zur Hochschule zurück. Dieser Weg wurde deswegen gewählt, weil er bereits früher von $Z u n t z$ und $S c h u m b u r g$ bei den Untersuchungen an marschierenden Soldaten benutzt und bei dieser Gelegenheit seine Länge genau eruiert worden war. Der Hin- und Rückweg zusammen betrug $24,75 \mathrm{~km}$. Nach ihrer Rückkehr wurde dann ein weiterer Versuch auf der Tretbahn gemacht, hierauf dieselbe Strecke von $24,75 \mathrm{~km}$ nach einer kurzen Mittagspause nochmals zurückgelegt und nach der Rückkebr neue Versuche auf der Tretbahn angeschlossen. Während des ganzen Tages wurde übrigens das Körpergewicht genau kontrolliert, das Gewicht der aufgenommenen 
Nahrung und der ausgeschiedenen Exkrete festgestellt, um so die Daten für die insensible Perspiration zu gewinnen.

Was die körperliche Beschaffenheit der beiden Versuchspersonen betraf, so war der Vegetarier K. M. von 1,635 m Körpergrösse, dabei ausserordentlich breitschultrig und von kräftiger, gleichmässig entwickelter Muskulatur. Die beigegebene Photographie ist neueren Datums und lässt die Armmuskulatur weniger stark hervortreten als es zur Zeit des Dauermarsches der Fall war. Dagegen zeigt sich der mächtige Thorax auf diesem Bilde sehr dentlich ${ }^{1}$ ). In der Tat braucht man diesen Mann nur zu betrachten, um einen lebenden Beweis vor sich zu sehen, wie wenig die vegetarische Diät bei verständiger Ausführung der Entwicklung und Erhaltung eines kräftigen und muskulösen Körperbaues entgegensteht.

Herr J. B. war grösser als Herr M. Seine Körpergrösse war 1,75 m. Er machte einen weit zierlicheren Eindruck und zeigte einen aussergewöhnlich schön proportionierten Körperbau. Seine Muskulatur dagegen war durchaus nicht so gleichmässig ausgebildet wie diejenige des Herrn M., was wohl sicherlich seinem mehr einseitigen Training zugeschrieben werden muss. Speziell an Armmuskulatur und Brustumfang konnte er sich nicht mit seinem Rivalen messen. Das mittlere Körpergewicht des Herrn M. betrug 61,175 kg, das des Herrn B. 63,18. Zur Beurteilung des Eiweissbestandes des Körpers geben die Respirationsversuche in absoluter Ruhe einen Anhalt. Es wurden gefunden als Mittel mehrerer miteinander gut harmonierender Ruheversuche:

\begin{tabular}{|c|c|c|c|c|c|c|}
\hline Name & 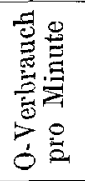 & 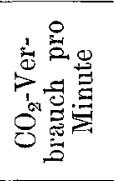 & 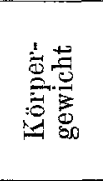 & 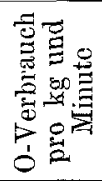 & 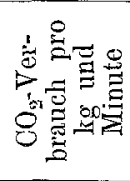 & R. Q. \\
\hline $\begin{array}{l}\text { M. } \\
\text { B. }\end{array}$ & $\begin{array}{c}\text { ссли } \\
336,4 \\
298,4\end{array}$ & $\begin{array}{c}\text { сcm } \\
254,55 \\
217,0\end{array}$ & $\begin{array}{l}\mathrm{kg} \\
61,175 \\
63,18\end{array}$ & $\begin{array}{c}\text { ecm } \\
5,499 \\
4,723\end{array}$ & $\begin{array}{c}\text { cсm } \\
4,161 \\
3,435\end{array}$ & $\begin{array}{l}0,76 \\
0,73\end{array}$ \\
\hline
\end{tabular}

Vergleichen wir diese Daten mit anderen, so finden wir, dass der Sauerstoffverbrauch des Herrn M. ein ausserordentlich hoher ist. Unter den kräftigen Männern, welche z. B. Magnus-Levy ${ }^{2}$ ) anführt, ist der höchste Wert der Sauerstoffausscheidung pro Kilogramm und Minute bei einem 24 jährigen jungen Mann $4,53 \mathrm{ccm}$.

1) Siehe Taf. X. Das Bild ist in maximaler Inspirationsstellung aufgenommen.

2) Magnus-Levy und Frnst Falk, Lungengaswechsel in verschiedenen Altersstufen. Arch. f. Anat. u. Physiol. 1899 Suppl. 
Zuntz und Schumburg erhielten für Herrn cand. med. P. einen Verbrauch von $4,12 \mathrm{ccm} 0$ pro Kilogramm Körpergewicht. In den Versuchsprotokollen wird angegeben, dass Herr P. eine sehr starke Muskulatur besessen habe. Der Wert des Sanerstoffverbrauches pro Kilogramm Körpergewicht bei absoluter Körperruhe für Herrn M. ist meines Wissens der höchste, welcher bisher bei gesunden Menschen festgestellt ist. Dagegen ist der Wert für Herrn B. zwar ebenfalls ein sehr hoher, doch existieren einige Angaben, in welchen derselbe bereits übertroffen worden ist. So hat $\mathrm{Lö} \mathrm{w}^{1}$ ) Daten angegeben, nach welchen bei besonders kräftigen Arbeitern der Sauerstoffverbrauch in der Ruhe ähnlich demjenigen des Herrn M. 5,36 bezw. 5,14 cem pro Kilogramm Körpergewicht betrug. Der Grund für diesen hohen Verbrauch muss augenscheinlich in der starken Muskulatur der betreffenden Individuen gesehen werden. Von den Faktoren, welche den Kraftverbrauch, für welchen der Sauerstoffverbrauch ja nur ein Mass ist, bedingen, fällt der eine, die Grösse der Körperoberfläche, wohl in diesem Falle fort, da ein wesentlicher Untersehied durch die Verschiedenheit derselben hier kaum bedingt sein kann, und so bleibt nur der durch den Eiweissgehalt, speziell die Muskulatur bedingte Verbrauch als unterscheidendes Merkmal bestehen, dessen Bedeutung ja neben anderen diesbezüglichen Befunden besonders schön wiederum aus den Angaben von $\mathrm{Zuntz}$ und $\mathrm{Schumburg}$ hervorgeht. Diese fanden, dass mit der im Verlaufe der Märsche sich kräftiger ansetzenden Muskulatur der Ruheverbrauch pro Kilogramm Körpergewicht bei ihren Versuchspersonen anstieg. So stieg er bei dem erwähnten Herrn P. von 4,04 cem auf 4,30 , bei Herrn cand. med. B. von 3,74 auf 4,24 ccm Sauerstoff, Man kann also aus diesen vorliegenden Werten für den Ruheverbrauch meiner Versuchspersonen M. und B. den Schluss ziehen, dass Herr M. der muskulaturkräftigere von beiden Personen war.

Die Resultate der Arbeitsversuche auf der Tretbahn mögen in folgenden Tabellen zusammengestellt sein. In dieser Tabelle enthalten Stab 6 und 7 den Gesamt-Sauerstoffverbrauch resp. Kohlensäureausscheidung, Stab 10 den dazu gehörigen respiratorischen Quotienten. Dagegen ist in Stab 8 und 9 der Sauerstoffverbrauch abzüglich des Ruhewertes zugrunde gelegt.

1) A. Loewy, Ueber den Einfluss der Abkühlung auf den Gaswechsel des Menschen. Pflüger's Arch. Bd. 46 s. 197. 1890. 
Physiologische Studien über Vegetarismus.
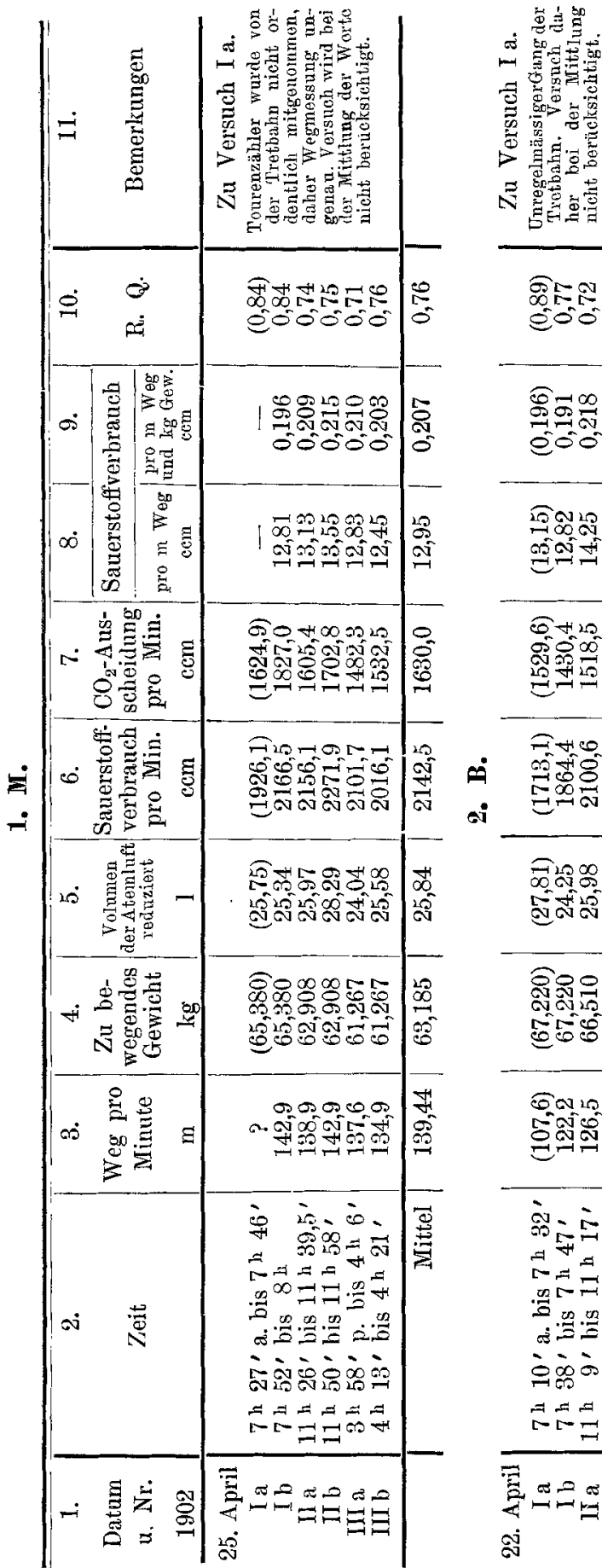

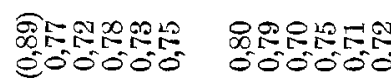

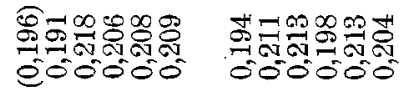

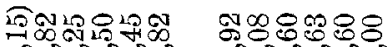

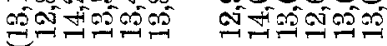
-

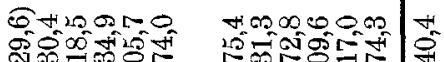
为布

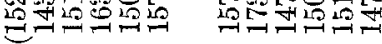

\begin{tabular}{|c|c|}
\hline 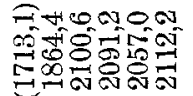 & 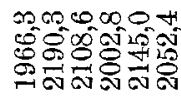 \\
\hline
\end{tabular}

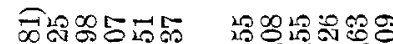

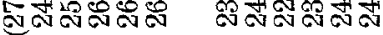

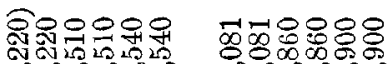

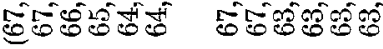

-

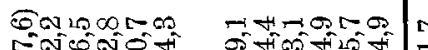

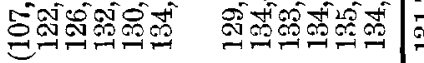

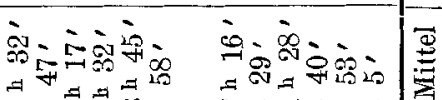

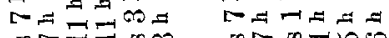

.ूत

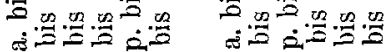

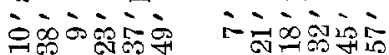

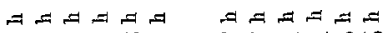

DEFT-

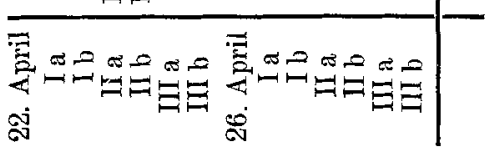


Das auffallende Resultat dieser Versuchsreihen ist die absolute Gleichheit des Sauerstoffrerbrauchs bei beiden Personen, pro Meter Weg und Kilogramm Gewicht berechnet. Wenn natürlich auch die Identität der Werte bis zur dritten Dezimale auf einem $\mathrm{Zu}-$ fall beruht, so ist die allgemeine Übereinstimmung der einzelnen Versuche untereinander doch eine so grosse, dass es schwer fällt, an blosse Zufälligkeiten zu glauben. Dieses Resultat wird besonders. interessant durch den Umstand, dass die Art, in welcher beide Personen die Muskelarbeit vollführten, eine durchaus verschiedene war. Der Vegetarier M. ging im Marey'schen Beugegang, welcher bekanntlich darin besteht, dass bei weitem Ausschreiten die Kniee niemals in Streckstellung gelangen. Dadurch wird nach Marey's Berechnung die zweckmässigste und schnellste Art des Gehens über grosse Strecken gegeben. Bekanntlich ist diese Art des Marsches bei den Bersaglieri der italienischen und den Spahis der französischen Armee eingeführt worden, und auch im deutschen Heere hat man wiederholt Versuche gemacht, diese Gangart, welche nach ihrer ganzen Natur ein Mittelding zwischen dem gewöhnlichen Gang und dem Laufschritt bildet, bei der Infanterie einzuführen. Der Gemischtkostler B. dagegen ging im athletischen Turnersehritt, indem er den Oberschenkel verhältnismässign. stark hob und die Kniee nach dem Aufsetzen des Standbeines durchdrückte: eine Gangart, welche durchaus nicht einen so zweckmässigen Eindruck machte wie die von dem Vegetarier M. gewählte. Sollte, was nach der ausgezeichneten Übereinstimmung der einzelnen Versuche untereinander durchaus wahrscheinlich erscheint, diesem Resultate ein allgemeines Gesetz zugrunde liegen, so würde sich dasselbe etwa folgendermassen formulieren lassen: Maximal trainierte Menschen leisten die gleiche Arbeit, auf welche sie trainiert sind, mit gleichem Verbrauch, unabbängig von der Art der Ernährung, speziell vom Eiweissreichtum der Nahrung, wenn dieselbe an sich ausreichend ist. Auch diebesondere Art, in welcher die Arbeitsleistung ausgeführtwird, ist nicht ausschlaggebend für den Energieaufwand, wenn nur die Muskelgruppen, welche in Frage kommen, für die Leistung maximal trainiert sind.

Ebenso schön treten diese Verhältnisse hervor, wenn wir den kalorischen Wert der geleisteten Muskelarbeit berechnen. Wir können dies nach der von $\mathrm{Zuntz}$ angegebenen und besonders in seinen Ver- 
suchen mit Schumburg am marschierenden Sol laten angewandte Methode. Hierbei wird der Sauerstoffverbrauch und die Kohlensäureausscheidung bei der Arbeitsleistung abzüglich des Ruheverbrauches der Berechnung zugrunde gelegt. Von diesen Werten werden diejenigen in Abzug gebracht, welche dem während der Arbeitsleistung zerfallenen Eiweiss entsprechen, für das die Stickstoffausscheidung im Harn den Massstab darstellt. Nach Abzug des für die Verbrennung des Eiweisses aufgenommenen Sauerstoffes und der dabei gebildeten Kohlensäure erhalten wir nunmehr neue Daten für Sauerstoffverbrauch, Kohlensäureausscheidung und respiratorischen Quotienten. Diese Werte sind auf die für die Arbeit verbrauchten Fette und Kohlehydrate zu beziehen. Auf den Anteil eines jeden dieser beiden Nährstoffe an dem Verbrauche wird aus dem respiratorischen Quotienten geschlossen (Genaueres hierüber s. Zuntz und Schumburg l. c. S. 259 ff.). Die Summe des kalorischen Wertes der bei der Arbeit über den Ruheverbrauch hinaus umgesetzten Nährstoffe ergibt den kalorischen Wert dieser Arbeit.

Leider konnte der Stickstoffgehalt des Harns unserer Versuchspersonen während der Übungsmärsche nicht ermittelt werden; dagegen erklärten sich beide Herren bereit, den während des Dauermarsches selbst entleerten Harn quantitativ aufzufangen. Wie wir später sehen werden, wurde jedoch der Dauermarsch nur von dem einen unserer Versuchspersonen, Herrn M., durchgeführt, so dass nur für diesen die Stickstoffausscheidung während des Marsches bekannt ist. Herr M. schied während des gesamten Marsches 19,01 g N im Harn aus. Ferner wurde auch der in den Kleidern enthaltene Schweiss gesammelt und sein Stickstoffgehalt bestimmt. Es wurden im Schweisse während des Marsches $1,5 \mathrm{~g} \mathrm{~N}$, in Summa also 20,51 g N ausgeschieden. Da der Marsch ca. 27 Stunden währte, kamen auf die Stunde $0,76 \mathrm{~g} \mathrm{~N}$, auf die Minute $13 \mathrm{mg} \mathrm{N}$. Letzterer Wert entspricht $78,8 \mathrm{ccm} \mathrm{O}_{2}, 62,5 \mathrm{ccm} \mathrm{CO}_{2}, 352,8$ kal. Diese Zahlen habe ich in Rechnung gestellt, obgleich ich mir natürlich bewusst bin, dass ich damit einen gewissen Fehler begehe. Doch kommt demselben zweifellos keine wesentliche Bedeutung zu, denn selbst, wenn ich das zerfallene Eiweiss gar nicht berücksichtige und die Annahme mache, dass nur Fette und Kohlehydrate für die Arbeit verbraucht worden wären, erhalte ich Werte, welche mit den in der folgenden Tabelle Stab 7 angegebenen fast vollkommenen identisch ist. 
W. Caspari:

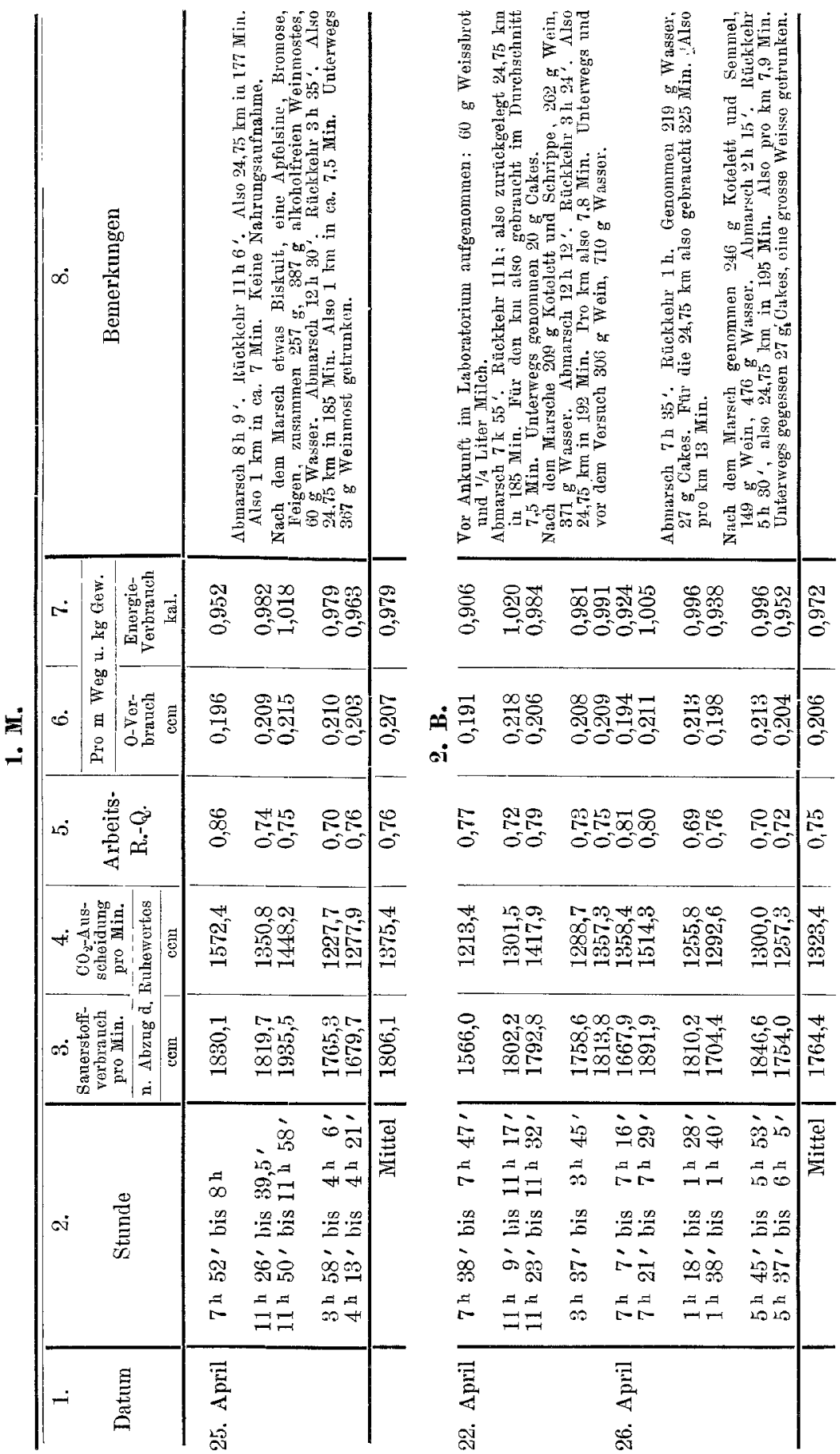


Zweckmässig erschien es mir ferner, in dieser Tabelle zugleich einen Überblick über die Nahrungsaufnahme während der Versuche zu geben (Stab 8).

Also trotz der Verschiedenheit der Ernährung besteht eine vollständige Übereinstimmung des kalorischen Wertes der Marscharbeit bei beiden Dauergängern, vollkommen konform mit der Übereinstimmung im Sauerstoffverbrauch.

Natürlich habe ich gesucht, in der vorliegenden Literatur Angaben zu finden, welche geeignet sein könnten, das hier aufgestellte Gesetz zu illustrieren und zu festigen. Leider aber existieren nur wenige Daten, welche sich mit den vorliegenden vergleichen liessen. Keine von den Versuchspersonen ron Katzenstein, Magnus-Levy, Zuntz und Schumburg haben bei ihren Marschversuchen eine Geschwindigkeit gewählt, welche an diejenige heranreicht, die den Versuchspersonen M. und B. die angenehmste war, und für welche augenscheinlich ihr Training auch das vorzüglichste gewesen ist. Dagegen hat Leo $\mathrm{Zuntz}^{1}$ ) bei seinen Untersuchungen über den Gaswechsel und Energieumsatz des Radfahrers Gehversuche angestellt, bei welchem er ein annähernd gleiches Tempo gewählt hat. Wenn ich unter Annahme eines gleichbleibenden Körpergewichts von $72,7 \mathrm{~kg}$ die entsprechenden Werte berechne, so finde ich folgende Zahlen:

\begin{tabular}{c|c|c|c|c}
\hline \multirow{2}{*}{ Datum } & \multirow{2}{*}{$\begin{array}{c}\text { Nr. des } \\
\text { Versuchs }\end{array}$} & $\begin{array}{c}\text { m Weg } \\
\text { pro Minute }\end{array}$ & \multicolumn{2}{|c}{ Sauerstofferbrauch } \\
\cline { 4 - 5 } & pro m Weg & $\begin{array}{c}\text { pro kg Gewicht } \\
\text { und m Weg }\end{array}$ \\
\hline \multirow{2}{*}{26. Okt. } & I & $\mathbf{1 4 5 , 5}$ & 15,928 & 0,219 \\
& III & 140,5 & 16,783 & 0,231 \\
& III & 135,74 & 16,215 & 0,223 \\
& IV & 137,09 & 15,563 & 0,214 \\
& V & 143,68 & 15,953 & 0,219 \\
& VI & $\mathbf{1 3 8 , 1 2}$ & 17,608 & 0,242 \\
\hline Mittel . . . . . . . & $\mathbf{1 1 4 0 , 1 1}$ & $\mathbf{1 6 , 3 4 2}$ & 0,225
\end{tabular}

Hier ist der Verbrauch für die gleiche Arbeit ein höherer, was aber nichts gegen die Gültigkeit des oben ausgesprochenen Gesetzes beweist. Für Leo Zuntz war diese Marschgeschwindigkeit die maximalste, welche von ihm erreicht werden konnte, und wir wissen, dass mit steigender Geschwindigkeit der Verbrauch pro Meter Weg und Kilogramm Gewicht ansteigt. Es ist daher nicht zu verwundern,

1) S. 26 und 27. Verlag von Hirschwald, 1899. 
wenn der Sauerstoffverbrauch bei L. Zuntz pro Meter Weg und Kilogramm Gewicht bei annähernd gleicher Geschwindigkeit wie diejenige, welche die Dauergänger gewählt haben, um $9 \%$ höher ist. In diesen $9 \%$ Ersparnis haben wir eben die Folgen des Trainings der Dauergänger zu erblicken. Erstaunlich kann nur sein, dass dieser Unterschied ein so geringer ist. Doch wird man dabei bedenken müssen, dass mehr oder weniger jeder kräftige junge Mann gerade auf die Körperbewegung des Gehens trainiert ist und besonders Leo $\mathrm{Zuntz}$ war ein rüstiger und geübter Fussgänger.

Betrachten wir noch einmal die kalorischen Werte für den Verbrauch pro Kilogramm und Meter zurückgelegten Weges bei unseren beiden Versuchspersonen. Wenn wir die Mittelwerte aus den zeitlich zusammengehörigen Versuchen berechnen, so finden wir folgende Zahlen:

\begin{tabular}{|c|c|c|c|}
\hline $\begin{array}{l}\text { Versuchs- } \\
\text { person }\end{array}$ & Datum & Nr. & $\begin{array}{l}\text { Kalorisches Äquivalent } \\
\text { d. Marscharbeit pro m Weg } \\
\text { und kg Gewicht }\end{array}$ \\
\hline M. & 25. April & $\begin{array}{l}\text { I } \\
\text { II } \\
\text { III }\end{array}$ & $\begin{array}{l}0,952 \\
1,000 \\
0,971\end{array}$ \\
\hline \multirow[t]{2}{*}{ B. } & 22. & $\begin{array}{l}\text { I } \\
\text { II } \\
\text { III }\end{array}$ & $\begin{array}{l}0,906 \\
1,002 \\
0,986\end{array}$ \\
\hline & 26. " & $\begin{array}{l}\text { I } \\
\text { III }\end{array}$ & $\begin{array}{l}0,965 \\
0,967 \\
0,974\end{array}$ \\
\hline
\end{tabular}

Wenn man diese einzelnen Zahlen vergleicht, so fällt für die Versuche bei M. am 25. und diejenigen von B. am 22 . der höhere Verbrauch bei Marsch II gegenüber demjenigen bei Marsch I auf. Wenn dieser Mehrverbrauch eine Folge von Ermüdung ist, so muss dieselbe doch eine auffallend geringe gewesen sein, weil er durch Nahrungsaufnahme annähernd kompensiert werden konnte. Dies geht aus dem Absinken der Werte für den Versuch III hervor, welcher nach mehr oder minder reichlicher Nahrungsaufnahme, aber auch nach einem weiteren Marsche von $24 \mathrm{~km}$ gewonnen worden ist. Immerhin zeigt sich der Verbrauch in Versuch III gegenüber dem in Versuch I durchweg gesteigert. In dem Versuch an B. vom 26. April zeigen Versuch I und II fast identische Werte. Erst Versuch III weist eine geringe Steigerung auf. 
Eine stetige Erfahrung bei allen diesbezüglichen Versuchen ist die Zunahme des Verbrauches mit wachsender Geschwindigkeit. Dieselbe ist von Katzenstein ${ }^{1}$, Zuntz und Schumburga ${ }^{2}$, Leo $\mathrm{Zuntz}{ }^{3}$ ) für den Menschen, von Zuntz und $\mathrm{Hagemann}{ }^{4}$ ) für das Pferd festgestellt worden, während in den Versuchen an Hunden sich diese Regel allerdings bisher nicht bestätigt hat ${ }^{5}$ ).

Auch bei diesen besttrainierten Männern, welche wir untersuchen konnten, zeigt sich das Ansteigen des Verbrauches für erhöhte Geschwindigkeit. Diesbezüglich liegen zwei Versuche an dem Vegetarier M. vor, in welchen die Marschgeschwindigkeit derartig gesteigert wurde, dass auch dieser Dauergänger das Tempo als ein sehr schnelles empfand. (Siehe nebenstehende Tabelle.)

Wir finden demaach:

bei einer Geschwindigkeit von $139 \mathrm{~m}$ in der

Minute einen Verbrauch von $979 \mathrm{kal}$. pro

Kilometer Weg und Kilogramm Gewicht, bei einer Geschwindigkeit von $177 \mathrm{~m}$ in der

Minute einen Verbrauch von 1169 kal. pro

Kilometer Weg und Kilogramm Gewicht.

Es wächst demnach der Verbrauch für eine

Vermehrung der Geschwindigkeit um $38 \mathrm{~m}$ pro Minute um 90 kal. pro Kilometer Weg und Kilogramm Gewicht.

Also für $1 \mathrm{~m}$ pro Minute um $5 \mathrm{kal}$.

1) Über die Einwirkung der Muskeltätigkeit auf den Stoffwechsel des Menschen. Pflüger's Arch. Bd. 49. 1891.

2) 1. c. S. $284 \mathrm{ff}$.

3) $1 . \mathrm{c}$.

4) 1. c. S. $309-315$.

5) N. Zuntz, Einfluss der Geschwindigkeit, der Körpertemperatur und der Übung auf den Stoffverbrauch bei Ruhe und Muskelarbeit. Pflüger's Arch. Bd. 95 S. 207. 1903.

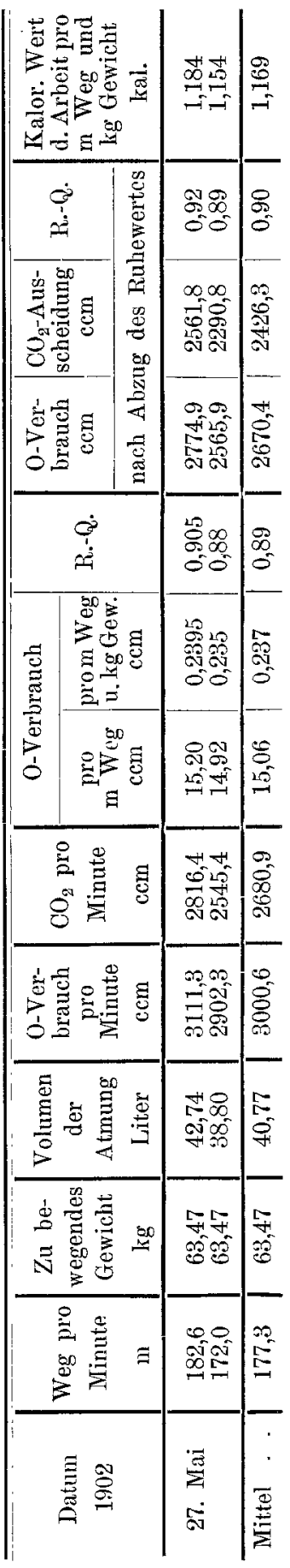


Vergleichen wir dieses Resultat mit den Daten, welche Zuntz und Schumburg aus dem bisher vorhandenen Material zusammengestellt haben (l. c. S. 287). Zuntz und Schumburg hatten bei ihrer Versuchsperson B. die Geschwindigkeit zwisehen Minutenwerten von $62,71 \mathrm{~m}$ und $89,06 \mathrm{~m} \mathrm{Weg}$, bei Versuchsperson P. zwischen $53,58 \mathrm{~m}$ und $93,33 \mathrm{~m}$ Weg variiert. Sie fanden bei B. für die Zunahme der Geschwindigkeit um $1 \mathrm{~m}$ eine Steigerung des Verbrauchs um 4,8 kal., bei P. um 2,3 kal. In gleicher Grössenordnung wie der Wert bei P. liegt die Steigerung des Verbrauches bei gleicher Geschwindigkeit für Leo $\mathrm{Zuntz}$. Dieselbe betrug zwischen 60 und $100 \mathrm{~m}$ Minutenweg 2,4 kal. pro Meter Geschwindigkeitszuwachs. Wesentlich grösser dagegen war sie bei L. Zuntz zwischen 100 und $143 \mathrm{~m}$ Minutenweg. Hier stieg der entsprechende Mehrverbrauch auf $10 \mathrm{kal}$, er ist also doppelt so gross wie derjenige, welchen wir trotz der viel grösseren Geschwindigkeit bei dem Dauergänger M. ermittelt haben.

Die Steigerung, welche die Erhöhung der Marschgeschwindigkeit für die gleiche Arbeitsleistung erfordert, und welche also besagt, dass mit Ansteigen der Gehgeschwindigkeit die Marscharbeit unökonomischer geleistet wird, tritt auch deutlich hervor, wenn wir die beiden Versuche an Herm M. mit erhöhten Marschgeschwindigkeiten untereinander vergleichen. Denn wie aus obenstehender Tabelle hervorgeht, finden wir für eine Marschgeschwindigkeit

von $172 \mathrm{~m}$ in der Minute einen Verbrauch von 1154 kal.

"183" " " " " 1184 "

Das bedeutet also für einen Zuwachs von $11 \mathrm{~m}$ Minutengeschwindigkeit einen Anstieg des Verbrauches um $30 \mathrm{kal}$, also pro Meter Weg um 2,7 kal. Dieser Mehrverbrauch ist beträchtlich geringer als der zwischen $139 \mathrm{~m}$ und $172 \mathrm{~m}$. Dies ist erklärlich, weil der Versuch mit einer Geschwindigkeit von $183 \mathrm{~m}$ pro Minute dem anderen zeitlich vorherging. Dieser erste Versuch strengte die Versuchsperson ersichtlich an und bewirkte wohl eine schnell eintretende Ermüdung, durch welche der Verbrauch im zweiten Versuche gesteigert worden sein mag.

Der Wettmarsch selbst wurde am 18. Mai 1902 früh von Dresden aus begonnen. Er bedeutete einen eklatanten Sieg des Vegetariers M. Derselbe verrichtete eine kolossale und meines Wissens auf diesem Gebiete einzig dastehende Leistung, indem er den Weg Dresden-Berlin, eine Strecke von $202 \mathrm{~km}$, in der Zeit von 
26 Stunden 58 Minuten absolvierte. Über die Einwirkung dieser enormen Muskelleistung auf das körperliche Befinden und die geistigen Funktionen des jungen Mannes haben $\mathrm{Al} b \mathrm{~b}$ und i $\mathrm{ch}$ bereits berichtet. Ich beschränke mich daher hier auf einige kurze Bemerkungen. Ich erwartete Herrn M. zunächst auf der Zwischenstation Jüterbog, $134 \mathrm{~km}$ von Dresden. Dort langte er als erster an. Sein Gesicht war blass, die Lippen cyanotisch. Er war ausserordentlich erregt. $\mathrm{Zu}$ eingehender Untersuchung konnte die Zeit nicht erübrigt werden. Erst nach seiner Ankunft in Berlin konnte Herr M. sorgfältiger untersucht werden. Dabei ergab sich, dass die Gesichtsfarbe blass, die Lippen cyanotisch waren. Die Temperatur im Rectum $38,2^{\circ}$, der Puls klein, fast fadenförmig 110. Der Harn enthielt Eiweiss und Blut, granulierte und hyaline Zylinder, spärliche Nierenpithelien. Die Herztöne waren leise, aber rein. Eine zwei Stunden nach der Ankunft von Herrn Dr. Levy-D orn vorgenommene Röntgenaufnahme zeigte normale Herzgrenzen.

Sensibilitätsprüfungen und Prüfungen des Zahlengedächtnisses ergaben eine balbe Stunde nach der Ankunft keine wesentlichen Veränderungen gegenüber den Befunden, welche wir in der Zeit des Trainings erhalten hatten. Überhaupt liessen die geistigen Funktionen nicht die geringste Einbusse erkennen. Nach der Rückkehr in seine Wohnung schlief M. etwa zwei Stunden und beschäftigte sich dann eifrig mit Korrespondenzen und geistiger Arbeit.

Der Gemischtkostler B. dagegen fiel vollkommen ab und gab den Kampf auf, noch bevor er die Hälfte des Weges zurückgelegt hatte.

Es ist vielleicht von Interesse, sich ein Bild zu machen von der Arbeitsleistung, welche der Vegetarier M. bei seinem Marsche vollführt hat. Natürlich lassen sich diese Werte nur in groben Umrissen feststellen, doch genügen die vorhandenen Tatsachen wohl sicherlich, um eine ungefähre Anschauung von der bei dem Marsche geleisteten Arbeit zu geben. M. legte in 26 Stunden 58 Minuten $202 \mathrm{~km}$ zurück. Das entspricht einer Minutengesehwindigkeit von $125 \mathrm{~m}$. Diese Geschwindigkeit ist etwas geringer als diejenige, für welche in den Versuchen auf der Tretbahn die oben angegebenen Werte gewonnen wurden. Dort betrug die geringste Geschwindigkeit $135 \mathrm{~m}$ in der Minute. Man wird aber sicher nicht $\mathrm{zu}$ hoch gehen, wenn man für die Berechnung des Kraftverbrauches die mittleren, bei M. für eine Geschwindigkeit von $139 \mathrm{~m}$ pro Minute 
ermittelten Werte zugrunde legt. Denn es wurden doch während des Marsches geringe Pausen für Nahrungsaufnahme usw. eingeschaltet. Vor allem aber wurde der erste Teil des Mar'sches sicher in viel schnellerem Tempo zurückgelegt, als es dem Durchschnitt entspricht, während sich im zweiten Teil zweifellos die Erhöhung des Kraftverbrauches durch Ermüdung geltendgemacht haben muss. Bei einer Geschwindigkeit von $139 \mathrm{~m}$, welche wir demnach der weiteren Berechnung zugrunde legen wollen, betrug nach den Versuchen auf der Tretbahn der Sauerstoffverbrauch pro Kilometer 12,95 Liter. Demnach berechnet sich der Gesamtverbrauch für den Marseh (202 km) auf 2616 Liter Sauerstoff. In gleicher Weise erhalten wir eine Ausscheidung von 1990 Liter Kohlensäure.

Die Gesamtstickstoffausscheidung während des Marsches betrug im Harn und Schweiss $21,51 \mathrm{~g} \mathrm{~N}$. Dem estsprechen 124 Liter $\mathrm{O}_{2}$, 99 Liter $\mathrm{CO}_{2}$ und 570 Kalorien. Es bleiben demnach 2492 Liter $\mathrm{O}_{2}$ und 1893 Liter $\mathrm{CO}_{2}$ für die Verbrennung von Kohlehydraten und Fetten. Der respiratorische Quotient beträgt 0,76. Bei Fettund Kohlehydratverbrennung entspricht einem Sauerstoffverbrauch von 2492 Liter und R.-Q. 0,76 eine Wärmeproduktion von 11842 Kalorien. Der kalorische Wert der Gesamtmarscharbeit hetrug also $11842+570=12412$ Kalorien oder, in mechanischem Maass ausgedrückt, $5275100 \mathrm{mkg}$. Da nach ühereinstimmenden Resultaten der meisten diesbezüglichen Untersuchungen etwa ein Drittel ${ }^{1}$ ) der umgesetzten Energie für nutzbare Arbeit verwendet werden kann, so ergibt sich daraus, dass $M$. während des Marsches eine nutzbare Arbeit von $1758000 \mathrm{mkg}$ geleistet hat. Da diese Arbeit in 26 Stunden und 58 Minuten vollführt wurde, so berechnet sich daraus eine 24 stündige Leistung von ca. $1564000 \mathrm{mkg}$.

So ausserordentlich gross diese Leistung auch ist, so ist es doch nicht die grösste 24 stündige Arbeit, welche bisher beobachtet worden ist. Wenn auch die Anbaltspunkte für die Berechnung der Arbeitsleistungen bei den einsehlägigen Versuchen ziemlich mangelhaft sind, so genügen sie doch, um festzustellen, dass dieselben noch grösser sind

1) Atwater gibt wesentlich niedrigere Werte für die Ausnutzung der Energie für mechanische Arbeit, nämlich nur ca. $20 \%$. Es kann das wohl lediglich an einer ungünstigen Anordnung seines Ergometers liegen. Auch Katzenstein fand ja bei Dreharbeit eine ganz ähnliche schlechte Ausuutzung der Energie. 
als die von M. vollführte Dauerleistung. Die eine dieser Maximalleistungen wird dargestellt durch den Rekord, welchen der bekannte Rennfahrer Miller auf dem Sechstagerennen in New York aufgestellt hat. Über diese Muskelleistung sind wir durch die Beobachtungen Atwater's ${ }^{1}$ ) gut unterrichtet. Am ersten dieser sechs Tage legte Miller 441,8 miles auf seinem Rade zurück. Dies entspricht einer Leistung von $710,9 \mathrm{~km}$. Unter Zugrundelegung der Daten von Le o Zuntz, welche natürlich, da Respirationsversuche an Miller nicht vorliegen, nur einen annähernden Begriff der Leistung geben köunen, habe ich die 24 stündige Arbeitsleistung Miller's auf $3288000 \mathrm{mkg}$ berechnet. Allerdings wird man von diesem Werte wohl noch einige Abstreichungen machen müssen, welche in erster Linie durch den maximalen Training Miller's gegenüber Leo Zuntz bedingt sind, ferner auch durch die Erschwerung der Arbeitsleistung bei Leo Zuntz durch die auf der Lenkstange angebrachte Gasuhr und Verbindung des Mundes mit der letzteren. Auch die Qualität des Rades wird eine geringe Minderung der Arbeit bei Miller bedingt haben. Wenn man aber auch für diese Abzüge nach Magnus-Levy ganz maximale Werte einsetzt, so ergibt sich immer noch für den ersten Tag des Rennens für Miller ein Minimalwert von $2100000 \mathrm{mkg}$. Also nicht unbeträchtlich mehr als der 24 Stundenwert der Arbeit des Herrn M. In annähernd gleicher Grössenordnung wie die Arbeitsleistung Miller's liegt der Wert, welchen $\mathrm{Tissié}^{2}$ ) bei einem Radrekord beobachtete. Dort legte der betreffende Radfahrer in 24 Stunden $620 \mathrm{~km}$ zurück, was einer Arbeitsleistung von etwa $3169000 \mathrm{mkg}$ unter Zugrundelegung der Werte von Leo Zuntz entsprechen dürfte.

Wenn wir uns fragen, welche Gründe wohl für den glänzenden Sieg des Herrn M. über den Herrn B. geltendgemacht werden können, und ob dieselben auf Konto der vegetarischen Ernährung zu setzen sind, so müssen wir zunächst die sehr auffallende Tatsache beachten, dass nicht nur M. als erster Sieger anlangte, sondern bei diesem Marsche die fünf ersten Sieger als Vegetarier bezeichnet

1) The effect of severe and prolonged muscular work on food consumption, digestion, and metabolism von W. 0 . Atwater und H. C. Sherman. Washington 1901.

2) Observations physiologiques concernants un record velocipedique. Arch. de phys. norm. et path. t. 24 . 1894 . 
werden. Es ist allerdings dabei zu bemerken, dass mehrere derselben in die Gruppe der Laktovegetarier zu rechnen sind, wovon ich mich bei meinen Beobachtungen des Dauermarsches selbst überzeugen konnte. Es liegt daher in der Tat die Frage nahe, ob etwa die vegetarische Diät den menschlichen Organismus für Dauerleistungen besonders befähige. Diese Anschauung ist wiederholt von vegetarischer Seite vertreten worden, hauptsächlich in Analogie mit den Leistungen der herbivoren Tiere, welche dem Menschen ja gerade durch ihre ausdauernde grosse Arheitsfähigkeit nützlich werden, während die Karnivoren zu grösseren Augenblicksleistungen befähigt sein sollen. Auch Bälz schliesst sich dieser Anschauung an. Die Behauptung, dass fleischfressende Tiere weniger zu Dauerleistungen geeignet sind als die Herbivoren, ist wohl kaum zutreffend. Mit Recht macht $\mathrm{Albu} \mathrm{u}^{1}$ ) nach $\mathrm{Ha}$ a c h e corne darauf aufmerksam, wie ausserordentlich gross die Dauerleistung der Eskimohunde in den Polargegenden ist. Andrerseits aber können für die Anschauung, dass vegetarische Diät zu körperlichen Dauerleistungen besonders befähige, die ausserordentlichen Dauerleistungen angeführt werden, welche Bälz von seinen vegetarisch lebenden japanischen Wagenziehern beschreibt, und welche auch von anderer Seite in Berichten über die Leistungen japanischer und chinesischer Kulis Bestätigung gefunden haben. Doch spricht gegen die Anschauung, dass eine gemischte Kost erhebliche Dauerleistungen nicht ermögliche, der Unstand, dass bei den grössten derartigen Leistungen, über welche wenigstens unsere wissenschaftliche Literatur verfugt, die eben zitierten Rennen Miller's und der Versuchsperson Tissié's, die Errährung keiue vegetarische gewesen ist.

Gerade aber auch auf dem Gebiete des Gehsports sind die ausserordentlichen Leistungen des bekannten Fussgängers Weston zu nennen, welcher seinerzeit von Flint ${ }^{2}$ ) und später von $\mathrm{Pavy}^{3}$ ) eingehend beobachtet worden ist. Die Leistungen dieses Professionals stehen kaum hinter denjenigen der Versuchsperson M. zurück. So legte er in den Versuchen, welche Pavy mitgeteilt hat, in einem zweitägigen Marsche täglich 90 miles $=$ ca. $149 \mathrm{~km}$ pro Tag, zurück, in einem weiteren dreitägigen Versuche 88 miles pro Tag $=$

1) 1. c. S. 80 .

2) New York Med. Journal 1870.

3) Lancet 1896. 
etwa $142 \mathrm{~km}$. Während dieser Versuchsreihe wurde ebenfalls eine nicht vegetarische Diät genommen.

Es kann danach die vegetarische Diät an sich nicht als ausschlaggebend für den Sieg der Vegetarier angesehen werden. Wir müssen uns also nach anderen Ursachen umsehen, welche den eklatanten Erfolg der Vegetarier zu erklären geeignet sind. Hier werden wir wiederum auf die Erwägung zurückgreifen müssen, welche wir bei der verhältnismässig erheblichen Kraftleistung des Hauptmanns H. am Schlusse des Versuchs im Einklange mit den Erfahrungen am Hungerer Succi erörtert haben: die Wirkung des Willens auf die Energieentfaltung. In der Tat ist es von vornherein begreiflich, dass in dieser Beziehung der Vegetarier den Gemischtkostlern gegenüber sich überlegen erweist. Die Innehaltung einer streng vegetarischen Diät ist heutzutage mit einer Fülle von Fntbehrungen und Schwierigkeiten verbunden, welche durch Selbstüberwindung, Überwindung gesellschaftlicher Hindernisse und nicht zum mindesten zahlreicher Bekrittelungen gesetzt werden. Man muss daher von vornherein als sicher annehmen, dass ein jeder, welcher eine streng vegetarische Diät durchzuführen imstande ist, schon deshalb über eine erhöhte Willenskraft verfügt. Hierzu kommt, dass gerade die Schwierigkeiten, mit welchen die Anhänger dieser Kostform bei der Durchführung ihrer Prinzipien zu kämpfen haben, nicht nur den Willen stärken, sondern auch geradezu den Fanatismus erwecken. Zur Stïtze dieser Behauptung braucht man nur einen Blick auf die vegetarische Literatur zu werfen, um zu sehen, in welch ausserordentlicher Weise der Fanatismus sich der Vorkämpfer dieser Richtung bemächtigt hat. Was aber die durch Fanatismus belebte Willenskraft an körperlichen und geistigen Leistungen verrichten kann, dafür liefert die Weltgeschichte mehr als ein Beispiel. Es ist ja auch ersichtlich, dass während es den Gemischtkostlern bei diesem Kampfe lediglich auf eine sportliche Leistung ankam, die Vegetarier gleichsam einen Kampf für ibre Lebensideale ausfoclıten und dadurch ihren Gegnern moralisch überlegen wareu. Diese Gesichtspunkte scheinen mir zu erklären, warum fünf Vegetarier (wenn wir die Laktovegetarier hier mitrechnen wollen) zuerst das Ziel passierten.

Dagegen scheint mir diese Überlegung nicht geeignet zu sein, den Sieg des Herrn M. über den Herrn B. zu erklären. Ein Mann, welcher, wie letzterer, die grössten sportlichen Erfolge errungen hatte, 
der Vertreter verschiedener Meisterschaften und Rekorde, ja eines Weltrekordes ist, ist ebenfalls naturgemäss bei einem derartigen Sportkampfe von grösster Willensenergie und besonderem Ehrgeize beseelt. Wir müssen uns also, um das völlige Versagen dieses Herrn zu erklären, nach anderen Gründen umsehen.

Da wird naturgemäss in erster Linie der Umstand in Betracht kommen, dass Herr M. als strenger Vegetarier auch stets abstinent gewesen ist, während Herr B. nachweislich während des Marsches selbst eine Flasche Wein mit Wasser verdünnt zu sich genommen hat. Die Fntscheidung der Frage, ob die Wirkung des Rotweins, welchen B. unterwegs trank, an seinem Abfall mit schuld gewesen sei, ist nicht leicht. Sie führt uns auf das ziemlich schwierige Problem der Wirkung des Alkohols auf die Muskelarbeit. Im allgemeinen wird man geneigt sein, bei langdauernden starken körperlichen Leistungen Alkoholgenuss nach Möglichkeit zu vermeiden, da zahlreiche Erfahrungen dafür sprechen, dass die Steigerung der körperlichen Leistungsfähigkeit, welche durch den Alkohol erreicht wird, nur eine vorübergehende ist und einer um so stärkeren Depression weicht. Daraus ergibt sich die Folgerung, dass bei körperlichen Arbeitsleistungen der Alkohol nur dann zu empfehlen ist, wenn bei starker Ermüdung nur noch eine geringe letzte Anstrengung von dem Ziele trennt, so dass die auf den Alkoholgenuss folgende Verminderung der Arbeitsfähigkeit, welche durch die Wirkung auf das Zentralnervensystem bedingt ist, nicht mehr ihren schädigenden Einfluss entfalten kann.

In guter Übereinstimmung mit diesen Erfahrungstatsachen stehen die Resultate der ergographischen Versuche von Frey $^{1}$ ), welche derselbe meiner Ansicht nach siegreich gegen die Angriffe von Destrée, Forel und Kräpelin verfochten hat. Aus den Versuchen Frey's ging hervor, dass der Alkohol auf den nicht ermüdeten Muskel einen schädlichen Einfluss derart ausübt, dass er die maximalen Arbeitseinzelleistungen wesentlich herabsetzt. Dagegen wurde das Ermüdungsgefühl durch den Alkoholgenuss bekämpft, und die Arbeit des ermüdeten Muskels erschien infolgedessen leichter. Man wird nicht leugnen können, dass diesen Versuchen freilich die Unsicherheiten der ergographischen Methode anhaften, und es ist

1) Alkohol und Muskelermüdung. Verlag von Franz Deuticke, Leipzig und Wien 1902. 
daher ein dringendes Erfordernis, die Einwirkung des Alkohols auf die Muskelarbeit durch Stoffwechselversuche zu prüfen. Hierüber liegen meines Wissens bisher nur die umfangreichen und exakten Versuche von Atwater and Benedict ${ }^{1}$ ) am Menschen vor. Diese Autoren drücken sich ausserordentlich vorsichtig in ihren Resultaten aus, indem sie die Schlussfolgerung ziehen, dass die Ausnutzung des Alkohols für Muskelarbeit sehr wahrscheinlich, aber durch ihre Versuche nicht exakt bewiesen sei. Dass dagegen ihre Versuche keinen Anhaltspunkt dafür gegeben hätten, dass die Energie des Alkohols nicht für die Arbeit ausgenutzt werden könne. Demgegenüber ist auf die bekannten Versuche von $\mathrm{Chauveau^{2 }}$ ) am Hunde ein Wert nicht zu legen. Dass diese Versuche die Unzulänglichkeit des Alkohols für die Muskelarbeit nicht beweisen, ist von mir, ganz besonders aber von Rosemann in einer ganzen Anzahl von Publikationen gegenüber dem Widerspruche von Kassowitz auseinandergesetzt worden. Wenn man aber auch nach unseren heutigen Kenntnissen anzunehmen geneigt ist, dass der Alkohol seine chemischen Spannkräfte in den Dienst der Muskeltätigkeit zu stellen imstande ist, so wird man die Gefahren, welche der Alkoholgenuss bei starken körperlichen Leistungen bietet, dennoch nicht gering schätzen dürfen. Dass dieselben sehr gross sind in all denjenigen Fällen, in denen nicht die vorsichtige Grenze innegehalten wurde, geht ja gerade aus den erwähnten Versuchen von Chauveau nach Rosemann's und meiner Ansicht auf das evidenteste hervor. Man würde daher wohl jeden, der eine erhebliche körperliche Anstrengung zu leisten hat, nach Möglichkeit von dem Genuss des Alkohols zurückhalten.

Dennoch aber scheint mir, dass die geringe Menge Alkohol, welche unsere Versuchsperson während des Marsches zu sich nahm, für das schlechte Resultat nicht verantwortlich gemacht werden kann. Dagegen spricht der Umstand, dass B. auch während des Trainings Wein zu sich nahm, und zwar, wie die Tabelle auf S. 576 ergibt, durchaus nicht ganz unerhebliche Mengen. Dabei aber arbeitete er bei den Tretbahnversuchen durchaus ökonomisch, und seine Leistung stand sicherlich gegenüber derjenigen seines Rivalen nicht erheblich zurück.

1) An experimental inquiry regarding the nutritive value of alcohol. Washington 1902.

2) Compt. rend. t. 132 p. 65 . Ebenda 1901 p. 110. 
Auch unsere Erfahrungen bei den anderen Dauerleistungen sprechen entschieden dagegen, anzuriehmen, dass geringe Mengen Alkohol bei derartigen Gelegenheiten eine allzu schädigende Wirkung ausüben. So sagt Atwater allerdings von Miller "he never uses alcohol or tobacco in any form, and his system of training involved no special deprivations". Bei der Angabe der täglich genommenen Nahrungsmittel finden wir aber, dass Miller am ersten Tage, an welchem er die obenerwähnte grösste Arbeitsleistung von 441,8 miles leistete, über 7 Liter Kumys trank. Bekanntlich ist Kumys ein alkoholhaltiges Milchgetränk. Die Analyse ergab allerdings einen verhältnismässig sehr niedrigen Wert von $0,52 \%$ Alkokol, immerhin eine doch nicht ganz zu vernachlässigende Menge. Weit grösser dagegen seheinen die Mengen Alkohols zu sein, welche die Versuchsperson Tissié's bei ihrem Rekord aufgenommen hat. Leider wird die Menge des genossenen Rums und Champagners nicht angegeben, Aber schon die Wahl der Getränke weist darauf hin, dass die Alkolaufnahme keine ganz geringe gewesen sein kann. In der Tat erwähnt auch Tissié, dass der Aufnahme des Rums eine vorübergehend erhöhte Kraftentfaltung folgte, auf welche aber schnell die Reaktion eintrat.

Alle diese Überlegungeu haben nicht den Zweck, die Frage nach der Wirksamkeit des Alkohols bei der Muskelarbeit zu entscheiden. Dieselbe kann nur durch weiteres Beibringen experimentellen Materials gelöst werden, wobei besonders die bisher noch gar nicht eingehend untersuchte Frage zu berücksichtigen sein würde, wie denn der Alkohol bei der Muskelleistung alkonol gew ohnter Individuen wirkt. Denn bisher sind fast stets dauernde oder vorübergehende Abstinenzler zu diesen Versuchen benutzt worden, eine Versuchsanordnung, die sicherlich ihre volle Berechtigung hatte von dem Gesichtspunkt aus, die Alkohol wirkung zunächst einmal möglichst rein festzustellen.

Die Überlegungen, welche wir hier angestellt haben, sollen lediglich dazu dienen, die Frage zu entscheiden, ob die Niederlage des Herrn B. auf den Alkoholgenuss zurückzuführen ist. Ich glaube, dass man nach dem Gesagten diese Annahme als höchst unwahrscheinlich wird bezeichnen müssen. Denn selbst, wenn die schädliche Reaktion des Alkohols eingetreten ist, so kann dieselbe bei den ziemlich geringen Mengen, welche Herr B. nahm, keine dauernde gewesen sein und hätte ihn daher, da er in Gemeinschaft 
mit dem Vegetarier M. seinen übrigen Konkurrenten weit voraus war, sicherlich nicht abhalten können, wenn auch nicht den Sieg davonzutragen, so doch einen Platz bei dem Dauermarsch zu belegen. Ich glaube, dass wir der Wahrheit am nächsten kommen werden, wenn wir als Grund für die Niederlage B.'s gegenüber dem Vegetarier M. gelten lassen, dass letzterer in der Tat dem ersteren an Muskelkraft und Leistungsfähigkeit überlegen gewesen ist, was ja auch durch den höheren Sauerstoffverbrauch des Herrn M. bei absoluter Körperruhe gestützt wird. Dass aber Herr B. dann völlig abfiel und nach kurzer Zeit den Wettbewerb aufgab, ist wohl leicht daraus zu erklären, dass seine Willenskraft gebrochen wurde, als er sehen musste, dass ihm der Preis des ersten Siegers zweifellos versagt war. Die eintretende Entmutigung liess ihn dann melrr und mehr zurückbleiben und führte ihn schliesslich dazu, einen Kampf aufzugeben, dessen Ausgang für ihn als einen Sportsman allererster Klasse auf jeden Fall ein beschämender sein musste.

Vielleicht ist es nicht ohne Interesse, auch die Wärmeregulation auf dem Marsche einer kurzen Betrachtung zu unterziehen, soweit unsere Daten einen Einblick in dieselbe gewähren. Zu diesem Zwecke habe ich folgende Berechnung angestellt:

Es wurde zunächst bei jedem Marsche während der Versuchszeit der insensible Gewichtsverlust festgestellt. Dieser wurde gefunden durch Abzug des um das Gewicht der Ausscheidungen vermehrten Endgewichts der Versuchsperson nach dem Marsche von dem um das Gewicht der aufgenommenen Speisen vermehrten Anfangsgewichte vor dem Marsche. An diesem Perspirationswerte ist eine stets nur sehr geringe Korrektur anzubringen für den Gewichtsunterschied des aufgenommenen Sauerstoffes und der ausgeschiedenen Kohlensäure. Die so gewonnene Zahl wird als Wasserverlust in Rechnung gestellt. Durch Multiplikation mit der Verdunstungswärme des Wassers erhalte ich das kalorische Äquivalent dieses Wasserverlustes. In derselben Weise wie oben wird aus den Daten der Respirationsversuche das kalorische Äquivalent der Marscharbeit berechnet. Von diesem Werte werden dje durch Wasserverdunstung abgegebenen Kalorien abgezogen und so der Wert der durch Strahlung und Leitung abgegebenen Wärmemenge ermittelt.

Auf diese Weise kommen wir zu folgenden Daten:

Der insensible Gewichtsverlust des Herrn M. am 25. April 1902 betrug von $7^{\text {h }}-11^{\text {h }} 15^{\prime}$ a. 2,06 kg. Während der Zeit legte er 
$24,75 \mathrm{~km}$ auf der Chaussee und 2,911 km auf der Tretbahn (Versuch I a und Ib) zurück, in Summa 27,661 km. Um den kalorischen Wert dieser Marscharbeit festzustellen, wurden die bezïglichen Angaben des Versuchs $\mathrm{Ia}$ und Ib gemittelt. Dann erhalte ich als kalorischer Äquivalent der Marscharbeit unter Benutzung der S. 575 angeführten Rechenmethode 1718 Kalorien. Während des ganzen Marsches wurden aufgenommen $27 ; 661 \times 12,97=359$ Liter $\mathrm{O}_{2}$ und ausgeschieden $27,661 \times 10,36=287$ Liter $\mathrm{CO}_{2}$. 359 Liter $\mathrm{O}_{2}$ wiegen $513 \mathrm{~g}$. $287 \mathrm{Liter} \mathrm{CO}_{2}=562 \mathrm{~g}$. Es wurden also mit der Kohlensäure $49 \mathrm{~g}$ mehr ausgeschieden, als mit dem Sauerstoff aufgenommen war. Diese $49 \mathrm{~g}$ sind von dem insensiblen Verlust abzuziehen, um den Wasserverlust zu erhalten. Dieser beträgt demnach $2,011 \mathrm{~kg} .1 \mathrm{~kg}$ Wasser verbraucht bei der Verdampfung 580,8 Kalorien, also 2,011 kg: $2,011 \times 580,8=1168$ Kalorien.

Es wurden also für den Gesamtmarsch verbraucht . 1718 Kal.

Kaloriseher Wert der Wasserverdunstung. . . . $1168 \%$
Also durch Strahlung und Leitung abgegeben. $.550 \mathrm{Kal}$. über die Wärmemenge hinaus, die der ruhende Organismus produziert.

Es wurden also $68 \%$ der durch die Arbeit produzierten Wärme auf dem Wege der Wasserverdunstung abgegeben.

Der Anteil der Wärme, welcher durch Verdunstung entfernt wird, ist natürlich ceteris paribus abhängig von den äusseren Umständen, in erster Linie der umgebenden Temperatur und der Luftbewegung. Auch die Feuchtigkeit der Luft spielt eine wesentliche, wenn auch nicht eindeutige Rolle. Am 25. April 1902 war die Temperatur im Mittel $+13^{\circ} \mathrm{C}$. Die Luft war sehr trocken, ca. $40 \%$ relative Feuchtigkeit. Der Tag war äusserst windstill, die Windstärke betrug 1 der diesbezüglichen meteorologischen Skala, d. h. es herrschte nur ein leiser Luftzug.

Ähnlich liegen die Verhältnisse beim zweiten Marsche des Herrn M., am 25. April. Bemerken möchte ich kurz, dass ich nur die respiratorischen Werte vom Versuch III a benutzt habe, nicht einen Durchschnitt von II b und III a. Grund dafür ist, dass zwischen Versuch II $b$ und dem Abmarsche die Hauptnahrungsaufnahme lag, so dass mir die Werte des Versuches III a diejenigen zu sein schienen, welche denen während des Marsches am nächsten stehen.

Ich erhielt so:

Gesamtwärmeproduktion . . . . . . 1654 Kal.

Durch Verdunstung abgegeben. . . . . . $989 n=60 \%$

Durch Strahlung und Leitung abgegeben . . 665 Kal. 
Die mittlere Temperatur während des Marsches betrug $16^{\circ}$. Die relative Feuchtigkeit war ganz ausserordentlich niedrig. Sie betrug nur $30 \%$. Der 25. April war der trockenste Tag des ganzen Monats. Windstärke 1.

In gleicher Weise habe ich diese Verhältnisse für Herrn B. berechnet. Ich habe dabei gefunden am 22. April 1902 für Marsch I:

Gesamtwärmeproduktion für den Marsch . . 1948 Kal.

Durch Verdunstung abgegeben . . . . . $983 n=50 \%$

Durch Leitung und Strahlung abgegeben . . 965 Kal.

Mittlere Temperatur $9^{\circ}$. Relative Feuchtigkeit $50 \%$. Windstärke 1 .

Für Marsch II:

Gesamtwärmeproduktion . . . . . . . . 1712 Kal.

Durch Wasserverdunstung abgegeben $\_. .1047,=61 \%$

Durch Strahlung und Leitung abgegeben . . 665 Kal.

Mittlere Temperatur $13{ }^{\circ}$. Relative Feuchtigkeit $50 \%$. Windstärke 2 (mässiger Wind).

Am 26. April, Marsch I:

Gesamtwärmeproduktion . . . . . . 1749 Kal.

Abgegeben durch Verdunstung . . . . . 1506 $n=86 \%{ }^{1}$ )

Durch Strahlung und Leitung abgegeben . 243 Kal.

Mittlere Temperatur $8,5^{\circ}$. Windstärke 2 (schwacher Wind). Die relative Feuchtigkeit der Luft schwankte während dieser Stunden in ganz aussergewöhnlicher Weise. Sie betrug im Mittel $50 \%$. Doch kamen Werte vor von $36 \%$ und entsprechende über $50 \%$.

Marsch II :

Gesamtwärmeproduktion . . . . . . $1727 \mathrm{Kal}$.

Abgegeben durch Verdunstung ..... $1050,=61 \%$

Durch Strablung und Leitung abgegeben . . 677 Kal.

Sehen wir von dem zweifelhaften Werte für B. am 26. April Marsch I $a b$, so lag der kalorische Wert der Schweisssekretion für Herrn M. und B. annähernd in der gleichen Grössenordnung, nämlich zwischen

1) Der Wert ist ein so ungewöhnlich hoher bei den herrschenden meteorologischen Verhältnissen, dass er verdächtig erscheint. Der Gewichtsverlust von B. während dieses Marsches war auffallend. (Siehe Tabelle S. 573.) Dabei brauchte B. pro Kilometer Marsch etwa die doppelte Zeit wie sonst. (Siehe Tabelle S. 576.) 
50 und $68 \%$ des bei der Marscharbeit produzierten Gesamtwärmeüberschusses. Doch waren die durch die Witterungsverhältnisse gegebenen Bedingungen bei den Märschen des M. einer Schweisssekretion günstiger als bei denen des Dauergängers B. Wenn trotzdem Herr M. nicht mehr schwitzte als B., so lag dies wohl an seiner zweckmässigeren Kleidung, welche derart gewählt war, dass die Luft gut durch die Kleider hindurchstreichen konnte, so dass das Schweisswasser auf der Haut selbst verdunstete. $\mathrm{ZuntZ^{1 }}$ ) weist darauf hin, dass die Wassersekretion durch die Haut, wie wir sie auch oben als Wasserverlust in Rechnung gestellt haben, nicht mit der wirklichen Wasserverdunstung identisch ist; denn je nach der Kleidung bleibt ein Teil des abgesonderten Schweisses in tropfbar flüssiger Form in den Kleidern zurück und kommt so für die Entwärmung des Körpers nicht in Betracht. Ein anderer Teil verdunstet in den äusseren Schichten und kommt infolgedessen der Entwärmung des Körpers nur wenig zugute. M. war während des Trainingmarsches mit porösen Unterkleidern bekleidet, B. dagegen führte die Trainingmärsche im gewöhnlichen Leinenhemd ohne Kragen in Jacke und Hose aus.

Auch während des Dauermarsches selbst war die Bekleidung M's. sehr zweckmässig Er trug eine dünne weite Leinenbose, welche bis zum Knie reichte und kurze Strümpfe, die die Waden frei liessen. Der Oberkörper war nur mit einem Netzhemd bedeckt. So war durch die Kleidung in gleicher Weise dafür gesorgt, dass die Abgabe dureh Leitung und Strahlung möglichst vollkommen war, als auch, dass die Verdunstung des abgesonderten Schweisses möglichst ergiebig und unmittelbar auf der Haut erfolgte.

So kummt es, dass die Schweisshildung bei M. während des Dauermarsches Dresden-Berlin eine auffallend niedrige war, wobei allerdings die niedrige Temperatur - ca. $8^{\circ} \mathrm{im}$ Mittel - und vor allem der Regen, welcher wiederholt eintrat, eine sehr wesentliche Rolle gespielt haben müssen.

Wie durch genaue Wägungen an Start in Dresden und al Ziel in Berlin festgestellt worden ist, betrug der gesamte Gewichts verlust von Herrn M. während des Marsches 3,385 kg. Der insensible Verlust stellt sich jedoch wesentlich höher, weil das Gewicht

1) Über die Wärmeregulation bei Muskelarheit. Vortrag, gehalten in der Balneologischen Gesellschaft. Deutsche Medizinal-Zeitung 1903 S. 3. 
der aufgenommenen Getränke und Speisen das des ausgeschiedenen Harnes und Kotes erheblich übertraf ${ }^{1}$ ). Wir fanden so einen insensiblen Verlust von $5,618 \mathrm{~kg}$.

Für den ganzen Marsch berechnet sich die Sauerstoffaufnahme auf ca. 2616 Liter, die Kohlensäureausscheidung auf ca. 1990 Liter. 2616 Liter $\mathrm{O}_{2}$ wiegen $3,741 \mathrm{~kg}$. 1990 Liter $\mathrm{CO}_{2}$ wiegen $3,792 \mathrm{~kg}$. Auf den respiratorischen Stoffwechsel ist demnach ein Gewichtsverlust von nur $51 \mathrm{~g}$ zu beziehen, was man bei einer doch nur angenäherten Berechnung wie die vorliegende vernachlässigen muss. Der Wasserverlust entspricht einer Wärmeabgabe von 3263 Kalorien. Der kalorische Wert der Gesamtarbeitsleistungbetrug wie oben berechnet, 12412 Kalorien. Durch Verdunstung wurde abgegeben 3263 Kalorien = $26 \%$; durch Strahlung und Leitung demnach 9149 Kalorien über den Ruhebedarf. Hierzu ist zu bemerken, dass die Wärmeabgabe durch Wasserverdunstung auf zwei verschiedenen Wegen erfolgt, nämlich einerseits durch die Wasserabgabe mit der Atemluft, andrerseits durch Schweissbildung. Nach einer Berechnung, welche ich auf Grund der Daten, welche Zuntz und Schumburg ${ }^{2}$ ) hierfür angeben, angestellt habe, ergibt sich, dass selbst von der geringen Wärmeabgabe durch Wasserverdunstung noch ca. $28 \%$ von den Atenwegen abgegeben wurden.

\section{Schlussbetrachtung.}

Betrachten wir noch einmal die Resultate, welche sich aus dieser Arbeit für die Bedeutung der vegetarischen Ernährung in physiologischer Hinsicht ergeben, so muss zunächst hervorgehoben werden, dass, nach den Erfahrungen und den Angaben der Versuchspersonen selbst, der strenge Vegetarismus meist nur vorübergehend als Nahrungsregime angewandt worden ist. So nährte sich selbst der Hauptmann $H$. nicht durchgehends streng vegetarisch, sondern nahm "dazwischendurch auch gekochte, gebratene und gebackene vegetarische Speisen sowie Milch und Butterbrot". Auch ist er nach dem Versuche zu gekochter vegetarischer Speisehauskost zurückgekebrt. Ähnlich teilte mir der vegetarische Dauergänger M.

1) Herr M. war auf dem Marsch von Radfahrern begleitet, welche für seine leiblichen Bedürfnisse sorgten, ihm die abgewogenen Speisen reichten und die Getränke abmassen sowie den Harn teils in Jüterbog, wo ich die Danergänger erwartete, teils in Berlin am Start ablieferten.

2) Zuntz und Schumbarg, 1. c. S. 203 . 
mit, dass, am Siegestage zu Hause angelangt, sein erstes gewesen sei, „einen mächtigen Topf saure Milch zu geniessen“.

Doch haben uns unsere Versuche und Betrachtungen wohl mit Sicherheit gelehrt, dass eine rein pflanzliche Kost, selbst rein pflanzliche Rohkosteinenkräftigen, jugendlichen Organismus auf böchster Stufe körperlicher und auch geistiger Frische und Leistungsfähigkeit zu erhalten vermag (Herr M.). Dennoch erscheint diese Diätform unzweckmäs.sig:

1. wegen der schlechten Ausnutzung der Kost, besonders aber der Eiweissstoffe. Diese tritt in allen mir bekannten diesbezüglichen Versuchen zutage derart, dass selbst im günstigsten Falle (Taniguti) der Stickstoffverlust im Kot ein ebenso grosser war als selbst bei der exzeptionell schlechtesten Ausnutzung gemischter Kost (Lö wy, Zuntz);

2. wegen der Reizlosigkeit der Kost;

3. wegen ihres grossen Volumens (Mori).

Doch lassen sich die Übelstände 1 und 3 durch Verwendung Kellog g'scher Präparate, 2 durch Anwendung von Würzstoffen, wie sie die Japaner erfunden haben, einigermassen bekämpfen.

Die Eiweissarmut der Pflanzenkost wird nur bei besonders unzweckmässiger Verwendung derselben (Hauptmann H.) als wesentlicher Einwand in Betracht kommen.

Von den Vorteilen vegetarischer Ernährung ist die Billigkeit derselben hervorzuheben.

Dagegen ist die Anschaung, dass die vegetarische Ernährung infolge ihres Mangels an Harnsäurebildnern der gewöhnlichen gemischten vorzuziehen sei, nicht erwiesen. Berechtigt ist der Hinweis auf die geringe Zufubr von Purinkörpern dagegen gegenüber einer übermässigen Fleischkost und in Fällen, welche in das Gebiet der Pathologie gehören.

Bezüglich der Leistungsfähigkeit bietet dievegetarische Kost sicherlich im allgemeinen keinen Vorteil gegenüber der gemischten.

Ich glaube demnach, dass die Ernährungsphysiologie jetzt imstande ist, auf alle Fragen, welche diese Seite des Vegetarismus betreffen, eine klare, eindeutige Antwort zu geben. Nur die Harnsäurefrage bedarf noch der weiteren Klärung und sicheren Entscheidung. 
Bei der Ausführung dieser Untersuchungen bin ich von zahlreichen Herren in liebenswürdigster Weise unterstützt worden. In erster Linie gebührt mein herzlicher Dank meinem verehrten Chef Herrn Geheimrat Professor Zuntz. Ausser ihm unterstützten mich besonders bei den Respirationsversuchen auf der Tretbahn die Herren Professoren Loewy und Durig sowie Herr Dr. Carl Oppenheimer. Ferner bin ich Herrn Dr. Cronheim zu Dank verpflichtet. Dieser nahm in Dresden am Start die Wägungen der Dauergänger und ihres Proviantes : vor. Den Herren Geheimräten Professoren Dr. Ewald und Goldscheider danke ich für die Möglichkeit der geeigneten Unterbringung des Ehepaares K. und des Hauptmanns H., Herrn Geheimrat Goldscheider und Herrn Dr. Alexander für die entgegenkommende Fürsorge für den Letzteren. Auch den Herren Professoren von den Steinen und Grünwedel vom hiesigen Museum für Völkerkunde sei an dieser Stelle mein ergebenster Dank für ihre freundlichen Mitteilungen ausgesprochen.

Nicht zum mindesten aber möchte ich auch denjenigen Herren hier meinen herzlichen Dank aussprechen, welche sich mit so grosser Opferwilligkeit als Objekte dieser Untersuchungen dargeboten haben. 


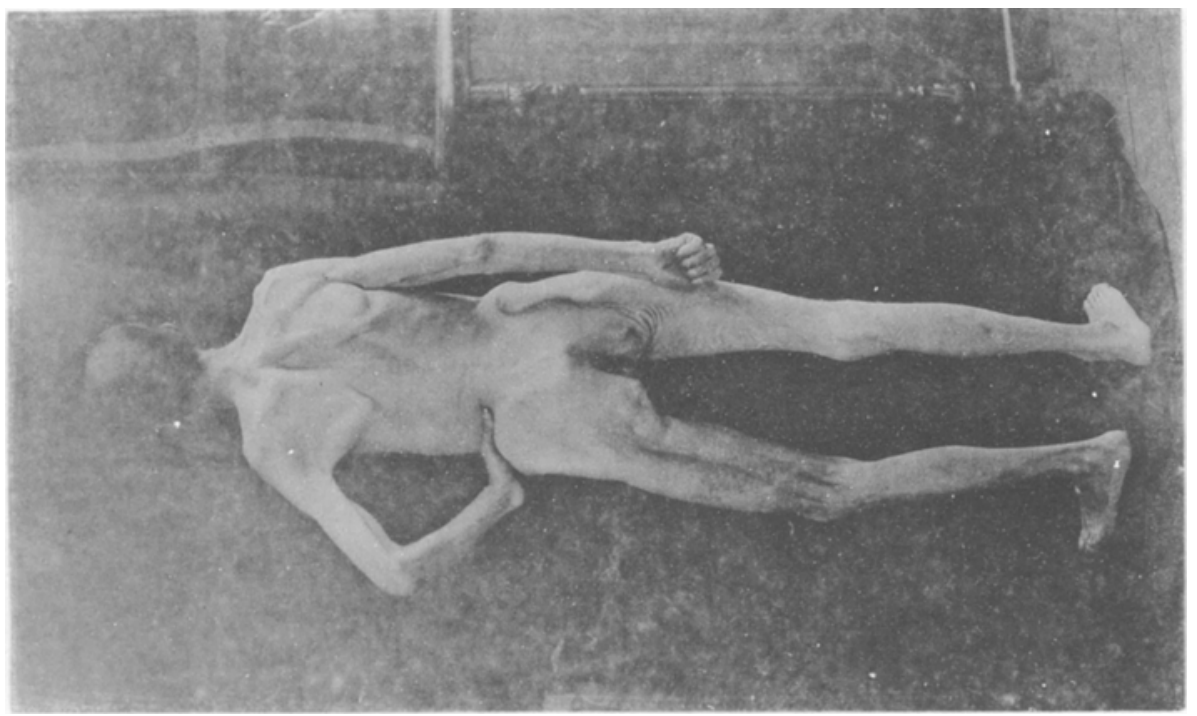

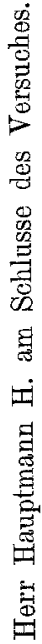

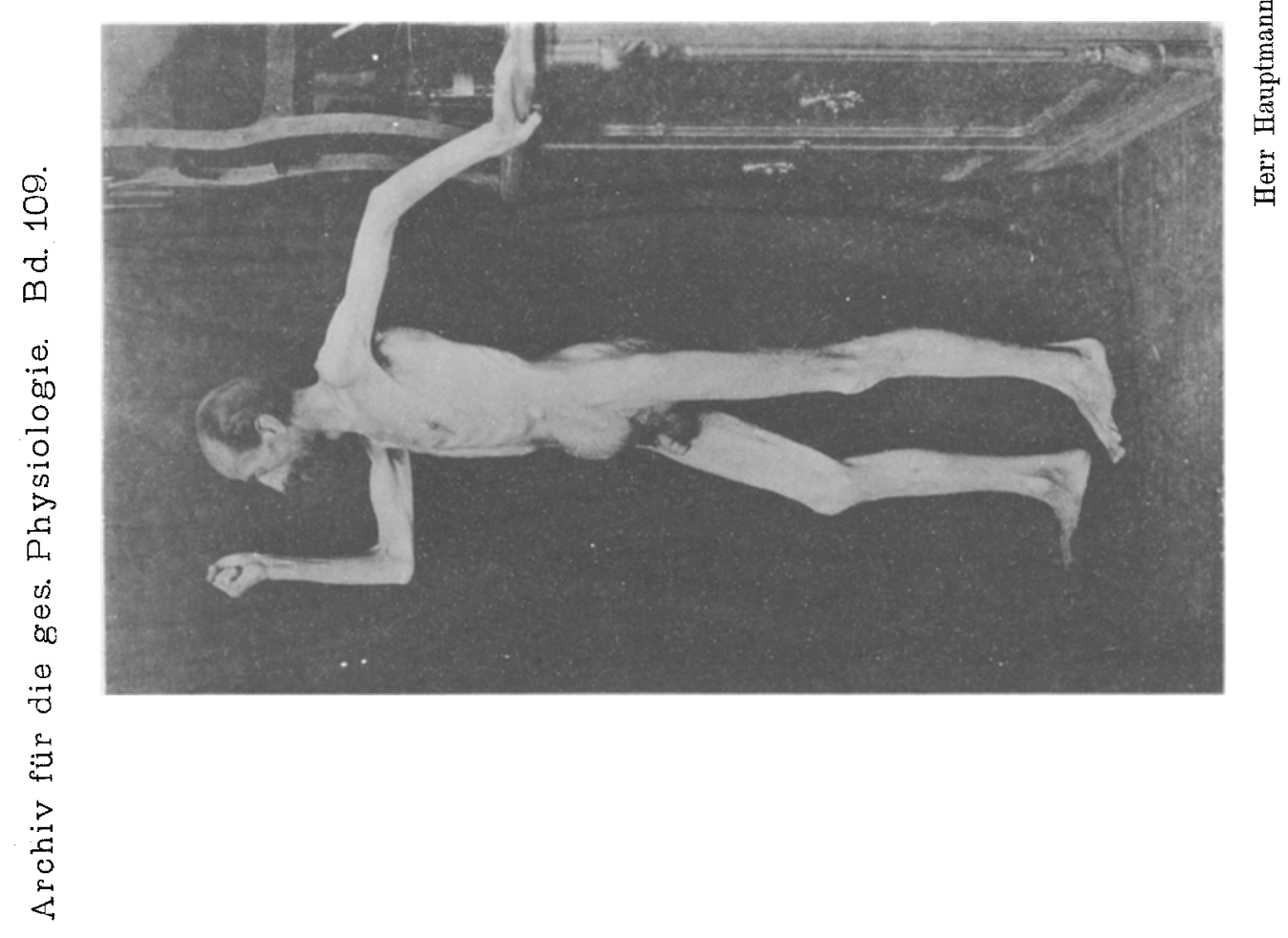




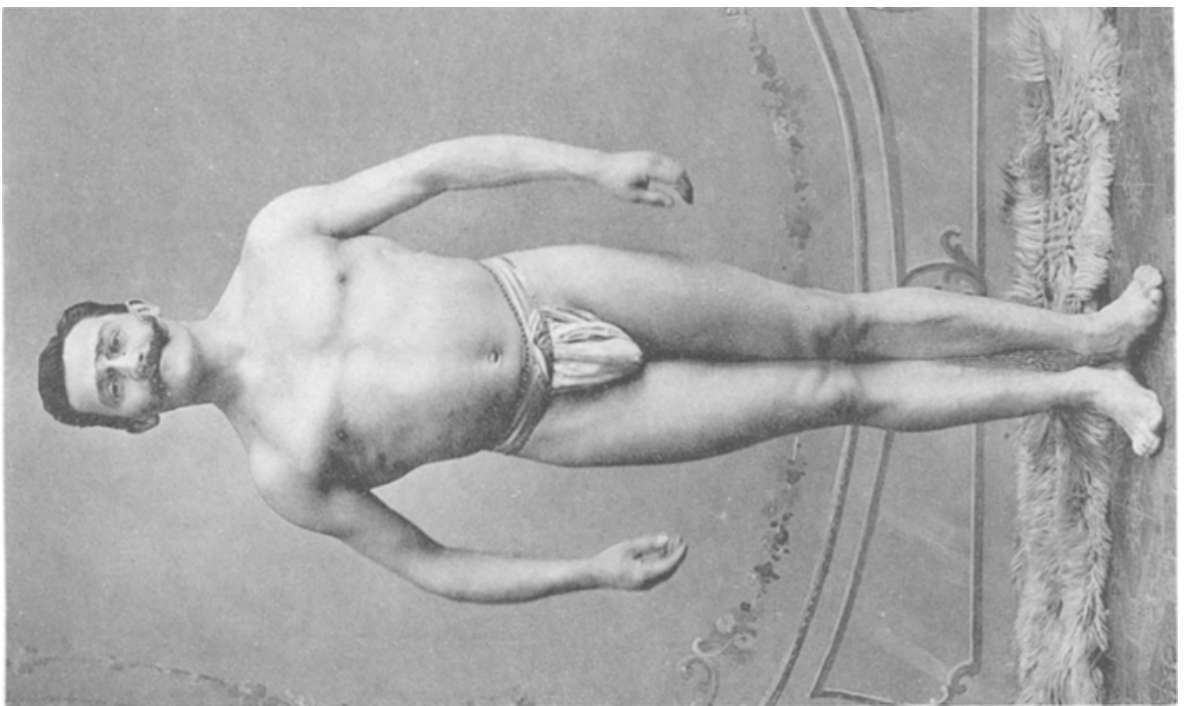

굴

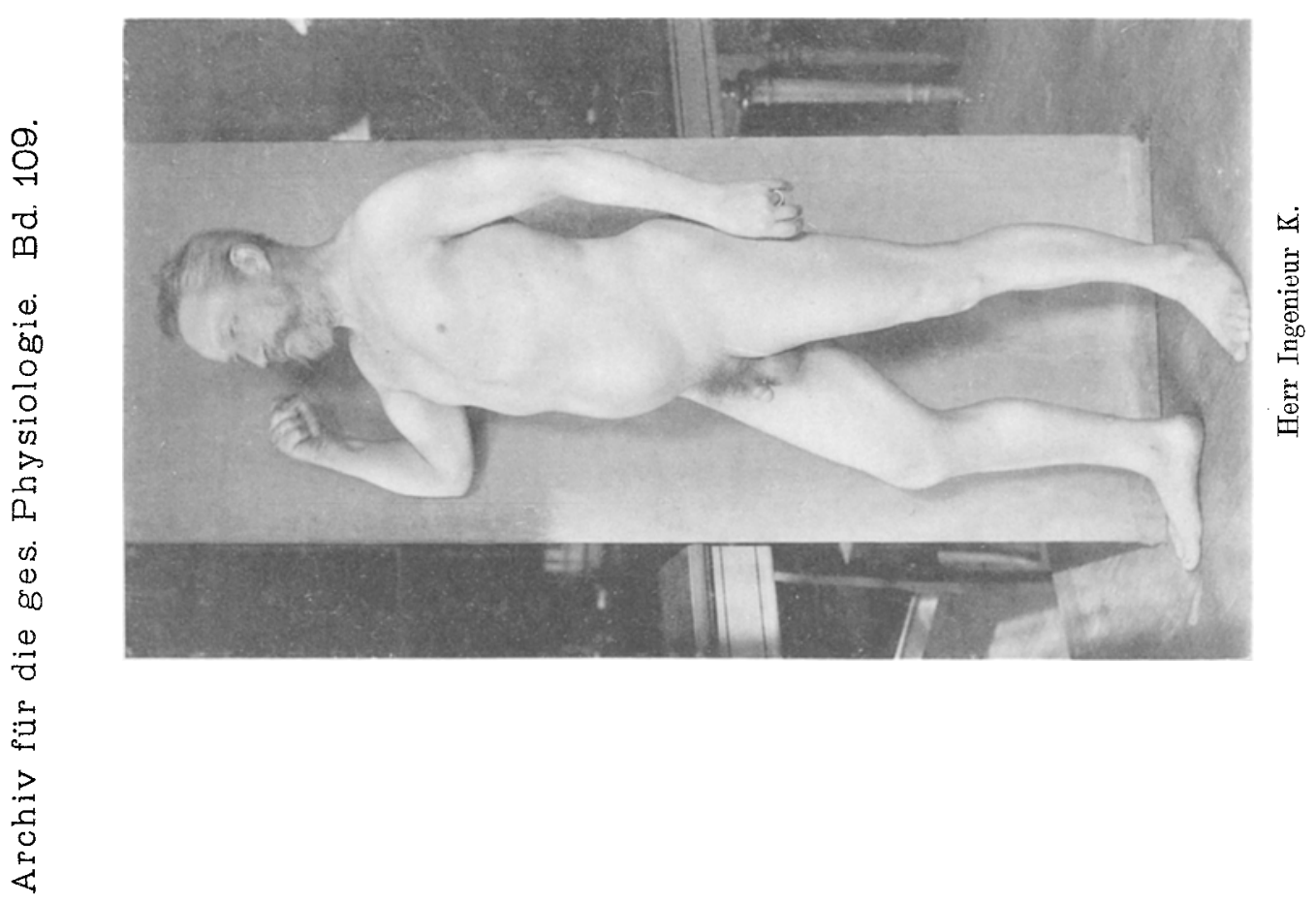

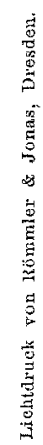


Arch. f. d. ges. Physiol Bd. 109.

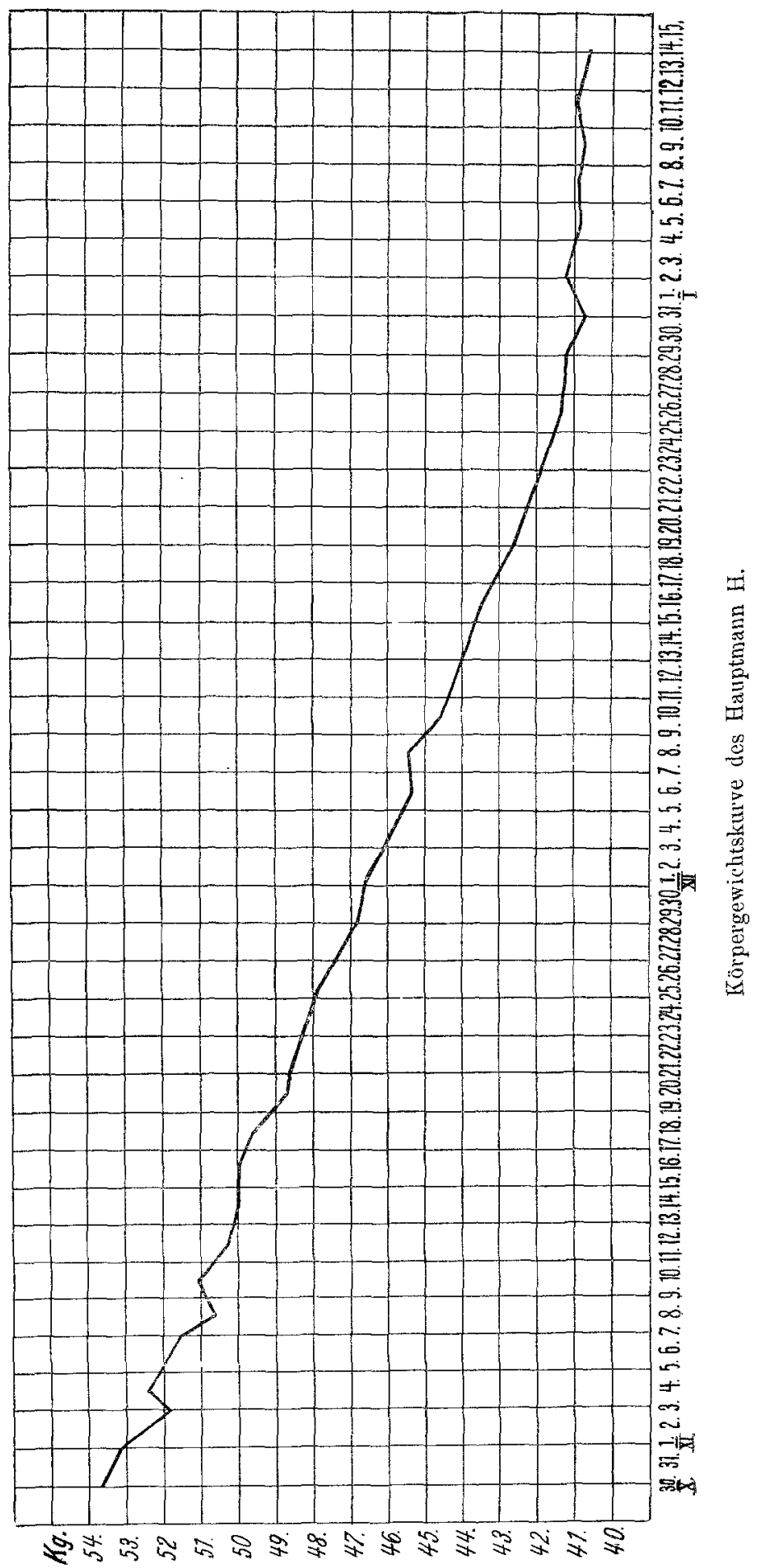


Taf XI.

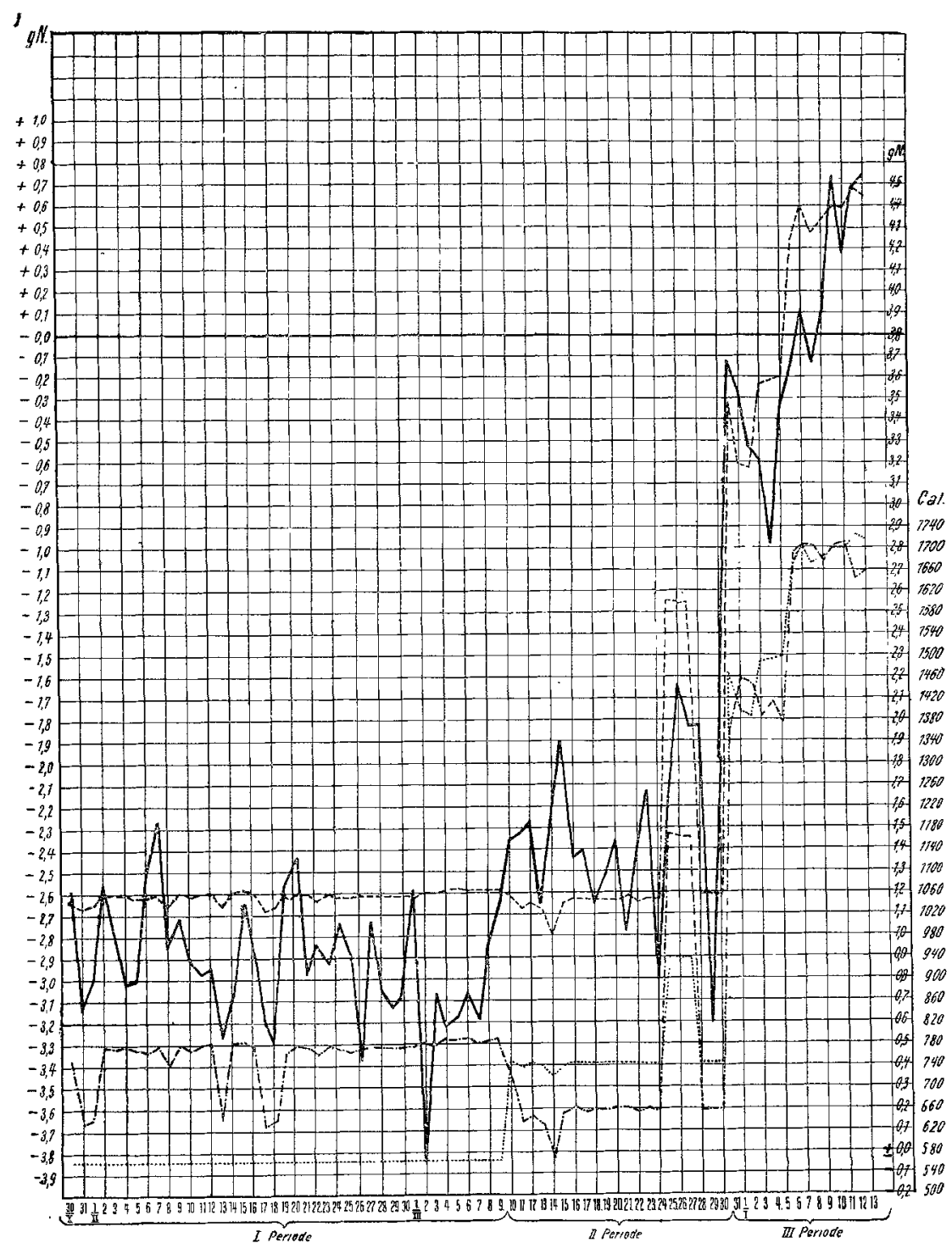

Kurve des Stoffwechsel-Versuches am Hauptmann H.

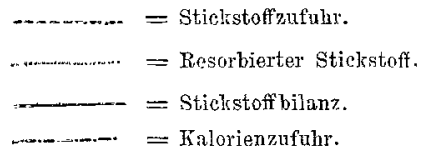

